Fecha de recepción: marzo 2021 Fecha de aceptación: abril 2021 Versión final: mayo 2021

\section{Divergencias en torno al concepto de funcionalismo en la historia del Diseño. Primera Escuela de Chicago, Bauhaus y HfG Hochschule für Gestaltung*}

Mark Michael Betts ${ }^{(1)}$

\begin{abstract}
Resumen: La relación entre los conceptos de forma y función, atravesó toda la historia del Diseño y la producción, desde la antigüedad hasta el presente. Esta relación, fue debatida, en las disciplinas proyectuales en los siglos XIX y XX, al punto de originar una corriente denominada como funcionalismo, como teoría y metodología en constante reformulación. El funcionalismo aparece en la historia de las disciplinas proyectuales como un concepto fundamental, porque condensó debates ideológico-políticos alrededor de la función social de la proyectación. Dichos debates, atravesaron los ámbitos pedagógicos, productivos y constructivos, desde los Estados Unidos hasta la Unión Soviética, cuando menos desde 1900 a 1980. Sin embargo, no todo diseño funcional es funcionalista. El funcionalismo se concibe aquí como un recorte históricoconceptual, desprendido de la Gran Tradición Funcional — de carácter atemporal-, que reunió principios, valores y modelos de carácter teórico y procedimental. De allí, que se releven y contrasten las conceptualizaciones de tres escuelas representativas: Primera Escuela de Chicago (1885-1915 aprox.); Bauhaus (1919-1933); y HfG Ulm (1953-1968), entendidas como fuentes primarias. Y sus críticas posteriores, entendidas como fuentes secundarias. Para ello, se adoptó la perspectiva historiográfica de la Historia Conceptual. Desde el punto de vista histórico y semántico, el concepto de funcionalismo operó como un registro de experiencias de diseño funcional del pasado; a su vez, representó expectativas a futuro, al fomentar cambios sociales para la equiparación de oportunidades de uso, hábitat y nuevas formas de comunicar. Aunque en la historia del Diseño y la Arquitectura aparece asociado a la frase de Sullivan L.H. (1896), 'la forma sigue siempre a la función', en este relevamiento se muestra que es una construcción de la crítica, o debe su emergencia a la crítica post Bauhaus. Esto evidencia su carácter controversial, debido a sus contiendas ético-políticas entre ideales liberales, socialdemócratas y marxistas.
\end{abstract}

Palabras Clave: Diseño, Divergencias - Forma - Función - Funcionalismo - Histórico Conceptual - Mitologías - Bauhaus - Primera Escuela de Chicago - HfG.

[Resúmenes en inglés y portugués en las páginas 278-279] 
${ }^{(1)}$ D.G. Mark Michael Betts. PhD en Diseño por la Universidad de Palermo, y Magister en Diseño Comunicacional de la Universidad de Buenos Aires, Argentina. Docente de Tiempo Completo de la Universidad del Norte, en Barranquilla, Colombia. Investigador Asociado en Minciencias. Miembro del Comité Editorial de la Revista KEPES, Indexada en la redes SCOPUS en Q1, y Publindex en A1.

Temas de Interés: Historiografía del Diseño, UX/UI Research, y Fotografía naturalista.

* Versión resumida para difusión. La tesis doctoral completa está publicada en el sitio web de la Universidad de Palermo https://www.palermo.edu/dyc/doctorado_diseno/documentacion/Tesis_Betts.pdf

Para Matt y Elvia

\section{Agradecimientos}

A Dios, que me otorgó la sabiduría y la perseverancia para continuar. A mi directora de tesis, Rosario Bernatene, por su guía, paciencia, y por cultivar en mi la precisión conceptual y la distancia crítica, necesarias para esta investigación en especial. Para todos los integrantes de mi familia, que comprendieron cómo mi ausencia me acercaba más a este momento. A mi amigo Ariel, quien me enseñó que la forma es igual de importante que el contenido. A la Universidad del Norte, y especialmente a los funcionarios que se solidarizaron conmigo durante estos seis años. Y, a la Universidad de Palermo, porque mis profesores y sus directrices, me guiaron hacia donde estoy ahora.

\section{Introducción}

¿Qué es lo más bello y adecuado? ¿Una cuchara de oro o de madera de hi-

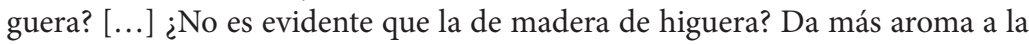
legumbre y, además, no podría romper la marmita ni derramaría la verdura, ni apagaría el fuego, dejando sin un plato muy agradable a los que iban a comer. En cambio, la de oro podría hacer todas estas cosas, de manera que, según parece, podemos decir que la de madera de higuera es más adecuada que la de oro, a no ser que tú digas otra cosa. (Platón, 391 a.C.)

Desde que Sócrates interroga a Hipias de esta manera, la humanidad se ha preguntado sobre la relación entre lo bello, lo bueno y lo verdadero. La historia sobre esta asociación es rica en diversas maneras de concebir la forma, y con ella, lo bello, en relación a la capacidad de cumplir con la función. En particular, la relación entre forma y función ha 
sido largamente historiada por varios autores, algunos de los cuales serán consultados en los capítulos siguientes de esta investigación. Interesa en especial su desarrollo desde los finales del siglo XIX y a lo largo del siglo XX, sin perder de vista sus antecedentes en los siglos anteriores. Esta relación se ha manifestado en las disciplinas proyectuales con particular insistencia, siendo objeto de numerosos estudios y análisis, al punto de generar una corriente que engloba y articula sus diferentes estadíos y significados, bajo el concepto de funcionalismo.

Para realizar su estudio es particularmente apropiada la perspectiva historiográfica de la Historia Conceptual, en cuya base teórica y metodológica se apoyará esta investigación. Encontramos referentes internacionales de esta corriente consolidada en Koselleck (1993, 2006, 2009, 2012), Sebastián y Fernández (2013), Rosenvallon (2003), Palti (2011, 2012), Chignola y Duso (2009), así como en maestrías y publicaciones específicas, entre otros. Esta orientación historiográfica permite ir más allá de las exégesis y atender las formas en que un concepto ha variado con el tiempo, según las culturas, las sociedades y los grupos de opinión. Esto permite identificar los contenidos de experiencia que ha acumulado en su estructura temporal y las expectativas innovadoras que incluye a futuro.

La historia del funcionalismo como concepto ha sido escogida, dado que éste cumple con todas las condiciones que la Historia Conceptual requiere para que amerite su investigación histórica.

Concepto - en palabras de Koselleck - no es cualquier término, sino aquél que alberga profundas disputas por su significado, que aglutina grandes campos de experiencia, y que condensa capas de significación de distintos momentos históricos. "Y son polémicos, porque distintos hablantes quieren imponer un monopolio sobre su significado" (Koselleck, 2006, p. 45).

Un concepto debe conservar su equivocidad a fin de poder ser concepto. Es verdad que el concepto está unido a la palabra, pero al mismo tiempo es más que la palabra. Una palabra se convierte en concepto - según nuestro método- cuando el conjunto de un contexto de significados sociopolítico [Bedeutungszusammenhang] en el que, y para el que, se utiliza una palabra entra todo él a formar parte de esa palabra. (Koselleck, 2009, p. 92)

No obstante, además de constituirse como concepto, el funcionalismo aparece en la historia del Diseño y la Arquitectura como un concepto fundamental. Según la visión histórica adoptada, se convierten en conceptos fundamentales aquellos que se vuelven insustituibles o no intercambiables, sin los que no es posible ninguna comunidad política y lingüística.

Por conceptos históricos fundamentales no hay que entender las expresiones específicas de las ciencias de la historia descritas en manuales y teorías metodológicas [Methodenlehren]. Más bien se trata de conceptos-guía del movimiento histórico [geschichtliche Bewegung], el cual, en el transcurso del tiempo, constituyen el objeto de la investigación histórica. Por ello la Historia [Historie] como ciencia remite, de forma obligada, al uso de las palabras descollantes en cada campo temático. [La cursiva es del autor] (Koselleck, 2009, p. 93) 
En este caso, el funcionalismo es un concepto fundamental en el campo de las disciplinas proyectuales por dos motivos. En primer lugar, porque condensó los debates ideológicopolíticos de una época, alrededor de la relación forma-función. Dichos debates, atravesaron los ámbitos pedagógicos, proyectuales, productivos y constructivos, al menos desde 1900 hasta 1990; tanto en el Diseño industrial y la Arquitectura, como en el Diseño de Comunicación Visual o Gráfico. En segundo lugar, porque alrededor de este concepto se constituyó una "matriz disciplinar" (Kuhn, 1962), que fundamentó marcos teóricos y metodológicos. Estos fundamentos fueron puestos en práctica en la mayoría de las escuelas de diseño y arquitectura del mundo; y en algunos casos, se siguen ejerciendo en la actualidad. Esto se ampliará en el capítulo 6 Conclusiones.

Sin embargo, no todo diseño funcional es funcionalista. Concebimos el funcionalismo como un recorte histórico-conceptual, desprendido de la Gran Tradición Funcional, - de carácter atemporal一, que reunió un conjunto de principios, valores y prácticas proyectuales, de carácter teórico y procedimental, difundidas en la formación profesional durante casi un siglo. Por estas razones, la presente investigación es ajena a la voluntad de establecer una etiqueta para clasificar obras.

A pesar de disponer de los conocimientos que la tradición funcional ha consolidado, el tema amerita un trabajo de investigación histórico-conceptual, que se proponga analizar y contrastar las distintas interpretaciones históricas, formuladas alrededor del mismo. En palabras de Koselleck: "dado que cada concepto fundamental, encierra un potencial histórico de transformación" (Koselleck, 2006, p. 46).

El concepto funcionalismo vincula la dimensión práctico-social de las disciplinas proyectuales con sus construcciones teórico-representacionales, con base en las cuales se pueden examinar históricamente las distintas escuelas y las orientaciones en Arquitectura, Diseño Industrial, Gráfico o Comunicacional. Se trata de explicitar los sucesivos cambios que el concepto de funcionalismo sufre a lo largo del tiempo, en los que va mutando de referentes. Para este fin se adoptará una concepción reconstructivo-histórica, con esquemas interpretativos basados en hipótesis hermenéuticas.

Estas hipótesis atenderán aspectos tanto semánticos, como pragmáticos. Esta perspectiva permitirá comparar y comprender los contextos intelectuales y políticos a los que remite el concepto, así como los enunciados teóricos, las metodologías y las prácticas que se generaron a su alrededor, dando un nuevo sentido a narraciones históricas que ya poseían un sentido original.

A su vez, varios marcos teóricos adicionales son convocados para comprender problemáticas asociadas a los procesos estudiados, — no por ello menos importantes -, tales como la Poética, en De Zurco (1971); la visión aristotélica, según Sinnot (2004); Todorov (1991); y la Filosofía Política, para abordar el positivismo, desde Habermas (1999); el utilitarismo desde Mill (1863) y Kymlicka (1995); y el marxismo desde Kymlicka, W. (1995) y Adorno, $(1966,1975)$.

El funcionalismo puede definirse hoy como un concepto polisémico y multifacético, dado que los significados y las experiencias que contiene, se han instituido por las constantes reformulaciones que emergen de las sinergias entre los conceptos de forma y de función. Su relevancia histórica se explica por las expectativas de cambio a futuro que propició. Más allá de la adaptación a un fin preciso, en el siglo XX, este concepto se destaca por asociarse 
a una actitud contestataria y socializante que, enfocada en la accesibilidad democrática de las viviendas y los artefactos, promete tanto la equiparación de las formas de uso y habitabilidad, como también cambios revolucionarios en las formas de comunicar. El concepto de funcionalismo manifiesta a su vez, neutralidad y maleabilidad terminológica. Esto lo vuelve de fácil adaptación en los enunciados, dado que, al vincular el ejercicio de la funcionalidad, con el diseño, los objetos y las personas, favorece las variaciones interpretativas según el marco de referencia con el que se lo asocie, ya sea biológico, lingüístico, moral o político.

La relación determinista señalada entre los términos forma y función, se halla condensada en la conocida frase "la forma sigue siempre a la función", precisada por el arquitecto americano Louis Henri Sullivan (1896). Este enunciado paradigmático expresará una regularidad a lo largo de la historia del Diseño, al modo de presupuesto general al que se alude en todo vínculo entre un antecedente y un consecuente, en una relación de causa y efecto. Si bien la ética del utilitarismo es convergente con las distintas facetas en que el funcionalismo se adopta en las disciplinas proyectuales, no sucede lo mismo con los presupuestos políticos y las aspiraciones epistemológicas, completamente divergentes en cada una de las vertientes en las que se exteriorizó. De allí, que los rostros heterogéneos que ha asumido este concepto, continúen sublimándose en modelos proyectuales, donde la preocupación objetiva por satisfacer los requerimientos humanos a través de los productos diseñados, subordinan sin demeritar las exigencias de la economía de mercado y los aspectos estéticos asociados a él. Para alcanzar dicha objetividad, el funcionalismo se desligó de las bellas artes, con la intención de otorgarle un fundamento científico a las teorías de la Arquitectura y el Diseño.

La revisión de las acepciones construidas de la noción de funcionalismo en la historia del Diseño se desprenderá de la producción intelectual de académicos reconocidos en el tema, delimitando su estudio exclusivamente a la Arquitectura, el Diseño Gráfico y el Diseño Industrial. La delimitación disciplinar se resalta, dado que este término, al figurar también en la Biología, la Antropología, la Sociología, la Semiótica y la Lingüística, entre otros campos de estudio, es abordado desde flancos hermenéuticos completamente distintos a los que caracteriza el universo de las disciplinas proyectuales y afines.

El vacío teórico-histórico, latente y actual, sobre el concepto de funcionalismo, exige superar las miradas que lo señalan exclusivamente como un formalismo unificado, supresor del ornamento y la decoración, o como la instauración tardía de una doctrina que fundamentó el ejercicio profesional de manera globalizada. En este sentido, el trabajo aspira a poner en cuestión varios estereotipos presentes en la bibliografía del Diseño, tales como: el funcionalismo es un 'estilo'; es una corriente proyectual creada por el arquitecto Louis Henri Sullivan; que la Bauhaus creó un 'formalismo' sobre esa base; o que el concepto sólo compete cuestiones de diseño y no profundas contiendas ético-políticas y epistemológicas, entre otros.

Esta tesis se enmarca espacial y cronológicamente en tres escuelas del Diseño emblemáticas, dado que sus actores aparecen como los que implementaron esta corriente, desde sus modelos académicos particulares. Los tramos cronológicos y cortes temporales sincrónicos que sitúan a estas instituciones, las ubican en los Estados Unidos y en Alemania, con la Primera Escuela de Chicago a finales del siglo XIX; Das Staatliches Bauhaus en Weimar, 
Dessau y Berlín, de 1919 a 1933; y la HfG Hochschule für Gestaltung, de 1953 a 1968, en la ciudad de Ulm.

En primer lugar, se relevarán las fuentes primarias, donde figuran los fundadores, instauradores y/o seguidores de estas tres escuelas del Diseño. En la Primera Escuela de Chicago: Henri Louis Sullivan $(1896,1918,1922)$ y Frank Lloyd Wright $(1908,1931,1953,1957)$; en Bauhaus: Walter Gropius $(1914,1919,1926,1943)$, Hannes Meyer $(1926,1928)$ y Mies van der Rohe (1923, 1927). Finalmente, en la HfG: Max Bill (1949, 1952, 1953, 1958), Tomás Maldonado (1955-1958) (1974, 1977, 1990, 2004, 2008), Gui Bonsiepe (1962-1968) (2003, 2016), y Otl Aicher (1991/1994).

En segundo lugar, lo expuesto por las fuentes primarias se contrastará con los enunciados de los teóricos e historiadores del diseño que realizaron ensayos críticos sobre el concepto de funcionalismo, y que configuran las fuentes secundarias: Abraham Moles (1973); Jean Baudrillard (1968, 1972, 1974); Bernhard Bürdek (1991/2002); Jan Michl (1997/2018) (2012, 2014); Fulvio Carmagnola (1995); Herwin Schaefer (1970); Víctor Margolín (1998, 2005); Tomás Maldonado (1974, 1977); Otl Aicher (1975, 1991/1994); Rosario Bernatene (1996, 2005) y Verónica Devalle (2009a, 2009b, 2012).

En Historia, tal como sostiene Koselleck:

...toda afirmación teóricamente fundamentada debe someterse al control metodológico de las fuentes para poder hacer afirmaciones sobre la facticidad del pasado, sin embargo, la realidad de los factores de larga duración no se fundamenta de forma suficiente solo a partir de las fuentes individuales como tales. (Koselleck, 2006, p. 22)

Por esto, el tema no se agota con citar prolijamente las fuentes, sino que requiere de su revisión posterior a la luz de las estructuras temporales que revela. En este sentido, el trabajo teórico indaga en los presupuestos éticos, políticos, epistemológicos y estéticos que subyacen a los distintos enfoques, donde se verifica el carácter polémico y problemático del concepto.

\section{Enunciado general del/los problemas de investigación}

Como en toda investigación sobre la historia del diseño, el tema también implica un problema proyectual. En nuestro caso, este problema consiste en que no hay una única forma que cumpla o garantice una función, sino que hay muchas. Lo que significa que en toda evaluación de un proyecto, se deberá admitir un grado de aleatoriedad en la elección de una forma para cumplir con las funciones requeridas. Aleatoriedad que puede responder a condiciones subjetivas del o los proyectistas, de disponibilidad de recursos, de expectativas de los receptores, entre otras. Esta aleatoriedad y contingencia en la resolución proyectual es esquiva, respecto a la exigencia racionalista de justificar lógica, objetiva y científicamente la mejor forma. En la biología, de donde proviene el emblemático enunciado "la forma sigue a la función", subyacente en toda la historia del funcionalismo, el proceso de adaptación de la forma de los organismos a sus medios lleva millones de años, temporalidad que no se condice con los cambiantes patrones sociales y culturales del diseño. Esta des-adaptación entre exigencias de objetividad, por un lado, y contingencia de las resolu- 
ciones, por otro, actúan como vectores contrapuestos que determinan que el problema se torne dilemático; de ahí que permanezca siempre vigente, amerite su estudio en distintos momentos históricos, se mantenga el interés y requiera su permanente actualización y reformulación teórica.

Históricamente, la relación entre los conceptos de forma y función atravesó toda la proyectación de los siglos XIX y XX, desde el equipamiento mobiliario doméstico hasta los utensilios, herramientas, máquinas, viviendas y edificios, tanto en su forma vernacular como académica. Por esto, interesa desentrañar las causas de su importancia y difusión al punto de originar una corriente, que denominada como funcionalismo, constituyó una teoría y metodología, en constante reformulación. Es necesario discernir cuáles fueron las causas de su auge como paradigma proyectual, y cuáles fueron las causas de su declive. Asimismo, importa identificar el contenido de las variables que lo convierten en permanente campo de disputa, tanto estético como ideológico, ético y político en las tres escuelas y la crítica posterior. Estas interrogaciones se formulan con mayor precisión en el siguiente listado de preguntas:

1. ¿A qué se debe la importancia histórica e historiográfica del concepto de funcionalismo? 2. Si las interpretaciones sobre el concepto cambian constantemente, ¿qué es lo que le otorga unidad y consistencia en el tiempo?

3. ¿Qué evidencias se encuentran en torno al origen del concepto en estas escuelas?

4. ¿Cómo se expresan las diferencias y similitudes conceptuales entre las tres escuelas, en torno a la relación entre forma, función, funcionalidad y funcionalismo?

5. ¿Qué contiendas ético-políticas se suscitaron alrededor del concepto entre las fuentes primarias?

6. ¿Cómo se manifestó el funcionalismo en las distintas áreas proyectuales?

Otras preguntas adicionales se enuncian y se responden en los capítulos 3, 4, 5 y en las conclusiones finales.

\section{Objeto de estudio}

El objeto de estudio que se aborda en esta tesis es la historia del funcionalismo como concepto en las disciplinas proyectuales. Se compara su tratamiento ético, estético, político y epistemológico al interior de tres escuelas representativas: Primera Escuela de Chicago, la Staatliches Bauhaus, la HfG Ulm, y en la crítica posterior a ellas.

\section{Objetivo General}

Caracterizar la emergencia del concepto de funcionalismo en las teorías y prácticas proyectuales de distintos momentos históricos y culturales, así como sus períodos de auge y decadencia.

\section{Objetivos específicos}

Realizar un análisis comparativo de las concepciones de función, funcionalidad y funcionalismo entre las fuentes primarias (Primera Escuela de Chicago, Bauhaus y HfG Ulm) y las secundarias, constituidas por los críticos posteriores. 
- Comparar la historia del funcionalismo en las distintas áreas proyectuales: Arquitectura, Diseño Industrial, Gráfico y Comunicacional.

- Relevar las principales ideologías políticas que participan en la disputa del concepto de funcionalismo.

- Identificar las bases éticas, estéticas y epistemológicas que posibilitaron su surgimiento y expansión.

- Describir las similitudes y las diferencias entre los distintos estratos sincrónicos en donde aparece el concepto funcionalismo — en analogía a los estudios estratigráficos-y relacionarlos con las estructuras diacrónicas que los sostienen.

\section{Marco historiográfico}

\subsection{Introducción al marco historiográfico de la Historia Conceptual}

El concepto de funcionalismo, se encuentra vinculado a diversas obras arquitectónicas y de diseño que hicieron parte del pasado, la descripción de la historia acontecida en sus distintos usos, necesita del lenguaje como su factor de transposición científica. Y será este el marco de nuestra elección. Si bien los conceptos se encuentran alojados en cadenas de enunciados, la Historia Conceptual permite comparar conceptualizaciones entre sí, que de otro modo quedan ocultas a la visión del historiador. De la reconstrucción de los acontecimientos en donde surge el término, gracias al uso e implementación de quienes consideramos que representan las fuentes de esta investigación, se prioriza el lenguaje usado por ellas en sus diversos contextos de enunciación.

Como categorías analíticas que referencian el presente de dichos acontecimientos y sus profundidades temporales, se emplean los enfoques metodológicos de la sincronía y la diacronía, para identificar a qué acepciones y fenómenos se relacionó. De allí que el funcionalismo justifique un análisis semántico y pragmático desde lo Histórico-Social e Histórico-Conceptual y aportes de la Historia de las Ideas, con el objeto de develar las transformaciones correlativas y los significados que describen el estado de las cosas y sus dinámicas particulares.

Los conceptos fundamentales son inalterables, en el sentido de que su formulación se mantiene en el tiempo, pero poseen una estructura temporal interna:

... cada concepto fundamental contiene varios estratos profundos, procedentes de significados pasados, así como expectativas de futuro distintos [...] Cuanto más generales sean los conceptos, más partidos pueden servirse de ellos. Se convierten en consignas [...] Así, nace una lucha de competencias respecto a la interpretación correcta y el uso correcto de los conceptos [...] De esta forma, se produce un litigio acerca de la verdadera interpretación política [La cursiva es del autor]. (Koselleck, 2004. p. 331) 
En este sentido, el funcionalismo como concepto fundamental en la historia de las disciplinas proyectuales, está cargado de interpretaciones polémicas que demuestran su riqueza. Por ello, esta investigación también focalizará en las corrientes socio-políticas que disputaron su significación.

Por último, Koselleck nos indica que "los conceptos formados con el sufijo -ismo- son representativos de los términos con una gran carga de innovación. La lista de estos -ismos- es extensa y comienza a principios del siglo XVIII" (Koselleck, 2006, p. 37). Son conceptos de movimiento y acción: en nuestro caso, el funcionalismo acumula un registro de experiencias pasadas, que combina con grandes expectativas de cambios a futuro. Con ello, "estos conceptos generan, en cierta forma, en un proceso inmanente al lenguaje, un potencial de movimiento y de modificación temporal con independencia de su contenido de realidad" [La cursiva es del autor] (Koselleck, 2004, p. 37).

Como concepto fundamental en las teorías del Diseño, al funcionalismo se lo ha venido asociando a distintas analogías y modelos proyectuales. Esto lo ha convertido no solo en un motivo de disputas ideológicas, éticas, políticas y epistemológicas, sino también en un campo de confrontación de significados a través de señalamientos ambiguos y generalizados. De allí, que se justifique su indagación a partir de la Historia Conceptual-como metodología sustancial—, y de la Historia de las Ideas-en la perspectiva de Quentin Skinner-, de manera complementaria. Estas metodologías, ayudarán a evidenciar, si lo que se ha dicho hasta ahora sobre el funcionalismo, concuerda con la documentación histórica, que se irá reconstruyendo en este trabajo a partir del uso de los conceptos y las acciones de sus principales actores.

Desde el enfoque heurístico, los conceptos pueden poseer un rostro jánico, es decir, si se orientan hacia el pasado, pueden referir a situaciones sociales y políticas que podríamos no llegar a comprender, de no existir reflexiones críticas sobre estas situaciones. Y si se orientan hacia el presente, puede descubrirse cómo la diversidad de significados que se han obtenido a través del tiempo y de sus experiencias ${ }^{1}$, pueden ser fácilmente comprensibles (Koselleck, 2009). La expresión jánico, original del psiquiatra americano Albert Rottenberg - basada en el dios romano Jano-, plantea una forma de pensamiento en la que, al concebirse dos o más ideas, aun siendo antitéticas, pueden encontrarse vinculadas a un mismo concepto.

\subsection{Entre lo histórico-social y lo histórico-conceptual}

Koselleck (2012), explica que: "en lenguaje kantiano: no hay experiencias sin conceptos y no hay conceptos sin experiencias" (p. 29). Desde el marco de la Historia Conceptual, el autor expone cómo la relación empírica entre el hacer y la disertación - o entre el actuar y el hablar-, se disuelve al momento en que se transita de la historia in eventu hacia la historia ex eventu. La historia, constituida por una comunicación oral de las generaciones coetáneas que compartieron sus experiencias, permanece gracias al registro escrito como su principal vehículo de transmisión. Debido a ello, el lenguaje y el texto escrito se dignifican como los factores primarios de la historia conceptual, al momento en que, la transmisión oral diluye los recuerdos con el deceso de las generaciones que los engendraron. 
De esta manera, la primacía antropológica del lenguaje - al describir la historia acontecida- adquiere un estatus epistemológico, gracias a la transposición científica de dichos recuerdos. $\mathrm{Al}$ ser la historia conceptual una epistemología en sí misma, la distinción analítica entre el nivel extralingüístico — es decir, lo que acontece-, y el lingüístico - su registro-, emerge como un principio antropológico fundamental. No obstante, Koselleck (2012), aclara que "siempre hay una diferencia entre la historia en acto y la articulación lingüística que la hace posible" (p. 14), sobre todo porque lo que sucede siempre es más de lo que la articulación lingüística posibilita o interpreta. Así ejemplifica: "la orden, la decisión colegiada o el grito elemental de matar no son idénticos a la violencia propia de matar" (p. 14), por lo que siempre hay un hiato, una falta de correspondencia entre dichos y hechos. Esta primacía antropológica del lenguaje, opera a partir de un doble movimiento. Por un lado, se usa para rastrear la autenticidad de cualquier experiencia histórica vivida, consignada en un enunciado coloquial o científico. Por el otro, para plasmar lo que no se ha puesto a la luz, de manera oral o escrita, por los historiadores.

Desde el momento en que un acontecimiento pasa a formar parte del pasado, el lenguaje se convierte en un factor primario sin el cual no es posible ningún recuerdo ni ninguna transposición científica de ese recuerdo. De este modo, la primacía antropológica del lenguaje en la descripción de la historia acontecida adquiere un estatus epistemológico. (Koselleck, 2012, p. 16)

Sin embargo, se debe contemplar que al uso del lenguaje escrito no le es indiferente el género en el que se enmarcan las historias, que pueden ir desde el mito hasta la novela. Debido a esto, el análisis riguroso de las fuentes lingüísticas debe llevarse a cabo solo desde el ámbito científico, porque es desde ese camino que se puede comprobar su autenticidad. No obstante, los historiadores se enfrentan a otro tipo de retos, que remiten el habla y el lenguaje a las transformaciones sociales. Por eso, cuando se intentan reconstruir los acontecimientos, el historiador prioriza el lenguaje usado por las fuentes, en sus diversos contextos de enunciación, ya que el uso de los conceptos y las acepciones propias de ese pasado para describirlo, conducen a la superación de los anacronismos.

Desde una perspectiva socio-histórica, para este autor, se debe investigar la relación entre las particularidades de cada acontecimiento, a los que se considera como sincrónicos, y las estructuras diacrónicas que los enmarcan. Koselleck sostiene que el discurso hablado también puede categorizarse como sincrónico, y el lenguaje ya existente como diacrónico, en una relación mutuamente dependiente.

Aun cuando en el corte sincrónico, que es una abstracción, la acción y la articulación lingüística están entretejidas, la transformación diacrónica, que es un constructo teórico, no tiene lugar en la «historia real»y en la conceptual en el mismo orden cronológico o ritmo temporal. (Koselleck, 2012, p. 25)

De todas formas, si bien un nuevo concepto puede plasmar, lingüísticamente, experiencias que antes no existían, su sentido, por muy nuevo y singular que sea, deviene virtualmente de un lenguaje del pasado, es decir, de un contexto lingüístico en el que figura siempre 
como heredero. De allí que la Historia Conceptual considere a la sincronía y a la diacronía, como dos categorías de análisis que se entrelazan de distintas formas, pero "nunca son aislables ni se pueden separar empíricamente [...] toda sincronía es eo ipso simultáneamente diacrónica" (p. 19). Esto se debe a que la suma de cada caso particular, condicionados por las situaciones económicas, políticas y naturales desde las que emergen, aun siendo sincrónicos y documentados, no pueden evidenciar las estructuras diacrónicas que condicionan sus transformaciones.

Con esta reserva utilizaré las categorías analíticas de sincronía, que hacen referencia al presente del acontecimiento, y de diacronía, que hacen referencia a la profundidad temporal, presente asimismo en todo suceso actual [...] Pueden elaborarse dos enfoques metodológicos como modelos simplificados. Uno se centra primordialmente en los acontecimientos, en las acciones plasmadas en el discurso, el texto y el acto; el otro se centra principalmente en las condiciones previas de carácter diacrónico y en sus transformaciones a largo plazo. (Koselleck, 2012, pp. 19-20)

Estos dos enfoques metodológicos son los que se articularán en el presente trabajo, dado que solo un listado de momentos sincrónicos constituiría un enfoque limitado e insuficiente. El análisis de las estructuras diacrónicas, es el aporte específico, que la Historia Conceptual y sus herramientas teóricas brindan, para comprender el devenir histórico de un concepto. En efecto, más allá de los hallazgos contrastantes entre los casos sincrónicos y particulares, se deben detectar las estructuras diacrónicas, debido a que la suma de los casos documentados, según Koselleck, es muda y no puede probar o evidenciar cómo se originaron. En sus palabras: "con ello abordamos los métodos de la historia conceptual, que — de forma análoga a la diferenciación entre acontecimiento y estructura - tienen que diferenciar entre el discurso actual y sus reglas lingüísticas". (Koselleck, 2012, p. 22) No obstante, las distinciones entre cada experiencia, luego de ser captadas son completamente comprensibles, solo y únicamente cuando las condiciones estructurales de ese cambio se repiten, porque es en el fondo de cada estructura repetitiva de donde emergen no solo sus cambios sutiles, sino también se registran y captan sus modificaciones.

Ahora bien, hay distintas velocidades de transformación. Existen aceleraciones y ralentizaciones que pueden agolpar o fracturar los estratos temporales; y los sutiles cambios que puede sufrir un acontecimiento, que hacen de él una realidad modificable. Estos agolpamientos o fracturas, a los que Koselleck señala como estratos temporales, no facilitan la transposición de lo extralingüístico, lo que complica la comprensión. Por eso, propone identificar qué significados asociados a una palabra se mantienen iguales y cuáles no, con el objeto de revelar - al interior de cada estrato-, los conceptos emergentes que se revisten de nuevas fórmulas.

Así, en esta investigación, la relación forma y función se presenta como la condición repetitiva de trasfondo, que permite la emergencia del concepto de funcionalismo, con sus múltiples vertientes. Para realizar esta tarea se utiliza la semántica como método científico, que tiene como función analizar la multiplicidad de significados que, sobrepuestos, en una palabra, se ajustan a una realidad cambiante. Los desplazamientos que causan la 
fractura entre un concepto respecto de su significado anterior, en reemplazo de uno nuevo, o por la sumatoria de varios significados, hace del método semántico una necesidad en la historia conceptual.

De todos modos, la Historia Conceptual no se limita al análisis semántico de los conceptos, sino que incorpora el Nivel Pragmático, —en otras palabras, del uso y la acción-, ya que, según Koselleck, las palabras y las acciones se potencian mutuamente. Efectivamente, se observa que, sobre el trasfondo de la vieja tradición funcional y las disputas sobre la relación forma-función-que atañe a esta investigación-, los nuevos significados aglutinados en el concepto de funcionalismo, provocaron a su vez nuevas acciones, en forma de enunciados, controversias y metodologías proyectuales. De allí, que los niveles semántico y pragmático, propios de la Historia Conceptual, puedan conducirnos a una reconstrucción asertiva.

Por otra parte, los conceptos pueden hallarse asociados a uno o varios significados en estratos de distinta profundidad. Koselleck (2012), pasa a definir este fenómeno como concepto de registro de experiencias, debido a que la transformación histórica de la realidad y los cambios que sufren los conceptos que intentan captarla, evidencian una carga de experiencias acumuladas a través del tiempo. No obstante, cuando los conceptos comienzan a adquirir pretensiones normativas, que proyectan una transformación, gracias a las reflexiones producto de objetivos jurídicos y morales, se pasa de un concepto de registro de experiencias, a un concepto generador de experiencias. Ahora bien, cuando desde el concepto generador de experiencias se anticipan elementos utópicos para ser alcanzados en el futuro, se salta a un concepto de expectativas. Lo que conduce a que en esta investigación se analice si el concepto de funcionalismo, sufrió estas mismas modificaciones a lo largo de su historia; lo que ayudará a explicar su dinámica interna.

Si bien los conceptos que se acuñan junto al sufijo ismo, como el que elegimos analizar, representan una carga significativa de innovación para Koselleck (2012), también pueden figurar como conceptos de expectativas, pero con una diferencia muy particular. Los conceptos formados con este sufijo comparten la particularidad de no poseer experiencias acumuladas en su momento de acuñación, lo que no hace de ellos un registro de experiencias. En relación a los conceptos que integran este sufijo, en la historia del Diseño, al no poseer un cúmulo de experiencias al momento en que se comienza a hablar de él, se explica el estupor que las primeras acusaciones - tanto del funcionalismo, como del adjetivo funcionalista, usados de modo despectivo-, causaron entre sus principales destinatarios, como Walter Gropius. No obstante, con el transcurrir del tiempo, el concepto de funcionalis$m o$, arrastró tras de sí, todas las experiencias acumuladas en relación al diseño funcional de otras épocas (como se verá en el apartado 4.6., al abordar el pensamiento de Herwin Schaefer). En nuestro caso particular, el funcionalismo resulta un concepto de registro de experiencias pasadas, que combina grandes expectativas de cambios a futuro. Con ello, "estos conceptos generan, en cierta forma, un proceso inmanente al lenguaje, un potencial de movimiento y de modificación temporal con independencia de su contenido de realidad" [La cursiva es del autor] (Koselleck, 2004, p. 37). 


\subsection{Mitologías persistentes en la Historia de las Ideas}

Si bien esta investigación historiográfica, en general, se fundamenta en los estudios de la Historia Conceptual, los aportes desarrollados por el académico inglés Quentin Skinner (2000), en su artículo: Significado y comprensión en la historia de las ideas, no deberían obviarse. En primer lugar, estos aportes previenen los errores en los que se cae habitualmente, cuando se interpretan textos de tipo histórico, y por otro, propone una metodología, para intentar descubrir la intencionalidad con la que los autores estudiados produjeron sus enunciados en determinado contexto. Cuando los historiadores se enfrentan a una obra que intentan comprender, suelen creer que el procedimiento adecuado para abordarla se encuentra condicionado por dos respuestas o metodologías ortodoxas, que aún gozan de una gran aceptación. Por un lado, se supone que el contexto de los factores políticos, religiosos y económicos determinan el sentido de cualquier texto histórico, debido a que proporciona el marco decisivo para lograr comprenderlo, camino al que Skinner define como un análisis contextual. Y por otro, se sostiene que el texto a través de su propia autonomía representa la única vía para comprender su verdadero sentido, de allí que excluya la reconstrucción contextual por el análisis textual.

Para Skinner, estas dos metodologías comparten la misma inadecuación, ya que sus enfoques - al contener confusiones y errores conceptuales empíricos-, no podrían considerarse como medios aislados suficientes para analizar obras literarias o filosóficas, en la búsqueda de la comprensión de cualquier enunciado.

Pretender entender la historia de las ideas, desde el estudio del texto mismo o solo a través de la reconstrucción del contexto social, es para Skinner una tarea insostenible, dado que analizar lo que un autor clásico dijo en una 'cultura ajena', conduce -empíricamente-, a que el historiador comprenda lo 'desconocido' en términos de lo 'conocido', a través de cualquiera de los dos enfoques o metodologías que elija. Esta manera determinante en la que opera la percepción y el pensamiento ineludible, dificulta la tarea del historiador, en su objetivo de interpretar adecuadamente el sentido histórico de las ideas de los textos que analiza.

En resumen, a la hora de hacer historia, Skinner (2000) encuentra que tanto los enfoques contextualistas como los textualistas - al modo de Leo Strauss-, son insuficientes. Esta insuficiencia se basa en la diferencia entre explicar y comprender. La explicación es causal; así, el texto es comprendido como un efecto de causas exteriores a él; como, por ejemplo, cuando se intenta explicar el significado de un texto determinándolo como un producto de los conflictos de clases imperantes en una sociedad, en un momento determinado. Pero, Skinner sostiene, que explicar un texto — dar las causas que lo produjeron-, no es lo mismo que comprenderlo. El contexto puede ser esencial para entender un texto, pero no lo agota. Hay un hiato que la lectura contextualista no puede superar, ya que supone que el texto se explica todo en determinaciones exteriores a él. Por el contrario, continúa este autor, si lo que buscamos es comprender un texto, entonces tenemos que atender a la intención significativa desarrollada en él.

No obstante, tanto la explicación como la comprensión del estudio histórico actual de las ideas se encuentra contaminado por paradigmas, que, al ser aplicados inconscientemente por el historiador, encubren una disfuncionalidad respecto del pasado que se intenta 
analizar. En otras palabras, en los intentos de perseguir la comprensión histórica, las expectativas que mueven al historiador pueden llevarlo a determinar que el autor - a quien busca interpretar-, haya dicho algo que nunca habría aceptado decir. En la intención de anatomizar dichos absurdos históricos alcanzados a partir de la implementación inadecuada de la exégesis, Skinner diversifica dichas mitologías en cuatro clases: la mitología de las doctrinas, de la coherencia, de la prolepsis y del localismo.

El caso más común de la mitología de las doctrinas, reposa en aquellas observaciones circunstanciales donde el historiador, a través de una similitud terminológica, le atribuye a un autor, no solo la concepción de una idea que no pretendió formular, sino también una sucesión, que en forma de doctrina es desarrollada ulteriormente por otros.

Por mitología de la coherencia Skinner (2000) caracteriza al peligro (tal vez más insidioso) de atribuir con demasiada ligereza una doctrina que un autor dado podría haber querido formular, pero que en realidad no tenía intenciones de comunicar" (p. 153). Si el exégeta no logra encontrar - en un texto-, un alto grado de coherencia, se concentrará en revisar la mayor cantidad de obras que estén a su alcance para construir una perspectiva o una interpretación unificada del sistema de un autor. De allí que la unificación del pensamiento - que niega las divergencias que un autor puede presentar a lo largo de su vida-, bajo la apariencia de un sistema cerrado, represente la base de esta mitología (p. 162).

Si bien la prolepsis se define como una figura retórica que anticipa aspectos que devendrán, Skinner considera que sigue siendo un recurso narrativo anacrónico, dado que desde el presente se recrea un acontecimiento que ocurrirá después. Así, califica de mitología de la prolepsis cuando el exégeta, al intentar describir con veracidad la significación histórica de un autor clásico, puede presuponer una visión de su causación histórica. Y con ello, una aparente anticipación de los aspectos que, originados en elementos clásicos, pudieron no estar presentes en las intenciones o las acciones descritas por el autor en cuestión.

Por último, según Skinner (2000), pretender comprender una cultura ajena o un esquema conceptual lejano, conlleva a que el historiador, al aplicar criterios de clasificación de su tiempo, corra el riesgo de encontrar algo en su análisis textual que proporcionará una descripción engañosa de familiaridad. A este absurdo histórico, Skinner lo considera como una mitología del localismo, que asume dos formas conceptuales. La primera, consiste en referenciar, de manera equívoca, el parecido entre el argumento de un autor con otro como una influencia causal; y la segunda en la conceptualización de un argumento, donde sus elementos extraños se disuelven con familiaridad engañosa.

El objetivo de rastrear el uso del concepto de funcionalismo, enmarcado en una diversidad de significados y fenómenos condensados aparentemente en la forma de una doctrina, y puesto en práctica desde el Diseño, en el contexto histórico y social en Chicago, Bauhaus y HfG, justifica un análisis particular. Para la realización de este análisis, la metodología de lo Histórico Conceptual propuesta por Koselleck, se complementará con el significado y la comprensión en las Mitologías presentes en la Historia de las Ideas de Skinner, para poder comparar lo que enunciaron las fuentes primarias, con lo que interpretaron las secundarias, en periodos posteriores, sobre ellas. 


\section{Genealogía del funcionalismo}

El presente análisis aborda también las genealogías que se han elaborado alrededor de este concepto. Entre los teóricos más representativos que lo han estudiado, resaltan el arquitecto inglés Peter Collins, y Robert Edward De Zurko, arquitecto de la Universidad de Columbia, Nueva York. A través de sus abordajes - contrastantes entre sí-, utilizando analogías coyunturales y linealidades, transitan por amplios recorridos con incisiva profundidad. Estas razones los habilitan como los antecedentes, o fuentes secundarias iniciales, desde las que se desarrollará la genealogía de este concepto, para esta tesis en particular. Las reflexiones de Collins y De Zurko, al ir más allá del mero origen del concepto, advirtieron sobre la intención de los teóricos de la arquitectura moderna, respecto de hallar nuevos referentes que satisficieran la necesidad de fundamentar sus teorías emergentes. Sin embargo, las adecuaciones y los ismos derivados de esta necesidad parecieron condensarse, de manera ambigua, en la frase mítica tan debatida en la arquitectura y el diseño: la forma sigue siempre a la función, quedando instalada como el axioma por antonomasia del funcionalismo.

\subsection{Consideraciones y reflexiones entre Collins y De Zurko}

Del rastreo historiográfico de Collins (1970) sobre el concepto de funcionalismo, se valora su análisis incisivo y la profundidad con la que trazó cada una de sus reflexiones, en torno a cómo la adecuación de las analogías biológica, mecánica, gastronómica y lingüística, no alcanzaron para fundamentar las teorías de la arquitectura moderna. Debido a ello, estas analogías, emergen para él como el intento heurístico frustrado de una transposición empírica hacia las teorías arquitectónicas del siglo XIX, que se condensaron bajo la figura del funcionalismo. Esto, porque para el mencionado autor, las soluciones espaciales no podían hallarse en los lugares comparativos de los organismos, las máquinas, la gastronomía y el lenguaje; sino en razonar e identificar las deficiencias y fortalezas de las obras arquitectónicas que ya habían sido construidas.

Lo más importante que se logra extraer de Collins (1970), es que el funcionalismo es decididamente una analogía. Si bien las analogías son útiles para comprender un fenómeno, o para ser usadas como métodos abductivos para lograr nuevas creaciones, no trascienden, aún en el mejor de los casos, más allá de su valor poético. En el conocimiento proveniente de las analogías, que se considera disruptivo, este autor identifica un valor poético basado en las semejanzas que proviene de la observación. Por ende, al considerar a la observación como subjetiva - no constatable, no universalizable, ni replicable-, piensa que no alcanza para funcionar como fundamentación científica. Por esta razón, Collins no halla fundamentos científicos para la arquitectura, y aunque la práctica de los racionalistas es lo que podría considerarse más cercano a la ciencia, el racionalismo tiene sus límites.

Aunque se pueda hablar de una conexión entre las disciplinas proyectuales y los sentimientos, "la relación entre arquitectura y ciencia siempre habrá de ser el fundamento de su existencia" (Collins, 1970/1998, p. 204). De todas maneras, aunque su tentativa por 
demostrar que las analogías fueron intentos fallidos por hacer inteligible la constitución de métodos para edificar de manera ideal, el escudriñamiento que se le imprime a las fuentes primarias que él reinterpreta, validaron en la mayoría de los casos, que no fueron tan inútiles como parece. La importancia de extraer los momentos más sustanciales de su texto radica en demostrar que, a excepción de las versiones morales y lingüísticas, las demás apreciaciones biológicas se dieron en el estudio de la Arquitectura y el Diseño. Esto es, que las innovaciones arquitectónicas y de diseño adaptables al contexto (montaña, mar, llanura, otros seres, etc.); e interactuantes con el ambiente (clima, recursos); y proclives a la partición y modulación (como una forma de reproducción celular), entre otras, ya estaban previstas en el lenguaje del sistema biológico. Esta asociación se retomará al final de la tesis, al observar las dependencias epistemológicas.

En las distinciones valorables de Collins (1970), también se halla una aclaración puntual, que consiste en que se debe diferenciar que una cosa es relacionar la belleza con los aspectos más simples de la eficiencia funcional, y otra es el hecho de que las analogías que se desprendan de ella respalden una corriente o doctrina para crear y construir edificios. A diferencia de Collins, la visión con la que De Zurko (1957) desarrolla su estudio sobre el funcionalismo, concentra un interés especial en la conexión existente entre los concep$\operatorname{tos}^{2}$ de forma y de función. Si bien el ya mencionado autor, en una de sus tantos análisis, define al funcionalismo como la puesta en práctica de los razonamientos resultantes de dicha conexión, recalca que no alcanzaron el desarrollo suficiente como para ser categorizados, con bases racionales, en forma de teoría. De Zurko (1957) también considera que las analogías representaron un punto de partida del funcionalismo, y las clasifica en tres categorías: mecánica, orgánica y moral/ética. Sobre las dos primeras plantea que, mientras la analogía mecánica se encuentra ligada a la Revolución Industrial y a la perfección con que fueron construidas las máquinas, la analogía orgánica se sustenta en que el concepto de perfección se halla en la naturaleza; y ambas son usadas como los espacios de inflexión de los arquitectos.

No obstante, en las reflexiones de ambos, los intentos por darle un fundamento a las teorías que se desarrollaron en el contexto de la arquitectura moderna tendieron a ser, para Collins, intentos ingenuos de teorización; y para De Zurko, dependencias carentes de una firme base racional. La importancia de haber relevado los análisis de estos dos autores radica en que, gracias a las analogías, se establece una divergencia con los estilos del pasado, y se abre una nueva historia de la arquitectura. Por otro lado, si bien el objeto de estudio de Collins y De Zurko se enfoca más en la Arquitectura y no tanto en el Diseño Gráfico e Industrial, la promesa epistemológica que parte de la biología representa para ellos un aspecto importante, que debía documentarse como una nueva puerta que se abría en la historia del diseño. En otras palabras, la Arquitectura y el Diseño, comienzan a desprenderse de los neos y los historicismos, para incorporar nuevas fundamentaciones tipológicas, morfológicas y constructivas, que las dignificarían como disciplinas proyectuales. 


\section{El concepto de funcionalismo en sus contextos de enunciación. relevamiento de las fuentes primarias}

\subsection{Presentación de las tres escuelas}

Las teorías de la Arquitectura moderna justificaron la adecuación de las analogías en Occidente como su punto de partida. Sin embargo, las visiones diádicas administradas por un orden de sucedaneidad — propuestas inicialmente por Cuvier y Saint Hilaire-, fueron criticadas por Collins y De Zurko como una base conceptual ambigua y utópica de alcanzar. Empero, el análisis sobre el pensamiento orgánico de Louis Henri Sullivan, condensado en su frase: la forma sigue siempre a la función, aunque mantuvo un orden móvil de sucedaneidad, es con Wright que dicha adecuación, alcanza un orden de simultaneidad: la forma y la función son una; como una máxima aplicable a la arquitectura de finales del siglo XIX y principios del XX. Este hallazgo, evidenció que tanto Sullivan, como su discípulo Frank Lloyd Wright, alcanzaron sus objetivos teóricos, poéticos y constructivos. Sullivan y Wright, al igual que otras fuentes primarias preliminares que se abordarán en este apartado, desarrollaron una filosofía del diseño que tuvo por objeto proyectar edificios en sintonía con el espíritu de sus épocas respectivas. Para ese momento, tales intereses se encontraban desligados de los arquitectos, debido a una búsqueda de la belleza a partir de la reutilización de los estilos del pasado. La filosofía que concibieron, en el contexto de la Primera Escuela de Chicago, abstrajo los aspectos esenciales de la vida norteamericana. La satisfacción de estos aspectos, que eran representados en forma de necesidades, propuso hacerlo a partir de una relación especial entre la forma y la función, adecuadas para ese fin. Dicha adecuación, le otorgaría el carácter diversificado a cada edificio en concordancia con el propósito para el que fueran creados. Los desarrollos en los campos del diseño y de la construcción de edificios en el contexto de la ciudad de Chicago, a finales del siglo XIX y principios del XX, aglutinaron una serie de técnicas divergentes que respondieron, inicialmente, a requerimientos económicos y sociales locales. Estos avances, se diseminaron, más tarde, por todo Norteamérica, conformando un movimiento arquitectónico al que se lo denominó como Primera Escuela de Chicago. Esta designación semántica, que se distinguía de los claustros de formación en Arquitectura de la época, cobró vida en las contribuciones que emergían de los estudios o agencias de Arquitectura creadas por: William Le Baron Jenney, Henry Hobson, Danield Hudson Burnham, John Root, Dankmar Adler y Louis Henri Sullivan, entre otros. Se le denominó también como primera escuela, dado que, en 1938, el arquitecto alemán Mies van der Rohe, al emigrar de Europa hacia Estados Unidos por los efectos de la Segunda Guerra Mundial, instauró un movimiento sucedáneo, designado como la Segunda Escuela de Chicago.

En Alemania, para principios del siglo XX, se comenzaron a gestar iniciativas pedagógicas con finalidades similares. Dichos intentos, tenían el objeto de encauzar y ampliar las facultades del arquitecto en concordancia con las exigencias de las sociedades alemanas y sus sistemas productivos. Una de ellas fue una escuela que nació en la ciudad de Wëimar en 1919: la Staatliches Bauhaus, fundada por el arquitecto Walter Gropius. El nuevo orden creador propuesto en la Bauhaus se enfocó en contrarrestar la indiferencia existente entre el arte de la época, en relación a las exigencias que demandaba la vida práctica de 
los hombres, y los sistemas de producción industrial. Para instaurar un vínculo entre las necesidades de las personas y la industria, Walter Gropius, junto a un grupo de profesores, presentó un programa pedagógico que pretendió poner en colaboración consciente: las virtudes del oficio artesanal y sus técnicas, la creatividad del artista, los avances de la ciencia, y la mecanización con la visión del comercio. El programa estaba fundamentado en estudios intensivos para redescubrir lo que Gropius denominó como la nueva gramática del diseño. Con esto se buscaba restablecer el objetivo original de las academias, que consistía en desarrollar teorías que partieran de hechos ópticos y de leyes naturales. El rol de estas teorías sería el de nutrir las artes para reestablecer su verdadera tradición en concordancia con la realidad ${ }^{3}$, en lugar de continuar incentivando la imitación de las formas del pasado. Dicho programa se concentró en un adiestramiento manual y mental, que promovía una nueva generación de arquitectos. Esta figura del nuevo arquitecto en formación, trabajaría en sus laboratorios de creación en correspondencia con los sistemas de producción de su momento. En otras palabras, el arquitecto de la Bauhaus devenía en creador y responsable de toda factura humana, desde el diseño de una silla hasta el urbanismo de toda una ciudad. Así, este nuevo arquitecto tenía como responsabilidad expresar la arquitectura derivada del ideal espiritual de una época. Sin embargo, el proceso de estandarización de sus objetos, sucedido más tarde, debido a la cercanía con la ciencia, la industrialización y a un interés concentrado en la funcionalidad, devino en un aspecto ascético, puro, geométrico y simplificado. Esto la convirtió en un blanco de críticas y debates, en donde algunos teóricos etiquetaron el resultado de muchos de sus ejercicios como "el estilo Bauhaus". Veinte años después del cierre de la Bauhaus en la ciudad de Berlín, provocado por el nacionalsocialismo, se funda en la ciudad de Ulm la HfG Hochschule für Gestaltung. La HfG (versión abreviada de su nombre), nació en 1953 como una escuela de Diseño que, fundada por Inge Scholl y Otl Aicher, proponía una formación orientada hacia la función social proyectual. De la mano de su primer rector, Max Bill, el 2 de octubre de 1955 tuvo lugar su inauguración, y si bien dicha función fue vista como una especie de continuidad de la tradición Bauhaus, su objetivo real se concentró en superarla, en concordancia con las condiciones económicas y productivas de ese momento. El estudio histórico de la escuela de Ulm, envuelta en consensos y disensos políticos internos (tal como sucedió con su predecesora), y a pesar de que las condiciones eran completamente distintas, sugiere dos aparentes fases dominantes. La primera es la del anteriormente mencionado Max Bill, que consistió en cuestionar la adición decorativa de la forma, donde la relación entre la forma y la función debía tender hacia la belleza y la perfección. La segunda es la de Tomás Maldonado, donde la ciencia y la investigación, en relación cercana con la industria y la tecnología, no debía dejar cabida para el arte.

Sin embargo, los aportes sobre el concepto de función, provenientes de las múltiples influencias, devinieron en una especie de racionalización que privilegió una visión sistemática de las funciones. Debido a ello, tanto Chicago, como Bauhaus y la HfG, ameritan indagaciones de corte historiográfico, para verificar si a través de los conceptos que implementaron cada uno de sus actores, que en esta investigación funcionan como fuentes primarias, se hallaron o no conectados a través de los ismos y los estilos. Entre ellos: el estilo Bauhaus, el estilo Funcional, el estilo Internacional y el Funcionalismo; todos estos son conceptos que aún hoy necesitan aclaración. En síntesis, a través de la voz de sus actores 
principales, se observará en qué aspectos estas escuelas manifestaron una continuidad, y en cuáles unas rupturas respecto de las trayectorias anteriores de Sullivan y Wright.

\subsection{Primera Escuela de Chicago}

\subsubsection{La postura de Louis Henri Sullivan: la visión orgánica}

Según la postura crítica que asume Sullivan con respecto a la arquitectura moderna americana, ésta adolecía de una patología que pedía ser tratada prontamente. En sus libros: Charlas con un arquitecto (Kindergarten Chats y otros escritos) de 1918, y Autobiografía de una idea, de $1922^{4}$, es directo en aludir a la manera en que los arquitectos reproducen las formas de los edificios del pasado. Según Sullivan $(1918,1922)$, estas características de los arquitectos se deben a la indiferencia y subvaloración de sus propias capacidades creativas respecto de las intelectuales, su rol ausente como representantes del espíritu democrático de los pueblos y sus épocas, el entorno económico, y una mirada sesgada de la arquitectura como el arte expresivo que posee una fuerte base social. En el texto de 1918, a partir de una conversación hipotética ${ }^{5}$ en la que recrea la relación entre un maestro y su leal aprendiz, Sullivan nos muestra la necesidad de estudiar la arquitectura a partir de su reflejo, es decir, de los edificios. Esto debiera hacerse con el fin de identificar, acusar y plantear un remedio para lo que amenaza su comprensión, debido a que, para él, la arquitectura es el producto de un gran arte plástico, que tiene como objeto representar los aspectos esenciales de una civilización.

\subsubsection{La significación de la arquitectura orgánica. Los edificios como pantallas}

La mirada ontológica de Sullivan (1918) lo lleva a señalar el comportamiento sumiso ejercido por los arquitectos norteamericanos, al repetir e importar, de otros tiempos y lugares, lo que él designa como el estilo. Tal estilo, surge como una solución formalista, estética y anacrónica, que no corresponde con el ritmo de su tiempo, al operar como una peste que intimida a la sociedad y acelera su decadencia. Además de criticar este grado obtuso de operatividad, Sullivan se concentra en explicar que los edificios que vemos, no son más que la imagen de un hombre que no vemos; y que el impulso para que refleje lo que debe ser, proviene exclusivamente del esfuerzo de ese hombre, al que denomina como el arquitecto. El arquitecto tiene la responsabilidad de diseñar y construir los edificios, anticipando que funcionen como pantallas. Los edificios como pantallas son portadores de un conjunto de valores que tienen como finalidad reflejar el espíritu del pueblo que eligió al arquitecto como su representante. Por ello, se encuentra obligado moralmente a proyectar, ${ }^{6}$ con sus formas surgiendo desde el interior hacia el exterior, la esencia cultural de quienes lo delegaron para la tarea de construir. Es de esta manera cómo explica que funciona la arquitectura orgánica. Sin embargo, si el arquitecto que el pueblo ha designado es indiferente, la arquitectura no será más que una cosa de un lugar y una época improcedente, por lo que su resultado será una imagen irresponsable y degenerada de lo que realmente debería ser.

La cuestión o el fenómeno general que hemos de investigar, es patológico en su aspecto inmediato y mucho más en su espíritu. Es un hecho triste, pero indudable, que la arquitectura norteamericana está desmoralizada y que el ar- 
quitecto no sólo está mentalmente desavenido con su arte, sino también social y económicamente, fuera de ritmo con su época [...] nuestros edificios, todos, son sólo una enorme pantalla detrás de la cual se oculta el conjunto de nuestro pueblo - aunque los edificios sean imágenes individuales de aquellos a quienes, como clase, el pueblo ha delegado y confiado su poder constructivo. Por lo tanto, y de acuerdo con esto, el estudio crítico de la arquitectura llega a ser no sólo el estudio de un arte - pues esa es una fase menor de un gran fenómeno- sino, in extenso, un estudio de las condiciones sociales que las originan; el estudio de un nuevo tipo de civilización en proceso de formación. Bajo este aspecto, el estudio de la arquitectura se convierte natural y lógicamente en una rama de las ciencias sociales. (Sullivan, 1918/1957, pp. 11, 14)

Sullivan explica su metáfora de los edificios como pantallas, ya que al responder estos a un deber moral $^{7}$, dan cuentan del espíritu fidedigno de un pueblo, la época para la que fueron originados, y las necesidades que se satisfacen a través de ellos. Es así como se debe analizar si el arquitecto logró abstraer, y luego representar -o en el peor de los casos, desfigurar-, a la sociedad que lo designó, gracias al carácter del edificio, y a su aspecto distintivo exterior, que es lo que lo diferencia de otros edificios, según su propósito. Esta es la razón por la que un edificio de oficinas no puede, bajo ninguna justificación, parecer un hotel, una tienda, un banco o un hospital. En sus palabras: "nada refleja más claramente el estado y la tendencia de un pueblo que el carácter de sus edificios. Son emanaciones del pueblo; representan para nosotros el alma de nuestro pueblo. Son como un libro abierto" [La cursiva es del autor] (Sullivan, 1918/1957, p. 56). El carácter vendría a ser, para Sullivan, la distancia que separa la evolución de la arquitectura orgánica, de la decadente arquitectura moderna norteamericana, donde gran parte de su sintomatología proviene de una relación perversa entre el monopolio establecido por el feudalismo, la educación y la acumulación de conocimiento que tanto profesan.

\subsubsection{El sentido tácito del valor}

La preocupación esencialista y moral de Sullivan (1918) lo lleva a juzgar que las verdaderas causas de un edificio no son externas sino internas, y ello se debe a la visión democrática $^{8}$ del arquitecto norteamericano. Dicha visión democrática la fundamenta a partir de lo que él llama el sentido tácito del valor. Esta visión consiste en poder entender la arquitectura en términos de significación ${ }^{9}$, donde las formas resultantes poseen y hablan en un lenguaje particular que va más allá del valor práctico y monetario, o valor dólar, ${ }^{10}$ como suele denominarle.

No obstante, tomado en conjunto, hay una conciencia general en la comunidad, de que existen ciertos valores que no pueden ser, ni son, medidos por el dinero; ciertos servicios prestados, cuya fuerza de causa, o mecanismo de cambio o escala de medida no es el dinero. Y es tácitamente sentido y reconocido, que tales servicios son de gran y positivo valor para la comunidad; que contribuyen a su riqueza, si la riqueza es tomada en su acepción más amplia y extensa. (Sullivan, 1918/1957, pp. 24-25) 
El valor práctico se refiere al papel que vinculará a la materia con el hombre, es decir, cuando un árbol es en potencia una casa, o una parte de ella, gracias al valor que posee su madera como protección. El valor monetario, por otro lado, no es más que la equivalencia de la materia en términos económicos, de allí que lo designe con mayor frecuencia como: el valor dólar. Sullivan explica que, cuando el arquitecto diseña y construye como se debe, transfiere un valor simbólico a la obra ${ }^{11}$. Esta transferencia conlleva que en el edificio se enaltezcan los valores anteriores que poseía la materia, de la que dependió para ser construido. Así, manifiesta que los materiales que se usan para construir, portan un significado implícito en su sentido objetivo/externo, y se transforman gracias al sentido subjetivo/interno que le infunde el arquitecto. La materia, objetiva por naturaleza, es reorganizada por lo que Sullivan distingue como la Filosofía de la Naturaleza Moral, "una fuerza mecánica, muscular, mental, emocional, moral y espiritual” (Sullivan, 1918/1957, p, 23), que parte de la subjetividad proveniente de su mente creadora. El valor, entonces, surge como una condición de transferencia, que va más allá del valor superficial de los materiales. Esto se debe a que el arquitecto abstrae el espíritu de una civilización, con el fin de convertir lo objetivo en subjetivo. Es de esta manera como transfiere un agregado inmensurable, que la materia antes por sí sola, no poseía: una parte de sí mismo, del espíritu del pueblo al que representa y del entorno al que pertenece, que es el lugar donde el arquitecto y el pueblo se diluyen como si fueran una sola imagen. Ver Gráfico No. 2.

\section{El Sentido Tácito del Valor en la Arquitectura Orgánica Según Louis Henri Sullivan (1918)}

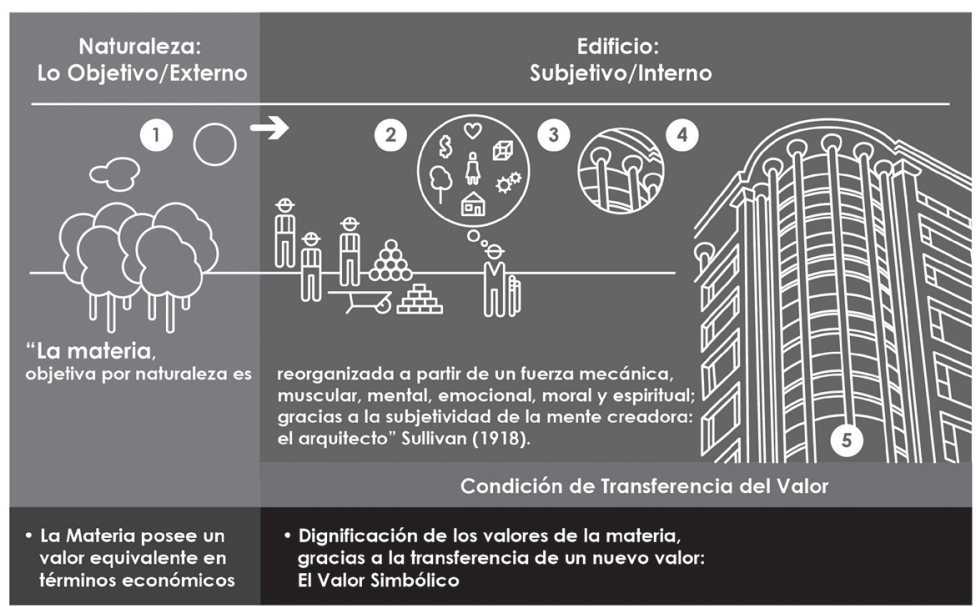

1. La Materia poseé un Valor Práctico y equivale a un valor monetario o valor dólar.

2. El arquitecto, a partir de la 'abstracción' identifica los aspectos esenciales de una civilización (su espíritu).

3. Luego, 'representa' y 'sistematiza' las funciones que satisfarán potencialmente las necesidades humanas, al aplicar la condición de 'transferencia' del valor; lo que dictamina el aspecto del edificio y su carácter. 4. Gracias a su forma resultante, el edificio funciona como la pantalla del espíritu del pueblo.

5. El edificio, en sus formas, es portador de un Sentido Tácito del Valor. 


\subsubsection{El pensamiento orgánico}

Pero, ¿cómo se supone que funciona este proceso de reorganización de la materia, a partir de la figura de la Filosofía de la Naturaleza Moral? Sullivan (1918) señala que el Sentido Tácito del Valor, habla de una manera sensible que va más allá del modo en que lo hacen las palabras en el lenguaje. Esto lo hace a través de un sinnúmero de imágenes, concebidas por un tipo particular de pensamiento: el Pensamiento Orgánico.

El verdadero pensamiento se formula mejor sin palabras que con ellas, por ello el pensamiento creativo debe ser formulado sin palabras [...] De ahí que sea necesario, pensar en términos de imágenes, de descripciones de estados de ánimo, de ritmo [...] La escritura es sólo el lento arrastrar de las palabras, a paso de tortuga, trepando laboriosamente, sobre un pequeño edificio que se asemeja al pensamiento. [La cursiva es del autor] (Sullivan, 1918/1957, pp. 42-43)

Esta figura, equivale a la sumatoria armónica entre el pensamiento intelectual ${ }^{12}$ y el pensamiento creativo que desarrollan, según él, los verdaderos arquitectos. Esta es la razón por la que sostiene que el arquitecto es un producto de la civilización, y como su producto, tiene el deber y la función social, de crear edificios que se correspondan con las necesidades reales del pueblo.

En su sentido más limitado, el valor de una gran pintura podría calcularse en base al costo del lienzo, de la pintura, y de una asignación diaria razonable por el trabajo manual de aplicar las pinturas al lienzo. Todos saben, empero, que no es así. Todos saben y sienten que el gran artista ha dado a las pinturas un valor que no poseían antes. Que les ha transferido algo de sí mismo y algo del mundo. Que ha convertido en subjetivo lo que antes era objetivo. (Sullivan, $1918 / 1957$, p. 25)

Sin embargo, para Sullivan, cuando el arquitecto, en nombre de la erudición, suprime el valor simbólico y su impulso creativo, y lo reemplaza por el pensamiento intelectual aislado en la relación entre feudalismo ${ }^{13}$ y educación (a partir del gusto y el estilo de las gentes con cultura), a la arquitectura no le queda más que convertirse en un mostrador de ocasiones, y al arquitecto en un revendedor de modas. Debido a esto, Sullivan toma una postura directa en contra de los eruditos y sus escuelas de Diseño, basadas en la re-implementación de los estilos arquitectónicos de otros tiempos, como templos egipcios, griegos y romanos entre otros, para solucionar de manera barata las necesidades de la vida norteamericana.

\subsubsection{Filosofía de la naturaleza moral}

No hay que malinterpretar a Sullivan (1918/1957), cuando se refiere despectivamente al pensamiento intelectual como el camino que nos desvía de la arquitectura orgánica. Lo que en realidad sugiere es que este tipo de pseudo-pensar, de naturaleza lógica, debe complementarse con el pensamiento creativo, de naturaleza instintiva, para que juntos accedan al Pensamiento Orgánico, que se conecta con la Filosofía de la Naturaleza Moral. Dicha filosofía, a partir de las dimensiones del hombre $e^{14}$, desarrolla el Don de la Abstrac- 
ción. Este don, habilita al arquitecto a partir de sus cuatro grandes acciones: la intuición, la imaginación, la inspiración y la expresión. Estas acciones, que funcionan en un grado significativo de sensibilidad, encaminan al arquitecto a abstraer adecuadamente la esencia de una civilización. Cada una de ellas se encuentra sujeta a su respectiva condición, que corresponde a una de las tantas etapas que el arquitecto debe tomar en cuenta, para poder alcanzar la arquitectura orgánica a través de sus obras.

Tiene ese exaltado sentido animal que puede por sí solo hallar el sendero al saber oculto; ese agudo e instintivo olfato en las cosas objetivas que conduce a las cosas subjetivas, y que llamamos Intuición [...] ....una concentración de la acción, una determinación de objeto en la selección de ese alimento de las facultades que, luego de ser asimilado, ha de convertirse a su vez en pensamiento y expresión por intermedio de un segundo deseo igualmente grande, igualmente intenso, igualmente insistente: el deseo de actuar. Este deseo de actuar lo llamamos Imaginación [...] Es esta divina facultad la que, en un instante iluminado, en ese momento supremo en que nacen las ideas, revela el fin con el principio, y libera, como a un vástago del hombre, aquello que previamente, $\mathrm{y}$ quizá durante indecibles centurias, había descansado, había permanecido dormido pero potente, en lo más íntimo de la naturaleza. Esta es la crisis suprema. Esta es la cumbre del alma, el fértil contacto del espíritu, la sonrisa generosa de la naturaleza — ¡el momento de Inspiración! [...] ...la última, y la más simpática, exuberante de vida y movimiento, copiosa en su lenguaje, es la Expresión, con los brazos abiertos, libre, dócil, altiva, dramática, variable, hermosamente pensativa, persuasiva, magnífica. A ella corresponde vestir la estructura del arte con una forma bella, pues ella es la perfección de lo físico, es lo físico en sí mismo, y la más alta realización de emotividad. [La cursiva es del autor] (Sullivan, 1918/1957, pp. 187-188)

En la mirada de Sullivan (1918/1957), la intuición, sujeta a la identificación, detecta una oportunidad, reto o problema potencial, que el diseño arquitectónico puede abordar. Es así como identifica y sintetiza los aspectos esenciales de una civilización; y traza, de esta forma, una imagen detallada de cada uno de ellos, que conforman la gran función que subsiste en su espíritu. La imaginación toma en cuenta todos estos aspectos. Ella los organiza, clasifica y subdivide de manera detallada y sistemática, para representarlos y traducirlos en forma de subfunciones. Al respecto, debe tenerse en cuenta que el espíritu, o gran función, representa la totalidad, y las subfunciones cada una de sus partes.

Entonces, deduzco, que, si lo deseo, puedo seguir y considerar a mi detalle como conjunto en sí mismo, y proseguir con la subdivisión regular y sistemática de función con forma, como antes, y siempre hallaré una similitud, una calidad orgánica - si adivino su intención - que desciende del conjunto a la más ínfima subdivisión del detalle. [La cursiva es del autor] (Sullivan, 1918/1957, p. 39) 


\subsubsection{Similitud que confirma su pensamiento analógico}

Para Sullivan, la inspiración emerge en una sucesión que propone un sinfín de soluciones - conceptuales y tentativas-, que responden a cada una de estas subfunciones, ya completamente sistematizadas. Por último, la expresión materializa la correspondencia entre las partes, y la gran función, que las cobija en el todo; a partir de una culminación a lo que los arquitectos llaman: la forma. Ver Gráfico No. 3.

\section{El Pensamiento Orgánico. Filosofía de la Naturaleza Moral y el Don de la Abstracción Según Louis Henri Sullivan (1918)}

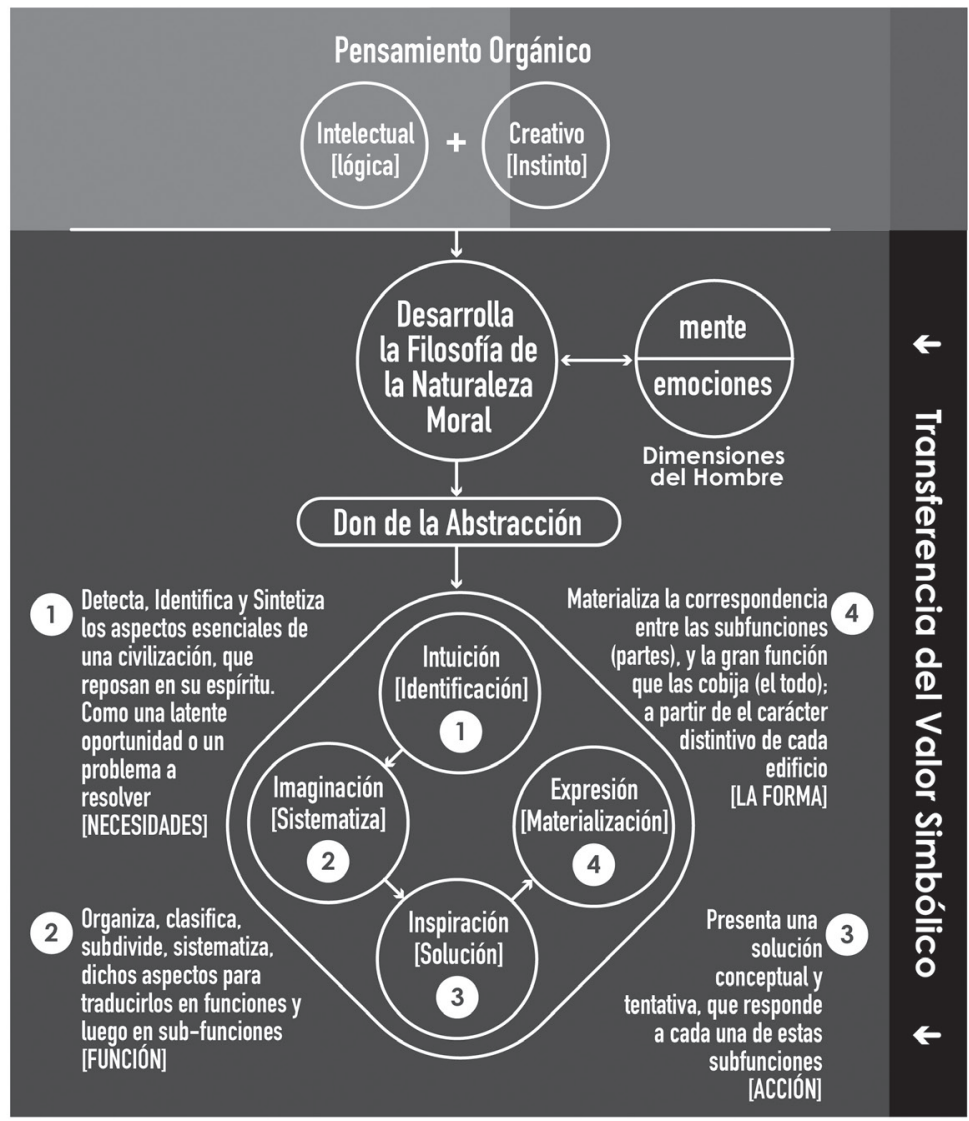

Gráfico No. 3. Elaboración propia 
Es así como el arquitecto, al acceder al pensamiento orgánico, desarrolla la filosofía de la naturaleza moral, que le otorga el don de la abstracción; y junto a sus cuatro acciones, es que alcanza la arquitectura orgánica. Esta cita de Sullivan, explica el sentido de su frase: la forma sigue a la función, dado que se fundamenta en una imitación del crecimiento de los organismos.

Es la ley invariable de todas las cosas orgánicas e inorgánicas, de todas las cosas físicas y metafísicas, de todas las cosas humanas y sobrehumanas, de todas las verdades manifiestas de la cabeza, del corazón, del alma, en que la vida es reconocible en su expresión, que la forma sigue siempre a la función. Esta es la ley. (Sullivan, 1918/1957, p. 203)

Sullivan (1918) hace responsable a las escuelas de Diseño de estimular a los arquitectos a aplicar el pensamiento intelectual, a partir de una especie de fórmula de conocimiento aislado, que se halla acumulado en los libros. Debido a esto, al no cultivar el don de la abstracción basado en la filosofía de la naturaleza moral, les cuesta reconstruir la esencia del espíritu de una civilización. Esta es la razón que los lleva a imitar las formas del pasado, o a importarlas de otros lados, junto al pulso de sus épocas y lugares respectivos. Dicha práctica no solo es la causante de la indiferencia cultural y democrática, sino también, de la ausencia material del carácter adecuado que respondería, según la relación dinámica entre la función y la forma, a la fisonomía ideal para cada edificio. En síntesis, si el arquitecto no aplica el pensamiento orgánico, no lograría desarrollar ese don, y tampoco podría sintetizar los aspectos esenciales de una civilización, es decir, sus formas de interacción, sus hábitos y valores distintivos; mucho menos representar y sistematizar las funciones que satisfarían sus necesidades. Por tanto, no transferirá el valor simbólico que debe proyectar el edificio para que funcione como una pantalla fidedigna que hable a través del lenguaje de sus imágenes. En un apartado de su texto de 1922, Autobiografía de una Idea, Sullivan sugiere la superioridad de las palabras sobre las imágenes:

En lo relativo a las palabras en sí mismas había llegado a formársele una aversión pasajera porque había notado su tendencia a ocultar vibrantes valores de la realidad inmediata. Por esto prefería pensar, sentir y contemplar sin recurrir a las palabras. A decir verdad, uno de sus pasatiempos favoritos consistía en pensar, sentir y contemplar deliberadamente sin recurrir a las palabras, creando así un universo sin palabras, en cuyo centro, silencioso, estaba él. (Sullivan, 1922/1961, p. 142)

Sullivan (1922), explica que esta confusión se debe también a la interrelación de un concepto que reposa en el germen de la abstracción, que debe ser comprendido y dilucidado, y que representa un escenario complejo que el arquitecto norteamericano no entiende, o no se preocupa por entender. Es este un concepto tan polémico que la arquitectura moderna, a diferencia de las culturas del pasado, no ha logrado discernir: el ornamento.

A partir de las invectivas de Adolf Loos, y los decálogos de los racionalistas puros, el ornamento fue un aspecto vapuleado, en el contexto de las teorías que abordaron la fun- 
cionalidad, debido a un axioma que lo escindió del ejercicio arquitectónico en la modernidad $^{15}$. Fue acusado por estos como un desperdicio de material, como elemento encofrado, revestimiento aplicado, o como un exceso burgués que se resistía, gracias a los arquitectos, a no dejar de cubrir los edificios norteamericanos. Siendo Sullivan (1918) un ornamentador por naturaleza, las críticas no se hicieron esperar. Sin embargo, el ornamento, para Sullivan, es todo menos lo que señalan Loos y los racionalistas. Para él, y aquí se halla su aporte divergente, una práctica arquitectónica puede ser funcional, así el arquitecto tome la decisión o no de usar el ornamento. Desde la postura de Sullivan, un edificio puede estar desprovisto de ornamentación, y puede igual reflejar a través de su pantalla el espíritu del pueblo al que representa. Porque es probable que se haya querido significar "noble y sencilla dignidad" (Sullivan, 1918/1957, p. 182).

En la teoría de Sullivan, se evidencia que el uso de la ornamentación es una cuestión de decisión, y se toma a partir de los procesos de abstracción que amerite cada civilización. Porque en un entorno, sea austero o de abundancia, el ornamento puede parecer o no un lujo innecesario, en lugar de verse como una necesidad. Debido a esto, no puede emerger en un edificio solo por el capricho del arquitecto o por una tendencia estilística de su comodidad. Sullivan explica que un edificio con ornamentación, surge casi como una expresión emocional de aquellos que lo usarán. Esto ocurre gracias a los aspectos que identifican la filosofía de la naturaleza moral del arquitecto, y que se pone en evidencia en las dimensiones de los hombres que lo encargan. Esta es la razón de que visualice al diseño ornamental como una substancia y no un añadido, (Sullivan, 1918/1957); debido a que le pertenece al edificio y al sistema de integración de todas sus partes. Para Sullivan, en la integralidad del ornamento, la masa estructural del edificio, y el ornamento son una sola cosa, que dialogan al no entorpecerse entre sí.

Es evidente que un diseño ornamental será más bello si parece parte de la superficie o substancia que lo recibe, y no un "añadido", si cabe la expresión. Si observamos bien, veremos que en el primer caso existe una peculiar simpatía entre el ornamento y el edificio, simpatía que no se observa en el último de los casos. Tanto el edificio como el ornamento se benefician con esta simpatía, pues cada uno realza el valor del otro. Y éste, según entiendo, es el fundamento de lo que podremos llamar un sistema orgánico de ornamentación. El ornamento, en verdad, se aplica en el sentido de ser separado, o agregado, o hecho de algún otro modo: sin embargo, debe parecer, una vez concluido, como si hubiera surgido de la substancia misma del material gracias a un agente benéfico, y allí existiera por el mismo derecho con que una flor aparece entre las hojas de una planta. Por medio de este método establecemos una especie de contacto, y el espíritu que anima la masa puede fluir al ornamento - ya no son más dos cosas sino una. (Sullivan, 1918/1957, pp. 183-184)

Por otro lado, su ingreso al M.I.T. (Massachusetts Institute of Technology) conocido también como el Tech, no influenció significativamente sobre él. En su regreso a Chicago, antes de viajar a Londres y luego a París, Sullivan conoció a John Endelmann, en el estudio del ingeniero William Le Baron Jenney. Este encuentro se produjo mientras Sullivan 
estaba en la búsqueda de cultivar y ampliar su experiencia laboral, y con ello, su portafolio. Junto a Endelmann, descubrió la indiferencia de las escuelas arquitectónicas, que no respondían a los espíritus de los pueblos norteamericanos, al suprimirlos en virtud del lenguaje reproducido de la tradición. Cuenta Sullivan (1922/1961), que, a esta postura, Endelmann la llamó "la teoría de las funciones suprimidas" (p. 147). Al compartirla este con Sullivan (por su representativo vínculo de amistad), aquel la tomó como una respuesta a la que denominó como la decadencia de la arquitectura norteamericana, y su vínculo con el feudalismo y la educación.

Más tarde, cuando Sullivan llega a Francia, con el anhelo de estudiar en la École National des Beaux Arts en París, conoce a Monsieur Clopet, quien fuera su profesor de matemáticas para el año de 1874. Con él aprendió que a todos los problemas se les halla la solución en su propia naturaleza inherente. Clopet afirmaba que todo problema contiene y sugiere su propia solución, premisa que Sullivan no dudó en trasladar hacia el diseño de sus edificios orgánicos, y de los más importantes de sus edificios de oficinas.

El problema del edificio alto para oficinas no se había resuelto porque no se buscó la solución en el seno del problema mismo, en su naturaleza inherente. Y cabe señalar aquí, después de años de observación, que la verdad más difícil de aprender, sobre todo por los intelectuales, es la verdad siguiente: que todo problema, cualquiera que sea su nombre o naturaleza, contiene y sugiere su propia solución; e invariablemente cuando se da con la solución, se ve que es de naturaleza sencilla, básica y evidentemente aliada del sentido común. Esto era lo que Monsieur Clopet quería realmente dar a entender cuando le dijo a Louis, en sus días de estudiante en París: "Nuestras demostraciones serán de tal naturaleza que no admitirán excepción alguna”. Monsieur Clopet no llevaba este principio más allá de sus matemáticas, pero Louis vio en un instante el infinito número de sus aplicaciones y el mundo de investigaciones que se abría ante él; pues al pasar este instante vio oscuramente, como a través de un velo, y llevó largos años la empresa de volver a aclarar la visión y dar con su fórmula. Por lo común, no se llega rápidamente a las invenciones, las cuales en realidad son soluciones. (Sullivan, 1922/1961, p. 223)

Para concluir el pensamiento de Sullivan $(1918,1922)$, un arquitecto, antes que arquitecto, es principalmente un hombre, y como hombre debe asumir la responsabilidad que acompaña a cada uno de sus poderes. Poderes que significan el potencial de lo que puede hacer a partir de los aspectos que configuran cada una de sus naturalezas: la física, la mental y la emocional. A la naturaleza física, Sullivan la define como el poder de elegir y manipular la materia, para que ésta pueda ser transformada en objetos serviles, a través de la fuerza y la destreza muscular de quien las moldea. Esto es lo que hace de todo hombre un trabajador, o un artesano hábil.

Así el hombre, trabajador, investigador, pensador, se hace cada día más unitario en el ejercicio de sus poderes: se convierte en el más gran trabajador. Pero hasta aquí sus resultados pueden ser puramente materiales, rigurosamente 
utilitarios y totalmente objetivos en el sentido corriente. La exposición de sus poderes hasta el momento en acción puede ser puramente intelectual y física: sin duda un aspecto unilateral. Pero el hombre tiene el poder del sentimiento, de la emoción: grandes poderes de su vida interior: de ahí que el hombre sea El Poeta. (Sullivan, 1918/1957, p. 93)

\subsubsection{Síntesis de la teoría sullivana}

La complejidad del universo conceptual que maneja Sullivan en su teoría, reflejada en la práctica de su arquitectura orgánica, es todo menos algo simple. El orden dinámico que la caracteriza lleva a que los elementos parezcan responder inicialmente a un orden de sucedaneidad básico. Sin embargo, si se lee a Sullivan con detenimiento, y se contrasta el sentido tácito que portan los edificios como pantallas que diseñó en el contexto de la arquitectura norteamericana, se advierte que cada concepto es dependiente. Esta dependencia no es solo respecto de un orden de sucesión, sino también de procedencia, entre los conceptos de forma y de función. El considerar todo esto, lleva a plantear que su postura consiste en una especie de ciclo, reactualizada con la misma velocidad, que las exigencias del entorno de cada civilización que las origina. Una relación teleológica e inescrutablemente móvil, donde la función condiciona la adecuación de la forma y todos sus aspectos, y donde el espíritu de los pueblos progresivos y cambiantes, presiona a que las formas novedosas que aún no emergen, sean dictaminadas a su vez a partir de nuevas funciones por abstraer. Lo anterior se produce en un ciclo reactualizante que no tiene fin, y esto constituye un lugar al que solo Coleridge logró acercarse, y donde Cuvier y Saint Hilaire, se perdieron en una linealidad determinista. "De la interrelación entre función y forma. No tiene comienzo, no tiene fin. Es inconmensurablemente pequeña; inconmensurablemente vasta; inescrutablemente móvil, infinitamente serena; íntimamente compleja, pero simple" (Sullivan, 1918/1957, p. 34).

Si bien Sullivan, con su lenguaje barroco, es complejo de descifrar, no es una meta imposible. El rastreo de sus conceptos, y la base en la que se sopesan estos, demuestra que la ambigüedad que tanto Collins como De Zurko señalan en él, emerge como interpretación alineada a la finalidad eminentemente poética de su teoría. También, cabe señalar que cuando una teoría arquitectónica se convierte en una práctica, y genera un patrón estético y formal, se tienden a usar indiscriminadamente los ismos.

Aunque Sullivan se esmera en explicar la relación móvil que establece entre sus conceptos de forma y de función, se debe aclarar que en ninguna parte de su obra habla de funcionalismo. Consecuentemente, de ninguna manera se lo puede mostrar como el creador o promotor de esta corriente, tal como figura, de forma errónea, en muchos trabajos de Historia. En todo caso, si se desea resaltar su pensamiento teórico, se debe hacer foco en su concepción de la Arquitectura Orgánica, y en su Filosofía de la Naturaleza Moral. Es ahí donde la función, lejos de quedarse en un mero positivismo utilitarista, se afirma operativa, tanto como espiritual y poética.

Algunos intelectuales afirman que su teoría se originó con base en los trabajos de Greenough, Fergusson, Ruskin, y Darwin, entre otros, a partir de influencias causales. Sin embargo, es difícil acordar con esto, ya que Sullivan es taxativo y a la vez variable en relación a sus influencias. En su texto Charlas con un arquitecto (1918/1957), tacha de cacofónicos 
a los maestros con los que se le asoció, y a la ciega veneración de sus seguidores. En sus palabras: "Digamos, también, basta a la cacofonía imperante; al aullido de la gran horda de Bedlamistas. El ronronear de la selecta compañía de los Ruskinistas. El rechinar de los Emersonistas. El chirriar de los Spenceristas" (Sullivan, 1918/1957, p. 206). En contraste, en Autobiografía de una Idea (1922/1961), un libro que publicó posteriormente y en el que se refiere a sí mismo en tercera persona, acepta haber hallado "mucho alimento" en las teorías de Darwin y de Spencer. Así lo describe:

...la verdadera labor de Louis consistiría de ahora en adelante en consagrarse a estudiar lo que el hombre pensaba actualmente y había pensado a través de los siglos. Así, la tarea se dilataba y el tiempo requerido aumentaba, pues él estaba aún en la etapa plástica de formación titubeante. En Darwin halló mucho alimento. La teoría de la evolución parecía estupenda. La definición de Spencer que implicaba la progresión a partir de una etapa simple e inorgánica, pasando por fases de desarrollo y diferenciación hasta llegar a una etapa compleja y muy orgánica, parecía ajustarse a su propio caso... (Sullivan, 1922/1961, pp. 180-181)

En Sullivan, no se entiende porqué en 1918 niega sus conexiones con Spencer y Darwin, pero en 1922 los describe como fuente de alimento para sus teorías. No obstante, lo que sí se puede demostrar en esta investigación, a partir de los análisis elaborados usando los tratados de Sullivan, que su universo conceptual - acompañado de una metodología sólida y estricta en su aplicación-, es el producto, o la influencia causal, de cuatro maestros que tuvo a lo largo de su formación. El primero de ellos fue Moses Woolson, al que conoció en la English High School de Boston, en septiembre de 1870. De él aprendió las bases de la geometría euclidiana, y al tiempo, los tratados del mundo botánico, a los que les encontró un vínculo convergente. De allí proviene su admiración hacia la naturaleza, el crecimiento de los organismos, y las similitudes que halló en las formas clásicas de la geometría, presentes en algunas especies de plantas y animales. Esta postura condujo a que su visión de arquitectura orgánica, no reconociera a la producción del hombre y su entorno, como la artificialización de la naturaleza en pro de su dominación. El hombre, como producto de la naturaleza, y toda su subproducción, deviene solo de ella. Los edificios (construidos según sus necesidades), son a los hombres, como los nidos a las aves. Esta es la razón por la que la Arquitectura orgánica es, para Sullivan, un producto natural. El segundo maestro fue John Hewitt, quien, en 1873, oficiaba como jefe de taller en la firma de arquitectos Furness \& Hewitt,en Philadelphia. A Sullivan le bastó trabajar solo cinco meses allí, para convertirse en un dibujante extraordinario, gracias al acompañamiento y las tutorías que recibió de John, hermano menor del socio de la firma George Hewitt. El tercero de estos maestros fue John Endelmann, a quien conoció al ingresar al estudio del ingeniero militar William Le Baron Jenney, el día de acción de gracias de 1873. En Endelmann, Sullivan encontró la serendipia que ampliaría los horizontes de su teoría de las formas y las funciones, gracias a un presupuesto planteado por Endelmann, al que denominó funciones suprimidas, y era el lugar donde la arquitectura debía generar una ruptura para alcanzar la coherencia 
con las necesidades del hombre. Sullivan (1922/1961), recrea su sorpresa al escuchar esta acepción que vinculaba las formas con las funciones:

Un día, John le explicó sus teorías de las funciones suprimidas; y Louis, asombrado, vio en un destello que aquí estaba la verdadera clave del misterio que hay detrás del velo de las apariencias. Louis era particularmente susceptible a la conmoción producida por la imprevista explosión de una sola palabra; y cuando la palabra "función" fue detonada por la palabra "suprimida", una idea nueva y enorme se configuró repentinamente y alumbró su mundo interior y su mundo exterior como si fueran uno solo. Así, con ayuda de John, Louis vio con más claridad el mundo exterior; y el mundo humano empezó a asumir una semblanza de forma y de función. (Sullivan, 1922/1961, p. 147)

Por último: Monsieur Clopet, profesor de matemáticas de Sullivan en la École National des Beaux Arts, París, 1874, que fue nombrado con anterioridad.

\subsubsection{De lo Orgánico y lo Mecánico. Según Frank Lloyd Wright}

Frank Lloyd Wright ha sido señalado como el alter ego de su Lieber Meister ${ }^{16}$; la visión del diseño a través de lo que él denomina como La Filosofía del Carácter Orgánico ${ }^{17}$, emergió más como una divergencia, que como una continuidad ambigua respecto de la teoría de Sullivan. Aunque el universo conceptual ${ }^{18}$ de Wright es tan complejo como el de su maestro (pero menos ornamentado), el uso de distintas palabras para designar las mismas ideas plantea un reto al reconstruir su forma de pensamiento. Esto se hace presente no solo en sus escritos, sino también en el sentido que portan cada uno de sus diseños.

$\mathrm{Al}$ ser acogido en el estudio de Adler y Sullivan, siendo muy joven, Wright advirtió que la Arquitectura Orgánica, de la mano de la Filosofía de la Naturaleza Moral, propuesta por Sullivan, se agotaría antes de que finalizara el siglo XIX. La razón de este agotamiento se encontraría en los cambios tecnológicos que corrían paralelos a esos tiempos. Si bien el pensamiento de visualizar la arquitectura como un crecimiento de adentro hacia fuera manifestó un consenso entre los tres, Wright (1957) en su texto A Testament, señaló que el uso de la máquina (no desde la producción que alienaba al hombre a partir de la cantidad, sino en función del hombre a partir de la calidad), generaría un salto que superarían las teorías propuestas por su mentor.

A principios del siglo XX, y de la misma manera que Sullivan, Wright (1957) estuvo en desacuerdo con la obstinación que caracterizó a los arquitectos americanos por revivir los estilos del pasado, importar estéticas de otros lugares, y jugar al eclecticismo con todo cuanto se hallara en los libros ${ }^{19}$. Esto se generaba como una tendencia social de los arquitectos, inadecuada para responder a los retos que las personas, en sus praderas y ciudades, demandaban de ellos; a este fenómeno lo designó como un rezago cultural. Este rezago cultural, Wright lo trasladó del dilema influyente entre el feudalismo y la educación, propio de las Escuelas de Diseño, acusadas por su mentor de estar sometidas a la influencia refractaria del American Institute of Architects (A.I.A.) ${ }^{20}$, como la institución responsable y validadora de esta tendencia social. "Las causas del rezago cultural que encontré residían en la tendencia social creada por los crecientes eclecticismos en la obra del A.I.A. [sic] 
Fruto muerto de una inadecuada educación arquitectónica. El verdadero carácter de la vida americana estaba siendo sumergido" (Wright, 1957/1961, p. 85). Esto, debido a que al A.I.A. le era indiferente un principio inherente velado en la vida de los americanos, pero que se hallaba contenido en lo que Wright (1953), en su publicación: El futuro de la Arquitectura, denomina como su Naturaleza. Wright lo define de la siguiente manera: "Naturaleza de un plan, un sentimiento, o una herramienta. Un hombre o cualquier cosa que le concierna, desde adentro. Naturaleza interior con N mayúscula. PRINCIPIO inherente" (Wright, 1953/1978, p. 274).

Wright, al usar el concepto naturaleza se preocupó de que no fuera confundido sólo con el espacio exterior y todas las cosas que esos espacios contenían, como las "nubes, los árboles, tormentas, el terreno y la vida animal" (Wright, 1953/1978, p. 274); espacio natural donde el hombre siempre interviene. El concepto naturaleza significa, y va mucho más allá, que el impulso interior de todas las causas y los efectos que mueven al hombre. En otras palabras, es el sentido que el hombre asume en relación a su origen, a las condiciones de su entorno o lugar, el momento en que se encuentra en el tiempo y la tecnología que desarrolla durante su existencia; todos estos son entendidos como los diversos medios de los que dispone para alcanzar sus fines. Este concepto de naturaleza, Wright (1953), lo amplía más tarde en1957:

Quisiera nuevamente eliminar la confusión demasiado a menudo causada por mi empleo de la palabra "naturaleza". Hace tantos años, cuando empecé a escribir y hablar sobre el tema de la arquitectura, yo usaba la palabra para significar "la esencia interior de toda causa y efecto". Mi sentido de lo "nativo" tomaba así la naturaleza más interior del principio poético como recta en cualquier cosa que consistiese o manifestase. Esto era la verdad respecto a cualquier objeto o condición: éste era para mí el innato sentido de origen [...] Recuerdo cómo, de muchacho, la primitiva arquitectura sudamericana - Tolteca, Azteca, Maya, Inca - removía mi asombro, excitaba mi ansiosa admiración [...] Aquellas grandes abstracciones americanas eran todas arquitectura de tierra [...] Estas eran creaciones humanas, cósmicas como el sol, la luna, las estrellas. ¿Naturaleza? Sí, pero la naturaleza del hombre tal como entonces era [...] El Dios del hombre, entonces, implicando una adoración de medios afines, ¿cómo ahora? Surgió en la escala de la construcción total una grandeza desde entonces nunca sobrepasada, rara vez igualada por el hombre, tanto en la verdad del plano como en la sencilla integridad primitiva de la forma. Arquitectura intrínseca al Tiempo, al Lugar y al Hombre. (Wright, 1957/1961, pp. 99-101)

De esta manera, el arquitecto se debe enfocar en los aspectos esenciales de los hombres para quienes diseña, con el fin de develar los insumos que corresponden a sus razones y emociones, para poder expresarlos en forma de necesidades. Sin embargo, para que el diseño pudiera plantear soluciones concretas a dichas necesidades, los arquitectos debían representarlas primero en términos de funciones. Dichas funciones responderían a partir de la forma, gracias a lo que Wright denominó como la fisonomía integral del espacio in- 
terior. "La Arquitectura nunca se conformará mucho tiempo con el caparazón solo o con nada que se le haga a éste en nombre de la Arquitectura. Ahora será concebida sólo como una fisonomía integral del Espacio Interior" (Wright, 1957/1961, p. 91). Wright (1953) sostiene que la forma no sigue a la función, sino que la forma y la función se convierten en una sola cosa; dado que la frase acuñada por su maestro, se convirtió en un eslogan incomprendido, del que, —-sostiene-, se ha abusado.

Este es un "slogan" del que se abusa. Es natural que eso ocurra con la forma. Pero en un nivel inferior, y el término es útil sólo cuando indica la plataforma sobre la que descansa la forma arquitectónica. Así como el esqueleto no es una finalidad de la forma humana ni la gramática es la "forma" de la poesía, así es la función respecto a la forma arquitectónica. El entrechocar de huesos no es arquitectura. Lo menos sólo, es más, donde lo más no sirve. La forma es predicada por la función, pero hasta donde la imaginación poética pueda llegar con ella sin destrucción, la trasciende. "La forma sigue a la función" resulta espiritualmente insignificante: una frase del montón. Sólo cuando decimos o escribimos "la forma y la función son una", adquiere significado la frase. [La cursiva es del autor](Wright, 1953/1978, p. 274)

Esta frase original de Wright (1953): lo menos sólo es más donde lo más no sirve, es una clara alusión a la frase de Mies: menos, es más. Sin embargo, si el pensamiento arquitectónico propio del siglo XIX, aún con el enfoque de Sullivan, era insuficiente para alcanzar el ideal de la fisonomía integral ${ }^{21}$, mucho menos lo iba lograr el dogmatismo clásico y las importaciones teóricas del A.I.A. Por ello, Wright planteó una divergencia en el pensamiento arquitectónico norteamericano, al combinar la revelación creativa del diseño, junto con la inventiva de la ciencia, la era de la máquina, la mecanización, y sus nuevos materiales. Los propuso como el único camino para alcanzar dicha fisonomía, ese lugar donde la forma y la función son una. Ver Gráfico No. 4. 


\section{Pensamiento y Práctica de la Arquitectura Moderna}

Según Frank Lloyd Wright $(1953,1957)$

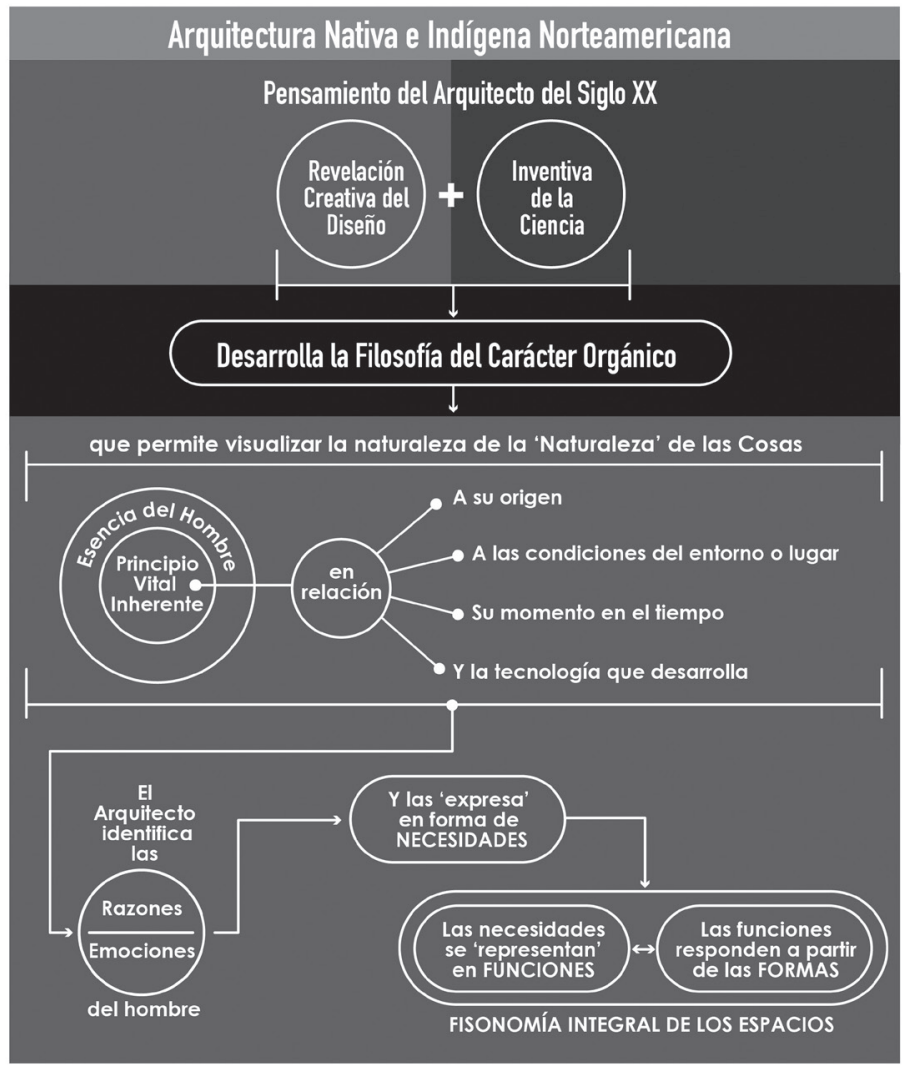

Gráfico No. 4. Elaboración propia.

Este cambio de pensamiento marcó el contraste que llevaría al siguiente nivel la práctica arquitectónica y con ella el diseño de los edificios del siglo XX, que fueron adaptados como los espacios adecuados, por y para la vida moderna. Así, la Filosofía del Carácter Orgánico, se planteó como un principio aplicable para cualquier lugar ${ }^{22}$ donde el concepto de función actúa como la representación de las necesidades. A su vez, las necesidades actúan como la expresión de las razones y emociones de la naturaleza del hombre para el que se diseña; y, por último, la forma actúa como su reflejo material. La función y la forma, al ser administradas por la fisonomía integral, dan vida al carácter, al propósito de los edificios, a sus objetos, dimensiones y espacios ${ }^{23}$. Aquí vale la pena otra aclaración, que gira en torno al concepto integral, como sinónimo también del concepto orgánico. El concepto orgánico 
es, para Wright $(1953,1957)$, sinónimo de integral, en cuanto a la relación que guardan cada una de las partes con el todo, y también el todo con cada una de las partes que configuran los espacios diseñados, imitando a los organismos que crecen desde el interior hacia el exterior, como les es natural. Ver Gráfico No. 5.

\section{Fisonomía Integral de los Espacios Diseñados}

Según Frank Lloyd Wright $(1953,1957)$

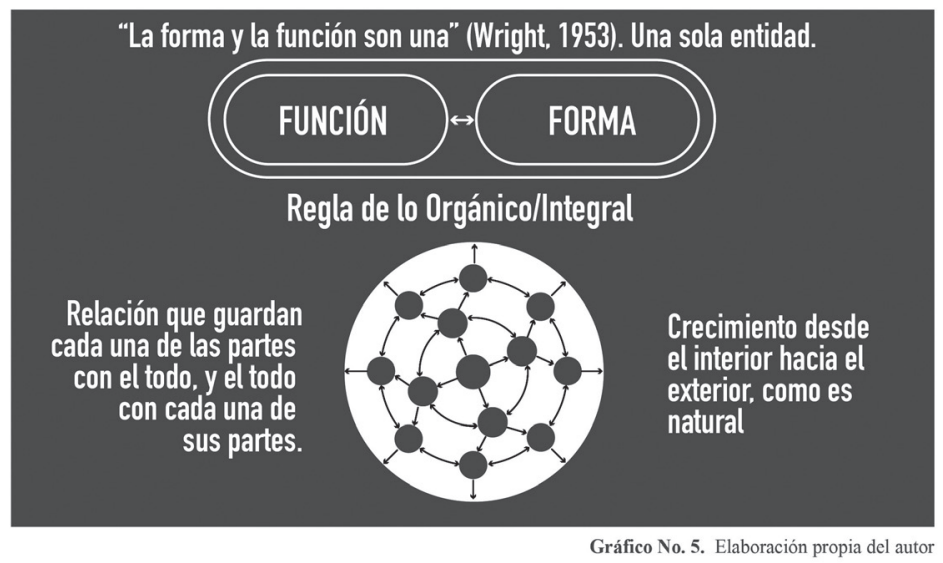

Esta perspectiva de Wright lucharía en contra del A.I.A., no solo buscando alcanzar el reconocimiento y la valoración de los principios nativos ${ }^{24}$ de una arquitectura originaria en Norteamérica, sino también de la hegemonía dogmática de la práctica arquitectónica clásica. Fue así como Wright demandó a los arquitectos erradicar las estéticas precedentes, que eran importadas y respaldadas por el A.I.A.

\subsubsection{Los 9 principios de la arquitectura}

La Filosofía del Carácter Orgánico emerge como una teoría arquitectónica nativa o indígena de Norteamérica, que halla su verdad en la manera en que desean vivir las personas, y no en el gusto auspiciado por todos los estilos nuevos y del pasado, etiquetados desde hace mucho tiempo con fechas de caducidad. No se malinterprete a Wright (1957) cuando toca el concepto estilo: si bien parece por algunos momentos validarlo y en otros negarlo, lo que en realidad elabora es una distinción entre el estilo falso, o caparazón, y el estilo intrínseco, como el reflejo de lo inherente. El primero corresponde a lo que el A.I.A. se ha obstinado en establecer como una verdad, en tanto el segundo propone al estilo intrínseco como la expresión poética del carácter que se reactualiza constantemente ${ }^{25}$, a partir de los 
requerimientos del hombre en relación al tiempo y al lugar en el que se ubican sus necesidades. Wright visionó a esta filosofía como una cura a los males de los que adolecía la arquitectura americana, y para ello la desglosó en nueve principios, creados para guiar el sentido y la práctica que sustentaría sus nuevas bases ${ }^{26}$. Esta nueva arquitectura, justificada por la línea central de la democracia americana ${ }^{27}$, colocó a la tecnología de la era de la mecanización en función del hombre, y no al hombre en función de ella.

La ciencia de la Máquina. Un poder que ya ha llegado a dominante poder mundial. El culto de este poder se ha acrecentado debido al hombre de ciencia. Pero la ciencia no es sino un útil en la verdadera civilización humana. La ciencia es inventiva, pero nunca creativa. (Wright, 1957/1961. p. 103)

Wright (1957), designó a estos principios de la siguiente manera: (1) Afinidad entre la Edificación y el Terreno, (2) Descentralización, (3) Carácter, (4) Tensidad y Continuidad, (5) Profundidad, (6) Espacio, (7) Forma, (8) Abrigo y (9) Materiales. Ver Gráfico No. 6.

\section{Principios de la Arquitectura Orgánica Moderna norteamericana Según Frank Lloyd Wright (1957)}

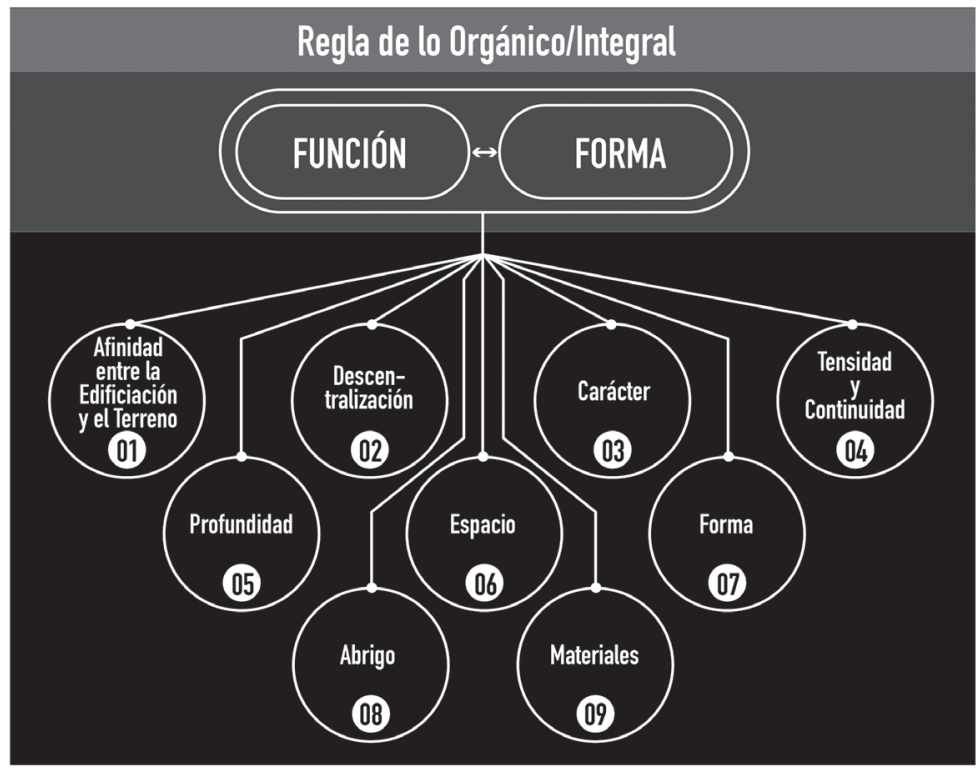

Gráfico No. 6. Elaboración propia. 
Principio 1: Afinidad entre la edificación y el terreno. Wright la define en un nuevo sentido de la proporción, sentido que toma en cuenta a la escala humana, o sea, la manera en la que el hombre se desplaza por el suelo, a la que denomina como: "don de la velocidad" (Wright, 1957/1961, p. 189), y la aerodinamicidad, impulsada por la velocidad que le ofrece la máquina. Todo ello, para determinar el ancho, largo, altura y peso ideal de los espacios que descansarán sobre "la ondulante pradera occidental" (Wright, 1957/1961, p. 189). Esta afinidad entre los edificios, el terreno y el hombre, Wright lo condensó en un solo término, al que designó como streamlined, lo que arrojó como resultado formas funcionales adaptadas a los métodos maquinistas.

De manera que, en ancho, largo, altura y peso aquellos edificios estaban en su lugar en la pradera, del mismo modo que el mismo ser humano, con su don de velocidad, estaba en su lugar en ella. El término "streamlined" (aerodinámico) nació entonces allí como expresión mía [...] Métodos maquinistas y estos efectos de planos chatos y líneas aerodinámicas aparecieron juntos por primera vez en nuestra arquitectura americana como expresión de nuevas maneras de alcanzar verdaderos objetivos en la construcción. El objetivo principal era la apropiación graciosa del arte de la arquitectura al Tiempo, el Lugar y el Hombre Moderno. (Wright, 1957/1961, p. 189)

Una de las tantas justificaciones de Wright (1957), para la creación del término streamlined, fue un problema que detectó en la mayor parte de los edificios diseñados a fines del siglo XIX. Este problema consistía en que la altura entre piso y techo, era excesiva en contraste con el ancho y el largo, que eran escasos y asfixiantes para la vida humana. Gracias a esta racionalización se potencializó el carácter, debido a que los techos de los edificios eran ahora bajos, rápidos y limpios; y se encontraban adaptados a la tranquila e intuitiva línea horizontal que combinaba la posesión del hombre sobre la tierra con la moderna acción de la máquina.

Principio 2: Descentralización. Emerge como una crítica al racionamiento excesivo que hacían los vendedores de tierras, en oposición a la necesidad de crecimiento que demandaban los espacios para la construcción. Según Wright (1957), los incendios, frecuentes y difíciles de mitigar en las ciudades de finales del siglo XIX y principios del XX, dejaron huellas visibles a su paso, y una de ellas fue el encarecimiento de todos los terrenos. Para Wright la descentralización urbana era un fenómeno inevitable, porque el alto valor de los terrenos volvió prolífico el diseño y la construcción de los famosos rascacielos, en los que Adler \& Sullivan eran expertos. Sin embargo, La Tiranía del Rascacielos, uno los apartados del texto de Wright de 1931, ARQUITECTURA MODERNA, The Kahn Lectures $^{28}$, describe cómo los rascacielos aparecieron como la manera de hacer más accesibles los lotes de tierra para la construcción; gracias a la multiplicación de la superficie de los suelos, apilados uno encima del otro. Para Wright, esa misma accesibilidad transformaría de manera negativa y con el tiempo, "los espacios urbanos amplios y relativamente vacíos, que aguardaban con serenidad” (Wright, 1931/2010, p. 213). Dichos espacios serenos, fueron reemplazados por la congestión masiva de la verticalidad comercialmente explotada, 
debido a la enorme necesidad de expansión y crecimiento. En otras palabras, el rascacielos que para Sullivan y Adler se crea como una contingencia por la carestía de los lotes y por la construcción en términos de innovación, se desfigura, para Wright, en un "flagrante abuso de un recurso comercial" (Wright, 1931/2010, p. 218). Recurso, que ahogaba a los ciudadanos con la altivez que caracterizaba el abuso presente en su verticalidad.

Wright (1931) planteó la descentralización como una solución, que proponía recuperar la sensación amplia del espacio, característico de la vida libre de los norteamericanos. Esta solución se ejercía a través del concepto de uso social del espacio, enfocado en edificaciones individuales y comunitarias en las afueras de la ciudad, para así alejarse evidentemente de la nuclearización que producía la masificación urbana. Un ejemplo de ello fueron los modelos de "Broadacre City, en Taliesin, en 1932" (Wright, 1957/1961, p. 192) hechos con el objeto de lograr la ampliación de un espacio inhumano. No hay que malinterpretar a Wright, al respecto de su mirada crítica del rascacielos. El también los diseñaba, pero con la visión de administrar el espacio de manera tal que el espíritu libre de los americanos, no se asfixiara en sus intenciones.

Principio 3: Carácter. Wright (1957) lo define como el significado que debe expresar un edificio a partir de su propósito, al hacer uso de él, y también al contemplarlo. El carácter es el resultado de una adecuación de parte del diseño, enfocado en la proyección de nuevas formas, orientadas a propósitos humanos específicos. En otras palabras, un edificio debe expresar su propósito a través de sus formas, lo que llevará a que los hombres lo interpreten exactamente para lo que fue creado. Este propósito puede ser el de un hotel, un banco, un hospital, o un edificio de oficinas. Asimismo, debe tenerse presente que, sin desfigurar el paisaje, debe ser longevo, funcional, accesible y bello.

Principio 4: Tensidad y continuidad. Estos principios surgen, en gran parte, gracias a la tecnología de la máquina devenida de la ciencia inventiva, subordinada por la revelación creativa del diseño. Dicho principio Wright (1957) lo definió como la relación novedosa que surge entre la tensidad ${ }^{29}$ y la continuidad. Si bien el primer concepto no existe en el idioma español, Wright lo acuñó como un derivado del concepto de tensión en la arquitectura, al que se pudo acceder gracias a los avances en el perfeccionamiento de la creación y producción del acero. Este perfeccionamiento le inyectó un grado cada vez más alto de resistencia al material, lo que facilitó el advenimiento de la fisonomía integral, presente en la arquitectura orgánica. El acero, junto al vidrio, permitió cambiar el orden de la construcción de las cajas (o estructuras de armazón), de los edificios tradicionales, que parecían máquinas pasivas sin alma, y no máquinas en función del alma o del espíritu del hombre, que era lo que él buscaba. Los edificios tradicionales, construidos de afuera hacia adentro, con sus voluminosas y pesadas paredes que dividían los espacios, fueron desplazados por una arquitectura liviana más eficiente. Esta propuesta arquitectónica, en vez de encerrar al hombre, lo puso en diálogo con el entorno interior y exterior gracias a la implementación del vidrio, y con ello el advenimiento de la luz natural. El acero permitió la tensidad o estiramiento del material, y al hacerlo generó una especie de continuidad suspendida, que es explicada por Wright con la analogía del hombre y el árbol. Parafraseando a Wright (1957) y emulando su acervo: así como el cuerpo de un hombre extiende 
horizontalmente sus brazos y dobla sus manos en ángulo recto hacia abajo, de la misma manera un árbol ${ }^{30}$ extiende sus ramas desde el tronco para darle continuidad - a su antojo-, a todas sus hojas hasta el final. El Voladizo, aplicado a los edificios y a la mueblería, surgió como la forma resultante en la relación entre la tensidad y la continuidad. El núcleo de acero, fuertemente construido en el centro y cubierto por hormigón liviano, permitió que las placas o losas, ya no macizas sino huecas, pudieran quedar suspendidas en el aire, albergando la calefacción radiante ${ }^{31}$. Esto se pudo lograr gracias a una estructura combinada entre acero delgado y una malla interna romboidal que daba sujeción al hormigón. Un ejemplo de ello fue la Torre del Centro de Investigación de S.C. Johnson Wax Building, diseñada por Wright para Herbert Johnson, ubicada en Racine, Wisconsin.

Cuando Wright hablaba acerca del rol del arquitecto a través de su filosofía de los espacios, no se refería solo al diseño de edificios. Con esa filosofía sugiere que el arquitecto, como el ente creador por naturaleza, -luego de Dios-, debe diseñar no solo el espacio interior y el exterior, sino también todo cuanto se contenga en él. Una muestra de ello son los muebles para oficina presentes en el a la administrativa del S.C. Johnson Wax. El parecido o unidad morfológica, a la que Wright bautizó como unidad orgánica, entre el diseño de los desktops y la mueblería del ala administrativa del Johnson, es completamente evidente. Este mismo principio, desarrollado con el acero y el vidrio, tanto en el Johnson como en muchas otras de sus obras, fue migrado hacia la madera, y a otros materiales en el diseño de los muebles de oficina.

Otro ejemplo arquitectónico de Wright del principio del voladizo, con fuertes núcleos de acero cubiertos con hormigón y losas huecas suspendidas en el aire, fue la primera casa Kauffmann; su importancia estuvo dada haber alcanzado el diálogo perfecto entre construcción, hombre y naturaleza. Esta edificación es conocida también como The Fallingwater.

Principio 5: Tercera dimensión. Wright (1957) explica que este principio, dentro de la arquitectura orgánica, no puede volver a verse como una simple sensación de espesor en el diseño de los espacios interiores. La tercera dimensión relativizó este concepto, debido a que los muros y paredes perdieron el grosor que funcionaba como sostén de las estructuras pesadas tradicionales. Ahora el espesor se transforma en profundidad, al generar una nueva sensación de espacio. Gracias a los nuevos materiales, y a los altos grados de resistencia del vidrio y el acero, las paredes se desprendieron de su defecto divisor para convertirse en "pantallas humanizadas, que definen y diferencian, pero nunca encierran u obstruyen el espacio" [La cursiva es del autor] (Wright, 1957/1961, p. 202). Ahora el hombre vive su espacio de manera natural, debido a que el interior y el exterior dialogan entre sí, sin manifestar una separación o división obvia. La libertad que se respira ahora por la amplitud, conduce al hombre hacia una sensación de libertad y armonía, a partir de un concepto novedoso de tridimensionalidad creada para ser disfrutada.

Principio 6: Espacio. Si bien el quinto principio poético, acerca del hombre como ser libre, generó una sensación de aire y amplitud por la no-interrupción entre los espacios interiores y exteriores, el principio sexto de Wright (1957), fungió como una apología a la tecnología y a las virtudes de los nuevos materiales, y condujo a los arquitectos a conjugar 
una poesía del diseñode los espacios. Los nuevos materiales derribaron las limitaciones que impedían el uso de formas inimaginables en la arquitectura. Una poesía emanada de la arquitectura orgánica, en términos sintácticos de formas y de funciones, pudo ser liberada; y fue así como los arquitectos, al usar las virtudes de estos nuevos materiales, crearon nuevos y bellos espacios. El "vidrio: aire en aire, para guardar el aire dentro o para dejarle afuera. Acero, delgado y fuerte como el hilo de la tela de araña"[La cursiva es del autor](Wright, 1957/1961, p. 203), permitieron una nueva expresión poética de la fisonomía integral, creada solo para satisfacer las necesidades por y para el hombre, sin las limitaciones previas.

Principio 7: Forma. La forma, como la expresión poética y material del diseño, es completamente diferente a todo lo que se había concebido antes, gracias a la nueva arquitectura orgánica, indígena y nativa, propuesta por Wright (1957). El concepto de unidad orgánica presente en ella, integra lo que antes se conocía de manera aislada como decoración. Al hablar de decoración hay que aclarar que no es lo mismo que el ornamento y tampoco la plasticidad que opera en él; estos representan tres conceptos distintos para Wright. El ornamento no aparece en el diseño como un adorno de la totalidad de la cosa, es decir, en el sentido del appliqué, como solía implementarse en la antigüedad clásica. La decoración por otro lado, si bien también es parte ahora de la totalidad del diseño, se refiere a aspectos fundamentales, presentes en los espacios como la iluminación, el estudio del paisaje y "la moderna artefactería" (Wright, 1957/1961, p. 205). Estos factores, antes aislados en la arquitectura, ahora se encuentran integrados de manera sistemática.

El ornamento, si es orgánico, nunca estaba sobre la cosa, sino que era parte de la cosa; por lo tanto, poco de la ornamentación de los órdenes griegos parecía otra cosa que pictórico. Encantador, pero "appliqué". Esta idea se me apareció y permaneció conmigo: toda plasticidad verdadera sería una cualidad parte de la cosa, nunca estaría sobre ella (aplicada a ella). Esto significa una positiva negación de la mayoría del ornamento clásico de los muchos estilos "clásicos". Por lo tanto, la plasticidad ordenaba que el ornamento fuera uno con la calidad estructural interior; su lugar era intrínseco. (Wright, 1957/1961, p. 126)

Principio 8: Abrigo. Este principio, visto como el techo que proporciona sombra a los hombres, no podía seguir operando para Wright de la misma manera. Así como el concepto de espacio Wright (1957), lo relativiza, a partir de los cambios generados en las formas y sus funciones, el techo debe significar mucho más que una tapa chata proveedora de sombra. La sensación de espaciosidad, como Wright le denomina, debe significar no solo esta idea, sino también la protección y el abrigo producidos por una sensación representativa de comfort; sensación que el hombre merece disfrutar en la seguridad de su propio ambiente en relación a la intemperie. La razón se encuentra en que "la arquitectura orgánica ve al abrigo no solo como una cualidad de aspecto sino de espíritu, como primer factor en cualquier concepto de ubicar al hombre dentro de su ambiente como un rasgo legítimo de él" (Wright, 1957/1961, p. 206). 
Principio 9: Materiales. Cada material posee en sí mismo un aspecto exterior y un significado, gracias a sus cualidades inherentes. El yeso y la madera, como afirma Wright (1957), deben significar y parecer lo que son. No puede un material imitar a otro porque genera un carácter de falsedad, y la falsedad no puede presentarse en la construcción. La era mecánica puso a disposición del arquitecto nuevos materiales para la construcción, y las propiedades de estos, junto a sus significados inherentes, liberó la creatividad contenida del diseño, al romper los límites físicos que los materiales tradicionales poseían. Las virtudes físicas del acero, el vidrio y el hormigón, administrados por la fisonomía integral de la arquitectura orgánica, alcanzó avances antes impensables, que liberaron, y luego reflejaron, el espíritu de los norteamericanos. Un espíritu que ya no podía, ni debía, mantenerse indiferentemente contenido por las formas eclécticas y caducas de la arquitectura del pasado.

Para sintetizar, siendo la fisonomía integral el factor sistemático que administra la dinámica entre forma y función, la influencia causal de Sullivan (proveniente de Monsieur Clopet), es evidente en la perspectiva de Wright; y se constata cuando propone que cada problema halla su solución en su propia naturaleza inherente. Sin embargo, se debe resaltar que los postulados de Coleridge lo influenciaron aún más, debido a que Wright, cuando habla de la relación de la fisonomía integral, lo menciona asiduamente.

...en nuestra arquitectura americana, apareció como innato un nuevo sentido del estilo. Una calidad connatural con el acto y el arte de la habitación moderna: ya no aplicada por el "gusto". (Otra vez: "tal como es la vida, así es la forma", Coleridge nos da tal vez un mejor slogan que "La Forma sigue a la Función"). Para los americanos como para todas las formas y matices de seres humanos en todas partes, el "estilo" se hace genérico: expresión poética del carácter. El estilo es intrínseco o es falso. Como característica del "espacio interior en que se vive" la vida del estilo es perpetuamente fresca. (Wright, 1957/1961, p. 203)

Esta segunda influencia en Wright, devenida de Coleridge (1812), se evidencia cuando se lee con minuciosidad la publicación titulada Coleridge’s Essays \& Lectures on Shakespeare: \& some other old poets \& dramatists, escrito por él en 1812, y publicada su primera edición en Londres, en el año 1907. En el apartado: Shakespeare, a Poet Generally, Coleridge, influenciado por el pensamiento de Shakespeare, y por sus estudios en Alemania sobre pensadores que ahondaron en la filosofía de la naturaleza (como Kant, Schelling, Lessing, entre otros), explica la distinción entre la forma mecánica predeterminada por el hombre, y la forma innata creada por la naturaleza. En dicho pasaje, Coleridge sugiere que la naturaleza, como un artista genial, le muestra al hombre a través de sus formas cómo imitar su ademán, desde el lugar del que le corresponde hacerlo, es decir, el arte. Con Wright, se cierra una tercera influencia proveniente de Thoureau, Emerson y Walt Whitman, en el que Wright define al último, como un profeta de la democracia, en el que convergían el espíritu del arte creador y la tecnología:

Thoreau, Emerson, eran nuestros. Sí. Y también, entonces, apareció Walt Whitman para dar la necesaria inspiración religiosa al gran cambio: nuestro nuevo lugar para el nuevo Hombre en nuestra Epoca. ¡Walt Whitman, profeta de nuestra democracia! Manifestó las 
verdades primitivas que yacían en la base de nuestra vida, las inspiraciones que necesitábamos para continuar espiritualmente con la "valiente soberanía del individuo". ¿No podría el espíritu del arte creador, desesperadamente necesitado por el hombre, encontrarse en el uso adecuado de las tecnologías radicalmente nuevas de nuestro tiempo, y así surgir? (Wright, 1957/1961, p. 37)

\subsubsection{Síntesis de las teorías de Wright}

Habida cuenta de lo sostenido hasta el momento, se deduce que la Filosofía del Carácter Orgánico, fue sintetizada por Wright gracias a la influencia de Sullivan, de Monsieur Clopet (quien fue maestro de su maestro), de Coleridge, Thoreau, Emerson y de Walt Whitman; y no desde Spencer, como afirma Collins. De este modo Wright logra conciliar el crecimiento orgánico, la inventiva mecánica, el espíritu creador del arte y los recursos tecnológicos aprovechables de la época; orientados en función y beneficio de todos los hombres. En los textos de Wright: A Testament (1957/1961), The Future of Architecture (1953/1978) y MODERN ARCHITECTURE, The Kahn Lectures. Princeton (1931/2010),se dilucida la influencia significativa que tuvieron las perspectivas de estos seis teóricos, en él. De allí que eleve una crítica a la educación artística americana, dado que se ubica de espaldas a los intereses que realmente se deberían tomar en cuenta en la formación. En sus palabras:

En nombre de John Ruskin y William Morris, se les enseña a los novatos a evitar y despreciar el instrumento principal de su época, como algo comercial y enemigo del arte. Y así llega el momento en que salen de allí, armado cada uno de ellos con su pequeño manual académico, que emplean como un remedio exterior, dondequiera que pueda aplicarse, aún cuando muchos de ellos saben en el fondo que su obra debe salir desde adentro... pero, ¿cómo? Y ésta es la educación artística en los Estados Unidos. (Wright, 1953/1978, p. 70)

La arquitectura orgánica de Wright define la construcción como el camino para que el arquitecto pueda diseñar edificios adecuados, donde la forma determinada por la sinceridad de los materiales, la naturaleza de sus propósitos, y el provecho de la máquina en función de las necesidades humanas, es moldeada desde el interior hacia el exterior de manera integral; tal como crecen los organismos.

Siempre desde entonces en la arquitectura orgánica he usado a la máquina y he desarrollado un sistema de construir de adentro hacia fuera, siempre de acuerdo con la naturaleza tanto del hombre como de la máquina - como podía verlo yo-, evitando los aspectos pasajeros hoy característicos de la arquitectura urbana. Encontré en la máquina un medio mejor para ensanchar el interés humano en la arquitectura moderna. Tampoco, en cuanto a estilo, he mirado nunca a la máquina como fin en sí misma, ni en cuanto al plano ni a la construcción ni al estilo. La cantidad nunca se sobrepuso a la calidad. (Wright, $1957 / 1961$, p. 190) 
De allí, que Wright (1957) hiciera hincapié en el cuidado que se debía tener sobre el uso indiscriminado de los ismos en el campo de la arquitectura, ya que los ismos terminan por contener $^{32}$, solo dentro del marco del estilo, no solo las ideas que surgen en los movimientos o innovaciones que se impulsan desde una disciplina, sino también el contexto proyectual y social que las origina. La teoría de Wright ejerció una ruptura crucial sobre las teorías arquitectónicas de ese tiempo, gracias a la superación de las tendencias estéticas y las soluciones formalistas, propias de la arquitectura americana de mediados del siglo XIX. Wright también aduce que el ornamento no es un elemento aplicado, sino por el contrario, se encuentra conectado con la calidad estructural interior de los edificios; planteamiento parecido a la visión integral del ornamento original de Goethe. A partir de esta reflexión se afirma que, en la arquitectura orgánica propuesta por él, los organismos, las máquinas y los edificios presentan más semejanzas que diferencias. Si bien Wright se esmera en explicar la unidad existente entre los conceptos de forma y de función, se debe aclarar que en ninguna parte de su obra habla de funcionalismo.

\subsubsection{Puntos liminares y de distanciamiento entre Sullivan y Wright}

La gran cantidad de analogías y de figuras poéticas, como metáforas, metonimias y sinécdoques, sumadas a la constante subjetivización de objetos, edificios y espacios, convierten los textos de estos dos arquitectos en claras estructuras de fundamentación poética. Los conceptos que Sullivan trae a colación, como la intuición, la inspiración y la expresión, son evidencia de un saber que se construye desde la propia subjetividad. De allí que se proponga que Sullivan no aspirara específicamente a un saber científico; aspiraba a una poiesis, o a un saber poético, que portara una fuerte fundamentación moral. Al hablar de la esencia del espíritu de una civilización, Sullivan se acerca indisimuladamente al romanticismo alemán. Hablar del espíritude un pueblo, de una nación, de una época, es utilizar el contexto histórico del espíritu de la época, o Zeitgeist, como corriente historiográfica emanada de Hegel y Dilthey.

Tanto en Sullivan como en Wright, se reconocen las intencionalidades poéticas, que hemos resaltado en italic (cursiva), por consiguiente, se deduce de sus textos que ambos concibieron una visión poética de la función, alejada de posiciones positivistas, y sin ninguna pretensión de convertirse en doctrina funcionalista. Se ha realizado esta revisión documental a fin de demostrar que las narraciones históricas que así lo expresan, caen en lo que Skinner (2000) identifica como mitologías de las doctrinas. Ellas se fundamentan en atribuirle a una persona, la intención de construir una tendencia, corriente, o doctrina que les sucediera; intención que el supuesto autor no expresó ni de la que tampoco dejó registro, y que difícilmente hubiera deseado. Las funciones de los edificios (y del mobiliario en Wright), son interpretadas desde visiones analógicas y/o metafóricas con la naturaleza. En los dos, la función es poetizada, y tiene un alcance mayoritariamente comunicativo, es decir, las formas deben transmitir/representar lo que el arquitecto interpreta, como las aspiraciones o el sentir de los conciudadanos.

Es necesario aclarar que sus analogías biológicas, sus concepciones de lo orgánico, y sus asociaciones poéticas con la biología, en sus variadas referencias, no se plasman de manera radicalen todos los casos, en la morfología de sus edificios u objetos, como en el diseño escandinavo de Alvar Aalto, Eero Saarinen, Arne Jacobsen o Tapio Wirkkala. Sullivan y 
Wright traducen en principios sus fundamentaciones poéticas. No obstante, sólo algunas de sus metáforas y conceptos como: ornamentación, nuclearidad, tensidad y continuidad, configuraron los novedosos núcleos estructurales de los edificios y cada uno de sus voladizos; y representaron una expresión morfológica tangible basada en una poética de inspiración biológica y orgánica. Lugares donde los árboles y sus ramas, al igual que el tronco humano y sus brazos extendidos, complementadas con las analogías morales y lingüísticas, no son más que la mímesis de una naturaleza que le provee al hombre su punto de referencia.

\subsection{Das Staatliches Bauhaus. Paradojas y desmitificaciones. Según Walter Gropius}

Europa, 1896 final del siglo XIX. En un clima donde los ingleses se jactaban de la supremacía industrializada, una débil disidencia artesanal ya no podía contener, con sus esfuerzos, sus efectos, detrás, una Alemania rezagada, perseveraba en superarla. Un período transicional, donde los cambios económicos, políticos y sociales demandaban la distinción de clases y, paradójicamente también, la independencia e integración precoz de hombres y mujeres al mundo laboral. Un momento de renovación estética en la que el Zeitstil, o estilo de la época, dejó de determinarse por la expresión individualizada; donde un nuevo romanticismo buscó hacer las paces con la uniformidad y la serialización. Como el resultado de estos cambios, surge la Staatliches Bauhaus, de la mano de sus meisters und auszubildende $e^{33}$ (maestros y aprendices). Esta escuela intentó durante catorce años, devolverle a Alemania lo que como movimiento y escuela pensó que necesitaba. Su fundador, Walter Gropius, es aún criticado por diversas causas, entre ellas podemos mencionar: su personalidad voluble - como la consecuencia de sus contradicciones conceptuales epocales-; su expresionismo radical inicial, sucedido por una supuesta afinidad ciega hacia el funcionalismo y el racionalismo; por último, sus ideas del ascetismo y la estandarización, que aún aparecen como índices de su nombre.

Su llegada y toma de posesión oficial del cargo de director de la escuela en Wëimar, ya ha sido estudiada por diversos teóricos como: Giulio Carlo Argan, Magdalena Droste, Nikolaus Pevsner, Reyner Banham, Joseph Rykwert, Tomás Maldonado, Mario de Micheli y Ezio Bonfanti, entre otros. Con base en lo anterior, no se pretende elaborar otra crítica más a las apologías o invectivas, que rayen sobre los mismos aspectos. En la búsqueda de algunos factores que mitificaron, sesgaron, o fueron dejados de lado, en torno a su ideología, sus enfoques pedagógicos, sus pensamientos y prácticas, —con respecto exclusivamente al concepto de funcionalismo-, es que se justifica una investigación que brinde aclaraciones de diversa índole. Entre estos factores, se encuentran los señalamientos constantes en torno a contradicciones por las que Gropius tuvo que explicarse - $\mathrm{o}$ en algunos casos directamente disculparse-, que giran alrededor de sus ideas acerca de las necesidades, la función, la forma y el estilo; ideas que aún hoy permanecen en debate. También, su censura política hacia el racionalismo que Hannes Meyer practicó como director de la escuela en Dessau, o el neutralismo excesivo - por no decir pasivo-, que caracterizó a Mies van der Rohe en la última sede de la Bauhaus en Berlín.

Este estudio pretende examinar cómo entendió Gropius las ideas de función y funcionalidad, cómo se refirió a ellas, en qué términos y en qué situaciones. Esto permitirá establecer 
si cabe hablar o no de funcionalismo, en los períodos que Gropius, Meyer y Mies dirigieron la escuela, y cuán apropiadas o injustas fueron las críticas que recibieron. Para ello, se seleccionaron sus textos más importantes, en la medida en que revelan con claridad sus formas de pensamiento, en relación a la cuestión funcional que nos ocupa. En este sentido, se trabajará con las siguientes fuentes primarias originales, organizadas de manera cronológica y por autores:

- Gropius, W. (1914). La contribución de las estructuras industriales para la formación de un nuevo estilo.

- Gropius, W. (1919a). Programa de la Staatliches Bauhaus de Weimar.

- Gropius, W., Taut, B. y Behne, A. (1919b). El Nuevo pensamiento en Arquitectura.

- Gropius, W. (1926). Principios de la Producción de la Bauhaus (Dessau).

- Gropius, W. (1943). Alcances de la Arquitectura Integral.

Primero, es necesario esbozar brevemente el complicado escenario político en el que todo se originó, según las voces de Antonio García Vila y Almudena de Maeztu, contrastadas con las posturas de Bruno Zevi, Enzo Collotti y Detleft M. Noack.

\subsubsection{La construcción de un gremio sin pretensiones clasistas}

En una breve reseña, el historiador C. Klein, en su obra: De los espartaquistas al nazismo. La república de Weimar, de 1968 consigna que:

...en 1918 se produce el levantamiento espartaquista en Berlín, que se extiende a otras zonas. La represión es asumida por fuerzas del ejército y contingentes de voluntarios monárquicos nacionalistas. Los dirigentes Rosa Luxemburgo y Karl Liebkneck son asesinados. F. Ebert es elegido presidente de la República y P. Scheidermann es nombrado canciller. El 11 de agosto de 1919 se promulga la Constitución que ordena la vida política en la República de Weimar [...] Los primeros años, fueron años de crisis. Crisis política, económica, financiera y monetaria, tentativas de putsch (tanto de la derecha como de la izquierda) separatismo renano y bávaro sacudieron a la joven república hasta 1923. Los acontecimientos se suceden a un ritmo de locura y frecuentemente son inextricablemente complicados. (Klein, 1968/1969, p. 45)

Antonio García Vila (2008), en Alma Mahler. El fin de una época, en el apartado Walter Gropius: La modernidad se mueve, -elaborado a partir de la correspondencia que sostuvieron Alma Mahler y Gropius-, ilustró los sucesos políticos emergentes un año antes de que este regresara de la guerra, y se posicionara como Herr Direktor ${ }^{34}$. En un caótico 1918, un grupo del frente soviético, de ideología comunista, que se alzaba cada vez con más fuerza, defendía la supresión de la división de clases, para eliminar la barrera de arrogancia que separaba a los artistas de los artesanos. Los soviéticos, que operaron inicialmente como grupos clandestinos vinculados a diversos sectores - principalmente en Weimar y en München-, lucharon por atenuar la desigualdad social. Esta desigualdad se debía, en parte, al poder de una burguesía alemana que obraba en favor de las pretensiones laborales 
excluyentes de la élite y las comunidades artísticas, y en detrimento del artesanado individual. La descripción que hace García aporta una visión significativa:

La rebelión había ya estallado. El 21 de marzo de 1919, el mismo día en que la Bauhaus, tras enormes polémicas acerca de su mismo nombre, abre sus puertas, Béla Kun establece una república soviética en Hungría, nacionaliza las tierras de labranza y organiza tribunales revolucionarios. György Lukács y László Moholy-Nagy, futuro colaborador de Gropius, se suman a la revolución sin dudarlo. Los conservadores ciudadanos de Weimar están aterrorizados, y no les faltan razones. Eisner, fundador de la República Popular Bávara era asesinado y tras dos meses de caos Ernst Toller, el 6 de abril proclama la República Soviética Bávara en Munich, desarma la burguesía, establece tribunales revolucionarios y crea el Ejército Rojo de Baviera. Una nueva era parecía próxima a nacer. Gropius compartía esa ilusión y sus programas se inspiraban en los del Consejo de Trabajo para el Arte de Taut. Para los ciudadanos de Weimar el bolchevismo entraba en su propia casa. (García, 2008, pp. 103-104)

La correspondencia que mantuvieron Gropius y su esposa Alma Mahler, fue abordada también por Almudena De Maeztu (2010), en su obra Alma Mahler Gropius. En este texto describe el período de la Primera Guerra Mundial, donde Gropius se desempeñó como teniente de húsares desde 1914 hasta 1918, e insinúa una afinidad muy cercana entre él y los soviéticos. Afinidad que no parece una casualidad, dado que fue con la anuencia del Consejo Obrero Comunista de Berlín, que Gropius accede a la dirección de la escuela (Noack, 1978). Aquí un extracto del manifiesto de Gropius de 1919, extraído del Programa de la Staatliches Bauhaus de Weimar: "formemos un nuevo gremio de artesanos sin las pretensiones clasistas que querían erigir una arrogante barrera entre artesanos y artistas. ¡Deseemos, proyectemos, creemos todos juntos la nueva estructura del futuro!" (Gropius, 1919a, en Conrads, U. 1964/1973, p. 77) ${ }^{35}$. Lo cual muestra que simpatizar con los movimientos revolucionarios, no significaba para Gropius abjurar de sus principios orgánicos y románticos sobre los gremios artesanales.

Sin embargo, los análisis que el arquitecto italiano Bruno Zevi y el historiador alemán Detlef M. Noack, elaboraron sobre los intereses de Gropius en los inicios del Bauhaus, apuntaron más allá de una simple afinidad de este con un movimiento soviético disidente, que buscaba restablecer el equilibrio entre los dos gremios. En su libro Historia de la Arquitectura Moderna, Zevi (1980), explicita la preocupación de Gropius por identificar los factores que distanciaban al materialismo académico - enseñado en las escuelas de arte y en los círculos intelectuales-, con los sistemas de producción alemanes artesanales e industriales. Zevi sostiene que Gropius, en los inicios del Bauhaus, invitó a personalidades como Paul Klee, Piet Mondrian, Theo Van Doesburg, Moholy Nagy, Wassily Kandisky, Mies Van der Rohe y Kasimir Malevich, entre otros, con el objeto de apoyar todo tipo de investigación técnica formal que integrara estas tendencias emergentes. Zevi también destacó la habilidad particular que tenía Gropius para conseguir ayuda financiera, misma que respaldaría muchas de sus iniciativas sociales. Entre estas iniciativas estaba la edificación popular, una especie de accesibilidad a la vivienda, orientada a las clases menos favore- 
cidas del proletariado alemán. Las aptitudes de Gropius lo condujeron, durante toda su trayectoria artística, a convertirse en una especie de índice del desarrollo arquitectónico en Europa desde 1914.

Por su parte, el profesor Noack (1978), en su texto Bauhaus: preliminares, objetivos, métodos y consecuencias, recrea los objetivos iniciales de Gropius, respecto de lo que debía ser un nuevo modelo de enseñanza y los medios necesarios para conseguirlo.

El Bauhaus fue fundado en Weimar en 1919 por el arquitecto Walter Gropius. Sus novedosas formas de enseñanza constituían una protesta contra la pedagogía que solía impartirse por aquel entonces en las academias de bellas artes y en las de artes decorativas y artesanía. Siguiendo el ejemplo de las construcciones medievales, la unidad artística tenía que reestablecerse bajo el predominio de la arquitectura. Otro de los ideales de esta primera época romántica del Bauhaus era el de dar forma al medio ambiente considerándolo obra de arte total. (Noack, 1978, p. 5)

No obstante, en el curso de su historia, la escuela y el propio W. Gropius realizaron varios virajes teóricos y políticos, tanto en el sentido de alejarse de los inicios románticos (y en algún caso místicos), como en el sentido de aceptar el desafío de la tipificación, la racionalidad del proceso proyectual y la producción en serie. En palabras de Enzo Collotti (1971):

Faltó, y una vez más se pone el acento en las insuficiencias de la socialdemocracia, la voluntad política de actuar en aquella dirección (de los problemas de fondo de la sociedad y la democracia en Alemania) y se buscó refugio detrás de la cobertura de razones técnicas y de las necesidades del momento [...] ...la incidencia de la teoría y de la iniciativa práctica de la Bauhaus no podía dejar de estar condicionada por el cuadro político-social existente [...] Así fueron definidos, precisamente, los límites dentro de los cuales podía moverse el reformismo social demócrata después de una revolución fallida. (Collotti, 1971, p. 15 , p. 26-27)

Las diferencias entre estas miradas anticipan, desde el inicio, que los estudios históricos, tanto de los aportes didácticos, técnicos y artísticos, como de los productivos, serán luego examinados en términos prioritariamente ético-políticos.

\subsubsection{El Punto de recolección moral y el orden de un nuevo estilo}

Cinco años antes de la creación de la Bauhaus, Gropius, en su artículo titulado: La Contribución de las Estructuras Industriales para la formación de un Nuevo Estilo (1914) ${ }^{36}$, ya había elevado una crítica al mismo materialismo característico de las Escuelas de arte, y a la formación intelectual de sus artistas de las décadas anteriores. Este era un aspecto liminar, señalado en las anotaciones de Noack y Zevi. Estas escuelas carecían, para Gropius, de un punto de recolección moral, donde cada una de sus representaciones egocéntricas no podían estar más lejos de obtener la sustancia de una época. 
A medida que las ideas de la época trascienden la materialidad empieza a resurgir, también en el arte, el deseo de una forma orgánica, de un estilo, y los hombres vuelven a comprender que la voluntad formal constituye por siempre el elemento determinante del valor en la obra de arte. Mientras que los conceptos espirituales del tiempo son todavía inciertos y oscilantes, y con la falta de una sólida meta unitaria, le falta también al arte la posibilidad de desarrollar un estilo y, por lo tanto, de recoger la voluntad formativa de muchos en una sola idea. Solamente en nuestros días estas ideas comunes de capacidad revolucionaria comienzan lentamente a librarse del caos de las concepciones individualistas. En las inmensas tareas de la época, que son aquellas destinadas a dominar organizativamente el sistema entero de las relaciones y las comunicaciones - todo el trabajo material e intelectual de los hombres - se encarna en una voluntad social inmensa. La solución de esta tarea mundial es cada vez más el centro ético de la era presente y, en ese sentido, el arte vuelve a tener una materia espiritual para representar simbólicamente en sus obras. [La cursiva es del autor](Gropius, 1914, en Maldonado, 1979, p. 184) ${ }^{37}$

La visión del arte del presente, según Gropius (1914), que debía sustentarse en una voluntad social de corte ético, no podía prescindir de estos insumos, debido a que su nuevo objetivo final se concentraba en representar de manera simbólica la esencia de las culturas distintivas propias de cada época, a través del estilo que se alcanzara a estructurar y madurar. Por lo tanto, el arquitecto como artista del presente y de su arte, es decir, el devenido en la modernidad, es un desarrollador de formas orgánicas ${ }^{38}$. A diferencia del artista del pasado, no debe operar como un decorador que apela a formas desarticuladas del ideal espiritual. Un nuevo rol, que al tomar en cuenta las exigencias espirituales y materiales que emergen de la vida práctica de los hombres, construye novedosas soluciones, gracias a los recursos tecnológicos que la ciencia pone en sus manos. Las ideas asociadas a ideales espirituales, formas orgánicas y espíritu del tiempo, eran comunes en el romanticismo alemán de Goethe y de Schelling, entre otros, y en la historiografía, de Hegel y Dilthey. Es de esta manera como, según Gropius, el arquitecto pasó de construir edificios, a la nueva tarea de construir, estaciones, fábricas y vehículos, donde las formas resultantes de esta edad presente, sirven y corresponden a la industria y el comercio.

La apreciación de la calidad y las virtudes de los materiales, unida a la administración estrecha y parsimoniosa del espacio y el tiempo, hacen parte ahora de su actividad creativa, según Gropius (1914). Es esta fuerza estilista como capacidad figurativa, basada en una eficacia estética que aprovecha los recursos de su tiempo, la que determina la forma y el ordenamiento que se les dará a los materiales. Al desplazar la concepción tradicional de la belleza natural del material, el arquitecto, con su fuerza estilista inocula un significado de su idea del todo, de manera poética, en todas sus obras, para que sean interpretadas tal como las trazó para sus observadores.

El arquitecto no se limitará a buscar por todas partes su significado, sino que llenará sus formas con una exageración poética que hará sensiblemente evidente, a cada observador, la idea fundamental del todo. Es justamente sobre 
esta fuerza estilista de la capacidad figurativa en que se basa la eficacia estética de una forma de arte, y no ya (como hay siempre que volver a afirmar) sobre la belleza natural del material. En la evaluación estética de las nuevas formas que han surgido bajo la influencia de las comunicaciones y de la industria se han tratado de suscitar la fe en un estilo de la funcionalidad y del material. Pero las leyes del material y de la construcción no deben ser confundidas con aquellas del arte [...] Todas las particularidades se subordinan a una forma figurativa grande y sencilla que, cuando haya sido encontrada su línea definitiva, deberá conducir a la expresión simbólica del sentido interno de las construcciones modernas [...] ... el tema del movimiento - el motivo decisivo de la época-, se manifiesta en múltiples formas, al ojo del observador. [La cursiva es del autor] (Gropius, 1914, en Maldonado, 1979, pp. 185-186)

Es la evaluación estética de estas nuevas formas la que, sujetas al ideal espiritual y provenientes de esta edad de las comunicaciones y de la industria, ha dado a luz un nuevo estilo; al que Gropius denomina como: el estilo de la funcionalidad.

Gropius (1914) aclara que, dentro de este nuevo estilo de la funcionalidad y del material, no se pueden confundir las leyes de los materiales de la construcción con las del arte. Esto, debido a que las creaciones de los arquitectos no emergen solo de su trabajo individual, porque en cada obra coinciden en una congruencia armónica dos pares de dualidades: la forma técnica con la forma artística, y la estabilidad aritmética con la estabilidad figurativa. La meta final, solo puede alcanzarse con la combinación entre el conocimiento analítico y la reacción sintética, entre los cálculos del ingeniero y la forma arquitectónica; solo mediante la sumatoria entre estos dos saberes se alcanza la forma orgánica, característica de este nuevo estilo funcional. El concepto de la velocidad y el movimiento aparecen como la expresión simbólica del ideal espiritual de esta época, la época de la moderna industrialización, y donde las máquinas, delineadas por el arquitecto, deben expresar a los ojos del observador lo que representan o simbolizan.

Lo expuesto demuestra con claridad que Gropius (1914), tempranamente tenía absoluta conciencia de la función simbólica de todo lo construido. Esto contradice las afirmaciones vertidas por Venturi, Brown e Izenour, citadas por Bürdek, acerca del primer funcionalismo de los años veinte como un "simbolismo no confesado" (Bürdek, 1991/2002, p. 223). El velero, el auto, los dirigibles, los aviones, etc., sin dejar de ser lo que son, al mismo tiempo representan símbolos que comunican el concepto de velocidad; un lugar donde lo técnico y lo artístico se funden en la unidad orgánica. Sucedidos en el mismo orden, Gropius da fe del camino a recorrer en la Contribución de las Estructuras Industriales para la Formación de un Nuevo Estilo:

La forma de torpedo de los autos; la envoltura continua que esconde a las máquinas modernas, son algunas de las tantas pruebas visibles del hecho que la cuestión de la forma ha empezado a poner en evidencia una función de primer plano en la vida industrial [... ... así los medios de transporte terrestres, acuáticos y aéreos (autos y ferrocarriles, paquebotes y veleros, dirigibles y aviones) se han transformado literalmente en símbolos de velocidad. Su imagen clara, 
que se capta con una sola mirada, no permite vislumbrar nada de la complicación del organismo. La forma técnica y la forma artística se han fundido en unidad orgánica. (Gropius, 1914, en Maldonado, 1979, p. 186)

\subsubsection{La Arquitectura del Futuro}

Cinco años después, en el Programa de la Staatliches Bauhaus de Weimar, Gropius $(1919 a)^{39}$ ya había sido nombrado oficialmente como director de las Escuelas Unidas ${ }^{40}$, aludiendo a la fusión entre la Escuela de Bellas Artes y la Escuela de Artes y Oficios, pertenecientes al Gran Ducado de Sajonia. Se subraya que su renombramiento como Das Staatliches Bauhaus, también se encontraba aprobado para ese momento. Una extensión de dicho programa se conectó con otro texto de Gropius (1919b), que vale el esfuerzo revisar, titulado: El nuevo pensamiento en Arquitectura, escrito en compañía de Bruno Taut y Adolf Behne, para el Arbeitsrat für Kunst en Berlín, también en abril de 1919; difundido en forma de folletos en la Exposición para los Arquitectos Desconocidos (Gropius, 1919b, en Conrads, U. 1964/1973).

La nueva figura del arquitecto, planteada por Gropius, prometía derribar la independencia autosuficiente e individual, por medio de una "colaboración consciente de todos los profesionales" (Gropius, 1919a, en Conrads, 1964/1973, p. 76). Y es aquí donde hace un llamado a los arquitectos, pintores y escultores, a que retornen "a conocer y a concebir la naturaleza compuesta de la edificación, en su totalidad y en sus partes" (Gropius, 1919a, en Conrads, 1964/1973, p. 76). Si bien el conocimiento especializado, para el momento en el que nace el Bauhaus, ya se había individualizado y diversificado para ser ejercido por diversos profesionales, este mismo conocimiento, con todas sus vertientes, debía regresar nuevamente, para Gropius, a una comunidad de trabajo.

Objetivos de la Bauhaus. La Bauhaus trata de reunir toda la actividad artística creadora en una sola unidad, de reunificar todas las disciplinas artesanales escultura, pintura, artes aplicadas y manuales - en una nueva arquitectura, como partes inseparables de la misma. El último, aunque remoto, objetivo de la Bauhaus es la obra de arte unitaria - el gran edificio- en la que no existan fronteras entre arte monumental y arte decorativo. La Bauhaus desea preparar a arquitectos, pintores y escultores de toda categoría para que se conviertan, según sus capacidades, en artesanos hábiles o artistas creadores independientes y fundar una comunidad de trabajo compuesta de maestros y aprendices que sea capaz de crear obras arquitectónicas completas - construcción, acabados, decoración y equipos- y que respondan en su conjunto a un mismo espíritu. (Gropius, 1919a, en Conrads, 1973, pp. 77-78)

A medida que avanza, las pretensiones de Gropius se hacen más claras, sobre todo si se conectan en ese punto en particular con El Nuevo Pensamiento para la Arquitectura escrito para el Arbeitsrat für Kunst (1919b). Debido a que la "fuente primera de la imaginación creadora" (Gropius, 1919a, en Conrads, 1973, p. 77), de esta nueva figura, podrá constituir todo en un solo conjunto, referido a todo lo que pueda ser creado a través de ella; Gropius incluye los edificios, sus espacios y toda clase de cosas. 


\subsubsection{Contingencia pedagógica. Ambigüedad y concreción}

Para sintetizar, se deduce que el Gropius de 1919 presenta algunos puntos liminares, de continuidad y otros de distanciamiento, con respecto al de 1914. Para la primera época, ya era evidente su actitud crítica frente a la conducta altiva del materialismo intelectual de las Escuelas de Arte y sus artistas. Estas, para Gropius, reflejaban en sus representaciones una carencia con el punto de recolección moral, y, por ende, indiferencia con el ideal espiritual de su época; ideas aún vinculadas con el idealismo y el romanticismo alemán. De todas formas, eso no debe detener las iniciativas de proponer una evolución formal destinada a descubrir una articulación, de parte del arquitecto, entre la vida y la forma. Hasta 1919, tenemos un Gropius mayormente focalizado en los problemas de forma, organicidad, simbolización, conocimiento técnico e inquietud espiritual, obra de arte unitaria y trabajo en común, acorde al espíritu epocal.

Gropius, que para 1914 ya había advertido estos problemas en las escuelas de arte de las décadas anteriores ${ }^{41}$, incluye en el manifiesto de 1919 un ítem especial acerca de cómo se debía enseñar la historia del arte en las escuelas. En el apartado Extensión de la enseñanza, subtítulo 3. La formación científico-teórica comprende, figura el punto: a) Historia del arte. En él, explicita que la historia del arte no puede ser "presentada en forma de historia de los estilos, sino como un conocimiento vivo de los métodos y técnicas de trabajo a lo largo de la historia" (Gropius, 1919a, en Conrads, 1964/1973, p. 81) ${ }^{42}$. Su esquema de enseñanza, a través de la Bauhaus, intentaba encauzar a futuro el desarrollo de una fuerza estilista, que pudiera comunicar un sentido que fuera más allá de la utilidad; porque para esa época eran esas las exigencias de la vida práctica. Aspecto que es más claro en el texto de 1914 que en los de 1919, tramo de tiempo en el que Gropius sostiene su apología acerca de la creación de nuevos estilos, diferentes de los pasados.

Otro aspecto a recalcar es la manera en la que comienza a sustituir el concepto de composición de 1914, ligado a las formas pedagógicas clasicistas de las academias, por el de construcción, cargado ideológica y políticamente de un futuro revolucionario. Aunque también estaba en Wright, se afirma que se adopta a instancias de los constructivistas rusos. Para 1919, la sustitución del término composición por el de construcción, comienza a manifestarse; sin embargo, Gropius no es preciso, ni hace aclaraciones sobre su uso o distinción de estos conceptos en estos textos.

Por otro lado, su propuesta en torno a la colaboración entre profesionales es cada vez más obvia, asociada siempre con la producción de formas orgánicas. En 1914 pensaba que, si el arquitecto trabajaba en estrecha colaboración con el ingeniero, esta unión produciría formas orgánicas. Este concepto necesita aclararse, dado que entre 1911 y 1915, Gropius había proyectado la fábrica FAGUS, donde es imposible percibir formas con analogías orgánicas, explicación que daremos más adelante.

El apartado antes mencionado: Extensión de la enseñanza. Punto 3. La formación científco-teórica, encierra un fuerte componente científico-teórico. Tal vez lo incluyó a propósito, en compensación a la exclusión del ingeniero de su fórmula pedagógica.

La formación científico-teórica comprende: a) historia del arte — no presentada en forma de historia de los estilos, sino como un conocimiento vivo de los métodos y técnicas de trabajo a lo largo de la historia; b) estudio de los mate- 
riales; c) anatomía —en el modelo vivo; d) teoría física y química del color; e) métodos racionales de pintura; f) conceptos fundamentales de contabilidad, redacción de contratos, adjudicación de obras; g) conferencias de interés general sobre todos los aspectos del arte y la ciencia. (Gropius, 1919a, en Conrads, $1964 / 1973$, p. 81)

Asimismo, el uso de los conceptos función y funcionalidad se vuelve evidente en su publicación de 1914, cuando advierte que las leyes de los materiales y la construcción, no deben confundirse con las que administran el arte; ideas funcionales que ya estaban presentes en los debates de la Werkbund y en el estudio de Peter Behrens, donde Gropius trabajó.

Si bien el concepto de lo funcional aparece en el texto como una respuesta puntual a dichas exigencias, apunta más hacia el sentido de una virtud potencial condensada en el estilo, es decir su funcionalidad, y menos como una aplicabilidad a través del ademán que caracteriza a un ismo.

\subsubsection{Estandarización funcional y economía racional}

En otro escrito que Gropius publicara en 1926, titulado Principios de la producción de la Bauhaus (Dessau), manifiesta que el objetivo de la escuela consiste en "estar al servicio del desarrollo actual del alojamiento, desde los simples utensilios domésticos hasta la vivienda acabada" (Gropius, 1926, en Conrads, 1964/1973, p. 143). Gropius (1926) luego explica cómo dichos utensilios deben estar relacionados entre sí, es decir, en relación a otros utensilios de una manera racional. Gropius manifiesta también que, para descubrir sus formas, éstas solo podrían ser determinadas por sus funciones. Para determinar dichas funciones, desde la Bauhaus propuso una investigación, de corte sistemático, teórico y práctico, en los campos ${ }^{43}$ formales, técnicos y económicos; con un rigor científico de cara a la actualidad. Del mismo modo adujo que el hombre moderno debe estar en correspondencia con su tiempo, por lo que "también necesita un hogar moderno adecuado a él y a su época, equipado con todos los objetos de uso cotidiano correspondientes al momento presente" (Gropius, 1926, en Conrads, 1964/1973, p. 143). Un objeto, para Gropius, viene determinado por su esencia. Y aquí aparecen por primera vez los conceptos objeto y esencia, en lugar del utensilio, con lo que precisa su acepción, al definirlo como aquello que, al ser determinado por su esencia, logra funcionar de manera correcta: que cumpla con su cometido. Esta concepción, científica y a la vez esencialista de la función, está muy lejos de las acusaciones rígidamente racionalistas que se le hacen a esta etapa de su pensamiento.

Un objeto viene determinado por su esencia. Para realizarlo de modo que funcione correctamente - un recipiente, una silla, una casa- primero se debe estudiar su esencia; puesto que debe cumplir plenamente su cometido, es decir, debe realizar útilmente sus funciones, debe ser duradero, barato y «bonito». (Gropius, 1926, en Conrads, 1964/1973, pp. 143-144)

Gropius (1926) recalca que el cometido de todo objeto útil, debe ser el de realizar sus funciones; también, que este también debe ser duradero $^{44}$, barato y bonito ${ }^{45}$, aunque no desglosa una tipología de dichas funciones. A continuación, lista cuatro condiciones que 
los objetos deben poseer: la aceptación del mundo de las máquinas y los automóviles, - su creación orgánica en relación con el presente-; la renuncia a embellecimientos o accesorios románticos ${ }^{46}$; la limitación de formas y colores básicos que sean comprensibles a todos; y la simplicidad y la sobriedad en todos sus aspectos: espacio, material, tiempo y dinero. En relación a este texto, entendemos que el colaborador que la Bauhaus pretende formar-ya no en Weimar sino en Dessau-, debe poseer el conocimiento y la práctica consciente de las relaciones fundamentales que reposan entre un par de dualidades: la técnica con la forma, y la artesanía con la industria. También, debe estar habilitado para desarrollar tipos [sic] estandard, pensados para las masas. Y aquí aparece la importancia de los tipos estandard por primera vez también, orientada para los objetos útiles como una fuerte necesidad social justificada; porque para él, "las condiciones de la mayoría de los hombres son iguales en lo esencial" (Gropius, 1926, en Conrads, 1973, p. 144). Con esta afirmación, Gropius justifica que la demanda de los objetos desarrollados para las masas, es más un tema de razón que de pasión. La máquina, vista como un medio que libera al individuo de su trabajo manual, satisface sus necesidades vitales a partir de una calidad que no poseen los objetos hechos a mano. La Bauhaus, que para Gropius (1926) evita el detrimento de la calidad de sus modelos en la reproducción mecánica, intenta, según él, abaratarlos gracias a los medios económicos de la estandarización. Y sobre esta, afirma que no se le debe temer en relación al individuo, porque emerge en términos de accesibilidad y no de coacción.

En esta publicación de 1926 - siete años posterior a sus manifiestos: El nuevo pensamiento en Arquitectura, escrito junto a Taut y Behne, y Programa de la Staatliches Bauhaus de Weimar-, se deduce que Gropius es más claro en cuanto a sus intenciones de ir más allá de la creación de los edificios y sus espacios. Estos son ahora designados dentro de una categoría más amplia: el alojamiento. Porque el alojamiento comprende, para él, el desarrollo de la vivienda acabada, en la que se incluyen los utensilios domésticos de uso cotidiano. Los talleres de la Bauhaus, que para Gropius eran "laboratorios" (Gropius, 1926, en Conrads, 1973, p. 145) de desarrollo, estudiaban la esencia del objeto en relación a otros objetos. Esto implicaba analizarlos como elementos que pertenecientes a diversos conjuntos, que funcionan dentro de un espacio sistematizado por sus funciones y condicionamientos naturales. Y aquí surge un aporte nuevo, que consiste en divisar los objetos como elementos individuales, que sujetos a grupos o familias, debieran pensarse para operar sistemáticamente en relación a otros grupos de objetos. Esta operación debía darse en función de la satisfacción de las necesidades vitales. A pesar de que Gropius no es muy claro en esta relación, se infiere que la silla, en relación a la mesa, al vaso, a la vajilla o a los cubiertos, y también todos estos relacionados entre sí, funcionan como objetos correspondientes en esencia a la relación con la necesidad vital de la alimentación. Estos objetos, estarían sistematizados en contraste con objetos orientados a otras necesidades vitales, como el lavabo del cuarto de baño respecto de la necesidad de la higiene. Esta relación, y la racionalización del objeto, no aparecen en los textos de 1914. De todas formas, la estandarización de los productos como una necesidad social, era entendible en términos de accesibilidad; y estaba muy instalada en Alemania, gracias al movimiento racionalizador, que tenía antecedentes en las publicaciones de 1912 de Christine Frederick. Este proceso se fue dando con la aplicación de metodologías científicas al estudio del trabajo doméstico; y más tarde, 
en 1921 con la Fundación del Comité del Estado para Eficiencia, de donde saldrían las Normas DIN-A. En 1925, se sumó en la ciudad de Frankfurt, un programa racionalizado y normalizado de construcción de viviendas y mobiliario, de gran aceptación y producción en serie (Heskett, 1985).

El desarrollo de prototipos debía ser sencillo y carente de formas ornamentales, debido a las limitaciones en torno a la calidad de los sistemas de producción industrial. Es de esta manera que el aspecto de los objetos creados en la Bauhaus, asociados al ascetismo y a la simplificación, aparecen como el efecto de todas sus causas. Con respecto a las necesidades, habría que agregar que la distinción que Gropius viera en forma de exigencias espirituales y materiales en su texto de 1914, se limitan en su visión de 1926, al par necesidad vital y necesidad social. La primera porque libera al individuo, y la segunda porque la demanda de las masas apunta a la estandarización. Sin embargo, si bien aborda en este texto los conceptos de necesidades, función, funcionalidad, economía y racionalidad, se aclara que su aplicabilidad a través de un ismo no se halla en él.

La creación de tipos estandard para los objetos útiles de uso cotidiano es una necesidad social. Las condiciones de vida de la mayoría de los hombres son iguales en lo esencial. Casa y utensilios domésticos son objeto de la demanda de las masas, su realización es más una cuestión de razón que de pasión. La máquina, capaz de producir productos estandarizados, es un medio eficaz para liberar al individuo de su propio trabajo material mediante la fuerza mecánica - vapor y electricidad- y satisfacer así sus necesidades vitales. [La cursiva es del autor](Gropius, 1926, en Conrads, 1973, pp. 144-145)

Es importante notar cómo el contraste entre el pensamiento del Gropius de 1919, con el de 1926, en relación a los conceptos de necesidades, función, objetos y satisfacción, presenta muchos cambios. En otros términos, es evidente una especie de transformación de sus ideas, donde la figura del artista y el espíritu epocal desaparecen de sus testimonios. Un Gropius correspondiente a 1926, se adscribe a la investigación sistemática, teórica y práctica, en los campos formal, técnico y económico, que eleva su preocupación por la función y la economía como su finalidad. Sin embargo, todo esto no implica descuidar lo que él denomina como esencia del producto o problema. Es notable el cambio de Gropius del primer manifiesto de Weimar de 1919, a los principios de la producción en Dessau de 1926. Se puede constatar como pasa de un tono enérgico, revolucionario e idealista, - respaldado por fuertes sujeciones éticas y artísticas-, a un Gropius más sereno, con una idea más concreta y amplia de la realidad industrial. En otras palabras, su pensamiento pasa a estar más distante del arte y más cercano a lo proyectual, lo funcional, y a la estandarización racional.

\subsubsection{Apologías y contradicciones}

En $1943^{47}$ Gropius publica el libro Alcances de la Arquitectura Integral, diecisiete años después de que divulgara los Principios para la Producción en la Bauhaus. Gropius (1943), comienza su texto defendiéndose, al aclarar que sus ideas se han interpretado de manera errada, como el cénit de la racionalización y la mecanización. Expresa allí, que la satisfacción del 
alma humana, como uno de los tantos aspectos de su nueva visión espacial, posee el mismo grado de importancia que los aspectos materiales. Así, recalca que la realización de dicha visión significa mucho más que obtener la economía estructural y la perfección funcional.

A menudo se han interpretado mis ideas como una cima de la racionalización y la mecanización. Esto conforma un cuadro totalmente erróneo de mis intentos. Siempre he destacado que el otro aspecto, la satisfacción del alma humana, es tan importante como el aspecto material, y que la realización de una nueva visión espacial significa algo más que la economía estructural y la perfección funcional. (Gropius, 1943/1959, p. 28)

En este punto aún no se entiende la incomodidad concreta que lo lleva a defenderse, pero a continuación, Gropius (1943) se pregunta a sí mismo ¿qué es lo que constituye un estilo? Y cuestiona con agudeza, el impulso irreprimible de los críticos por clasificar con rótulos y etiquetas los movimientos contemporáneos, producto de la arquitectura y el urbanismo, antes de alcanzar su desarrollo total; y con ellos a las figuras humanas que los alientan.

Comprendo que soy una figura cubierta de rótulos, quizás hasta el punto de hallarme envuelto en la obscuridad. Nombres como "Estilo Bauhaus", "Estilo Internacional", "Estilo Funcional", casi han llegado a ocultar por completo el núcleo humano que alienta detrás de todos ellos y me siento ansioso, por consiguiente, de practicar algunas hendiduras en este maniquí que me ha enfundado la gente atareada. (Gropius, 1943/1959, p. 19)

Gropius declara a continuación, que un movimiento en estado fluido, no puede constituir en sí mismo un estilo; debido a que los estilos se definen como la repetición sucesiva de una expresión que, al haber encontrado su denominador común, se establece o enmarca en un período.

¿QUÉ ES LO QUE CONSTITUYE UN “ESTILO”? El impulso irreprimible de los críticos por clasificar movimientos contemporáneos todavía en estado fluido, colocando a cada uno de ellos prolijamente en un ataúd sobre el que aplican el rótulo de un estilo, ha aumentado la difundida confusión en cuanto a la comprensión de las fuerzas dinámicas del nuevo movimiento en arquitectura y urbanismo. Lo que buscábamos era un nuevo enfoque, no un nuevo estilo. Un estilo es la repetición sucesiva de una expresión ya establecida como denominador común para todo un período. Pero el intento de clasificar en un "estilo" o "ismo" y con ello congelar el arte y la arquitectura vivientes, mientras todavía se hallan en la etapa formativa, probablemente ahogará en lugar de estimular la actividad creadora. [La cursiva es del autor] (Gropius, 1943/1959, p. 109)

Si bien esto es cierto, se debe reconocer que las críticas hacia el formalismo surgieron al interior de la propia escuela, y desde visiones tan dispares como la de Paul Klee y Hannes Meyer, entre otros (Bonfanti, 1971, p. 117). 
Ha sido menester un cuarto de siglo de lucha intensa y grávida para hacer nacer estas formas [...] Pero esta evolución ha encontrado obstáculos: teorías confusas, dogmas y manifiestos personales, dificultades técnicas y, finalmente, los peligros provenientes de los fuegos fatuos del formalismo. ¡El peor de todos fue que la arquitectura moderna llegó a constituir una moda en varios países! La imitación, el esnobismo y la mediocridad han distorsionado los elementos fundamentales de sinceridad y sencillez sobre los cuales se basaba este renacimiento. Frases espurias como "funcionalismo" y la "aptitud para un fin equivale a la belleza", han desviado la apreciación de la nueva arquitectura hacia canales secundarios y puramente externos. [La cursiva es del autor] (Gropius, 1943/1959, pp. 81-82)

Gropius plantea que, en el período de la industrialización, esta integración o unidad se perdió, por no lograr que las necesidades humanas se mantuvieran por encima de los requisitos económicos industriales; lo que derivó en un ambiente caótico. Aquí, por primera vez, Gropius (1943) usa el concepto ambiente. Gropius, en este apartado, plantea una especie de crisis, al expresar que al ser humano se le ha degradado al emplearlo como herramienta industrial. Para él, esto distorsiona el equilibrio alcanzado con la Bauhaus, debido a la humanización de la máquina. "La clave para una exitosa reconstrucción de nuestro ambiente - la gran tarea del arquitecto-, será nuestra determinación de que el elemento humano sea el factor dominante" [La cursiva es del autor] (Gropius, 1943, p. 95). $\mathrm{Al}$ respecto, recuerda que para idear nuevos medios con fines humanos, el Bauhaus ${ }^{48}$ intentó hallar un equilibrio entre las exigencias utilitarias, estéticas y psicológicas. Allí donde afirma, que "no se consideraba el funcionalismo como un mero proceso racionalista: abarcaba también los problemas psicológicos. La idea era que nuestro proyecto operara tanto física como psicológicamente" [La cursiva es del autor] (Gropius, 1943, p. 113). Y de esta manera llega a la conclusión que las necesidades emocionales son igual de imperativas que las necesidades utilitarias, y por ello demandan satisfacción. Es allí donde opera lo que Gropius denomina como la "gramática de la composición" (Gropius, 1943, p. 46), donde el sentido simbólico y comunicativo de los objetos útiles va mucho más allá que su utilidad. Siendo la máquina y las nuevas potencialidades de la ciencia el gran interés de la Bauhaus, éstas fueron enfocadas solo y exclusivamente al servicio de la vida humana.

La idea era que nuestro proyecto operara tanto física como psicológicamente. Comprendíamos que las necesidades emocionales son tan imperativas como cualquier necesidad utilitaria, y exigen satisfacción. La máquina y las nuevas potencialidades de la ciencia revestían para nosotros gran interés, pero la tónica no se dirigía tanto hacia la máquina misma como hacia el mejor uso de la máquina y la ciencia al servicio de la vida humana. (Gropius, 1943/1959, p. 113)

Sin embargo, luego de analizar el texto, advertimos que las molestias de Gropius se centran en dos aspectos. El primero, al ser señalado como el promotor de un instituto que desarrolló tres formalismos: el Estilo Bauhaus, el Estilo Funcional, y el Estilo Internacional ${ }^{49}$. El segundo señalamiento plantea que, a través de su práctica, la subordinación del hombre 
en relación a la máquina, y la segmentación de sus necesidades, no se hicieron esperar. De todas formas, si bien Gropius exhibe diversas explicaciones en relación a estos dos señalamientos, es inevitable no advertir varias inconsistencias que serán puntualizadas. Las distinciones que elabora en torno al estilo, - en contraste con el movimiento en formación-, derivado de su enfoque pedagógico, presenta argumentos sumamente claros y justificables; mientras, censura al estilo Bauhaus, al estilo Funcional y al estilo Internacional como lo que supuestamente son: formalismos.

\subsubsection{El funcionalismo para Gropius}

Para Gropius, el concepto del estilo, no es en realidad una noción peyorativa. Porque si el estilo es la repetición sucesiva de una expresión ya establecida como denominador común para todo un período, es probable que, con el tiempo, un movimiento en estado viviente de crecimiento, pueda llegar a convertirse en él. Esto justificaría su visión favorable acerca del concepto, en los textos de 1914 y 1919. Lo que, a Gropius, en realidad, le parece peyorativo, es rotular anticipadamente con un ismo-o con el concepto estilo-, a las fuerzas dinámicas de dicho movimiento en formación, debido a que se anula su voluntad de crecimiento y capacidad creativa. Sin embargo, hasta aquí iría todo bien, si Gropius luego no afirmara que en el intento de la Bauhaus por establecer un equilibrio entre las exigencias utilitarias, estéticas y psicológicas "no se consideraba el funcionalismo como un mero proceso racionalista: abarcaba también los problemas psicológicos" [La cursiva es del autor] (Gropius, 1943, p. 113). ¿Cómo puede Gropius, por un lado, exaltar que el funcionalismo no era un mero proceso racionalista, que abarcaba los problemas psicológicos como parte referencial del proyecto de la Bauhaus, y al tiempo considerarlo como una frase espuria? A esto se suma la etiqueta colocada por sus críticos, que anticipa y pone de moda la imitación formalista de un movimiento apenas en formación.

Cuando Gropius reclama, al principio del texto, que sus ideas se han interpretado como la cima de la racionalización y la mecanización, conformando un cuadro erróneo de sus intentos, no debe olvidarse que, en su texto de 1926, Principios de la producción de la Bauhaus (Dessau), existen nexos entre sus testimonios y estas acusaciones. La díada entre las exigencias materiales y espirituales, que Gropius presentara en su texto de 1914: $\mathrm{La}$ Contribución de las Estructuras Industriales para la formación de un Nuevo Estilo, reaparecenen el texto de 1943, Scope of Total Architecture, descritas ahora en tres díadas. Estas díadas toman forma de exigencias, que se traducen a su vez en necesidades: materiales/ espirituales, físicas/psicológicas y utilitarias/emocionales.

El arquitecto del futuro debiera crear mediante su obra una expresión original, constructiva, de las necesidades espirituales y materiales de la vida humana, renovando así el espíritu humano en lugar de recitar nuevamente el pensamiento y la acción de épocas anteriores. [La cursiva es del autor] (Gropius, 1943/1959, pp. 64)

Curiosamente, esta clasificación de las necesidades, estructurada de esta manera, para 1926 se planteó en la forma de una sola díada: necesidad vital/social. Donde la indiferencia del alma humana, subordinada a la liberación material de la fuerza, era más un tema 
de razón, que, de pasión, y la economía una causa de la estandarización. No obstante, recordemos que en ese momento Gropius aún mantenía una perspectiva esencialista de las funciones. Esta perspectiva no excluía su estudio científico, lo que explica simplemente el carácter multifacético de las posturas de Gropius, quien combinaba o amalgamaba aspectos sensibles, creativos y racionales, con algún sesgo metafísico.

\subsubsection{Las distintas etapas de pensamiento de Gropius}

Más allá de las diversas Bauhaus, nos interesa la figura de Gropius, y sus diferentes formas de pensamiento, sucedidas por sus prácticas - unas veces conflictivas, otras coherentes y en otras divergentes-; evidenciadas en torno a la relación con los conceptos de: necesidad, forma, función y funcionalismo. De todos modos, hay que aclarar que las etapas que observamos en su pensamiento, no se relacionan con los cambios de ciudad que atravesó la institución.

En 1914, se encuentra un primer Gropius. Un crítico sereno en oposición a ciertos aspectos de las escuelas de arte, como el materialismo, el enfoque intelectual, y a la reutilización indiscriminada de las formas del pasado. Para él, esto desembocaba en creaciones egocéntricas, de espaldas a la esencia de una época. Un Gropius defensor del estilo, con un fuerte corte ético, que exige la comunión entre el arquitecto y el ingeniero para el desarrollo de formas orgánicas, que contribuyan a las estructuras para el advenimiento de un nuevo estilo. Un estilo donde la utilidad, envuelta por un contenido simbólico, expresará las exigencias espirituales y materiales de la modernidad.

Luego se tiene un segundo Gropius, el idealista y revolucionario de 1918 que, sumido aún en la primera guerra mundial, mostraba afinidades con la revolución soviética, y al mismo tiempo, con el socialismo alemán. Un Gropius que ambicionaba un enfoque pedagógico para una nueva escuela; que quería hacer de esta el lugar donde el artista y el artesano, respaldados por la ciencia y los beneficios de la producción industrial, trabajarían en comunidad para la gestación de una arquitectura del futuro. Una arquitectura que, en concordancia con la vida práctica de los hombres, construiría una unidad orgánica que fuera mucho más allá de la simple utilidad, y que respondiera a un mismo espíritu. Un Gropius, en definitiva, que no se puede asociar al funcionalismo.

Un tercer Gropius surge en 1926, indiferente a la figura del artista, concentrado en lo funcional y en su análisis racional, pero sin desatender lo que concibe como la esencia del objeto. Un Gropius que, más cercano a la ciencia, apoya la tipificación y estandarización accesible de los objetos duraderos, sistematizados en relación a otros objetos. Un interesado en la satisfacción de las necesidades vitales y las necesidades sociales; estudioso de la funcionalidad, y universalista en su concepción de lo humano.

Y un cuarto y último, el de 1943 a 1963, el más polémico de todos. Un Gropius ambivalente, contradictorio, y aparentemente más sensible a los intereses del alma humana; el Gropius que tipologizó las necesidades en tres díadas, traducidas luego en exigencias para ser satisfechas por las funciones. Uno que se defiende de las críticas, los rótulos y fuegos fatuos de los formalismos que lo oscurecen, supuestamente, en nombre de los estilos y los ismos: del ascetismo, del funcionalismo y del Estilo Internacional. Alguien que madura la idea de que los objetos creados por la Bauhaus poseían una gramática comunicadora de un sentido que va más allá de la utilidad. Que si bien no se reconoce funcionalista/racionalista, 
fue un arquitecto que evidenció, por medio de su pensamiento y práctica proyectual, más continuidades que divergencias en torno al concepto de la funcionalidad, de allí que sea catalogado como defensor del funcionalismo.

De todas formas, el único atisbo sobre el concepto de funcionalismo en Gropius, emerge solo en esta última forma de su pensamiento, en una década ya posterior al cierre de la Bauhaus, y apurado y presionado por la crítica. Cuando se afirma aquí que es el único atisbo, se debe a que no es clara su posición frente al concepto. Pareciera aceptarlo, según los alcances positivos que se le atribuyeron, y al mismo tiempo rechazarlo, al encontrarse inscrito en la figura de un formalismo.

A pesar de las muchas influencias que operaron en Gropius, se advierte una intencionalidad contraria a la de F.L. Wright, en el sentido de evitar todo contenido poético, tanto en su teoría, como en la pedagogía o en sus obras. Las disciplinas proyectuales no pueden evitar producir una poética propia, dado que la ausencia de intencionalidad poética es una poética en sí misma. Así, la intencionalidad de Gropius busca asociarse a otros referentes, en general, con analogías lingüisticas y finalidades técnicas, no vinculadas a la analogía biológica, por más que en varias oportunidades mencione lo orgánico. Es posible que, por orgánico, Gropius entienda algo cercano a lo que Aristóteles enuncia en su Poética, cuando entiende que la trama debe constituir una totalidad orgánica, como un ser vivo. Para este filósofo, la totalidad orgánica es una unidad autónoma de sentido, formada por partes solidarias o interdependientes. En el caso de una composición narrativa, la solidaridad o la interdependencia entre las partes (los prágmata o los hechos) está dada por relaciones de necesidad o de verosimilitud, y no por factores extrínsecos, como la constancia, o unicidad del sujeto de las acciones, o la asociación temporal ${ }^{50}$. De Zurko (1957/1970), también parafraseando a Aristóteles, sostiene que "para los románticos alemanes, la forma orgánica significó primordialmente organización, o sea, la relación armoniosa de las partes con el todo. Tuvo asimismo implicaciones metafísicas" (p. 179).

\subsubsection{El organicismo y la cuestión del espíritu en Gropius}

En el caso de Gropius, la referencia a la forma orgánica asociada a la funcionalidad, parece estar mayormente vinculada al estudio de la tradición funcional del arquitecto alemán: F. Weinbrenner. Estas ideas eran compartidas también por Emerson - en los Estados Unidos-, y Coleridge — en Inglaterra-. De Zurko (1957/1970), al considerar a Weinbrenner como un arquitecto funcionalista, citó las ideas que el segundo consignó en dos de sus textos de 1819, que trataron sobre dibujo, perspectiva y teoría arquitectónica. En ellos, Weinbrenner sostenía que, a los estudiantes de arquitectura, no se les debía enseñar el método de imitar a los antiguos; en palabras de De Zurko:

Weinbrenner, condenó la práctica prevaleciente de enseñar a los estudiantes de arquitectura el método de copiar a los antiguos [...] Este pasaje de Weinbrenner sobre la consecución, por medio del diseño funcional, de un carácter casi espiritual, nos revela que en su análisis de la arquitectura hay involucrados valores éticos y morales. Según Weinbrenner, el fin es anterior a la forma. [...] Weinbrenner, comparó la arquitectura, en ocasiones con la forma orgánica. Aplicaba el principio de que la belleza radica en la concordancia de la forma 
con el propósito, tanto en los organismos y en la arquitectura, como en los objetos de la producción industrial. (De Zurco, 1957/1970, pp. 179, 181-182)

Tanto la mención reiterada al espíritu como el principio de unidad orgánica en Gropius, son difíciles de entender y pueden prestarse a confusiones, dado que a Gropius se lo describe en la mayor parte de la bibliografía como un defensor de los ideales revolucionarios socialistas en el '19; y los conceptos de organicismo y de espíritu, son conceptos clave de raíz romántica que también fueron usados por el nacional-socialismo. No obstante, en la extensa investigación que desarrolló Jeffrey Herf (1984/1993), en su texto El modernismo reaccionario. Tecnología, cultura y política en Weimar y el Tercer Reich, nos aclara lo siguiente:

Los defensores del romanticismo alemán del siglo XIX han hecho una observación simple pero importante: no había una línea recta entre el romanticismo y el nazismo. Además, ni siquiera en Alemania era la tradición romántica exclusivamente derechista o antitecnológica. Por el contrario, el romanticismo afectaba a todos los segmentos del abanico intelectual y político de la Alemania en Weimar [...] ... varios autores destacan la contribución romántica al humanismo liberal y socialista del siglo XX. La tesis de Gouldner es que el romanticismo alemán del siglo XIX influyó decisivamente sobre la teoría social de principios del siglo XX: Max Weber, Georg Simmel, Georg Lukácks y la Escuela de Francfort. (Herb, 1984/1993, p. 42)

Hasta Tomás Maldonado (1974), recayó en tratar de entender qué quiso decir Gropius con unidad orgánica, en la que se unían Arte y Técnica. En palabras de Maldonado:

La aportación de Gropius fue la idea de una forma concebida como una «unidad orgánica», en la que se unen la técnica y el arte. Esta idea de «unidad orgánica», formulada de una manera algo sumaria por Gropius en su artículo Der stilbildende Wert industrieller Bauformen (1914), ponía de manifiesto oportunamente una de las tesis más originales sostenidas por los teóricos del protofuncionalismo, tesis defendida sobre todo por W. Hogarth (1753), C.N. Ledoux (1804) y F. Weinbrenner (1819). Al final, Gropius —después del especialismo Manifiesto del Bauhaus, que J. Ruskin y W. Morris hubieran podido suscribir- volvió a sus preocupaciones precedentes. El artículo Grundsätze der Bauhaus Produktion (1925) precisaba muy claramente el sentido real de la idea de «unidad orgánica» propuesta diez años antes. «La búsqueda de nuevas formas con medios que tengan en cuenta, no solamente los objetos en sí, sino también su empleo; ...posibilidad de crear un objeto bello, basándose en el dominio absoluto de todos los factores económicos, técnicos y formales - de los que el objeto creado debería ser el resultado- y no guarneciéndolo exteriormente con ornamentos decorativos».[La cursiva es del autor] (Maldonado, 1977, pp. 137-138) 
A diferencia de Wright—donde la figura emblemática para su época era el poeta-,para el primer y segundo Gropius es el arquitecto. En ambos casos, las connotaciones son de raíz romántica. Del mismo modo, en Gropius es necesario aclarar que su concepción de lo orgánico, - en sus variadas referencias-, no se lleva a la morfología de sus edificios u objetos, sino que se traduce en un principio organizador que integra la fundamentación personal, social, estructural, tipológica y productiva del proyecto.

Así, para Gropius, su concepción de la función, migra de ser una fundamentación espiritual en sus comienzos (1914-1919), a convertirse en una fundamentación esencialista, recostada en la técnica, con objetivos democratizadores, sin dejar de lado la estética, pero entendida ésta como cuestión intelectiva, más que poética o emotiva. A pesar de sus resabios románticos, a Gropius le aplica la caracterización de Koselleck sobre Diderot y la Enciclopedia: "Como ilustrado consecuente, no toleraba ningún apoyo en el pasado. El objetivo que explica su accionar era acabar con el pasado tan rápidamente como fuera posible, para que fuera puesto en libertad un nuevo futuro". Y como futuro, Gropius entendía que le competía la construcción de una nueva época. "En alemán, Modernidad/ Edad Moderna [Neuzeit] y nueva época [neue Zeit] son, como se puede ver, expresiones semejantes", tal como lo sugiere Luis Fernández Torres (2009), en la Revista Anthropos, en el apartado: Un texto fundacional de Reinhart Koselleck, (p. 92). Esta conjunción, muestra en Gropius una particular síntesis entre los ideales románticos y los de la ilustración.

Lo que es seguro es que, así como no se le puede atribuir a Sullivan la intención de construir una corriente funcionalista, tampoco se le puede atribuir a Gropius la intencionalidad de construir un nuevo estilo funcionalista, so pena de caer en una mitología de las doctrinas, como explica Skinner (2000).

La exposición que se ha realizado sobre los textos de Gropius, y los enunciados que realizó en defensa propia, dejan abiertas algunas preguntas que se repiten al analizar Ulm, y que será necesario responder cuando se comparen las fuentes primarias con las secundarias: ¿Cuál es la importancia del tema del estilo? ¿Qué aspectos socio-políticos se jugaban atrás de esta crítica?

\subsection{Desde Die Weiße Rose hacia el concepto Ulm. Max Bill, Tomás Maldonado y Gui Bonsiepe}

Veinte años después de la clausura de la Bauhaus en Berlín, ocasionada por el asedio nazi, se funda la HfG, Hochschule für Gestaltung, en la ciudad de Ulm. La HfG fue creada en 1953, gracias a sus fundadores Inge Scholl y Otl Aicher, y si bien su nuevo modelo pedagógico se fundamentaría en lo que precisaron como una función social proyectual ${ }^{51}$,el contraste ideológico de dos de sus rectores - Max Bill y Tomás Maldonado-, generó una diversidad de conflictos internos que mellaron su continuidad. La supuesta visión obstinada que se le adjudicó a Bill, —de pretender que la HfG se convirtiera en una sucesora de la Bauhaus, con miras a superarla-, junto a las diferencias en el contexto de las condiciones de producción de su predecesora, sumados a la reticencia de sus funcionarios, profesores y estudiantes a las exigencias del estado alemán —en la era Adenauer-, conllevó a una falta de consenso que ocasionaría su cierre en 1968. Si bien es ineludible 
contextualizar el escenario en el que esta escuela emergió, se aclara que esta investigación se enfoca en cómo entendieron Bill y Maldonado, durante sus respectivas direcciones, las ideas de función y funcionalidad. Todo ello, con el objeto de verificar, por un lado, si el concepto de funcionalismo se practicó en los períodos que dirigieron la escuela, y por otro, si las críticas funcionalistas que se les atribuyen, son enteramente válidas. En este sentido, se seleccionaron los textos más relevantes que, a partir de un análisis, aporten claridad sobre las formas de pensamiento al interior de la HfG, en relación a la cuestión funcional. En esta oportunidad se alterará la cronología, comenzando por la visión que Tomás Maldonado efectuó sobre la escuela y sobre su primer director Max Bill, para luego efectuar las comparaciones pertinentes con las opiniones de éste, Aicher y Bonsiepe. Previo a esto, es necesario esbozar, brevemente, el complicado escenario político en el que todo se originó. Se trabajará con las siguientes fuentes primarias originales, organizadas por autor.

- Maldonado T. (1955a). Ulm 1955.

- Maldonado T. (1955b). Max Bill y el tema del Estilo.

- Maldonado T. (1958). El Diseño y las nuevas perspectivas industriales.

- Maldonado, T. (1974). Vanguardia y Racionalidad. Artículos, ensayos y otros escritos 1946-1974.

- Maldonado T. (1977). El Diseño industrial reconsiderado. Definición, historia, bibliografía.

- Bill, M. (1949). Gute Form.

- Bill, M. (1952). Beauty from Function and as Function.

- Bill, M. (1953). The Basis and aim of Aesthetics in the Machine Age.

- Bill, M. (1958). Function and Gestalt.

- Bill, M. (1979). Del Funcionalismo a la Función.

- Bonsiepe G. 1.10 El Discurso de Ulm (1962-1968).

- Bonsiepe, G. (2003). Sobre la relevancia de la HfG Ulm

- Bonet, Juan. (1980). Entrevista con el Arquitecto y Pintor suizo Max Bill.

- Betts, M. (2016). Entrevista a Gui Bonsiepe.

\subsubsection{Un ideal educativo sociopolítico}

En febrero de 1943, a solo diez años del cierre de la Bauhaus, los hermanos Sophia y Hans Scholl, líderes del movimiento de resistencia pacífica Die Weiße Rose ${ }^{52}$ (La Rosa Blanca), fueron ejecutados por el régimen nazi. La razón de su ejecución fue difundir panfletos en la Universidad Ludwig-Maximilians de München, en contra del militarismo de Adolf Hitler. El 8 de mayo de 1945, con la finalización de la Segunda Guerra Mundial, si bien la sociedad alemana aún se encontraba atomizada entre disidentes del nacionalsocialismo, demócratas y antisemitas, la necesidad de reconstruirla emergería como un imperativo al que se le llamó Stunde Null, designado también como la Hora Cero.

En 1949, cuatro años después de la guerra, según el HfG-Archiv Ulm, algunos sobrevivientes del movimiento La Rosa Blanca, entre ellos: Inge Aicher Scholl (hermana de los ejecutados), Otl Aicher (esposo de Inge) y su amigo Hans Werner Ritcher, planificaron el desarrollo de una escuela fundamentada en la formación política y el diseño ambiental. La fundación Geschwister-Scholl-Stiftung (Hans and Sophie Scholl College), creada por Scholl, sería el soporte para la creación de dicha escuela. Los intereses formativos, funda- 
mentados en el ideal de los hermanos desaparecidos, se enfocarían en fortalecer las ideas democráticas en la conciencia de los jóvenes de una nación, que no estuvo preparada para contrarrestar a tiempo los efectos que trajo consigo la propaganda del partido nazi; este fortalecimiento se daría a partir de la edificación de un nuevo concepto de cultura. Según el HfG-Archiv Ulm, los aportes del comisionado americano responsable de Alemania, John McCloy, junto al programa de Ayuda Europea de Noruega, y la Dirección de Finanzas de Alemania Occidental, condujeron a que finalmente se pudiera llevar a la realidad este proyecto. Su planificación preliminar, enfocada en la política y en las artes, terminó por convertirse en lo que se conoce hoy como la Hochschule für Gestaltung, HfG.

Inge Scholl y Otl Aicher desarrollaron el Centro de Educación de Adultos de Ulm (el vh) después de la Segunda Guerra Mundial. Ellos, divisaron la educación política y el diseño ambiental como formas de fortalecer las ideas democráticas y alentar el surgimiento de una nueva cultura. Inge Scholl instituyó la fundación Geschwister-Scholl-Stiftung en recuerdo de sus hermanos Hans y Sophie Scholl, quienes fueron ejecutados en 1943 por los nazis, por pertenecer al grupo de resistencia «White Rose». Esta fundación se convirtió en la institución de apoyo detrás del futuro HfG. Desde 1949, Inge Scholl, Otl Aicher y Hans Werner Richter comenzaron a planificar una escuela de política y arte en Ulm. (HfG-Archiv Ulm, 1948, p. 2) ) $^{53}$

\subsubsection{La redefinición de los términos de una nueva cultura moderna}

La HfG se consideraría luego como una institución de formación que, desde la tradición importada del Bauhaus, intentaría articular las exigencias de la vida práctica de las sociedades alemanas, en coherencia con la producción industrial y sus lógicas del capitalismo emergentes. Los profesionales que surgieron de ella, se distinguirían más tarde como diseñadores. De allí que Bill, en 1954, invitara al artista concretista y diseñador argentino, Tomás Maldonado, a unirse a la institución. Más adelante, los profesores Walter Zeischegg, Friedrich Vordemberge Gildewart y Hans Gugelot, fortalecerían también el equipo de formación para que la HfG alcanzara sus fines.

Luego de su llegada a Ulm, en 1954, comienza a redactar su primer artículo, que publicaría un año después, titulado: Ulm 1955. En él, destacó la confrontación permanente con la tradición del Bauhaus, y la relación entre el diseño y la industria, enmarcada en la sociedad capitalista, como las constantes de su interés durante su permanencia. En el momento en que se decidió retomar la función social de la actividad proyectual devenida del Bauhaus, la dirección de la escuela atestiguó una orientación que continuaba con la tradición. Pero, al encarar condiciones políticas, económicas y sociales diferentes a las de ese entonces - desde las que se dispusieron nuevas soluciones_, literalmente, para Maldonado, la escuela superó la tradición. Si bien es obvio que la HfG insistió al principio en dicha tradición, la naturaleza de los nuevos hechos la condujeron a virar, más tarde, hacia direcciones distintas. Parafraseando a Maldonado (1955a), la manera en que los pioneros del Bauhaus confrontaron sus problemas, no correspondería con las situaciones a las que la escuela se estaría enfrentando en ese momento. 
En ese mismo artículo, Ulm 1955, Maldonado recuerda cómo luego de la primera posguerra, el Bauhaus apostó a la necesidad de instituir una nueva cultura moderna en general, y en función de esa cultura, aclara, se crearon formas en su nombre, que fueron señaladas por la escuela de Ulm como nefastas. Esta dura adjetivación se basaba en considerar que obstruían las relaciones sociales auténticas, e impregnaban la vida cotidiana de falsas ilusiones; lugar, donde la competencia comercial, los formalismos y los estilos, de espaldas al bienestar, se promovían como un beneficio al alcance de todos. Maldonado destaca cómo la escuela que se estaba construyendo en Ulm, se proponía redefinir los términos de una nueva cultura.

La escuela de Ulm quiere señalar el camino a seguir para lograr el nivel más alto de creatividad, pero a la vez y no en menor medida, señalar cuál ha de ser la finalidad social de esta creatividad, es decir, indicar cuáles son las formas que merecen ser creadas y cuáles no. [La cursiva es del autor] (Maldonado, 1955a, en Maldonado, 1974, p. 70)

En otras palabras, la HfG no colocaría su acento sobre lo moderno en general, como se hizo en el Bauhaus, sino en una clase de creatividad y modernidad que subrayarían su preocupación social. Seguidamente, lo expone a través de un ejemplo, donde el diseñador industrial o el proyectista ${ }^{54}$, - que trabajan para la gran industria, al menos en algunos sectores-, se debate entre servir a la sociedad o al programa de ventas y a su competencia comercial.

En oposición a las pretensiones de la gran industria, como Maldonado (1955a) le llama, este defiende que, aun trabajando para ellas, el diseñador no puede, ni debe, abandonar la responsabilidad que tiene con la sociedad.

La HfG hace suya la tesis según la cual el proyectista, aun trabajando para la industria, ha de continuar asumiendo sus responsabilidades frente a la sociedad. En ninguna circunstancia sus obligaciones para con la industria podrán anteponerse a sus obligaciones con la sociedad. Se ha de propiciar la formación de un nuevo tipo de proyectista que, en las actuales y difíciles condiciones de la sociedad capitalista, sepa crear objetos concebidos al margen de cualquier oportunismo o profesionalismo. Objetos que unas veces tendrán la función de satisfacer las exigencias concretas de la vida cotidiana del hombre, pero otras veces estarán destinados a enriquecer su experiencia cultural. [ La cursiva es del autor] (Maldonado, 1955a/1974, p. 70)

De los planteamientos de Maldonado (1955a), se deduce su censura hacia la continuidad con el pasado, evidenciando una actitud a contracorriente con la tradición del Bauhaus. No obstante, si bien en este texto no responsabiliza a alguien en particular como causante de dicha confrontación, sí lo hace respecto de la dirección de la escuela para ese momento; que, aunque no lo menciona, suponemos se vincula a Max Bill. Cuando habla de la importancia de lo que se está construyendo en Ulm, Maldonado asume un tono ambicioso al describir una especie de finalidad social de alto nivel, que la dirección de la escuela se 
compromete a alcanzar. Dicho camino, que indicará cuáles formas serán dignas de ser creadas y cuáles no, nos demarca una especie de condición moral obligatoria e intrínseca a la actividad proyectual; cabe destacar que, hasta ese momento, tal actividad, se encontraba orientada solo hacia la industrialización.

Si bien se comprende la dirección hacia la que Maldonado (1955a) se dirige, la diversidad conceptual de cada una de sus reflexiones, merece una aclaración. Por ejemplo, ¿qué significan para él la cultura moderna, la creatividad y la modernidad? En un texto muy posterior de 1990, El futuro de la modernidad, Maldonado será bien explícito en adherir, lo que Habermas define por proyecto moderno, es decir "un proyecto basado en la emancipación”, (Maldonado, 1990, p. 19). En su momento, desde el análisis del artículo Ulm 1955, la cultura moderna es uno de los varios aspectos que hacen parte de una gran articulación entre necesidades, tecnología, creación, producción y contexto. El diseño, por medio de la finalidad social creativa, responde a estas necesidades a través de formas instituidas como objetos funcionales, que se reproducirán en serie para satisfacerlas. Tales objetos representan a esa sociedad, de allí su finalidad, donde más allá del concepto clásico de la cultura como conocimiento, expresan la cultura como un reflejo. Sin embargo, si la cultura no se expresa, los mecanismos y las condiciones a las que se sujeta, virarán hacia el servicio del programa de ventas y a la competencia comercial, con el objetivo de mantener estable sólo los intereses de la economía.

Para Maldonado (1955a), cuando los movimientos en desarrollo se supeditan solo al aspecto estético, terminan por reproducirse como formalismos. Así, atenúan la conexión entre las exigencias de la vida y la forma, como una expresión fraccionada que limita el alcance del bienestar, y aumenta la competencia social, como su mejor contingencia [La cursiva es del autor]. La redefinición de esta nueva cultura, propuesta en Ulm, exige una instauración permanente de la relación que, a través de las investigaciones en torno a la forma y la función, garantizan su articulación. A pesar de ello, Maldonado sabía muy bien que las intenciones idealistas de la $\mathrm{HfG}$, de conciliar esta relación entre el diseño y el capitalismo alemán, sería todo, menos una tarea fácil. De allí que, según él, no se pueda seguir pensando en términos de cultura moderna en general. Con esta especie de redefinición, tal vez idealista, tal vez progresista o liberadora, opositora de los estilos y de todo lo moderno generalizado, es posible que Maldonado se respalde en ese concepto nuevo de modernidad del que tanto habla. Una modernidad que, en relación con el diseño, el capitalismo, la economía y la producción, reclame de ellas y para ella misma, un fuerte contenido social.

\subsubsection{La anulación de los estilos}

Maldonado (1955a), considera la proliferación e institución de los estilos como una patología. En otro de sus textos, titulado: Max Bill y el tema del estilo (1955b) esboza las contingencias que Bill desarrolló para intentar contrarrestar dicho fenómeno. Así afirma que, desde el Bauhaus, Gropius manifestó que nunca se tuvo la intención de difundir un estilo. Sin embargo, la idea del estilo, como la pretensión de la anulación de los estilos, o el estilo no-estilístico, caducó mucho antes de que su validez y espontaneidad alcanzaran sus objetivos; "calcificándose al fin en un estilo, quizá más atractivo, pero no por ello menos limitado" (Maldonado, 1955b/1974, p. 66). Este fue el fenómeno que confinó al Bauhaus 
como sinónimo de un estilo: El Estilo Bauhaus. En otras palabras, a un modernismo de apariencias, donde la idea de que la forma sigue a la forma, fue preponderante.

—no se sabe si bien por transmutación de sus elementos propios, por reacción contra ellos, por exigencias externas, o por todas esas causas a la vez- a un estilismo a ultranza, a un estilismo (y esto es lo peor) al servicio de las intenciones menos escrupulosas de la política de mercado. En una expresión, a un «modernismo de apariencias», con sus diversas variedades, a cuál más aberrante, vestigios sin gloria de un largo proceso que al principio parecía lleno de promesas. Esto es lo que sucede en el campo de las formas creadas para la industria $[. .$.$] la idea de que «la forma sigue a la forma» está conquistando,$ por todas partes, día a día, un mayor número de adeptos. [La cursiva es del autor] (Maldonado, 1955b/1974, p. 66)

Así, Maldonado (1955b) aclara que lo que se pretendía detrás de las intenciones del noestilismo, no consistía en frustrar los intentos de convertirse en un estilo. Contrario a ello, lo que se ambicionaba era sortear las antiguas maneras de concebirlos, que formatearían el juego constante de sus apariciones y reemplazos. A pesar de este horizonte poco afirmativo, es decir, un entorno en que del estilo no se podía escapar, aclara que las experiencias acumuladas desde el comienzo de siglo hasta ese entonces, condujeron a maniobras que buscaron mitigar dicha patología, y encauzar la relación coherente que debía existir entre las exigencias de la vida y las formas. Max Bill es para él, una de esas personalidades significativas, que avivó la definición de una nueva postura en torno a estos términos ${ }^{55}$. El aporte que Maldonado ve en Bill, es que las obras y los productos industriales diseñados por este, aunque indirectamente apuntan a un estilo, comunican un deseo de coherencia. Allí, el estado ideal de las cosas, desde un objeto hasta una ciudad, se define como una suma de funciones en unidad armónica, que responden a tales exigencias. Respecto de los objetos diseñados por Bill, Maldonado declara que emerge una coherencia diferente, un estilo que es todo menos algo dogmático o cerrado; donde la intención de uniformar no se subordina a la de formar. Explica lo que para él significa su unidad de estilo, o Stileinheit, importada de Adolf Loos, que no se alcanzará simplemente con la adición decorativa de la forma. Y aquí, Maldonado (1955b) expone en profundidad que, contrario a lo que se proponían los precursores del funcionalismo, apoyados en el axioma de Sullivan: la forma sigue a la función, en Bill, la forma y la función no guardan una relación lineal, sucesiva y continua, debido a que la adición decorativa no puede reducirse a considerarse solo como un rechazo a la ornamentación.

En Bill, forma y función no tienen una relación lineal, sucesiva y continua, sino paralela, simultánea y discontinua. «La forma — escribe Bill- es el resultado de una colaboración entre forma y función que tiende a la belleza y a la perfección» Pero se apresura a añadir: «no se ha de cometer el error, según esta definición, de creer que la forma pueda ser determinada por medio de los simples datos de un problema. (Maldonado, 1955b/1974, p. 68) 
Si bien el razonamiento de Bill, concibe un concepto de forma complejo, mucho más que el determinado por una serie de datos o requerimientos de un problema -obviamente expresados racionalmente-, en su teoría se insinúa algo más que eso. Ese algo más, lo deja librado al creador y a su búsqueda incesante de la perfección. A partir del análisis de este autor, se concluye que, la relación entre la forma y la función de Bill es compleja, debido a que articula la noción griega del tekhné, como el saber hacer con causa, con el de poiesis, como un proceso/método de construcción de cosas bellas. Esto contrasta con la postura de Maldonado, que pretende ser fundamentada científicamente en la episteme. Según, Zubiri (1988), para Aristóteles, la noción de episteme consistiría en demostrar la interna necesidad de lo que no puede ser de otra manera, como la estricta relación de lo que necesariamente debe ser así, sustentado bajo una relación de necesariedad.

\subsubsection{La racionalidad del diseño frente a la irracionalidad del mercado}

En 1958, cuatro años después de su estancia en Ulm, Maldonado publicaría el texto: El Diseño y las nuevas perspectivas industriales. En él, describe de manera más amplia, las reflexiones y los debates en torno a las contradicciones que afectaron a la $\mathrm{HfG}$, durante su primer periodo de funcionamiento. Maldonado (1958) relata que fue una época muy difícil para todos ellos, dado que coincidió con la fase más agresiva de la era Adenauer, donde Alemania, con el respaldo de los Estados Unidos, inició la transición del capitalismo hacia el neocapitalismo ${ }^{56}$. En este artículo, denuncia cómo las intenciones de la industria alemana se tornaron invasivas, al elevar diversos requerimientos a la HfG, de manera parecida a como se le había exigido antes al Bauhaus.

Lo que la industria alemana quería entonces de nuestro instituto no era muy diferente de lo que, cuatro décadas antes, había pretendido del Bauhaus; que contribuyéramos a crear un alibi vagamente cultural para su programa de producción. Nosotros éramos conscientes de ello, pero nos hacíamos la ilusión [...] de que era posible conciliar los intereses de la producción del neocapitalismo naciente con los intereses de los usuarios. Esto más tarde se vio que era un error grave de valoración. En el momento en que nos dimos cuenta de ello, y adoptamos una actitud de denuncia e incluso de rebeldía [...] el destino de nuestra institución ya estaba marcado. (Maldonado, 1958/1974, p. 71)

Maldonado (1958) recuerda como Hannes Meyer, durante su dirección en el Bauhaus, asumió una actitud similar, en contra de los peligros que traerían consigo los formalismos artísticos, bajo las estrictas reclamaciones de la industria alemana de ese período. De lo que se deduce que, ni la voluntad crítica de Meyer en Dessau, ni la actitud visionaria de Maldonado o las coaliciones entre profesores y estudiantes en Ulm, serían suficientes para contener estas demandas. La postura de la HfG, -al rechazar que el diseño industrial se convirtiera en arte, no parecía ser gratuita. La razón se encontraba en que tanto Maldonado como Aicher, desconfiaban de la relación que el arte venía guardando desde hace mucho tiempo - de manera disimulada -, con la cultura; en el sentido que estetizar la vida cotidiana, terminaba ocultando sus contradicciones y sometimientos. 


\subsubsection{El responsable de la continuidad con la tradición}

En contraste con los textos analizados anteriormente, en el libro El Diseño Industrial Reconsiderado, que Maldonado publicara en 1977, la decisión respecto de la debatida continuidad dentro de la tradición originaria del enfoque preliminar de la HfG, es adjudicada abiertamente a un responsable. En este texto, reconstruye el escenario cuando Scholl, Aicher, y Bill —como su primer rector-, inauguraron el Instituto (Maldonado, 1977). Al principio recuerda que se aceptó la continuidad propuesta por Bill, pero no en términos de mera restauración, es decir, se le daría continuidad al Bauhaus, pero luego de validar la vigencia de sus presupuestos didácticos, culturales y organizativos.

Esta situación derivó en discusiones que cuestionaron el valor del camino trazado, lo que condujo a Bill, en 1956, como sostiene Maldonado (1977), a dimitir del cargo de rector. Las direcciones a las que estuvo sometida la HfG no se limitaron, como comúnmente se suele creer, a dos rectorías. Si bien hubo dos direcciones dominantes, la de Bill y la de Maldonado, en el texto HfG Ulm: visión personal de un experimento en democracia y educación en Diseño, de Heiner Jacob (2005), se incluye un apartado donde el autor describe todas las rectorías que administraron la escuela. De 1954 a 1957, Max Bill. En 1958, Aicher, Gugelot y Maldonado. En 1959, Aicher, Kesting y Maldonado. En 1960, Kalow, Rittel y Vondemberge-Gildewart. En 1961, Kalow, Gugelot, Rittel y Vondemberge-Gildewart. En 1962, Ohl, Maldonado, Rittel y Vondemberge-Gildewart. En 1963, Aicher. De 1964 a 1965, Maldonado. Y de 1966 a 1968, Ohl.

En complemento, y según el HfG Archiv Ulm Museum (2020), la escuela contaba con los Departamentos de: Diseño de Productos (Produktgestaltung), Comunicación Visual (Visuellen Kommunikation), Construcción (Bauen), Información (Information), y Cine (Filmabteilung) ${ }^{57}$. De todas formas, Maldonado (1977), se pregunta ¿cuáles son los efectos en el desarrollo de la HfG en los siguientes doce años, después de la partida de Bill? Allí define lo que será el concepto Ulm:

Cambia sustancialmente el plan de estudios, que refleja la importancia atribuida, en el nuevo concepto, a las disciplinas científicas y técnicas. Cambia el planteamiento didáctico del "curso fundamental», que intenta reducir al mínimo aquellos elementos de activismo, intuicionismo y formalismo herederos de la dialéctica propedéutica del Bauhaus. Cambia, en fin, el programa del departamento de diseño industrial, que se orienta definitivamente hacia el estudio y profundización de la metodología de la proyectación. Lo que más tarde se llamará el «concepto Ulm», y que ejercerá una profunda influencia en todas las escuelas de diseño industrial del mundo. [La cursiva es del autor] (Maldonado, 1977, p. 76)

Maldonado (1974), en sus textos Ciencia y Proyectación, de 1964, y Notas sobre Comunicación, de 1961, compilados al interior de su Vanguardia y Racionalidad, refiere a la metodología de la proyectación en relación al diseño industrial. Esta se extendía al campo de la edificación industrializada, y al funcionamiento comunicativo, orientado especialmente al mejor entendimiento del sistema hombre-producto y hombre-máquina. En todos los casos, lo dominante era alejar la producción y construcción de la creación artística, y 
orientarla a un enfoque tecnológico, con aportes de las disciplinas científicas. Se trataba de un procedimiento racional riguroso para alcanzar soluciones, en sus palabras, objetivas, que no dependían de la retórica de la persuasión, de teoría poética alguna, de los gustos del consumidor y menos aún de interpretar sus preferencias (Maldonado, 1974).

\subsubsection{La autoría influyente de las orientaciones}

Si bien en la historia del instituto, existió un antes y un después de Bill en torno al tema de lo pedagógico, no sucedió lo mismo al respecto de los productos proyectados en la HfG para la industria. Estos productos, desarrollados por los profesores, en colaboración con los estudiantes, reflejaron la orientación estético-formal de Bill. Maldonado (1977), ratifica que incluso los profesores Aicher y Gugelot, llevaron a cabo un trabajo en colaboración para la compañía Braun, que consistió en el diseño y desarrollo de una línea de productos, que más tarde se tornó en el estilo Braun, distinguido por la búsqueda de la unidad en la unidad. Maldonado explica que, siendo esta orientación la base de la Gute Form, a su juicio, el caso del estilo Braun en la industria, se constituyó en el banco de pruebas de la misma.

En los años cincuenta, los docentes de la Hochschule für Gestaltung, Gugelot y Aicher, hacen una aportación decisiva a la elaboración de la línea de los productos de la firma Braun, de Frankfurt. De ahí se desarrollará el llamado «estilo Braun», un fenómeno de gran interés para nuestro tema [...] el «estilo Braun» es un ejemplo de la búsqueda de la unidad en la unidad. A nuestro juicio no existe un caso parecido en toda la industria contemporánea. Pero precisamente por esto, el «estilo Braun» constituye un formidable banco de pruebas para la concepción de la gute Form, como alternativa al Styling. (Maldonado, 1977, p. 77)

Lo particular de su análisis, es que insinúa que estando la HfG, con Aicher y Gugelot, a contracorriente de esta orientación, es la Gute Form un acto de disenso de Bill, que al transformarse en consenso devino en el estilo Braun. Al final, concluye que si bien el neocapitalismo alemán copta la Gute Form - al convertirla en el estilo Braun-, sería injusto sostener que dicho estilo, también denominado como «estilo Ulm», sea el equivalente a una especie de Styling Design alemán. La disidencia en contra de los estilos, nuevamente convertida en estilo, ilustra que, de las lógicas del neocapitalismo alemán, ni la HfG pudo escapar.

Para reflexionar, de los textos de Maldonado analizados hasta ahora: Ulm 1955 (1955a), Max Bill y el tema del Estilo (1955b) y, el Diseño y las nuevas perspectivas industriales (1958), se deduce que el concepto de funcionalismo lo define como un referente proveniente solo de sus precursores del siglo pasado. Entre varios de estos precursores, destaca a Sullivan como uno de sus representantes. Dado que los precursores del funcionalismo, sosteniendo el axioma de Sullivan la forma sigue a la función, le imprimieron un orden lineal, sucesivo y continuo, que rechazaba la ornamentación, esta concepción, según Maldonado, es superada gracias a Bill. Para Bill, dicha relación debe ser paralela, simultánea y discontinua. De esta manera, se entiende que Maldonado justifique hasta aquí, es decir, 
en estas tres publicaciones, que, tanto en el Bauhaus como en la HfG, se desarrollaron investigaciones en torno a las formas y a las funciones, más no que el funcionalismo operó en la práctica resultante de cada una de ellas. Dichas investigaciones fundamentaron sus esquemas pedagógicos en constante desarrollo, que tendrían por objeto alcanzar un ideal de coherencia exigida por la función social de lo proyectual ${ }^{58}$, gracias a la finalidad social creativa ulmiana.

No obstante, si aún quedan dudas acerca de la postura de Maldonado sobre el funcionalismo, estas se aclararán cuando se refiera el rol de Hannes Meyer. Meyer era realmente un opositor de los formalismos, porque para él desdibujaban la fórmula: la función por la economía, característica de los productos desarrollados en su rectoría; y si en el Bauhaus como en la HfG no existió una práctica del funcionalismo como destaca en los tres primeros textos analizados, ¿por qué parece vincular a Meyer con dicha práctica en su texto El Diseño Industrial Reconsiderado, de 1977? Curiosamente, en este texto, que es posterior a los otros, Maldonado sostiene que el funcionalismo sí imperó en el Bauhaus a partir de una vertiente técnico-formalista, gracias a Gropius, en contraste con una técnicoproductivista, que respaldada por las voces detrás de la revista suiza $A B C$, Meyer llevó al Bauhaus en 1926.

Meyer lleva al Bauhaus el espíritu de la revista Suiza $A B C$ - Beiträge zum Bauten (1924-1928), dirigida por H. Schmidt (1893-1972), R. Roth (1893) y M. Stam, y de cuya redacción era miembro desde 1925. ABC representaba el funcionalismo técnico-productivista, en contraste con el funcionalismo técnicoformalista, imperante en el Bauhaus después de 1923. La concepción de Meyer, antes de su llegada a Weimar aparece claramente testimoniada en dos documentos: en el número monográfico de $A B C$ sobre el arte abstracto (1926), a su cargo, y en el artículo «Die neue Welt», aparecido en la revista Das Werk (1926). Sobre todo, en este último se constata [...] Meyer afirma [...] El arte es composición, el objetivo es función. La idea de la composición de un muelle nos parece absurda y, ¿qué decir de la composición de un plan urbanístico o de un apartamento? Construir es un proceso técnico, no estético, y la de idea de funcionalidad de una casa se opone a la composición artística». [La cursiva es del autor] (Maldonado, 1977, p. 68)

La respuesta viene dada por el hecho de que el término funcionalismo recién comienza a ser usado, y vulgarizado, a partir de 1940 aproximadamente, como una categoría unificante para diversas prácticas orientadas a fines operativos. Pero Maldonado (1977), se esfuerza en presentar al funcionalismo como lo entienden C. Schnaidt y Scolari (1971): "una expresión ideológica, más allá de las instancias tecnológicas" (p. 153).

A Meyer (1926) le parece absurda la idea de composición, no solo porque se encuentra ligada a lo estético, sino también porque no puede definirse como un proceso técnico, razón por la que se contradice con la función práctica de cada cosa. Así, define que construir no es un proceso estético, sino un proceso técnico, que se fundamenta en cada cosa creada según su necesidad. 
La exposición de muestras, los silos para los cereales, el music-hall, el aeropuerto, la silla de oficina, el artículo en serie. Todas estas cosas son producto de la fórmula: función por economía. Ésas no son obras de arte. El arte es composición, el objetivo es la función. La idea de la composición de un puerto nos parece absurda, ¿pero y la composición de un plano urbanístico, de una casa habitacional...? Construir no es un proceso estético, sino un proceso técnico, y la composición artística se contradice con la función práctica de una casa. [ $\mathrm{La}$ cursiva es del autor] (Meyer, 1926, en Maldonado, 1979, p. 250)

Meyer (1926) describe cómo la forma que configura la apariencia, el color del material, la estructura de las superficies de cada cosa, surge de manera automática gracias a la concepción funcional de una actividad que deviene en una construcción pura. Dicha construcción pura es universal, y su expresión internacional es la ventaja de la época. Allí la estandarización es su respuesta racional, porque las emociones, los sentimientos y los impulsos solo pueden habitar, $-\mathrm{y}$ tienen que volver a su lugar original-, según Meyer, en las relaciones de los hombres, y no en las cosas que se crean para ellos.

En el texto de Meyer (1926), se puede comprobar su justificación a la mecanización, a la velocidad, y a la nueva apariencia de las cosas y sus formas, como un producto de la fórmula: la función por la economía. Meyer entiende que las necesidades humanas solo se pueden satisfacer a través de las utilidades prácticas; argumento que suprime las necesidades emocionales. De allí, se entiende porqué Maldonado vincula a Meyer con el funcionalismo técnico-productivista en vez del funcionalismo técnico-formalista.

No obstante, la polémica entre formalistas y productivistas (también constructivistas) no nació con Meyer, y tampoco en la Bauhaus. Estas tendencias representaron dos alas -o perspectivas-, en permanente disputa, en la década del 20 en Moscú, y en la propia Vjutemás. Para relevar estas posturas enfrentadas se puede acudir al documento de N. Dokucaev, de 1925, de tendencia formalista, y por otro lado al ensayo de A. Gan en V. Quilici (1969): El constructivismo, citados y analizados por Nicolini, Accasto y Fraticelli (1971). Estas tendencias expresaron profundos enfrentamientos ideológicos dentro del campo estalinista, por el contenido de las principales propuestas político-económicas de los planes quinquenales, y por el rol de ingenieros, técnicos y artistas en ellos. En palabras de los autores, el ala productivista se caracterizaba por "anular en la producción el arte como actividad específica” (Nicolini, Accasto, Fraticelli, 1971, p.72). Meyer expresó su afinidad con esta postura, de allí, que Maldonado la rescate, para decir: "un funcionalismo basado fundamentalmente en la exaltación del productivismo, del antiesteticismo, del realismo, del colectivismo y del materialismo" (Nicolini, Accasto, Fraticelli, 1971, p. 60).

Por lo tanto, de esta revisión, se debe recalcar que Maldonado funciona como fuente primaria cuando el concepto de funcionalismo es estudiado en el contexto de la HfG. Sin embargo, cuando ejerce su papel como crítico en el contexto del Bauhaus, funciona allí como fuente secundaria. Esto lleva al autor de esta investigación a afirmar que el concepto Ulm, desde sus instancias de enseñanza, metodología y desarrollo, contenidas en su modelo de proyectación, hace de Maldonado un admirador y seguidor de Hannes Meyer. La inclinación por el diseño racional de los productos, que encuentra sus respuestas en la ciencia y no en el arte, en la razón y no en el alma, en el método y no en los sentimientos y las 
emociones, nos lleva a deducir que Meyer fue al Bauhaus, como Maldonado fue a la HfG. De todo esto, es necesario añadir la mirada que Aicher (1991) traza en su texto: El Mundo como Proyecto, ${ }^{59}$ en torno, específicamente, al concepto de funcionalismo. Aunque lo considera como un esfuerzo - por parte de la arquitectura moderna-, en definir funciones que estuvieran en concordancia con los requerimientos de una sociedad cambiante, el fundador de la HfG lo recuerda como un episodio del pasado, que tuvo que concluir de manera forzada.

La llamada superación del funcionalismo es una afirmación sustantiva, no una moda. Es una conclusión de todo punto forzosa cuando la arquitectura sigue negándose a definir funciones, cuando vivimos en una sociedad que ha dejado de preguntarse por el sentido, qué debo hacer, qué es justo, a dónde va esto, a dónde conduce aquello [...] Entonces, ¿ cómo puede un arquitecto preguntarse aún por criterios de funcionalidad, por criterios de uso, de edificación, de ejecución, de utilización de materiales, cuando construir ya no significa atender necesidades, sino producir signos y engrosar la multitud de horizontes semánticos de la cultura? (Aicher, 1991/1994, p. 91)

El funcionalismo, propio de la arquitectura según él, fue desplazado por la satisfacción de criterios que ya no tenían nada que ver con las necesidades biológicas de las personas, sino con la producción de signos que alimentaban y motivaban los horizontes semánticos de la cultura, la producción y por ende la economía. Se aclara que, para Aicher, aunque el funcionalismo fue un sinónimo de definición de funciones en coherencia con las necesidades, en su texto no menciona que se haya practicado oficialmente en Ulm.

\subsubsection{Un segundo Max Bill}

Sin embargo, si se revisa la compilación de textos de Max Bill: Form, Function, Beauty = Gestalt, publicado en 2010, evidenciamos cambios sustanciales en su pensamiento, que en los textos de Maldonado no se advierten. En esa publicación, se recopilan un sinnúmero de escritos de Bill que van de 1949 hasta 1958. En sus dos primeros textos: The Good Form (1949) y Beauty from Function and as Function (1952), el análisis que Maldonado elabora sobre él, se corrobora de manera asertiva y contundente. No obstante, en el artículo The Basis and aim of Aesthetics in the Machine Age, Bill (1953) expresa cómo las ideas que había sostenido antes, entre ellas, la del papel preponderante de la belleza como una función paralela a las funciones técnicas, debía ser superada; pero mantiene la idea de la armonía entre las funciones bajo el concepto de la Gestalt. Así, sostiene que el objetivo de la estética en la edad de la máquina, debería basarse, exclusivamente, en la preocupación por servir a las personas a través de una totalidad de funciones en unidad armónica, donde sus cualidades deben también ser evaluadas bajo los principios de solidez, valor de uso, belleza y asequibilidad.

De este texto se concluye que Bill (1953), concibe la belleza ya no como una función paralela a las funciones técnicas. Su idea de belleza es ahora un principio, que, junto a otros principios como la solidez, el valor de uso y la asequibilidad, se evalúan por las cualidades que prestarán sus funciones. Para explicar mejor esta postura del pensamiento de Bill en 
1953, cuando era aún parte de la HfG, se analiza el texto Function and Gestalt, que publicara cinco años después. Allí Bill (1958) amplía no solo la genealogía y el significado del término función, sino también su aplicabilidad instrumental en las disciplinas del diseño. Allí el referido autor sostiene que, si bien la acepción del término función podría variar según el campo en el que se use, su concepción original proviene de las matemáticas. Leibniz, que en 1684 acuñara ese concepto ${ }^{60}$, veía las funciones algebraicas como variables, donde el valor de cada una de ellas, dependía a su vez del valor de las otras. Esta dependencia, denotaba para Leibniz, según Bill, un comportamiento de correlación, que expresado en forma de números en el campo de las matemáticas, trazaba la teoría de la función en su sentido más puro a través de una correlación causal. Debido a que la correlación causal era la premisa básica de la teoría de la función, el referido autor sostuvo que dicha acepción, no solo se amplió aún más en las matemáticas, sino también llegó a adecuarse e implementarse en otras disciplinas.

Esta concepción de la función va más allá de la causalidad, aunque también veo en la causalidad - la relación de causa y efecto- como parte de la función. La causalidad es la premisa básica de la teoría de la función. La relación de causa-efecto es a su vez el resultado de la función. (Bill, 1958/2010, ubicación 1466 de 2338)

En el diseño, la función, dice Bill (1958), significa una relación coherente entre una cosa con otra, entre una cualidad en relación a otra, planteadas en un mismo plano y en un mismo nivel. Por lo tanto, cuando se habla en el campo del diseño de cumplir con una función, se hace alusión a producir una forma o un objeto, para satisfacer una necesidad concreta a través de los medios apropiados.

Existe una concepción de que el término función, estrictamente hablando, se refiere únicamente a una función matemática. Esto se debe a que Leibniz, el fundador del concepto matemático de la función, que descubrió, hacia 1684, las funciones algebraicas del cálculo diferencial e integral; es decir, las variables cuyo valor depende del valor de otra variable. El término de Leibnitz se amplió aún más en matemáticas, hasta el punto en que la disciplina ahora es inconcebible sin él. Correspondientemente, entonces, el término función denota el comportamiento de una incidencia en relación con otra. Describe una correlación. En matemáticas, esta correlación se puede expresar en números, y por esta razón, las matemáticas y la logística representan el campo ideal para la teoría de la función más pura. En su sentido más amplio, más general, sin embargo, función significa la relación de una cosa a otra. Por lo tanto, cuando hablamos de cumplir una función, estamos hablando de producir algo para satisfacer una necesidad, o simplemente cumplir una función utilizando los medios apropiados. (Bill, 1958/2010, ubicación 1448-1460 de 2338)

Las funciones proyectadas desde la relación causal entre cada uno de sus principios, arrojan la claridad necesaria para determinar las formas que los configurarán. Bill (1958), 
afirma que cuanto más precisa sea la definición de cada una de las funciones, más claros serán los requisitos, más coherente será su diálogo, y así más unificado será su resultado. Esta armonía en la unidad, donde las funciones en una relación causal de dependencia dialogan entre sí, sin impedirse, es lo que Bill denomina como Gestalt.

Bill (1958), concluye con el cuidado que los diseñadores deben tener, para no caer en los tres peligros que acechan en el camino del diseño y el desarrollo de los objetos. Los enumera empezando por las artes decorativas, siguiendo por el gusto popular - popular taste-, y terminando con el formalismo con el que se asoció al Bauhaus y a la HfG: el funcionalismo.

Hay tres peligros constantes acechando en el camino del desarrollo: 1. Las artes decorativas; 2. El llamado gusto popular; 3 . El funcionalismo. Por arte decorativo me refiero a algo que se aplica al objeto con la intención expresa de crear algo hermoso, y que más o menos se interpone en el camino de sus funciones reales. ¡Por "sabor popular" — ¡en comillas invertidas! - No quiero decir lo que los consumidores generalmente quieren, sino lo que los fabricantes piensan que es más fácil venderles. Finalmente, el funcionalismo (como cualquier otro -ismo) es propenso a la disimulación. Actúa como si su objetivo fuera cumplir con una disimulación. En este sentido, puede verse como una rama del arte decorativo, cargada con las mismas deficiencias, o como una pseudosolución reducida a las funciones puramente materiales. (Bill, 1958/2010, ubicación 1526-1532 de 2338)

De los dos textos analizados de Bill ${ }^{61}$, en correlación con las publicaciones de Maldonado y Aicher, surgen varias observaciones. Aunque su pensamiento presenta claras sujeciones con la Gestalt, la belleza y la forma, que pueden verse en sus publicaciones Die gute Form (1949) y Form und Kunst (1952)_analizados por Maldonado-; o también en The Good Form (1949) y Beauty from Function and as Function (1949)_analizados por el autor de esta investigación-, no sucede lo mismo en The Basis and aim of Aesthetics in the Machine (1953).

En The Basis and aim of Aesthetics in the Machine, Bill (1953) plantea una divergencia que enfocada en tres aspectos certifica una supresión a su antigua orientación: la superación del papel de la belleza como función, la estética de la máquina sólo orientada al servicio de las necesidades, y las cualidades de los objetos enfocadas al bienestar social. En su artículo Function and Gestalt (1958), dichos aspectos se amplían y el cambio se vuelve más radical. En él, vemos a otro Bill, uno que considera la acepción correlacional de la función importada de las matemáticas de Leibniz; un detractor del arte decorativo, del gusto popular, del funcionalismo y de todo lo superficialmente material; uno completamente distinto al descrito por Aicher y Maldonado. En torno a estas posturas, la entrevista que Juan Manuel Bonet le hiciera a Max Bill en $1980^{62}$, arroja claridad cuando toca el tema de su dimisión como rector en 1956. Bill da a entender que, aparte de su postura, dentro de la escuela existían otras dos, que iban a contracorriente de su visión del diseño dentro de la escuela, tema que será abordado a continuación. 


\subsubsection{Las variantes heterogéneas producto de la filosofía de Ulm}

En esta entrevista de Bonet (1980), Bill insinúa que en la HfG lo que prevaleció fue una especie de diversificación política, sujeta a factores distintivos, que fueron defendidos por las coaliciones con las que se identificaron estudiantes y profesores, lo que condujo a la fuerte confrontación que hemos estado estudiado.

De toda esta diversidad política, que generó una multiplicidad de imágenes de la HfG, el diseñador industrial Gui Bonsiepe, quien fue estudiante y luego profesor en la escuela de Ulm, ilustra este fenómeno desde su perspectiva. En su artículo El Discurso de Ulm, publicado en: Modelos de Ulm, Modelos post-Ulm, Hochschule für Gestaltung Ulm 1953-1968, Bonsiepe (2003), recrea el clima intelectual que se vivió en la HfG, de 1962 a 1968. En él explica, cómo el periódico del instituto ${ }^{63}$ creó una especie de plataforma internacional que funcionó de 1958 a 1968, como ventana pública de difusión de sus actividades, investigaciones, proyectos en desarrollo y resultados de enseñanza. Las publicaciones estarían divididas en dos fases, que según Bonsiepe, difirieron no sólo en torno a su formato inicial, sino también en su concepto editorial. Los ejemplares del 1 al 5 corresponden a la primera fase, y fueron publicados de 1958 a 1959. Los de la segunda fase -6 al 21 -, fueron publicados desde 1962 hasta 1968.

Se procuraba reflejar la posición oficial de la institución, si bien esto podía dar la impresión de que la escuela tenía un carácter monolítico. Esta lectura de la HfG Ulm — así como de la Bauhaus— es incorrecta. No había "una” HfG Ulm, del mismo modo en que no había "una” Bauhaus, sino más bien variantes heterogéneas, que podían reconocerse luego de un análisis textual preciso. Ciertamente que esta multiplicidad rica en matices, con sus profundas divergencias, permanece oculta para una lectura simplista y esquemática, que cree haber solucionado todo con la palabra - “funcionalismo"-, un término absolutamente problemático [...] La acusación levantada por críticos conservadores contra los representantes de la HfG Ulm durante los quince años de su existencia - de que la institución estaba siendo debilitada por sus controversiaspuede parecernos hoy en día (y no sólo hoy en día) una evidencia de su fuerza y su productividad [...] un discurso sobre el diseño crítico y no-conformista, se debe en gran medida a Tomás Maldonado, la figura intelectual central de la HfG Ulm. Él estaba detrás de las innovaciones pioneras del concepto de Ulm - un trabajo que nunca fue reconocido y nunca pudo ser reconocido por el provincialismo localista del contexto de la HfG Ulm. La HfG Ulm sufrió el mismo destino que la Bauhaus. [La cursiva es del autor] (Bonsiepe, 2003, p. 15)

\subsubsection{Una clara herencia Ulmiana}

Por otro lado, en una entrevista a la que accediera Bonsiepe para el autor de esta investigación en 2016, a la pregunta asociada al concepto de funcionalismo en la HfG, su postura ilustra el cuidado que hay que tener con el uso de ese concepto en dicho contexto. Así, describe que el debate del funcionalismo, como postura en torno a las tareas proyectuales, y debido a la ambigüedad del término función, condujo a diversas confusiones. Bonsiepe aclara que el concepto función posee diversas acepciones dependiendo del campo discipli- 
nar en el que se aplique. Desde la ingeniería se encuentra asociado a la eficiencia física que puede poseer un mecanismo; en matemáticas a la dependencia de un valor sobre otro; en la informática a una rutina; pero en el diseño se entiende el término dentro de los rituales del uso de un producto. De allí, que Bonsiepe afirme que el diseño no es arte, porque el segundo se opone a la funcionalización; la instrumentalización, indisoluble respecto del diseño, no es constitutiva para el arte. El funcionalismo, que para Bonsiepe partió de una mirada determinista de las ciencias naturales, terminó por trasladarse a la arquitectura, y luego al diseño, transformándose en una especie de doctrina donde la correspondencia entre formas y funciones se asoció con el imperativo de la forma sigue a la función. Si bien este lema es importante para Bonsiepe, como advertencia para que el diseñador no olvide la importancia de las diversas funciones con las que debe cumplir un artefacto, y que, por otro lado, la forma - como categoría máxima-, no impere sobre el resto de factores de su configuración, no hay que olvidar que el concepto de función va mucho más allá de todo ello.

No estoy de acuerdo con la frase de cuño determinista «La forma sigue a la función» [...] Es válido el lema de Sullivan como una alerta para el diseñador que no debe olvidarse de la función del artefacto, y que no debe tratarlo como una quantité négligeable. Es válido también como una alerta para el diseñador no deba tratarlo como una categoría máxima sobre el resto de factores [...] Uno de los más exitosos ejemplos de la vigencia del funcionalismo como idea de facilidad de uso y facilidad de aprendizaje son los productos de la empresa Apple. Estos productos reflejan una clara herencia ulmiana, lo que Jonathan Ive reconoció sin que esto le quite méritos por los trabajos excelentes que ha hecho [...] Entonces el funcionalismo no está tan muerto o superado como a veces con gesto condescendiente los seguidores del postmodernismo declaran. (Betts, M. 2016, en impresión, p. 5) ${ }^{64}$

En otro texto de Bonsiepe (2008) Sobre la relevancia de la HfG Ulm, él explica cómo los artefactos diseñados en Ulm poseían una carga semiótica. La semiótica, como disciplina, fue vista y estudiada en la HfG, como parte importante de la fundamentación para la formación en Diseño. En Ulm, afirma Bonsiepe, el equilibrio que guardaba la materialidad de cada objeto con su dimensión simbólico-comunicativa, evitó que el diseñador fuera visto como el outsider de la industria, es decir como un mero productor de signos, y también cómo el antiguo y simple dotador de formas.

De todas maneras, se deduce que, aunque la HfG tuvo el propósito de equilibrar la dimensión simbólico-comunicativa - proveniente de los estudios en Ulm sobre semiótica一, en relación a la funcionalidad de cada objeto diseñado, por equilibrio habría que entender una subordinación de la primera a la segunda. Esto, entendido en razón de que no se podría poner un énfasis excesivo en esta dimensión. O como lo describe Bonsiepe, darle el lugar que los contextos económicos del mercado, le otorgarían más tarde. El componente semiótico que poseyó cada artefacto creado en la HfG, fue para Bonsiepe una realidad. Sin embargo, la variante determinista y limitante que construyeron los críticos en torno al funcionalismo de los productos proyectados en Ulm, intentó atacar la base racional implícita en ellos. Dicha crítica resultó, según Bonsiepe, en una versión caricaturesca y 
simplista, porque estaba fundamentada, según Bonsiepe (2008), en una supuesta ausencia de la subjetividad, los sentimientos y las emociones; todos estos, aspectos que en la HfG de Ulm sí se tomaban en cuenta para el desarrollo de los productos.

\subsection{Conclusiones del capítulo}

Afirmar que el funcionalismo se reduce a ser un estilo, que señala una tendencia de apariencia simplificada como respuesta única a una tipología de funciones prácticas, es un error. No sólo obvia su contenido semiótico y el cúmulo de funciones asociadas a él, sino también critica ciegamente lo que en la Bauhaus y en la HfG se esmeraron en defender: el ideal de coherencia que se exigió desde la función social proyectual. Una situación similar a lo que sucedió con la Primera Escuela de Chicago, pero en un contexto completamente diferente. Bonsiepe concluye que esta simplificación sesgada por los críticos del funcionalismo proviene de las interpretaciones de las disciplinas no proyectuales, debido a que sus intereses reposan en el manejo de los instrumentos simbólicos, como la sociología, por ejemplo.

No obstante, Bonsiepe también recalca que analizar el concepto desde el servicio prestado por los objetos solo a partir de su funcionalidad, sería hoy un tanto anacrónico y desfasado. Así, recuerda que, si bien en el pasado, las funciones de los objetos eran el centro de atención, hoy lo es la instrumentalización del diseño subordinado a los imperativos del marketing, es decir, la función que un artefacto debía prestar al usuario se ha visto desplazada por el cómo debe funcionar en el mercado. Bonsiepe concluye planteando la vigencia del funcionalismo como idea de facilidad de uso y facilidad de aprendizaje, reflejados en los productos de la empresa Apple.

Para sintetizar, se afirma que en Bonsiepe vemos una HfG que contrasta con las diversas fases de pensamiento de Bill ${ }^{65}$, y las posturas radicales de Aicher y Maldonado. En Bonsiepe, se ve una institución integral y divergente, donde el diseño, sin ser un sustituto del arte, le da lugar en algunos de sus campos, y donde su función social no puede interpretarse como una glorificada actividad mesiánica. No obstante, ni el eclecticismo de Gropius; ni el enfoque racional de Meyer; ni el neutralismo de Mies; ni la censura del arte de Aicher y Zeischegg; ni la belleza funcional y multifacética de Bill; ni el valor científico otorgado al diseño - gracias a Maldonado-, pudo impedir que los estilos continuaran materializándose.

De Ulm se extrae un concepto de funcionalidad en permanente conflicto, en tanto se lo acusa de ser precursor de un formalismo. Este carácter dilemático, y en tanto tal, imposible de resolver, acompañará al concepto de funcionalismo hasta hoy. No ya como promesa de un futuro mejor, sino que aparece como un concepto envuelto en disputas ideológicas por su significado. Tironeado entre sus vínculos indisolubles con la noción de belleza, y censurado por su posible asociación con el arte, al que se lo concibe sólo como resabio burgués. La aparición en público del concepto de funcionalismo, en el propio contexto de Ulm, emerge de la mano de fuertes disputas ideológico-políticas, comunes también en las vanguardias soviéticas, que lo asocian sólo a la función social y a lo técnico-productivo, con carácter revolucionario. 


\section{Impactos posteriores a Ulm. Análisis comparativos de las fuentes secundarias}

Luego del cierre de la HfG en 1968, muchos teóricos del Diseño abordaron la cuestión funcional en sus investigaciones, y el concepto de funcionalismo se expandió hasta convertirse en modo de una matriz disciplinar en la proyectación (Kuhn, T. 1962), ya sea para venerarlo o para criticarlo. Esto se muestra en la diversidad de autores y textos, que reflejaron las múltiples polémicas y reñidas posturas, atravesando claustros y congresos de todos los países, al menos hasta la década de los noventas. De esa amplia lista de autores, seleccionamos aquellos que nos proporcionan las miradas más divergentes y que, en su rol de fuentes secundarias, se prestan a la comparación con lo expuesto en el capítulo anterior por las fuentes primarias. Estas comparaciones con respecto a la Historia Conceptual, se realizarán desde la metodología de Koselleck, Reinhart (1993, 2004, 2006, 2012). Y respecto a la Historia de las Ideas, se hará según la metodología Quentin Skinner, (2000), expresadas donde corresponda, bajo los subtítulos de Relativizaciones. Así, se analizarán textos de: Abraham Moles (1973), Jean Baudrillard (1968, 1972, 1974), Bernhard Bürdek (1991/2002), Jan Michl (1997/2018), Herwin Schaefer (1970) y Víctor Margolín (1998), en primera instancia.

\subsection{Una crisis indeterminada. Reduccionismos y críticas}

Los debates sobre estos temas fueron especialmente intensos y ricos en autores latinoamericanos, entre ellos: el mexicano Oscar Salinas Flores (1992); los brasileros Jair Diniz Miguel (2006), Iraldo Alves Matías y Leovitor N. Dos Santos (2014); los argentinos Alejandro Crispiani (2011), Aquiles Gay, Lidia Samar (2007), entre otros. Se seleccionaron a posteriori, de estas lecturas, otros dos textos históricos de estas latitudes, ya que se caracterizan por un enfoque disruptivo: Rosario Bernatene (1996, 2005), y Verónica Devalle (2009). Estas autoras, elevaron definiciones, señalamientos y críticas sobre el concepto de funcionalismo que, aún tras la clausura de la HfG en Ulm, continuó ejerciéndose como propuesta proyectual, en Europa, Estados Unidos, Japón y América Latina. A su vez, las autoras elegidas difieren en sus perspectivas, según se trate de la historia del diseño de productos o del diseño industrial, del diseño para la comunicación visual o del gráfico, o de la arquitectura. Este análisis, permitirá extraer conclusiones acerca de los factores comunes y las diferencias en la historicidad del funcionalismo, según las distintas áreas proyectuales desde las que se aborda.

\subsection{La ética de lo superfluo, según Abraham Moles}

Abraham Moles (1973), en su texto El Kitsch. El arte de la felicidad, explica como la 'tesis' funcionalista se fundamenta en la evolución del ambiente y en las relaciones que los hombres establecen con su medio. La visión objetiva de estas relaciones - donde la sinceridad de los materiales tratados tal cual son, prevalece por encima de cualquier simulación-, 
surge como un antagonismo a la proliferación de lo considerado inútil. Según Moles, en el funcionalismo, las preocupaciones estéticas se encontraron subordinadas a la pureza de las relaciones del hombre con las cosas. Y aquí vale una aclaración, ya que para él las cosas no pueden considerarse como objetos, dado que las primeras hacen parte del Umwelt, $-\mathrm{o}$ ambiente natural-, que el hombre interviene para ser convertido en un espacio artificial, lugar en el que verdaderamente nacen los objetos.

\subsubsection{La herencia de Sullivan y Gropius, puesta en debate}

Si bien, para Moles, esta relación proviene de la influencia de Sullivan, y otros teóricos, es recién con Gropius que toma forma y se oficializa en el Bauhaus, en 1918.

La preocupación estética se subordina, en el funcionalismo, a la pureza de las relaciones del hombre con las cosas [...] la escuela funcionalista se remonta al siglo XIX, con Sullivan, Eiffel, Van de Velde y Horta, pero solo es aceptada en el momento de su plenitud, cuando Gropius funda el Bauhaus en Weimar, en 1918. (Moles, 1973, p.148)

Se impone entonces una pregunta ¿qué factores vincularon a estas escuelas con el funcionalismo, para llegar a confundir a cada uno de sus integrantes como funcionalistas? Ningún estudioso se atrevería a decir que Van de Velde o Víctor Horta eran predominantemente funcionalistas, más bien, siempre estuvieron asociados al Art Nouveau; solo con algunas incursiones en diseños más geométricos. Con respecto a la Bauhaus ya hemos visto que era un crisol de corrientes muy diferenciadas, por lo que difícilmente podríamos hablar de una sola escuela funcionalista. El concepto de función como la base de esta doctrina, como lo denomina Moles (1973), llegó a definirse de manera filosófica como todo aquello que, mientras funciona, mantiene una relación concordante entre los elementos que configuran su totalidad. Es decir, "en el sentido de Goethe, una relación necesaria entre los elementos de un sistema, de un tipo tal que al conocimiento de la posición de un elemento corresponderá el conocimiento de la de otro (definición matemática)" (Moles, 1973, p. 153).

Los avatares de la idea de funcionalidad es una sociedad en desarrollo. Vimos que, después del nacimiento y florecimiento de un arte de la acumulación, de la decoración y de la irrealidad, de un arte del neo-algo que caracteriza al Kitsch del 'siglo 1900', surgió el funcionalismo como un proceso de reacción violenta contra las características fundamentales del ambiente de la Umwelt de objetos y de formas propuestas a los hombres de la sociedad burguesa. Vimos, así mismo, que el funcionalismo se erigió en doctrina fundamental del arte moderno gracias a los esfuerzos de los miembros del Bauhaus de Weimar, Dessau y Berlín. [La cursiva es del autor] (Moles, 1973, p. 174) ${ }^{66}$

La perspectiva sistemática y cibernética, para Moles (1973), sobre las consideraciones expuestas de la función, estructuró diversos métodos ${ }^{67}$ que tomaban en cuenta los problemas biológicos, sociales, técnicos y estadísticos del hombre. Este aporte, implicó el trazado de 
varios principios, donde la ergonomía, la economía de medios, el análisis factorial de los deseos, la eliminación del decorado y la simulación de un modelo de prueba, constituirían las exigencias previas al desarrollo de una "maqueta completa que funciona y que provee un simulacro concreto de la realidad futura" (Moles, 1973, p.158).

LOS MÉTODOS DEL FUNCIONALISMO. Los métodos del funcionalismo resultan de las consideraciones expuestas sobre la función. Distinguiremos varias, que se aplican universalmente y se oponen en cierto modo a los principios del Kitsch que examinaremos antes: 1) Principio de Ockham o eliminación del ornamento. Puede admitirse que un objeto usual corresponde a una eliminación del elemento inútil. 2) Estructuración por economía de movimiento: a partir de la ergonomía se analizan los movimientos y esfuerzos generalizados (sin olvidar el esfuerzo psicológico de adaptación). Mencionemos, por ejemplo: la cocina funcional, el estudio del lugar de trabajo, el estudio del rincón del fuego. 3) Estructuración por economía de medios: el término 'economía' se traduce en utilidades, en el sentido de la teoría de los juegos. 4) Análisis factorial de los deseos: por ejemplo, un ventilador será: flexible, más pequeño, más potente, más barato, más liviano. 5) Método de los modelos: se constituye un modelo o maqueta completa que funciona y que provee un simulacro concreto de la realidad futura. [La cursiva es del autor] (Moles, 1973, pp. 157-158)

Estos métodos sofisticados, pusieron a prueba cada objeto diseñado, a partir de un análisis sintáctico o una semiótica de las funciones, basada en una jerarquía lógica y ramificada, donde la toma de decisiones de los diseñadores en función del mercado y la adecuación racional, se deducen desde la función general hacia las microfunciones más específicas:

En este caso existe, pues, un método lógico del diseño: es suficiente tomar las decisiones en función de los deseos del mercado o de la adecuación racional, yendo desde la superfunción más general a las microfunciones más específicas, y realizando un riguroso inventario de éstas: a esto denominamos análisis funcional. [La cursiva es del autor] (Moles, 1973, p. 159)

Moles (1973) aplica al análisis del diseño en general y del funcionalismo, en particular, los aportes provenientes de la semiología y de la lingüística estructural desarrollados a partir de las primeras décadas del siglo XX, pero que se desarrollaron y socializaron en los años ‘ 60 .

\subsubsection{El neokitsch, antagonista de la función social proyectual}

La alienación, de la actitud consumista posterior a la Segunda Guerra Mundial—encubierta por el diseño funcionalista, según Moles (1973)—, restó a las masas la posibilidad de elevarse por encima de los objetivos que la industria y los productos instituyeron sobre ellas. La adquisición de los objetos, cada vez más acelerada, apareció como el imperativo de una "ética de lo superfluo, de lo perentorio incorporado y del consumo a ultranza" (Moles, 1973, p.174). Moles, explica que el funcionalismo comienza a caer en contradicción, dado 
que la respuesta de la economía se impulsaba en el consumo antiasceta, y el ascetismo funcional - que construía objetos duraderos-, no podía hacer nada al respecto. La segunda contradicción, aparece cuando, a través del gadget, se logra introducir con éxito una funcionalidad a cada objeto inútil que se producía, con la pretensión de apelar a la eterna modernidad del Bauhaus. Y la tercera, que contribuyó a su declive final, fue lo que Moles (1973) detalló como la función significante. Dicha función, logró que el signo, al envolver cada producto fabricado, motivara a los consumidores no solo a comprar de manera desmedida, sino también a desecharlos prematuramente. En ese contexto, el status social al que podía pertenecer-o aspirar-, un individuo no se medía por la posesión de un amontonamiento de objetos propios, sino a partir de la velocidad vertiginosa con que los reactualizaba. Si bien, este concepto es original del crítico del diseño: Jean Baudrillard, Moles lo importa para explicar cómo la función significante, "supera la función funcional en el nivel de consumo actual" (Moles, 1973, p.176). Debido a que la pureza - que caracterizaba las relaciones que el hombre establecía con su medio-, se oponía también a esta función significante, el funcionalismo sucumbió finalmente ante su propia crisis, dándole paso al neokitsch, como la respuesta objetiva que tomaba las exigencias del mercado como su única prioridad.

\subsubsection{Relativizaciones sobre las afirmaciones de Moles}

Según la metodología de la Historia de las Ideas, propuesta por Skinner (2000), Moles (1973) cae en dos absurdos históricos. Por un lado, le atribuye a Sullivan una doctrina, la del funcionalismo. Para afirmar esto, se basa solamente en observaciones circunstanciales, y en una similitud terminológica, con el concepto de función, que el autor no parece haber formulado, y con la que tampoco tuvo la intención de contribuir; esto se constata en los textos analizados en esta investigación. La ausencia de los conceptos de: diseño asceta, y de funcionalismo, en las teorías de Sullivan, es obvia, ya que como antagonista de los estilos no se hubiese atrevido a defenderlos. Respecto de sus textos, tanto en sus versiones en inglés como en español, no figuran estos conceptos en lo que hemos hallado hasta ahora. El segundo desajuste histórico de Moles (1973), se basa no solo en atribuir a Sullivan, entre otros, el origen de esta doctrina, sino también la continuidad de la relación objetiva del hombre con su medio, supuestamente heredada por Gropius en el contexto de la Bauhaus. No obstante, desde el análisis elaborado sobre las divergencias de Gropius - que se desarrollan en el subcapítulo 3.3. Das Staatliches Bauhaus, Paradojas y desmitificaciones-, puede sostenerse que esto no es así. Se puede comprobar en ese acápite que las causas de las contradicciones del funcionalismo, que Moles le atribuye, no aparecen en los textos analizados de Gropius, para el año en el que aparentemente la doctrina alcanza la aceptación, o sea, en su momento de plenitud.

Los enunciados funcionales de Gropius — de 1914 a 1918_, que se encuentran en las publicaciones analizadas en esta investigación —-desde el marco metodológico de lo Histórico-Conceptual y lo Histórico-Social de Koselleck-, y desde-la Historia de las Ideas de Skinner-, no presentaron evidencias empíricas de la presencia del concepto de funcionalismo. Solo en 1926, en un Gropius indiferente al arte, enfocado en la ciencia, en lo funcional, en lo racional, preocupado por la estandarización de los objetos duraderos, la satisfacción de las necesidades vitales y sociales, solo en este tercer Gropius es que se pueden 
establecer atinos y paralelos con las premisas de Moles (1973); y con reservas, se rubrica, que esto ocurre únicamente en algunos aspectos. Hasta aquí, Moles no solo elaboraría, según la Historia de las Ideas de Skinner, una Mitología de las doctrinas, sino que también establece una Mitología de la Coherencia, en una interpretación unificada que obvia las divergencias latentes en el pensamiento de un autor multifacético como lo fue Gropius.

\subsection{La era de los significantes, según Jean Baudrillard}

Si se revisa la tesis doctoral de Baudrillard escrita en 1968, El Sistema de los Objetos, y también su publicación de 1972, Crítica a la economía política del signo, el sociólogo francés discreparía con Moles por presuponer que el enemigo mortal del diseño es el kitsch. Ya que el kitsch, luego de haber sido aniquilado por el Bauhaus, renace de sus cenizas en la forma de un neokitsch que, gracias a la irracionalidad proliferante de los bienes de consumo de un sistema económico alienante, triunfa sobre el ethos riguroso de la función y el desbordamiento de la racionalidad del diseño. Este triunfo, representa para Moles la crisis y la derrota de los seguidores de esta doctrina.

\subsubsection{La racionalidad del modelo económico}

Sin embargo, Baudrillard (1972/2007) recalca que a Moles se le olvida que la base de todo el sistema económico y los procesos de consumo, provienen también de una estructura que "es también racional y perfectamente coherente consigo mismo" (p.239). La consigna de la funcionalidad, asevera Baudrillard, la realiza el sistema económico todos los días, ya que la mentalidad consumidora promovida por la máquina económica-contra la que supuestamente lucharon los académicos del funcionalismo-, es adecuada a su fin.

La fórmula de la Bauhaus es, en resumen: existe para toda forma y todo objeto un significado objetivo determinable, su función. Lo que en lingüística se llama el nivel de denotación. La Bauhaus pretende aislar rigurosamente este núcleo, este nivel de denotación; todo el resto es la ganga, es el infierno de la connotación: el residuo, lo superfluo, lo excretorio, lo excéntrico, lo decorativo, lo inútil. El Kitsch. Lo denotado (funcional) es bello, lo connotado (parásito) es feo. Mejor aún: lo denotado (objetivo) es verdadero, lo connotado es falso (ideológico). Detrás del concepto de objetividad, es en efecto todo el argumento moral y metafísico de la verdad de todo lo que está en juego [...] La herencia kantiana y platónica del funcionalismo es manifiesta: la moral, la estética y la verdad se confunden en ella en un mismo ideal. [La cursiva es del autor] (Baudrillard, 1972/2007), p. 240)

La crítica que hace Baudrillard del análisis de Moles, en torno a la objetividad presente en el funcionalismo, advierte que este examen no puede fundamentarse como una respuesta del diseño a la irracionalidad del sistema económico. 
Por lo tanto, no hay contradicción: el modelo de la racionalidad fue originalmente y sigue siendo de manera fundamental el de lo económico; es natural que sea la funcionalidad del sistema económico la que prevalezca. El diseño puro no puede hacer nada en este caso, ya que esta racionalidad fundada sobre el cálculo, es la misma en que se inspira. [...] Su contradicción aparente no es sino la consecuencia lógica de su complicidad profunda. ¿Qué los diseñadores se quejan de ser mal comprendidos y de su ideal desfigurado por el otro sistema? Todos los puritanos son hipócritas. (Baudrillard, 1972/2007, pp. 239-240)

Así, concluye, que "no hay verdad del objeto, y la denotación no es nunca otra cosa que la más bella de las connotaciones [...] Si no hay más utilidad absoluta del objeto, también se acaba lo superfluo, y todo el edificio teórico del funcionalismo se hunde" [La cursiva es del autor] (Baudrillard, 1972/2007, pp.240-241). Los académicos, adscritos al funcionalismo, según Baudrillard, quisieron controlar el dominio de los significados para aislar la objetividad en las funciones. Sin embargo, cuando los objetos comenzaron a envestirse con signos - gracias a la moda y a la relación que guardaban con otros objetos como índices de la distinción de clases-, se resignaron a la subordinación, el resto de sus valores. En otras palabras, en su genealogía de los valores, Baudrillard (1972) sostiene que el Valor Signo, subordina al Valor de Uso, al Valor de Cambio y al Valor Simbólico, donde los tres últimos solían configurar la base de la economía política marxista. En este punto, ni aún las formas creadas por el diseño puro, objetivo y funcional, podrían llegar a escapar. Baudrillard recalca, que, si el diseño se halla ahora inmerso en la moda, no hay que criticarlo o compadecerlo, porque es el resultado del cálculo de los significados que el Bauhaus trazó como su primera teorización. La era de los significantes, - o de las marcas-, que señalan y teleguían a cada objeto y a su consumidor es lo que impera, auto justificadas por la funcionalidad. De allí, que Baudrillard sostenga que nunca existió una irracionalidad de parte de un sistema económico que luchara en contra de la racionalidad del funcionalismo; su derrota no se basa en una crisis, simplemente el diseño puro retorna al modelo racional en el que se originó.

\subsubsection{Relativizaciones sobre las afirmaciones de Baudrillard}

Gropius pareciera declararse funcionalista en 1926, y se sostiene 'pareciera' porque lo insinúa cuando reclama la autoría de los textos de Meyer. Pero, en 1943, se desentiende de los rótulos que le atribuyen como representante de los ismos y los estilos. Esta es una fase clave, dado que habla de una especie de gramática del diseño y la composición, donde el sentido simbólico y comunicativo de los objetos útiles que se diseñaron gracias al Bauhaus, fueron, según sus discursos, más allá de la utilidad; y donde satisfacer las necesidades emocionales era igual de importante que satisfacer las utilitarias. Es en este punto donde consideramos que se pueden relativizar las afirmaciones de Baudrillard (1972/2007). Se recuerda que el sociólogo francés, sostuvo que los académicos del funcionalismo, no se percataron de que la consigna de la funcionalidad la realizaba el sistema económico todos los días, por lo que esta doctrina,simplemente, era adecuada a su fin. Así, el funcionalismo sucumbe, y no por una crisis, sino por negar el retorno al modelo racional del que originalmente partió. No obstante, Baudrillard olvida, que el entorno en el que se desarrollan 
las relaciones de las personas con los objetos -inmersas en el fenómeno del consumo-, no dependen solamente de la racionalidad del sistema económico. Tampoco debe olvidarseque el sistema económico alemán entreguerras, estaba signado por la extrema reducción de recursos, con ninguna asociación posible a una sociedad de consumo.

Por otro lado, la gramática del diseño y la composición, originada en el Bauhaus, es proyectada como un modelo complejo y similar a las estructuras comunicativas del lenguaje, que debe poseer sus propios códigos elementales de escala, forma y color. Por esto, no se la puede reducir llanamente - como lo hace Baudrillard-, al mundo estructuralista al que pertenecen los significados y los significantes. Como se sostuvo anteriormente, si bien las teorías semióticas comenzaron de mucho antes, estas solo se desarrollan y socializan recién en la década de los '60 del siglo XX. Por lo que tanto Moles (1973), como Baudrillard $(1968,1972,1974)$, aun cuando sus ideas y teorías realizan importantes aportes al análisis - solo desde la sociología y el estructuralismo-, terminan cayendo en un anacronismo histórico. Esto, porque atribuyen a una etapa histórica anterior, ideas y conceptos de una etapa histórica posterior. No obstante, si bien Gropius y sus seguidores plantearon una visión sistemática de las necesidades —en relación a las funciones_ en su etapa de 1926; y si bien Baudrillard advirtiera que ellos establecieron estas estructuras como un modelo referencial para controlar los significados, se aclara, que el concepto de denotación no aparece en los textos analizados en esta investigación; ni en Gropius, Meyer o Van der Rohe. Aún así, si estas estructuras hubiesen sido gestadas en el Bauhaus, con el fin de conectar el concepto de función con el de objetividad — aspecto último que sí hicieron-, tampoco se halla el concepto de connotación como sinónimo de lo superfluo, según especula Baudrillard desde su enfoque disciplinar, ni la semiótica de las funciones, como sostiene Moles. Es posible que Baudrillard (1968, 1972, 1974), desde su enfoque posestructuralista, se haya atrevido a trazar una similitud terminológica entre las estructuras del lenguaje y sus códigos de significación, con la objetividad de los significados y la objetividad de las funciones. Recordemos que, Gropius (1943), lo que hizo fue tomar de referente los códigos y las funciones del lenguaje para establecer una nueva forma de lenguaje visual que fundamentara su gramática del diseño y la composición. Aunque Baudrillard pueda acertar en que el sistema económico es todo menos algo irracional, la denotación y la connotación - como categorías lingüísticas - no se advierten en lo discursivo de las publicaciones analizadas, por lo que estarían por fuera de su contexto intelectual.

Si el diseño ha de ser un lenguaje específico de comunicación para la expresión de sensaciones subconscientes, debe poseer sus propios códigos elementales de escala, forma y color. Necesita su propia gramática de la composición para integrar estos códigos elementales en mensajes que, expresados a través de los sentidos, unen el hombre al hombre más estrechamente que las palabras. [ $\mathrm{La}$ cursiva es del autor] (Gropius, 1943, p. 46)

Tanto Baudrillard como Moles caen en una mitología de la coherencia, dado que al señalar a Gropius como un académico funcionalista monolítico, es evidente que no se tomaron el trabajo de identificar las cuatro divergencias de su pensamiento halladas en esta investigación. 


\subsection{La idea limitada de la función. Según Bernhard Bürdek}

El diseñador y economista alemán Bernhard Bürdek (1991/2002), en su texto: Historia, Teoría y Práctica del Diseño Industrial, publicado en su primera edición en alemán en 1991, sostiene que el diseño estuvo marcado por la doctrina del funcionalismo durante mucho tiempo, dado que el esfuerzo del diseñador se concentró, por décadas, a crear respuestas que, en forma de soluciones, debían responder objetivamente a las necesidades sociales.

\subsubsection{La concordancia entre la vida y la forma}

Bürdek (1991/2002) enfatiza que un malentendido acerca de la frase de Sullivan form follows function (la forma sigue a la función), condujo a que dichas respuestas, si bien presentaban un alto grado de funcionalidad, se desdibujaran. Esto se debía, a que se le atribuyó a Sullivan un concepto de función limitado, como si Sullivan entendiera lo funcional solo desde lo práctico y lo técnico. Esta idea de la función, que obviaba la dimensión de los signos, condujo a que las funciones comunicativaso indicativas que debían portar los productos diseñados, continuaran representando un tabú para los diseñadores. Bürdek (1991/2002) explica, que, en Sullivan, las funciones indicativas vinculadas a una dimensión semiótica tomaban como referente la emulación de la naturaleza. Ya que cada objeto de la naturaleza, declara Bürdek, al reinterpretar a Sullivan, posee una forma que nos indica su significado, que tiene como fin distinguirse de otros objetos y también al hombre que se beneficia de ellos:

Esta idea limitada de la función se apoya en un evidente malentendido de los presupuestos de Sullivan. Esta idea, para Sullivan giraba también en torno a su dimensión semiótica: "Cada objeto de la naturaleza posee una forma, un aspecto exterior, que nos indican su significado y que lo distingue de nosotros mismos y del resto de los objetos" (Louis H. Sullivan, 1896). Wend Fischer (1971) recordó que para Sullivan no se trataba simplemente de satisfacer las necesidades de la finalidad de los productos o de los edificios, sino de la posibilidad de reconocimiento de la vida en su expresión, de la forma de la función física tanto como de la función espiritual. Sullivan deseaba un acuerdo y una concordancia absolutas entre la vida y la forma. [La cursiva es del autor] (Bürdek, 1991/2002, p. 56)

La concordancia entre los conceptos de función y necesidad, según la exégesis que Wend Fisher también elabora de Sullivan, y que Bürdek (1991/2002) cita con puntualidad, más allá de una finalidad de los productos y los edificios, lo que se buscaba era la posibilidad del reconocimiento de la vida en la expresión material, dado que la forma debía seguir a la función y esa era la ley. Una especie de concordancia entre la vida y la forma, en otras palabras, un acuerdo de la función física (dimensión práctica o técnica) con la función espiritual. No obstante, Bürdek declara que los presupuestos de Sullivan en la historia del Buen Diseño, se han malentendido, de allí que apenas se haya logrado reflejar su idea, y se aclara que de manera limitada se ha llevado a la práctica en aquellos que decidieron continuarla. 


\subsubsection{El ornamento como un delito}

Según Bürdek (1991/2002), una de las interpretaciones limitadas de los presupuestos de Sullivan devino, gracias a la emergencia del diseño objetivo, con el arquitecto austríaco Adolf Loos. Éste último, sostuvo que el diseño debía supeditarse solo a las funciones 'prácticas', ya que los elementos decorativos que entorpecían el uso de los productos debían ser considerados como superfluos, porque representaban un despilfarro, o una inadecuada administración del material. Loos, que había estado en contacto con Sullivan en la Exposición Universal de Chicago —-donde se desempeñó como delineante de arquitectura y maestro de albañilería-, en 1893, llegó a Europa con la idea de que el diseño debía someterse solo al uso, lugar donde la ornamentación ya no podría tener cabida. El funcionalismo — gracias a la influencia de Loos, según Bürdek (1991) —, obtuvo sus primeros frutos en el Bauhaus por medio de la estandarización y racionalización de los productos, tanto en el diseño como en la arquitectura.

El desarrollo del diseño objetivo empezó en Europa con Adolf Loos (Ornamento $y$ delito, 1908), y en esencia fue impulsado por las formas de producción industrial que se iban extendiendo rápidamente [...] Las ideas de Loos obtuvieron sus primeros frutos en la Bauhaus. El Funcionalismo allí producido se consideró una superación del concepto del estilo, si bien se convirtió, en virtud de su aplicación rigurosa, en un nuevo estilo, a saber, en el símbolo de una reducida élite intelectual y progresista [...] Con posterioridad, este concepto se trabajó teórica y prácticamente sobre todo en la Escuela Superior de Diseño de Ulm en los años sesenta. El concepto allí inferido, del 'Buen Diseño', fue la doctrina oficial del diseño hasta los años ochenta. (Bürdek, 1991/2002, p. 56)

Bürdek afirma que la doctrina del funcionalismo, se trabajó en la HfG desde los sesenta, y se extendió hasta los ochenta bajo el concepto de 'Buen Diseño', conocido también como la Gute form. En realidad, las reflexiones teóricas y las prácticas sobre la Buena Forma o el Buen Diseño de Max Bill eran anteriores a Ulm. De este Buen Diseño, Bill ya había realizado una exposición en 1949, lo que significa una imprecisión o desfase temporal en la tesis de Bürdek (1991/2002). Además, esta interpretación seguramente ofendería a Maldonado, ya que desestima sus esfuerzos teóricos y pedagógicos al frente de la Ulm, por superar la visión de la Gute form de Bill.

\subsubsection{Las formas rigurosas provenientes de la racionalidad}

Sin embargo, cable aclarar, que el funcionalismo en Ulm, alcanzó para Bürdek (1991/2002) la categoría del estilo, gracias a la negación de los aspectos semánticos y a la limitación del componente semiótico a los problemas sintácticos, como consecuencia de la reducción del trabajo proyectual solo a principios matemáticos. La orientación del pensamiento cartesiano ulmiano se basó, para Bürdek, en un ansia por la racionalidad, las formas y las construcciones rigurosas, que determinaron el contenido y la apariencia de cada objeto diseñado. No obstante, Bürdek también recuerda que fue el mismo Hans Gugelot quien hizo referencia en 1962, a la relación existente entre el diseño originario en la Escuela de Ulm y el signo, dado que, en la HfG, se supuso que el hombre debía entender el lenguaje 
de las cosas en el ámbito de su propio círculo cultural; por lo tanto, de Bürdek se deduce, que Ulm no fue indiferente al mundo de los signos. Si bien para Bürdek, aparentemente, la simbología no existía en la tradición del funcionalismo - debido a que se encontró sujeta a una interpretación permanente de las funciones técnicas del producto en un alto grado de orden-, las funciones simbólicas, mucho más ideológicas que funcionalistas, no tuvieron siempre la misma interpretación.

\subsubsection{Relativizaciones sobre las afirmaciones de Bürdek}

Desde la genealogía que Bürdek (1991/2002) elabora en torno a este término, sugiere que "el 'primer funcionalismo' de los años veinte ya era un 'simbolismo' no confesado" (Venturi, Brown e Izenour, 1979), puesto que se erigió él mismo en signo de progreso tecnológico" (p. 223). Es curioso observar, con qué soltura y liviandad Bürdek (1991/2002) habla de simbolismo no confesado en la década del '20, cuando Gropius ya había hablado de simbolismo desde 1914. En palabras de Gropius: "Todas las particularidades se subordinan a una forma figurativa grande y sencilla que, cuando haya sido encontrada su línea definitiva, deberá conducir a la 'expresión simbólica' del sentido de las construcciones modernas" (Gropius, 1914, pp. 185-186) ${ }^{68}$.

Bürdek (1991/2002) también afirma que "una mirada retrospectiva muestra sin embargo que, entre 1920 y 1930, el funcionalismo del período de la Bauhaus no alcanzó a ser más que el símbolo de una minoría intelectual y progresista" (p. 223). La pregunta que surge de su tesis es: ¿cómo pudo el aporte de esta minoría —es decir Gropius y sus seguidores-, trascender a lo que se denomina como funcionalismo en la actualidad, si el mismo Gropius negó la existencia en el Bauhaus de este concepto?

En realidad, Gropius no necesitaba de las ideas de Loos; las razones funcionales ya tenían una larga tradición en Alemania e Inglaterra desde el siglo XIX, información que fue relevada por De Zurko (1957). Además, al hablar Gropius de obra de arte unitaria; espíritu de la época; unidad orgánica; y un estilo de la funcionalidadque debía comunicar la expresión simbólica de la época moderna, obviamente no coincidía con las ideas de Loos.

Aunque el funcionalismo, en las reflexiones de Bürdek (1991/2002), pareciera haber sobrevivido en el quid de las funciones implementadas por los diseñadores hasta el día de hoy, no se entiende porqué el discurso de esta fuente secundaria — entre otras-, no concuerda con las fuentes primarias a las que responsabiliza de la autoría de dicha doctrina.

\subsection{Orden en contradicción, forma y función. Según Jan Michl}

El historiador y crítico de las teorías del diseño moderno, Jan Michl (1997/2018), en un artículo publicado en su página $w^{70}{ }^{70}$, bajo el título de: Form follows WHAT? The modernist notion of function as a carte blanche, traza una crítica desde la que intentó relativizar la noción modernista de la función, como una fórmula que podría ser aplicada a cualquier requerimiento o problema de diseño.

\subsubsection{El significado de una doctrina}

En su crítica, Michl (1997), afirma que el significado de la doctrina: la forma sigue a la fun- 
ción, ${ }^{71}$ originaria de Sullivan, se convirtió más tarde en una especie de brújula, que orientó la práctica profesional de los arquitectos y los diseñadores a otro nivel. Dicho lema, que, según Michl, parte de una inviable idea basada en soluciones preordenadas, calificó a los revivalistas y a los estilos eclécticos del siglo XIX como opciones estéticas inválidas; esto, gracias a su nuevo, unificado y moderno lenguaje formal, producto de su filosofía. Según Michl, esta filosofía fue la responsable de que la Arquitectura y el Diseño alcanzaran la categoría de actividades artísticas autónomas, donde dichas profesiones, respaldadas por la bandera del funcionalismo, institucionalizarían su acercamiento formal y esteticista. Michl (1997) también sostiene que, aún en la actualidad ${ }^{72}$, el lema se sigue poniendo en práctica, pero en otro sentido; dado que estimula a los diseñadores con un propósito diferente, donde diseñar productos consiste en adecuar soluciones estéticas a requerimientos no-estéticos. En otras palabras, donde las formas se expresan en necesidades, sin que las primeras vayan en contradicción con las segundas. Sin embargo, Michl recalca que, en este uso actual del lema, no se incluyen soluciones preordenadas, y mucho menos prohíbe el uso de una estética, estilo o lenguaje formal particular. "Acá el único punto para emplear el lema parece ser para recordar al diseñador que las soluciones estéticas seleccionadas deben apoyar los propósitos no-estéticos que el producto está intentando cumplir" (SUMMARY, and A CAVEAT, párr. 2) ${ }^{73}$. Michl, al parafrasear al diseñador holandés Peter Paul Koch (2003), explica que, sin tocar la idea o el significado original de la frase atribuida a Sullivan, Koch la reinterpreta como una regla que el diseñador debe tener presente para no verse influenciado solamente por tendencias formalistas. Porque si la forma llega a convertirse en una meta misma, evadirá el principio racional del diseño funcionalista que se autodefine, ambiciosamente, como el medio adecuado para un fin.

\subsubsection{Una ley natural y omnipresente}

Michl (1997), ratifica que el lema que guía dicha doctrina, fue acuñado por Sullivan, en su artículo El edificio de oficinas artísticamente considerado, publicado en el año de 1896. Allí se propone que, al estar el diseño administrado por una ley natural y omnipresente, sugería que una parte de la esencia del problema, contenía en sí misma su propia solución. El orden sucesivo y preordenado, que consistió en afirmar que las formas aparecen luego de que los requerimientos son traducidos a funciones, famoso entre los diseñadores modernistas americanos, fue cuestionado explícitamente seis meses después, por su antiguo socio Dankmar Adler, al anular de la frase - la forma siempre sigue a la función-, la palabra 'siempre'. Esta crítica, llevó a Sullivan, según Michl (1997), a que en sus publicaciones sucedáneas -entre ellas The Kindergarten chats and other writings (1918), y Autobiography of an Idea (1922), título al que Michl califica como ostentoso-, la frase la forma sigue siempre a la función, como el nodo de su filosofía del diseño, apareciera en sus escritos cada vez con menos fuerza. El motivo que justificó esta actitud, según Michl (1997), consistió en una supuesta contradicción de la que se percató Sullivan, gracias a Adler. En sus memorias, Sullivan, luego explicó que para 1880 estaba poniendo a prueba una fórmula que había evolucionado a través de la contemplación de los seres vivos, que aspiraba a devolverle a la arquitectura su virtud como arte vivo. 
El mismo Sullivan, llamó la atención hacia éste nuevamente, en sus memorias de 1924, publicadas bajo el ostentoso título "La autobiografía de una idea". Ahí, el lema fue mencionado - aunque sin mucha elaboración-, cómo el nodo de su filosofía de diseño. Sullivan escribió que en el principio de la década de 1890 estaba poniendo a prueba una fórmula que había evolucionado a través de una contemplación de los seres vivos, que la forma sigue a la función, lo que significaría, en la práctica, que la arquitectura podría de nuevo convertirse en un arte vivo, de adherirse a esta idea. (Michl,1997/2018, párr. 7).$^{74}$

Michl (1997) recalca, que, a finales del siglo XIX, este lema se encontraba limitado a su círculo de amigos y admiradores, y que solo comenzó a ganar popularidad —en el año de 1935-, entre los modernistas americanos, gracias a una publicación de Hugh Morrison, titulada como H. Louis Sullivan: Prophet of Modern Architecture. Para finales de los años treinta del siglo XX, según Michl, Sullivan se inmortaliza en Norteamérica, como un "autor de un axioma sobrecitado de forma y función" (Michl, 1997/2018, párr. 8). Es en este momento en el que su lema ingresa a Europa vía Inglaterra, según Michl, gracias a la publicación del arquitecto alemán Walter Curt Behrendt, con el título de Modern Building: It's Nature Problems, and Forms. De ese texto, Michl enfatiza que Behrendt (1930) conectó y exaltó los desarrollos de la arquitectura moderna de América con los de Europa, destacando no solo los principios expuestos por Sullivan, sino también los de Greenough. De allí, que Michl garantice que, Gropius entró en contacto con los estudios de Sullivan, mucho después de emigrar de Alemania hacia Norteamérica. Por otro lado, aunque Gropius haya mencionado el dictum en una conferencia en Londres en 1934, esta filosofía fue virtualmente desconocida en la Bauhaus:

Gropius conoció el lema tan solo después de su emigración de Alemania; en cualquier caso, parece bastante certero que, en la Bauhaus, el lema como tal, en contraste con la filosofía que resume, fue virtualmente desconocido. Desde la mitad de la década de 1930 en los Estados Unidos, y el final de la de 1940 en Europa, el lema de Sullivan empezó a ser utilizado como un resumen taquigráfico de las ambiciones de los diseñadores y arquitectos modernistas. Recapitulaba que la afirmación modernista de la Época Moderna estaba impregnada con nuevas, preordenadas formas, una nueva, predestinada estética intrínseca a la época, implicando que el deber primario del diseñador modernista, eclipsando todos sus demás deberes y lealtades, era servir como un tipo de partera (32, 19a) para esta estética objetiva, considerada independiente de cualquier gusto o preferencia. (Michl, 1997/2018, párr. 8) ${ }^{75}$.

\subsubsection{Una inviable idea de soluciones preordenadas}

Empero, y aunque Michl (1997/2018) le da crédito a la originalidad de Sullivan, catalogándolo como el padre del lema, la pequeña genealogía que elabora sobre el término función - y no de funcionalismo-, vincula al padre Carlo Lodoli, a Waldo Emmerson y a Horatio Greenough, como sus antecedentes. Lodoli, para Michl, aparece como el primero 
en introducir la noción de arquitectura orgánica, de la que también hablaría Sullivan más tarde, fundamentada en consideraciones funcionales y racionales. Un texto escrito por Francesco Milizia, acerca de los arquitectos más representativos, fue el medio por el que Greenough entraría en contacto con la noción de función heredada de Lodoli. Partiendo de esta noción, argumentó, que el principio de creación de la naturaleza consistía en adaptar las formas a las funciones, aspecto del que debían apropiarse los diseñadores. Si bien Michl, asegura que Sullivan expresaba en su lema lo propuesto por Greenough, el segundo no llegó a condensarlo en una feliz y aliterada formulación, donde la arquitectura orgánica, al imitar a la naturaleza, se proyectaba de adentro hacia fuera como es natural. A pesar de ello, para Michl, la influencia más fuerte sobre Sullivan estuvo representada por Waldo Emerson, conocido y muy cercano a Greenough también. Emerson (1830), desarrolló una noción conocida como la metafísica de la Arquitectura, que consideraba a esta de manera ontológica, como el resultado antagonista de las decisiones arbitrarias y caprichosas, a las que apelaron los arquitectos de su época. En su lugar, para Emerson, la Arquitectura significó el resultado de las necesidades. Esta metafísica de la Arquitectura, al fundamentarse también en una inteligencia superior que invocaba actos creativos - tomando a la naturaleza como el referente por antonomasia-, conllevó, según Michl, a que Sullivan —como el sucesor de las teorías de Emerson-, fuera catalogado también como trascendentalista. Por otro lado, Michl (1997) alega, que la noción de función, fue visualizada por los admiradores del funcionalismo como una especie de sinónimo de propósito, lo que obviaba el funcionamiento real que un producto debía llevar a cabo. Es decir, una cosa es que el diseñador proyecte que un producto funcionará de determinada manera para que cumpla con su propósito - o con los propósitos para los que fue creado-, y otra muy diferente es que, dentro de su funcionamiento, emerjan aspectos que no fueron tomados en cuenta en el resultado de su uso final. A esta dualidad, Michl la designa como funcionamiento previsto y funcionamiento real. La noción de función, para los seguidores del funcionalismo, se concentró en el propósito del funcionamiento previsto, dado que ese es el punto de partida para el diseño objetivo, que defiende las formas como el factor sucedáneo de la función justificada por la necesidad. Este punto de partida, como el núcleo de esta doctrina, dejó por fuera de sus cálculos a los deseos, las demandas y las preferencias subjetivas. Así, esta demanda objetiva que, según Michl, se gestó en Lodoli, y continuó con Emerson y Greenough, terminó por desarrollarse en Sullivan, para luego ser heredada por Gropius, pero con éste último en Estados Unidos y no en el Bauhaus de Alemania, como se suele creer. Michl (1997/2018) finaliza su invectiva, cuestionando si ese preordenamiento de que la forma siempre debía seguir a la función, podía ser un punto real y objetivo de partida. Este cuestionamiento se basaba en que, en las ciencias, la forma precede a la función como el mecanismo objetivo de observación, lo que en el funcionalismo plantearía una contradicción por su orden inverso:

Ninguna ciencia contemporánea, natural o social, usa la noción de función en el sentido que los diseñadores y arquitectos funcionalistas lo hicieron [...] la noción científica de función siempre se refiere a lo que un objeto o fenómeno existente hace en cierto contexto. Si nos preguntamos acerca de la función del corazón en fisiología humana o la función de las fachadas en el paisaje urbano, 
corazones y fachadas deben existir antes que alguien empiece a preguntarse acerca de sus funciones. Tanto en las ciencias naturales como en las sociales la forma precede a la función: la noción de función nace de observar formas y fenómenos existentes. En la teoría funcionalista del diseño, por otro lado, es exactamente lo contrario: se afirma que la función precede a la forma. (Michl, 1997/2018, párr. 13) ${ }^{76}$.

En síntesis, Michl (1997), critica la visión modernista de los seguidores del funcionalismo, como la imitación de un ideal que, determinó un nuevo lenguaje formal, fundamentado en soluciones preordenadas; donde la sucedaneidad hereditaria entre función y forma, sirvió como garante del diseño objetivo.

\subsubsection{Relativizaciones sobre las afirmaciones de Michl}

Al someter a revisión las afirmaciones de Michl (1997), se hallan varias imprecisiones e inconsistencias que valdría el esfuerzo resaltar. Desde un estudio de lo Histórico-Conceptual y lo Histórico-Social, al intentar reconstruir el linaje de un concepto - o una noción, como Michl le llama-, se debe tener sumo cuidado, porque las experiencias no podrían existir sin una transposición conceptual, y a su vez los conceptos tampoco, si no hubiese experiencias con las cuales conectarlos. Se afirma en esta tesisque Michl homologa descuidadamente las experiencias asociadas al concepto de función,establecidas por Lodoli ${ }^{77}$ (1753), con las de Emerson (1830, 1841), Greenough (1852), Sullivan (1896) y Gropius (1926). Desde un estudio Histórico Social, Michl parece olvidar que los contextos cronológicos que determinaron sus conexiones, fueron completamente diferentes; al igual que las condiciones sociales y las transformaciones sincrónicas y diacrónicas adscritas a cada época, entre los conceptos y sus experiencias.

Se sostiene, que las observaciones circunstanciales y la similitud terminológica, que Michl (1997) cree hallar entre el concepto de función, y en su aplicabilidad estética objetiva -dentro del marco metodológico de la Historia de las Ideas-, es definido como un absurdo histórico o una mitología de las doctrinas. El funcionalismo, que Michl desprende de Sullivan, es un concepto que Sullivan no formuló, al menos, en los textos analizados en esta investigación. Por otro lado, referenciar, de manera equívoca, el parecido entre el argumento de un autor con otro como una influencia causal - al sostener que lo que pensó Lodoli sobre el concepto de función, y la arquitectura orgánica, fue heredado luego por Emerson, y más tarde por Greenough y Sullivan, y de Sullivan hacia Gropius-, representa otro error, conocido como la mitología del localismo (ver capítulo uno). Aún cuando Greenough y Sullivan hubiesen tenido un mismo marco metafísico de referencia, dicha especulación no podría sostener que Waldo Emerson - por ser trascendentalista- representara su influencia directa. La razón de que no se sostenga en este caso en particular, se debe a que no cumple con las tres condiciones necesarias para explicar el predominio de un autor sobre el otro, planteadas por Skinner y descriptas en el capítulo uno de esta tesis. Con respecto a la continuidad, que Michl le atribuye de Emerson hacia Sullivan, sabemos que al arquitecto americano solo puede vinculársele con Darwin y Spencer, y esto con reservas. Esto puede verificarse en el apartado previo, 3.2.1.6. Síntesis de la teoría sullivana. 
Finalizando con las influencias y las continuidades, el lema de Sullivan no pudo ingresar exclusivamente a Europa solo desde Inglaterra, y tan tarde como asevera Michl (1997) con la publicación de Behrendt. Existieron dos vías, al menos, que demuestran el contacto previo de Gropius con el dictum previamente. La primera de esas vías, surge gracias a la presencia de Loos en la Exposición Universal de Chicago, en 1893. Varios años después de que Loos regresara a Europa, socializó con los integrantes de la Secesión Vienesa, entre ellos Joseph Olbrich, Oskar Kokoschka, Alma Mahler y el círculo de artistas y diseñadores que lo conformaban, los avances en Arquitectura que se estaban desarrollando, gracias a la Primera Escuela de Chicago. A este argumento, se le añade la conferencia que Loos dictó en la Akademischer Verband für Literatur und Musik, en Viena, en el año de 1910 titulada Ornament und Verbrechen. Esta misma conferencia, se publicaría en 1913 en Francia, y luego en alemán el 24 de octubre de 1929, en el periódico alemán Frankfurter Zeitung, bajo el título Ornament und Verbrechen. Es posible que Gropius conociera, —gracias a Mahler, su esposa-, no solo el dictum, sino también la producción de objetos que Loos comenzó a desarrollar. Dichos objetos, estaban basados en la concepción sesgada —o limitada - del concepto de función original, aprendido de Sullivan; aspecto último del que Bürdek dio fe. A Loos se le acusa de importar de manera fragmentaria los aportes del movimiento gestado en la Escuela de Chicago, dado que su fundamento metafísico se quedó atrás, de allí el evidente discurso racional radical en contra del ornamento, presente no solo en Loos, sino también en cada uno de los objetos diseñados por él; contrario a la capacidad simbólica que poseía el ornamento integral, característico en la teoría de Sullivan.

El segundo camino de contacto, fue en la exposición arquitectónica de Berlín, en el año de 1909, donde Gropius tuvo contacto con Frank Lloyd Wright, y con él, el legado de su maestro, reflejado en la recopilación de los trabajos litográficos que reunían las grandes obras de Wright. Dichas obras, configuraron el Portfolio Wasmuth, llamado así porque fue publicado oficialmente por Ernst Wasmuth, en 1911. De allí, que las continuidades sean censurables, debido a que, desde la historia de los conceptos, se considera un absurdo histórico pretender creer que los conceptos - y las experiencias vinculadas a ellos-, pueden ser reinterpretados y puestos en práctica en otros contextos, como si fueran continuidades inmutables. También, la inviable idea basada en soluciones preordenadas, tan criticada por Michl (1997), se relativiza, dado que en el apartado 3.2.1. La postura de Louis Henri Sullivan: la visión Orgánica, en una cita de su texto The Kindergarten Chats and Other writings, de (1918/1957, p. 18), se demuestra que el lema la forma sigue siempre a la función, responde a un orden de sucesión simple y complejo a la vez, al que Sullivan denomina como una interrelación inescrutablemente móvil. Estas dos afirmaciones, respaldarían un orden teleológico, creacionista y móvil de sucesión, con un grado doble de causalidad; presentes en las teorías de Sullivan y no al enfoque teológico unívoco como Michl (1997) se esmera en demostrar.

Debe recordarse que el arquitecto, según Sullivan, abstrae el espíritu de una civilización con el fin de convertir lo objetivo en subjetivo; así, transfiere un agregado inmensurable, que la materia antes, por si sola, no poseía. La objetividad, en Sullivan, le pertenece a la naturaleza y no al arquitecto, por lo que el argumento de Michl se debilita aquí, gracias a una especulación o familiaridad terminológica. Por otro lado, con Gropius, se podría decir que la hipótesis de Michl se acerca un poco más, pero solo en una de sus etapas diver- 
gentes de pensamiento; dado que Michl cae en una mitología de la coherencia al unificar la totalidad del pensamiento de Gropius con la objetividad del diseño. Cuando Gropius (1926) considera que las condiciones de la vida de los hombres eran iguales en lo esencial - en los principios de la producción de la Bauhaus en Dessau-, podría decirse que fue en esa instancia donde Michl se acercó, a lo que denominó como demandas objetivas o la objetividad estética del diseño.

No obstante, en toda la bibliografía analizada de Sullivan y Gropius en esta investigación, al figurar como detractores de los estilos, no podría aceptarse una transposición del concepto de función hacia el funcionalismo, dado que los ismos cristalizaban el potencial de desarrollo que podría llegar a poseer cualquier movimiento de diseño en gestación.

\subsection{La atemporalidad de la tradición funcional. Según Herwin Schaefer}

El crítico del diseño, Herwin Schaefer (1970), en su texto Roots of Modern Design: Functional tradition in the 19th century -en su versión en español: Las raíces del Diseño Moderno-, explica cómo la tradición funcional, que fundamentó las bases del diseño vernacular y técnico-y con ello al diseño funcional originados en el siglo XIX-, se mantuvo sumergi$d a$ en el anonimato durante mucho tiempo. Un siglo después, una práctica proyectual dio luz a un sinnúmero de objetos y espacios que se distinguieron por sus formas geométricas, gracias a la supuesta relación que guardaban entre los conceptos de racionalidad y de función. Aunque dicha práctica quiso ampararse en la atemporalidad de la tradición funcional que la precedió, su preocupación radical por lo formal derivó en lo que se conoció después como estilo funcional moderno.

4.6.1. La coetaneidad entre la tradición funcional y los estilos ornamentados del pasado De los aportes de Schaefer (1970), se deduce que la tradición funcional y el diseño funcional coexistieron en el siglo XIX, siendo el estilo funcional moderno un fenómeno posterior. No obstante, aunque señala que los pioneros de este estilo intentaron reclamar la legitimidad de su práctica a principios del siglo XX, el mantener afinidades con el cubismo, obvió, en ocasiones, la coherencia que tanto defendieron entre los conceptos de razón y función. Por otro lado, aunque la eterna tradición funcional motivó, de manera evidente al diseño funcional y tras bambalinas a los pioneros del estilo funcional moderno, su existencia invisible se debió en gran parte a la coetaneidad contextual que compartió con el diseño victoriano y otros estilos ornamentales del siglo XIX. De allí, que se siga mirando al siglo XIX como una época de la que emergieron una serie de estilos ornamentados creados exclusivamente para una placentera sociedad aristocrática.

El descubrimiento crucial es que el diseño de la forma funcional es anterior al estilo funcional del siglo XX con el cual lo asociamos más frecuentemente. En el siglo XIX, la forma funcional existía en el ámbito técnico - en equipos industriales y científicos [...] existía en los campos del transporte, en carruajes, barcos, trenes, en equipamiento deportivo y en instrumentos musicales. Y existía en lo vernáculo; en el diseño de antiguos objetos útiles de todos los días, 
cuyas formas eran el resultado, a través de los siglos, de la adaptación intuitiva de la función originalmente basada en la producción artesanal industrial. Produjo la forma funcional modesta y no decorada en el mobiliario, vidrio y menaje, y de otros elementos hogareños como algo que se da por descontado. La preocupación común al diseño técnico y al vernáculo era la función. (Schaefer, 1970, p. 4)

Schaefer (1970), hace hincapié en que al libro de Nikolaus Pevsner — publicado en 1936 en Inglaterra-, Pioneros del Diseño Moderno, se le debe gran parte de esta confusión. Pevsner (1936), si bien releva de manera profunda los alcances de la maquinaria y las formas utilitarias funcionales - desde William Morris hasta Walter Gropius-, excluyó de sus estudios, el diseño anónimo vernacular, técnico e ingenieril; aspecto que lo llevó a construir una versión fragmentada de ambos contextos sociales y cronológicos. Para Schaefer, las investigaciones de los historiadores del diseño Sigfried Gideon (1948) —en La mecanización toma el mando-, John A. Kouwenhoven (1948) —en Made in America-, Walter Dexel (1939) —en Deustches Hanwerksgut, eine Kultur- und Formgeschite des Hausgeräts-, y Lewis Mumford (1934) —en Técnicas y Civilización-, presentan contribuciones desde el diseño vernacular a la tradición funcional del siglo XIX, desde Estados Unidos y Europa, como antecedentes al diseño moderno del que tanto habla Pevsner.

La tesis de Schaefer(1970), amerita un análisis conceptual, en torno a varios términos. En primer lugar, el concepto de vernacular, lo entiende como la manera nativa, común, popular y espontánea de construir en lugares y períodos determinados; algo no sujeto a círculos académicos, vanguardias o corrientes estilísticas legitimadas. El papel de este tipo de diseño, que lo hace técnico — como también lo denomina-, incluye: microscopios, bicicletas, cámaras fotográficas, entre otros. Estos objetos, gozaron de un carácter incógnito, y aunque emergieron a finales del siglo XVIII e inicios del siglo XIX, a partir de formas claras y racionales, se manifestaron paralelos al desarrollo ornamental, que alcanzaba su cénit para estas mismas épocas. Es a esta tradición funcional a la que Schaefer señala como la precursora de los modelos para el diseño funcional, y posteriormente para el estilo funcional moderno. Y aquí vale otra aclaración: dado que de la tradición funcional devinieron los modelos del diseño moderno, solo después del siglo XX — afirma Schaefer-, es que se comienza a hablar de moderno como sinónimo de funcional, y no antes; ya que este concepto comenzó a asumir el papel tanto de cualidad como de estilo.

Miramos ahora retrospectivamente al período del estilo funcional moderno como algo casi, sino completamente, en el pasado. Lo que parecía milenario mientras duró ha resultado ser una fase; lo que fuera aceptado como formas 'atemporales' 'más allá de los estilos' resultaron ser después de todo, manifestaciones de un estilo, con un período de vida que ha llegado a su fin [...] Las claras y racionales formas encontradas en la tradición funcional devinieron en los modelos para el diseño moderno. Fue después de 1900 que uno hablaba de moderno como sinónimo de funcional, queriendo significar con esto tanto una cualidad como un estilo. En las primeras décadas de nuestro siglo, los defensores del diseño moderno confiaban en que la adopción de la tradición 
funcional habría de llevar a un estilo más allá de los estilos, un mundo de formas permanentemente válidas. (Schaefer, 1970, pp. 4-5)

\subsubsection{Reavivamientos y reminiscencias}

Según Schaefer(1970), aunque los pioneros del estilo funcional moderno insistieron ciegamente en dignificar el estilo - a través de formas que se instituyeran de manera permanente-, en las décadas de los 50 y 60 del siglo veinte, esta postura se vio erosionada y opacada, por un reavivamiento del Art Nouveau, el Art Déco, el Cubismo y las reminiscencias victorianas. Ese surgimiento etiquetó al estilo funcional moderno como un estilo frío, conforme a los estándares modernos. Probablemente esta sea la razón por la que "el funcionalismo es frecuentemente rechazado explícitamente; y se haya vuelto una mala palabra" (Schaefer, 1970, p. 4). Esta nueva etapa, definida por Schaefer como la fase posmoderna del diseño, enfatizó y buscó cualidades opuestas de las que se pensaron inicialmente como diseño moderno. Para Schaefer, el concepto de fase, podría definirse como una etapa histórica, que al aglutinar pequeñas divergencias, se sucede o precede con otras, por sus diferencias significativas. En términos de Koselleck (2012), esta acepción se asemeja al concepto de diacronía o profundidad temporal, que aglutina la transformación correlativa entre un concepto y los estados de las cosas que designa. Para el mencionado autor, esto ocurre a través de los estratos temporales o acontecimientos sincrónicos, que se fueron dando al interior de cada época distintiva en la historia conceptual del Diseño.

Por otro lado, si la tradición funcional puesta en práctica por los ingenieros a principios del siglo XIX, desembocó en figuras geométricas, fue porque estas representaron las formas que más funcionaban para sus requerimientos; de allí que obtuvieran siempre resultados prácticos. En contraste, los seguidores del estilo funcional, por la afinidad que guardaban con el cubismo, tuvieron resultados meramente formales. Esta es la razón por la que Schaefer (1970), demarca los puntos de inflexión cronológicos, cuando visualiza a la tradición funcional como continuidad atemporal, condensada en la figura de una fase creativavital permanente. Sobre esta fase es que se montarán luego el diseño funcional, como fase apreciativa posterior, y elestilo funcional - con su fase exhibicionista en las décadas de entreguerras- sujeta a la modernidad.

El concepto moderno, sostiene también Schaefer (1970), sufrió un deslizamiento semánti$\mathrm{co}$, dado que para la actualidad ${ }^{78}$, moderno significa algo diferente a lo que concibieron los antiguos seguidores del estilo funcional. Si bien este concepto connotaba lo funcional para sus adeptos, hoy para los jóvenes es sinónimo de actualizado, sin importar cuán alejado esté su significado de su connotación funcional original. Esto demuestra que la recepción y uso de los conceptos es contingente a las etapas históricas y circunstancias culturales. Como muestran los estudios de Recepción (Warning y Jauss 1979) y la metodología de la historia conceptual, los significados que construyen los receptores o usuarios de un término, son independientes, tanto del que realiza la crítica especializada como del origen del término mismo.

El nuevo y duradero orden basado en la razón y en las formas puras, se mira hoy, para Schaefer, despectivamente, como un estilo efímero, donde las formas de los objetos actuales repelen —en términos del esteta Fulvio Carmagnola (1995) —, reclamar la fría docilidad de la funcionalidad. Empero, aún las formas más racionalizadas propuestas en el estilo 
funcional, tampoco fueron el producto objetivo de un cúmulo de funciones sistematizadas, tal como sus académicos y discípulos se esmeraron en instaurar. Las formas puras, producto del estilo funcional - y aquí la tesis de Schaefer alcanza su punto más álgido-, no fueron el resultado de un orden, que basado en la razón intentó alcanzar a partir de la objetividad la satisfacción de las necesidades. Estas necesidades eran iguales en lo esencial, al menos en el contexto de la Bauhaus en Dessau. En realidad, la predilección ciega por las formas geométricas - específicamente las platónicas como el círculo, el cuadrado y el cono, dice Schaefer (1970)—, fueron reconocidas como un dogma por sus creadores, y convertidas posteriormente en una fórmula, por los practicantes del estilo funcional moderno. Y esto no representa un accidente, sostiene, dado que el estilo funcional moderno coincidió con la ascendencia del cubismo, y no sería una casualidad tampoco, ya que tanto Gropius, como Braque y Breuer, fueron igual de cubistas que el mismo Picasso. De esto se deduce el por qué intentaron desprenderse del viejo fantasma del expresionismo tardío, con el que todo comenzó en el Bauhaus. Una época, aquella, donde el movimiento moderno - que gozó de tanta popularidad-, intentó instaurarse como un estilo permanente, en contra de todos los estilos devenidos del pasado. Sus seguidores, justificados ciegamente por la objetividad de las funciones, proclamaron irónicamente la función como determinante de la forma, estando realmente guiados por valores formales externos y distintos a ella.

Adherentes al estilo, eran ciegos, a menudo deliberadamente ciegos, al hecho de que los valores formales que eran aceptados, no siempre derivaban puramente de consideraciones funcionales, aunque la función se mencionara como fuente y razón. Había una armonía de la geometría, la austera belleza de la tecnología y para los creyentes, esto bastaba. Esto no es para decir que el estilo funcional era 'frío' y por ende, emocionalmente estéril. Era emocionalmente satisfactorio para sus devotos porque los valores formales austeros que ofrecían eran justamente, aquellos deseados. Tampoco se puede decir que ningún diseño verdaderamente funcional se haya creado durante este período. A menudo las mejores soluciones funcionales, eran halladas en las abstractas formas geométricas relevantes para ese tiempo. Uno debe simplemente señalar, la ironía de un período que proclamaba la función como determinante de la forma y, sin embargo, estaba guiada por valores formales externos a la consideración de la función. (Schaefer, 1970, p. 5)

\subsubsection{Lo vernacular: el padre anónimo del estilo funcional}

Por otro lado, el diseño vernacular — técnico e ingenieril—, fruto de la tradición funcional, y representante del diseño funcional presente en la producción artesanal o industrial — de finales del siglo XVIII y principios del XIX_-, era ya una realidad. Schaefer declara que para 1851, una diversidad tipológica de objetos fue expuesta en Londres, en un evento conocido como la Gran Exhibición del Palacio de Cristal. Si bien el diseño victoriano estuvo presente en gran parte de los artículos exhibidos en ella, la presencia de aquellos que poseían un carácter racional y funcional fueron evidentes. Objetos industriales vernaculares, como navajas, revólveres, armamento de uso militar, botas, hachas, herramientas, 
carruajes, mecanismos navales, instrumentos musicales, entre otros, que se exponen en el texto de Schaefer - provenientes de Estados Unidos y de Europa, contrastaron como artículos modestos, frente a aquellos que presentaban una decoración excesiva, que los hacía extremadamente llamativos, pero prácticamente inutilizables. A pesar de la evidente presencia de la tradición funcional que portaba cada uno de estos artículos, Schaefer recalca que a diferencia de la mayoría de los periodistas - que exaltaron el inventario de artículos ornamentales por encima del diseño vernacular o ingenieril—, la Reina Victoria, Richard Redgrave y otros comentaristas, tuvieron otra postura. Estos últimos señalaron, en el mismo orden, lo interesante e instructiva que representó la estética de la máquina, manifestando también que era una lástima que lo ornamental prevaleciera al punto de excluir lo considerado útil y su noble simplicidad; aun considerando Redgrave que la decoración tiene su parte buena y necesaria en el diseño.

\subsubsection{Consideraciones y relativizaciones de Schaefer}

La tesis de Schaefer logra demostrar lo imprecisa que ha sido la historia del Diseño, al intentar catalogar al siglo XIX, como un contexto en el que proliferaron los eclecticismos de los estilos del pasado, y el auge de la producción de objetos recargados de una ornamentación patológica. Esta misma imprecisión se mantiene respecto del siglo XX, al describirlo vagamente como una especie de segundo renacimiento, donde unos pocos pioneros del diseño moderno - gracias a la racionalidad y el ascetismo formal-creyó secularizar la ornamentación al producir objetos estandarizados, cercanos a lo accesible y a lo humanizado. No obstante, aunque Schaefer demuestra que la tradición funcional proveyó las raíces del diseño moderno, su intencionalidad - tal vez por el anonimato en el que se encontraba, no logró o no buscó instaurarse como un estilo; en esto se diferencia de los representantes del estilo funcional, que lo hicieron a partir de la figura del estilo no estilístico.

Se deduce de Schaefer, por un lado, que, el aporte de la tradición funcional comienza a aparecer en el diseño de objetos para uso militar y cotidiano, como dos de sus variados contextos de uso. Por el otro, la relación objetiva entre forma y función - que buscaba establecerse como un movimiento de diseño, en los Estados Unidos-, surge a finales del siglo XIX con Sullivan y Wright, como detractores del uso de estilos del pasado y del eclecticismo académico de la arquitectura americana. En la Primera Escuela de Chicago, la intencionalidad de instituir un movimiento de diseño no era anónima. Schaefer no ignora este detalle, por lo que afirma con mucho cuidado que la tradición funcional — proveniente de la fuerza vernacular-, no excluye los aportes de la arquitectura americana, devenida de los ecos influyentes que Greenough ejercería, sin saberlo, en la filosofía de la arquitectura moderna de Sullivan y Wright. De todas formas, Schaefer no enfoca su reflexión en la Arquitectura, sino que se concentra mayormente hacia el Diseño Industrial. 


\subsection{Historia de las influencias soviéticas y holandesas en el diseño funcional. Según Verónica Devalle, Rosario Bernatene y Víctor Margolín}

Para la socióloga y crítica de las disciplinas proyectuales, Verónica Devalle (2009), la visión sesgada del origen, y la relación existente entre el Diseño y el Movimiento Moderno, contribuyó a la mitificación de la disciplina como un dominio homogéneo y consolidado. Esto lo ubica en el contexto de los Estados Unidos y Europa, a finales del siglo XIX y principios del XX, y afirma que surgió para desplazar el arte, gracias a la ruptura entre la Arquitectura con sus filiaciones clásicas.

\subsubsection{Una genealogía heterogénea del Diseño}

En su texto La Travesía de la Forma (2009a), la genealogía diversificada de una disciplina que refleja una práctica enfocada en la producción de viviendas, los objetos cotidianos y la comunicación visual, se distingue más por una especie de heterogeneidad. Esta travesía de la forma, si bien se originó en distintos escenarios con condiciones particulares, tanto respecto de su arraigo norteamericano y eurocentrista, como en su migración latinoamericana décadas después - hacia la Argentina y otros países-, no representó un marco unívoco y legítimo en torno al debate por la forma, y a la producción de los bienes materiales que emergieron como el reflejo de dicha constitución (Devalle, 2009a). Devalle no niega que, para finales del siglo XIX, la inminente agonía del arte empujó a que se abrieran discusiones en función de un nuevo horizonte de acción, que retomara las riendas de la producción material. No obstante, aclara que los artistas forjaron estadios divergentes, que corrieron paralelos a las reflexiones conformadas por gremios de artesanos, arquitectos e ingenieros, disidentes de la concepción clásica de la forma. Adicionalmente, al origen de las áreas proyectuales se le unió un nuevo contenido, correspondiente a un contexto heterónomo, definido por la emergencia de un pensamiento crítico social, que orbitaba en torno a tres esferas: la económica, la técnica y la científica. En otras palabras, el Diseño comienza a apropiarse del discurso de la Modernidad, período histórico devenido del siglo XVIII. En este orden de ideas, Devalle(2009a) considera que el Diseño adquirió el estatus de disciplina moderna, de manera parecida a como lo alcanzó la sociología, la economía política y las ciencias positivistas.

La Modernidad parece haber asumido el mandato del Diseño, y el Diseño haber absorbido el contenido profundo de la Modernidad, al punto que es difícil referir a uno en particular sin que emerja la cadena asociativa: Modernidad, Diseño, Diseño Moderno, vanguardia, Bauhaus, Arquitectura Moderna, síntesis de las artes, ahistoricismo, proyecto, utopía, liberación de las necesidades, conflicto social. (Devalle, 2009a, p. 72)

Sin embargo, aunque esta apropiación de contenidos entre el par Diseño y Modernidad, y toda la cadena asociativa de conceptos que emanaron de su relación, generaron una nueva derivación semiótica, la relación entre los conceptos de forma, función, funcionalismo, productivismo, socialismo y planificación, permanecen velados por una incorrecta mediación de la historiografía; dado que la Historia del Diseño adolece de un ambiguo 
punto de partida y de un orden asertivo de sucesión. La sugerencia de Devalle se concentra en rastrear lo que denomina como compactos de significación, como aquellos lugares donde reposan tanto las fracturas, como las continuidades de la disciplina, que ameritan ser rastreadas (Devalle, 2009a, p. 72). Así, señala varios puntos de inflexión, que considera como los escenarios donde el Diseño comenzó a ganar terreno decisivo en el problema de la forma. De allí que el diseño tuviera después, como responsabilidad: la concepción de los productos; el ennoblecimiento del trabajo industrial, con base en las reflexiones del Werkbund, en Alemania a partir de 1907; el CIAM en 1928 en Suiza; y la figura del Constructor Publicitario en la URSS de 1923, devenido de Maiakovsky y Rodchenko, entre otros.

\subsubsection{La importancia del valor gráfico}

Devalle (2009a) exalta que - en contraste con los escenarios alemanes, británicos y suizos-, el contexto político en el que emergió la gráfica soviética adquirió un estatus de autonomía, gracias a la atmósfera post-revolucionaria impulsada por una Nueva Política Económica (NEP). De allí, que la movilización de los artistas, publicistas y pedagogos se centraran en la disolución del arte a través de una figura diferente. La búsqueda de intelectuales orgánicos - también denominados como obreros de la cultura-, que no excluían a los artistas, surgió con el fin de viabilizar un orden social distinto, configurado por los que deberían ser los verdaderos responsables de las representaciones colectivas. Dichas representaciones, que gozaron de un alto contenido semiótico, tenían la función de ser "uno de los vehículos de expansión de los ideales y metas revolucionarias, desempeñando un rol pedagógico, al cubrir aquello que las letras no podían hacer; interpelar a un pueblo mayoritariamente analfabeto" (Devalle, 2009a, p. 92), lugar donde el espacio urbano se comenzaba a configurar como un todo político (p. 93). El Constructor Publicitario soviético, constituyó lo que Devalle denomina como el valor gráfico. Este valor gráfico estuvo dado por el desarrollo de una práctica discursiva, por medio del poster, la experimentación tipográfica y la toma de la ciudad a través de la comunicación de masas. Así, alcanzó lo inimaginable: la significación que en materia visual superaba el simple problema de la forma, como el dispositivo enunciativo que articulaba todos los lenguajes. Devalle (2009a) aclara que, dicho Constructor Publicitario - o grupo propagandístico soviético-, fue "creado por Maiakovsky y Rodchenko en los años subsiguientes a la Revolución Rusa [...] ... se trata del primer ejemplo de constitución de un valor gráfico, una nueva práctica discursiva legitimada por paradigmas estrictamente estéticos o políticos" (Devalle, 2009a, p. 98). De allí que el valor gráfico que portaba la gráfica autónoma aparezca, para ella, como no deudora del debate del Movimiento Moderno, es decir, como el lugar donde la imagen establece no solo una relación con el imaginario y la conciencia colectiva en el espacio público. La imagen debe también relacionarse con la trazabilidad de los aspectos que fueron constitutivos y precedentes de la disciplina, por antonomasia, de la comunicación visual: el Diseño Gráfico. Lo que, en definitiva, a nuestro juicio, expresa una verdadera ruptura o discontinuidad en la historia de la comunicación gráfica, dada por la innovación en el dispositivo citado, tras el cual, ya nada será igual en la comunicación visual y el diseño gráfico contemporáneos. 
Estamos ahora en condiciones de definir lo que hemos llamado valor gráfico. Consiste justamente en lo señalado: el procedimiento mediante el cual la gráfica se transforma en un dispositivo enunciativo, subsumiendo, regulando - dosificando- los mecanismos propios de otros lenguajes (fotografía, plástica, ilustración) para transformarlos en una unidad mayor. Se trata de un mecanismo semiótico que abarca —en su integración - las particularidades de los lenguajes recuperados, que establece su ubicación en el espacio público y los medios de comunicación, y propone un interlocutor universal (asociado generalmente al ciudadano, al consumidor, o al espectador) [...] el lugar de cruce entre la gráfica, su visualidad y la recuperación de la "entonación" - la voz- del discurso serán privativos de este dispositivo enunciativo. Una acción comunicativa capaz de transformar la letra en imagen, la voz en grafía, la gráfica en enunciación. [La cursiva es del autor] (Devalle, 2009a, pp. 106-107)

\subsubsection{La clara influencia rusa en el Bauhaus}

Devalle (2009a) señala puntualmente esta diferencia constitutiva, dado que para ella solo después de 1923 en Weimar, el Diseño como dispositivo enunciativo portador de una acción comunicativa, se hizo presente. Para la autora, eso se produce gracias a la incorporación oficial del húngaro László Moholy-Nagy, al círculo de docentes de la Bauhaus, trayendo consigo los logros de Maiakovsky y Rodchenko. Es por este camino que Devalle considera a Moholy-Nagy como partícipe del "segundo período de la escuela, cuando se produce un pasaje de una concepción artístico-artesanal hacia otra de sesgo técnico y experimental" (Devalle, 2009a, p. 94). Antes de ello, en Weimar, esta concepción no existía, de allí que esta investigadora sostenga que el giro radical que registró el Bauhaus se dio cuando se visibilizaron las influencias constructivistas provenientes de Rusia. La aclaración es válida, de su parte, ya que el imaginario masivo ha mitificado el Bauhaus como un escenario homogéneo de consolidación del Diseño, al que, en ocasiones, le es indiferente la distinción entre "lo que sucede en el interior del campo del diseño y lo que circula masivamente como imaginario del mismo" (Devalle, 2009, p. 103). Adicional a ello, Mies Van der Rohe se reunió en Berlín en 1922 con Malewitsch y Lissitsky, en la exposición Suprematista y Constructivista, lo que ratifica un claro intercambio con actores del Bauhaus; aspecto que respalda la tesis de Devalle.

\subsubsection{El funcionalismo de raíz formalista}

Por su parte, María del Rosario Bernatene, desde su visión de la historia del Diseño, trabajó este tema en dos textos: Ética y estética del funcionalismo (2005); y La historia del Diseño Industrial reconsiderada (2015), en su Capítulo 2. En el primero, la autora califica a la estrategia de exhibición funcionalista como enmascaramiento de procedimientos formalistas en el diseño y la arquitectura del siglo XX. Para desarrollar esta tesis, Bernatene se apoya en los estudios que realizara el lingüista e historiador Tzvetan Todorov $(1991,2005)$ sobre la teoría de la literatura de los formalistas rusos. Los estudios abordan la descripción de sus procedimientos poéticos y cómo éstos se difundieron a través de las demás vanguardias rusas, hacia los campos del diseño, la arquitectura y el arte. Para esto, Bernatene sigue los lineamientos ya trazados por el historiador de la arquitectura 
Manfredo Tafuri (1973), pero la aplica para explicar la metodología de proyectación de productos.

Si bien Bernatene (2005) reconoce la gran tradición funcional en el diseño de productos de la que habla Herwin Schaefer, considera que con las vanguardias soviéticas se acusa una ruptura con dicha tradición de carácter utilitario. Discontinuidad que se produce en el pasaje del siglo XIX al siglo XX, al punto que, en el siglo XX se puede hablar de una refundación de la cuestión funcional sobre otras bases teóricas, lingüísticas e ideológicopolíticas. Los cambios derivados de los aportes de los formalistas rusos implican para la autora una ruptura epistemológica en las áreas proyectuales. Estos nuevos procedimientos formales van más allá de una cuestión estética de reducción y geometrización de partes, para constituir poco a poco una metodología proyectual, un método constructivo de la forma, a veces oculto bajo la denominación de funcionalismo.

Además de la influencia de las vanguardias rusas, por un lado, y la gran tradición funcional de occidente por el otro, en esta refundación, la autora reconoce que cuentan multiplicidad de factores, sean estos otros creadores, y corrientes intelectuales de la época que coadyuvaron en la construcción de la racionalidad proyectual o el funcionalismo como una cuestión de principios. Entre estos podemos puntualizar los siguientes: Peter Behrens de la $A E G$ y el Werkbund alemán; la lucha contra el ornamento por parte de Adolf Loos; la experimentación estética del movimiento De Stijl; la inspiración en una estética de la máquina; el ascetismo de origen teosófico y estoico; la influencia de los pitagóricos; el racionalismo de origen cartesiano y hasta la ética puritana.

Sin embargo, para Bernatene (2005) el núcleo de esta ruptura epistemológica se produce a partir de la poética formalista. Nacida de la unión de grupos de investigación lingüístico-literarios de Petersburgo y Moscú, que existían desde antes de la Revolución Rusa. El OPOIAZ de San Petersburgo y el Círculo Lingüístico de Moscú, aunque publicaron sus investigaciones entre 1914 y 1930, venían gestándose desde 1907, pretendiendo liberar el signo poético de todo nexo lógico-semántico e histórico-cultural. Tinianov (1981), pone de manifiesto la primacía del procedimiento en la estructura de la construcción formal, "Donde lo sensible no es la estructura de las palabras sino su construcción, su disposición" (Chlovski). De aquí, que hablar de formalismo, en este contexto, esté ligado al estudio científico de las estructuras del lenguaje. En palabras de Tafuri, M. (1973), en El Socialismo realizado y la crisis de las Vanguardias, citado por Bernatene,el procedimiento formalista se reducía a:

El alejamiento semántico, el divorcio entre signo y significado, la creación de sistemas de signos capaces de inferir significados inéditos, la destrucción de los cánones rítmicos y métricos, la técnica del alejamiento, se revelan al fin como instrumentos claves del método formal en lucha contra el universo reificado de lo cotidiano.(Tafuri, 1973, p. 51)

Respecto de las palabras de Tafuri, la autora hace el siguiente análisis:

...el alejamiento semántico, con el objeto de aislar los signos de sus antiguos referentes y articularlos desde una nueva configuración, aparece como el axioma 
que los rusos persiguieron para romper con la tradición y la subjetividad, que funcionaban como núcleo de transmisión del lenguaje y la ideología burguesa. [La cursiva es del autor] (Bernatene, 2005, p. 9)

La función poética - siempre para los formalistas - , reconoce otra forma de asociación, no ya entre significante y significado, - que se daba para Saussure (1913) a partir de una relación vertical - , sino entre una palabra y la otra en la cadena del discurso o motivación horizontal, que no conduce al significado. "Esta motivación 'horizontal' que prioriza la combinación entre una palabra y la otra más que entre significante y significado, va en el sentido del 'autotelismo' o finalidad en sí mismo, que para los formalistas define al enunciado poético" (Bernatene, 2005, p. 7). De allí que la autora sostenga, que los formalistas rusos, lo que realmente buscaban, era convertir el estatuto del lenguaje en puro objeto físico. En palabras de Todorov (2005), citadas por Bernatene: "es un lenguaje reducido a su sola materialidad, sonidos o letras, un lenguaje que rechaza el sentido" (Bernatene, 2005, p. 21).

Bernatene, trae un ejemplo del texto Walter Gropius y el Bauhaus, de Giulio Carlo Argan (1957), que muestra de forma elocuente, como esta actitud toma cuerpo luego en Gropius: "La desconfianza hacia todas las simbologías formales no desaparece ni siquiera ante la simbología inmediatamente poética de Wright. Para Wright el vidrio puede llegar a ser, según el caso, aire, agua, o luz, para Gropius sigue siendo un plano translúcido" (Bernatene, 2005, p. 7). Este es el ejemplo más didáctico de como funciona el procedimiento, intentando anular las metáforas, las analogías y las simbologías.

Para la autora, las premisas heredadas del formalismo ruso, valen tanto para las posteriores vanguardias soviéticas como para el Bauhaus, Ulm y el tratamiento de diseño de los productos de la marca Braun; ya que la suma de artificios como sistema quedó en la estructura del proyecto. En palabras de Eichenbaum (1925), citado por Tafuri: "forma es sobre todo un tender hacia una racionalidad proyectante" (Tafuri, 1973, p. 69). Siguiendo a estos autores, Bernatene explica que, del formalismo no se obtienen formas, sino "una manera de construir el objeto de estudio" (p. 12). Dicho objeto de estudio es el proyecto, o proceso proyectual, como serie de rasgos y pasos específicos. Poética abierta si se quiere, que admite infinidad de repertorios, al que el Bauhaus dio un determinado repertorio formal según sus inquietudes, Ulm le dio otro, y así sucesivamente; metodología que se mantiene aún hoy en los talleres de diseño. Y esto fue posible, gracias a la influencia formalista en la práctica proyectual de los años 20's en adelante. "No hay ninguna vanguardia en Rusia que pueda prescindir de ligar su historia a la de la escuela formalista" (Tafuri, 1973, en Bernatene, 2005, p. 6).

Los formalistas rusos, influidos por la estética kantiana, concentrarán su objeto de estudio en las relaciones internas entre las partes (autotelismo), sin depender de los usos posibles, ni finalidades externas (heterotelismo), ni tampoco usándolas como excusa para la experimentación. Esto abrió el campo de estudio a la experimentación proyectual o Proyectualidad, como metodología para el tratamiento de la división y posterior articulación entre las partes, las dinámicas operativas de interrelación entre signos, y todo un espectro de teorías asociado; liberando al Diseño de su dependencia del arte y la ingeniería. 
Sólo con la superación del utilitarismo de los objetos y la repetición mecánica de los estilos del pasado, es que se puede llegar a constituir el diseño industrial y su metodología proyectual; que contrasta con el diseño ingenieril y el diseño estilístico (Art Nouveau, Art Dèco, etc.).). (Bernatene, 2005, p. 12)

En cuanto a los recursos formales, "como las finalidades externas no determinan el repertorio de formas a usar, sino que este nexo es aleatorio (una misma función puede resolverse bien de muy diferentes maneras)" (Bernatene, 2005, p. 11). La autora opina que Maldonado - así como los historiadores posteriores-, enmascaran, consciente o inconscientemente, las resoluciones estéticas, — tan arbitrarias como cualquier otra-, bajo la bandera ética de la contracción al fin. Bernatene, habla de enmascaramiento, dado que estos autores conocían las investigaciones de Tafuri (1973) y Todorov $(1970,1991,2005)$, sobre el universo formalista y su procedimiento creativo.

Mientras lo predominante en la metodología proyectual, sea el tratamiento de los condicionantes externos bajo un procedimiento autotélico, para Bernatene (2005), el concepto de funcionalismo, no puede sostenerse.Para la autora, esta categoría "se ha convertido, -más allá de ser una excelente idea-fuerza-, en un obstáculo epistemológico que ha dificultado la atención de la dimensión poética como pilar de la constitución disciplinar del Diseño" (p. 16); ya sea en el Diseño Arquitectónico, Industrial o de Comunicación Visual. Bernatene, concluye pensando que, probablemente, el gran logro del funcionalismo, ya sea como corriente, doctrina, escuela o teoría, "haya sido el haber devuelto dignidad a las cosas sin aura, como denominaba Benjamin a las obras de la reproductibilidad técnica, para diferenciarlas de las obras investidas de religiosidad y simbolismos de poder de los siglos anteriores" (Bernatene, 2005, p. 15).

\subsubsection{Influencias constructivistas en el funcionalismo alemán}

En torno a la hipótesis sobre las influencias rusas en el Bauhaus, la postura del teórico del Diseño Víctor Margolín (1998), en su libro: The Struggle for Utopia. Rodchenko, Lissitzky, Moholy-Nagy, 1917-1946, concuerda en algunos aspectos con las afirmaciones de Devalle y Bernatene. En su investigación, Margolín sostiene que Gropius invitó a Moholy-Nagy a la Bauhaus a principios de 1923, con el fin de reemplazar a Johannes Itten como docente. En su decisión, influyó el grupo $K U R T^{79}$, aparte de la postura favorable al respecto del neerlandés Theo van Doesburg. Margolín afirma que Gropius decidió integrar el constructivismo al discurso del diseño alemán no solo por los logros alcanzados por los soviéticos en las artes constructivas, sino también por las afinidades que guardaba con el movimiento De Stijl. En su tesis, Margolín cita al historiador del arte rumano Erno Kállai (1923), dado que Kállai, junto a Moholy-Nagy y a otros teóricos, reflexionó sobre el constructivismo, dentro del Bauhaus, con el objeto de plantear nuevas argumentaciones, que cuestionaban la construcción artística de los productos, en el intento de establecer conexiones objetivas con la vida cotidiana. De allí, que Margolín, a través de Kállai, sostenga que los productivistas rusos adoptaron un enfoque utilitario en vez de uno estético:

Al oponerse a la construcción artística de los objetos cotidianos, que era el objetivo del productivista ruso, argumentó que si uno debía hacer objetos de 
uso, entonces debería adoptar un enfoque utilitario y dejar atrás las preocupaciones estéticas. Como ejemplos, citó los diseños arquitectónicos de Oud, Mies van der Rohe, Hilberseimer y otros, así como el trabajo de los ingenieros. (Margolín, 1998, p. 77) $)^{80}$

La definición del constructivismo, para Kállai, debía representar la economía y la precisión, fundamentos que asumiría más tarde el constructivismo alemán, de la mano de Moholy-Nagy y Lissiztky, con la estética del funcionalismo presente en el Diseño y la Arquitectura. Por otro lado, Margolín asume, que el constructivismo no solo sentó las bases de la nueva tipografía - que Jan Tschichold desarrollaría para la industria de la imprenta alemana en 1925-, sino que también fundamentó las bases del estilo Arquitectónico Internacional, y la estética del Diseño Industrial. Para este autor, estos fueron 'promulgados' en la Bauhaus, en el mismo orden por Mies van der Rohe, Moholy-Nagy y Marcel Breuer, a partir de la claridad y la objetividad como cualidades que el arte y el diseño de una sociedad tecnológica deberían poseer.

\subsubsection{La convergencia de tres caminos distintivos}

El funcionalismo, tal como sostiene Devalle (2009), refleja la conciencia de una dimensión funcional, gracias a la austeridad, la transparencia de la forma en diálogo con la tecnología, su ser técnico, su preocupación ética, y la utopía de la liberación de las necesidades; fundamentación que lo ubicó más tarde junto a las artes constructivas. De allí, que respecto de los intentos por definir el canon del diseño y vincularlo a la industrialización —en otro de sus textos: Historia de los Diseños en América Latina, Contenido y Perspectivas Teóricas $y$ Metodológicas -, Devalle (2009b), afirme que el funcionalismo hoy se visualice como un episodio de una época pasada en la historia del diseño, y ya no como su fundamento. A esto se añade que, mucho antes del funcionalismo, ya existía una predecesora dimensión funcional, y también una lógica constructiva interna; como sugiere al citar a Herwin Schaefer (1970) a través de Campi (2013), por lo que la funcionalidad propuesta en Bauhaus no es tan inédita ni original. Si bien la influencia constructivista en el Bauhaus se registra en 1923 - gracias a la incorporación de Moholy-Nagy a la escuela, tal como bien lo señala Devalle-, Gropius, por medio de la creación del Centro de Reuniones de todas las corrientes figurativas en Weimar, como sostiene Zevi (1980), ya había socializado con Wassily Kandisky, Kasimir Malewitsch, y su discípulo, Eliazar Márkovich Lissitsky. Los artistas soviéticos habían sido invitados a la Bauhaus para compartir sus experiencias con los estudiantes, y de estos intercambios fue que emergió la decisión de reemplazar el concepto de composición por el de construcción. Empero, en Devalle (2009b), no se perciben indicios decisivos de que el funcionalismo, se haya manifestado en el contexto del constructivismo ruso.

Tanto Bernatene como Devalle, trazan un análisis valorable de los aportes rusos, la primera desde el concepto de la inoculación de una dimensión semiótica en el diseño de comunicación visual; y la segunda rescatando la dimensión poética en el origen de la proyectualidad, desde la pretensión — utópica - de ausencia total de significación. La actividad creativa, como le denomina Lázar Márkovich Lissitzky (1920) en su texto PROUN, funcionó como su base, o punto de partida con la superación del concepto de composición por el de construcción: 
La construcción es aspiración a crear un objeto singular y concreto. A diferencia de la composición, la cual no hace sino discutir sobre diversas posibilidades formales, la construcción afirma. El compás es el cincel de la construcción, el pincel es el instrumento de la composición (p. 58) [...] El «Proun» nos lleva a la construcción de un nuevo tipo de cuerpo. Surge aquí el problema de la funcionalidad. Llamamos fin, en cierto sentido, a lo que queda a nuestras espaldas. La actividad creativa lleva el hecho a su realización y el hecho se convierte en exigencia. (Lissitzky, 1920,pp. 58-59).

Por otro lado, para Margolín (1998), el funcionalismo alemán estuvo adscrito a dos etapas: el funcionalismo, a secas, que al igual que en Schaefer (1970), estuvo basado en un enfoque utilitario, que se destacó por la economía, la precisión, la claridad y la objetividad. Y una segunda fase, la del constructivismo alemán, que evolucionó más tarde en la estética del funcionalismo en la Arquitectura y el Diseño. En otras palabras, la segunda fase del funcionalismo, representó un equilibrio entre las preocupaciones funcionales y las preocupaciones estéticas, que, en el constructivismo soviético, para Margolín, solo pudo ser alcanzado por los rusos años después. De lo que se deduce que el interés de los soviéticos hacia el Bauhaus no parece haber sido tan fortuito. Los constructivistas miraban de cerca los avances alemanes, de la misma manera que los alemanes a ellos; se podría hablar más de un intercambio de saberes y prácticas, que de una influencia en una sola dirección.

\subsection{Consideraciones y reflexiones del capítulo}

La reflexión con la que cierra este capítulo, más allá de recrear los puntos liminares y de distanciamiento velados en las críticas y misticismos de las fuentes secundarias que tocan el concepto de funcionalismo, promete señalar cómo la cuestión funcional —al establecer disruptivas metodológicas de corte proyectual-, se condensó en tres especializaciones prácticas y distintivas del Diseño: el Diseño Arquitectónico, Gráfico e Industrial. Más allá de la contaminación figurativa entre unas y otras obras, de cada especialización práctica del diseño se puede desprender una historia particular de su relación con la dupla entre forma y función, (ver ampliación en el capítulo seis, Conclusiones).

En el caso de Moles y Baudrillard, analizar el concepto de funcionalismo, desde dos enfoques próximos pero heterónomos al diseño - como la ciencia y la sociología-, redujo sus discusiones solo al fenómeno del consumo. Moles (1973), por su parte, lo analizó como una doctrina asceta que, en contraposición al Kitsch, defendió la utilidad preponderante de los objetos diseñados, dándole la espalda cada vez más a las nuevas lógicas del mercado. Y Baudrillard (1972), como una racionalidad que, gracias a sus precursores, representó una postura obstinada que enfocó la objetividad, la lingüística estructural y la semiótica, solo a la dimensión práctica y denotativa de las funciones. Tanto Moles como Baudrillard, definen al funcionalismo desde el diseño industrial, como un intento metodológico frustrado, dado que los diseñadores - al defender estas posturas como sus fundamentos permanentes-, no quisieron adaptarse a los requerimientos siempre cambiantes de la economía y el mercado. 
En contraste, Bürdek (1991/2002), traza un paneo histórico a través de las escuelas de diseño, y conecta hipotéticamente la teoría de la comunicación con las funciones simbólicas. A partir de eso, deduce que el funcionalismo, especialmente el originado en el Bauhaus, emerge como un simbolismo no confesado. Así, sostiene que el funcionalismo, resulta de un malentendido de las ideas de Sullivan; el intento por la superación de los estilos; y la influencia de las ideas radicales de Loos. Y si bien comienza en la Bauhaus, es en la HfG de Ulm donde alcanza su cénit y profundización, como la teoría que fundamentó el concepto del Buen Diseño.

Por su parte, Michl (1997) ve la frase de Sullivan: 'la forma sigue a la función', como el credo de una doctrina que, basada en una idea de soluciones preordenadas, tomó la noción de función como sinónimo de propósito. Dicha visión, estimuló a los diseñadores a adecuar soluciones estéticas a requerimientos no estéticos, es decir, que las formas adquirieran correspondencia con las necesidades; autodefinida como la imitación de un supuesto ideal creativo proveniente de una inteligencia no humana. Michl analiza cómo los principios teóricos funcionalistas, que adoctrinaron a los arquitectos americanos del siglo XIX, fueron adoptados en la arquitectura alemana de principios de los treinta. Si bien el funcionalismo se habría originado en la Arquitectura, contaminó más tarde las metodologías proyectuales del Diseño Industrial.

Por otro lado, para Schaefer (1970), el argumento valorable acerca de la atemporalidad que goza la tradición funcional, da cuenta del concepto de funcionalismo, como la belleza de un ideal cubista que hoy es rechazado explícitamente. Para este autor, a diferencia de la tradición funcional, de donde se originó, el funcionalismo no pudo sobrevivir por fuera de la moda y del estilo, ya que sus seguidores no hallaron la manera de sostener la coartada de las funciones objetivas, que ocultaba las verdaderas preferencias por los formalismos geométricos.

Para Margolín (1998), el enfoque disciplinar más destacado del funcionalismo, se concentró en el Diseño Gráfico, ya que su estética, coincidió con la apropiación del constructivismo en el Bauhaus, gracias al "tipógrafo y artista publicitario Jan Tschichold" (Margolín, 1998, p. 78). Los aportes de los rusos, desde un segundo flanco, adquirieron protagonismo gracias a la comunicación y el desarrollo de posters, acogidos en el Bauhaus, bajo la figura del Constructor Publicitario o grupo propagandístico creado por Maiakovsky y Rodchenko; del que da fe Verónica Devalle (2009). Es claro que la práctica discursiva que dignificó la gráfica rusa con total autonomía, el Bauhaus se la debe a los soviets, que orientada a la comunicación de masas contagió, en buenos términos, los lenguajes visuales de los cartelistas alemanes.

Desde Bernatene (1996, 2005, 2015), las premisas heredadas del formalismo ruso, fueron más allá de las formas y de lo que querían decir dichas formas, dado que su aporte no se concentró en esa búsqueda, sino en la emergencia de nuevas metodologías proyectuales, que inspiradas en el estatuto del lenguaje, reducirían la significación a un estado de materialidad que rechazaría su sentido.

De toda esta reflexión, podemos concluir que la Bauhaus, como predecesora de la HfG, respaldada por su relación entre la forma y la función, tampoco hubiese pasado de un romanticismo sin ornamentación, de no haber asimilado las influencias provenientes de las vanguardias rusas y holandesas. De esto dan fe, evidentemente, Margolín (1999), Devalle 
(2009) y también Bernatene (2005); tanto en la Arquitectura, como en el Diseño Gráfico y el Diseño Industrial. En el caso de estos tres autores, aunque reflexionan desde sus respectivas áreas disciplinares, sus afirmaciones se concentran en una ruptura epistemológica significativa del diseño, que fue provocada por las vanguardias rusas ${ }^{81}$. Sus deliberaciones en torno a las nuevas prácticas que debía ejercer el diseño, gracias a los avances de los soviets, enunció varias perspectivas valorables, puesto que el objeto de estudio de estos tres teóricos, derriba la sacralización del Bauhaus como el único e inédito centro europeo de la poiesis metodológica proyectual. Se puede afirmar que, contrario a lo que se suele pensar, el Bauhaus funcionó más como un epicentro de tensiones. Aunque operó solo por catorce años, consiguió orquestar una mixtificación funcional de numerosas iniciativas y posturas proyectuales procedentes de distintos lugares. Los constantes disensos y consensos, desgarramientos y enfrentamientos, de tipo político, social y artístico, que sufrió la Weimar de 1918, la convirtió en el escenario ideal para que se cimentaran las primeras bases de un centro de debates teóricos y de discusiones profundas. Allí, donde Gropius y sus demás docentes lograron alinearlas a las necesidades de un mundo que necesitaba deconstruirse para reconstruirse.

No obstante, la pregunta que surge frente a esto, es ¿qué fue lo que entendieron entonces las fuentes secundarias por funcionalismo, para distinguirse tanto de lo que plantearon los actores del Bauhaus y la HfG?

Para Moles (1973) fue el intento infructuoso de los académicos del Bauhaus, por defender la objetividad de las funciones, la durabilidad, la estandarización y el consumo de los objetos diseñados, en el contexto de un mercado que mostraba cada vez más afinidad hacia la prodigalidad, la inutilidad y la caducidad. Para Baudrillard (1972), fue una racionalidad que sirvió de coartada funcional a una lógica de distinción de clases, inmersa en el fenómeno de un consumo cada vez más acelerado, ya no de objetos sino de signos. Para Michl (1997) fue un orden absurdo de sucesión entre dos conceptos, que contaminó todas las disciplinas del diseño. Para Schaefer (1970), que es quien menos implementa el término, lo entendió como un estilo funcional, caracterizado más por las formas geométricas que por su destino de uso. Bernatene (2005), lo define como una práctica proyectual basada en una metodología racional, donde la función o la finalidad de los productos, fue una excusa para la experimentación formal. Bürdek (1991/2002), lo entendió como una práctica proyectual que no se hizo responsable de manera evidente e inmediata de su función simbólica. Para Devalle (2009) emerge como una de las derivaciones semióticas del par Diseño y modernidad, donde la austeridad y la transparencia servil del objeto fue un episodio en la historia del Diseño y no su fundamento permanente. Y para Margolín (1999), como un cimiento caduco, en el que en algún momento se basaron las disciplinas del Diseño; pero caduco, ya que las funciones de un producto - al entenderse de manera estrecha y puritana-, obviaron la pluralidad o el espectro amplio de lo que verdaderamente necesitaba la gente. De las miradas de cada uno de estos autores, podemos reflexionar que la lectura de la influencia de un cierto discurso funcionalista, importado de Estados Unidos hacia Europa, fue al menos sesgada, cuando no, tendenciosa. En Europa, se utilizó la invocación funcionalista, para nombrar una metodología proyectual racional y una variante formal aleatoriamente geométrica, surgidas gracias a la confluencia de las vanguardias europeas y rusas en las tres escuelas: Vjutemás, Bauhaus y HfG Ulm. 
¿Por qué la construcción que hace la crítica del funcionalismo, a partir de los años cincuenta -fuentes secundarias-, es tan distante de la que realizaron los actores principales en la década de los años veinte - fuentes primarias-?

Es posible que fuera necesaria dicha distancia temporal, para establecer una perspectiva histórica apropiada, que pudiera identificar una tendencia. Dicha tendencia, se consigue priorizando los aspectos comunes entre estas áreas disciplinares, más que sus divergencias. Esta dilucidación de aspectos comunes, fue lo que condujo a que el funcionalismo fuera reducido a un uso universal del término, donde su única e hipotética metodología proyectual, sumada a una cierta estandarización tipológica, se decantó en una ausencia de ornamentación con similitudes estéticas geometrizantes.

En consecuencia, el uso por parte de las fuentes secundarias de este concepto, contrasta significativamente con lo que dicen las fuentes primarias, en todos sus contextos de enunciación. Por ello, se explica, que esta noción no puede aprobarse como sinónimo de las sinergias y las relaciones implícitas entre las formas y las funciones, que provinieron desde diferentes flancos geográficos. Por lo que el funcionalismo no debe usarse de manera teleológica ni como índice, síntoma, y/o fundamento teórico determinante de todas las formas de pensamiento y prácticas proyectuales que emergieron de ellas, tanto en la Bauhaus como en la HfG de Ulm. Aunque los esfuerzos de las fuentes secundarias del capítulo dos y cuatro son valorables, se aclara que el concepto de funcionalismo, como se ha estudiado en esta investigación, no se corresponde con lo expuesto por los actores de las escuelas de Diseño a los que se vincula, que representan las fuentes primarias del capítulo tres. Se rubrica también, que cuando este término aparece - explícitamente por Gropius en el '43, o es mencionado por otros-, es censurado como la omisión de una inadecuada exégesis. Se afirma esto con incisividad, dado que el funcionalismo, según Sullivan, Wright y Gropius, surgió como un error de interpretación. Para Bonsiepe y Maldonado como un término meramente problemático, del que se reflexionó en Ulm y del que hablan, a posteriori de su participación en la HfG; ya que homogeneizó en una sola etiqueta las diversas perspectivas constitutivas del movimiento moderno.

Esto último, vale como una conclusión provisoria: el funcionalismo, como corriente, principio o idea-fuerza, fue mayoritariamente una construcción de la crítica, posterior a lo que manifiestan las fuentes primarias. Esta construcción no alcanzó para registrar la totalidad de las sinergias y relaciones, originadas en diferentes épocas, momentos y velocidades, tal como lo sostiene Reinhart Koselleck (2009), en su texto: Introducción al Diccionario histórico de conceptos político-sociales básicos.

Ismos, promotores e indicadores de un proceso que se desarrolla con distinta rapidez en las distintas capas sin que los ismos lleguen en algún momento a poder registrar la totalidad. Líneas de fuga de la filosofía de la historia impregnan todo el vocabulario. (Koselleck, 2009, p. 97)

\subsubsection{Tres historias diferentes}

A pesar de la profusa contaminación figurativa, de la que habla Marchán Fiz (1996), entre las obras de las artes plásticas, arquitectónicas, gráficas y de diseño de productos, cada campo especializado del Diseño hizo una apropiación histórica particular de esta cues- 
tión. Para lo cual, analizaremos las diferencias entre ellas y luego los aspectos en común. En el Diseño Gráfico, también conocido como Diseño para la comunicación visual,-como lo desarrollaron Lázar Lissitzky; Alexandr Ródchenko; Vládimir Tatlin; Vládimir Mayakovski; Liubov Popova; y Varvara Stepánova, entre otros-, desde 1915 en adelante, no necesitó del dictum sulliviano la forma sigue a la función. Los soviets se apoyaron unos a otros en la pintura futurista, cubista, neoplasticista, suprematista y constructivista. Dado que la función de comunicar fue una necesidad entre los diseñadores rusos, debieron lograr que las masas no alfabetizadas entendieran los mensajes. A veces, apelaban al naturalismo, las formas no objetivas y la fotografía documental, pero no se justificaban ni lo explicaban a partir del concepto de función. Sus objetivos estaban focalizados en reemplazar la noción de composición por la de construcción, cuestionar el individualismo para reemplazarlo por el colectivismo y edificar un lenguaje visual impersonal, al margen del estilo. Herbert Bayer, en la Bauhaus, sin tener este contexto tan exigente, ni principios tan radicales, continuó esta propuesta constructiva.

El Diseño Industrial, o diseño de productos, había dado cuenta de la gran tradición del diseño funcional, tanto en Europa como en Estados Unidos. Y la extendida discusión sobre la relación entre la forma y la función en el pensamiento alemán del siglo XVIII (ver Collins y De Zurko en el capítulo dos) tampoco fue deudor de la influencia de Sullivan y Wright; aun cuando ésta se hubiera dado, como historiza de manera imprecisa, Jean Michl. Pero, el tratamiento de esta estrecha relación sucesiva entre la forma y la función, sí se tradujo en un objetivo acompañado de una metodología en el proceso proyectual, dado que el tratamiento racional de la función a cumplir, demandaba extensos desarrollos de posibles formas, para elegir de manera teleológica, la más adecuada para un fin. En estas decisiones se tuvieron en cuenta aspectos ergonómicos, técnico-productivos y de costos (todos cuantificables). Esta metodología, de división y jerarquización de los problemas y sus partes, su tratamiento técnico-formal y su reordenamiento final, fue la que se universalizó a posteriori de la HfG de Ulm, sobre todo en Latinoamérica.

Sin embargo, fue en la Arquitectura donde mayormente se debatió, de forma crítica, la herencia de Sullivan y Wright, más como recurso discursivo que como legado teórico, metodológico o estético. Ya que, como se ha visto hasta ahora en esta investigación, lo que se catalogó como formas funcionales, devino de una metodología de base racional, que, al igual que en el diseño de productos, fundamentó las decisiones proyectuales conforme a requerimientos objetivos. Tales requerimientos, provenientes del lugar, los materiales, el clima y los usos, fueron resueltos mayoritariamente a partir de una estética cubista, neoplasticista y constructivista, que, si bien no provino de los Estados Unidos de la mano de Sullivan, puede asociarse en parte a Frank Lloyd Wright.

Vale el esfuerzo aclarar, como la apropiación y el tratamiento de la cuestión funcional, se reflejó en los diversos campos disciplinares que atañen al diseño. De todas maneras, se sugiere diferenciar las prácticas concebidas en el Bauhaus y en la HfG, de las prácticas proyectuales de hoy. Ya que las profundas discusiones y los compromisos políticos de esas épocas, se distinguen sustancialmente de las tendencias banales - o modas-, características de la actualidad. Estas modas se repiten todavía, y cambian mecánicamente en los talleres y estudios de diseño, de un día para otro, según los vaivenes del mercado. Vaivenes con los que los actores de la Bauhaus, en todas sus facetas, y la emblemática HfG de Ulm, lucharon de manera utópica en el pasado. 


\section{Reflexiones y consideraciones epistemológicas, ético-políticas y estéticas}

El objeto principal de esta investigación se ha concentrado, hasta ahora, en rastrear las divergencias del concepto de funcionalismo, exclusivamente desde la historiografía. Sin embargo, sus acepciones terminológicas documentan un $\operatorname{core}^{82}$, que entiende la epistemología, la ciencia, la ética, la política y la estética como sustancia de sus fundamentaciones.

\subsection{Acepciones del funcionalismo}

Las aproximaciones ontológicas y conceptuales elaboradas por autores como Fulvio Carmagnola, Will Kymlicka, Jean Baudrillard, y Thomas Kuhn, entre otros, funcionarán no solo para respaldar esta cuestión, sino también para derribar las aporías construidas en torno a este concepto. De allí, que el objeto de este apartado se concentre en revelar desde esta probable convergencia-, cómo una determinante totalizadora o una coartada omnicomprensiva, diluyeron los factores derivados de las miradas distintivas y/o mixtificadas del funcionalismo, presente o no en estas tres escuelas ${ }^{83}$ emblemáticas del Diseño.

\subsubsection{Epistemológica y científica}

Para analizar las bases epistemológicas de lo que fuera denominado como funcionalismo, solo y exclusivamente como una corriente proyectual, en esta investigación se acude a las caracterizaciones que construyó el esteta Fulvio Carmagnola (1995), en su texto: El Alma de los Objetos, como disparadoras de esta reflexión:

Es posible encontrar una solidaridad cultural profunda entre la epistemología moderna y la concepción funcional y utilitaria del objeto industrial. En efecto, el funcionalismo, en lo que se refiere a las formas de uso y a la concepción tecnológica del objeto, es análogo al fundacionismo epistemológico. Éste último nace con la revolución científica y con la estrategia de la representación cuantitativa de la naturaleza por medio de las ciencias exactas. Por su parte, la cultura funcionalista y utilitaria de los objetos nace casi un siglo más tarde, con la revolución tecnológica y con la distinción estructural entre forma de uso y forma de arte. Aunque el funcionalismo, como específica corriente creativa propia del diseño, es mucho más tardío, el contexto que lo hace posible, nace precisamente con la separación entre belleza y utilidad, que forma parte de la historia de la tecnología moderna y que es canonizada en el plano estético por el sistema kantiano. Hemos afirmado que hoy en día se abre un espacio estético ampliado por una poética no funcional del objeto de uso. [...] El racionalismo funcionalista es el lenguaje específico, la ideología específica, la poética del producto industrial moderno en su fase madura; es el fruto de una selección cultural, que ha excluido otras posibilidades. (Carmagnola, 1995, pp,61-62, 64-65).

De esta tesis, habría que preguntarse, si la poética específica del objeto, propagada y practicada en el funcionalismo, es asertiva para todas las etapas de transformación que sufrió 
el uso del concepto, desde la Escuela de Chicago, hasta la Bauhaus de —1919 a 1933—, y la HfG Ulm. La indagación que Carmagnola traza, es construida en la década de los años noventa; que, en contraste con las fuentes primarias, no es reconocida como tal para ese momento. Adicionalmente a ello, implementa un concepto de funcionalismo, de corte abarcativo, que homogeneiza no solo las fases y transiciones que sufrió la Bauhaus en su interior, sino también las distinciones entre diversas escuelas de pensamiento y áreas proyectuales, posteriores a ella. Estudiar sus afirmaciones, nos lleva a cuestionar si el funcionalismo fue, en realidad, deudor de la revolución científica y la estrategia de la representación cuantitativa de las ciencias exactas.

Efectivamente, la funcionalidad como se ha definido en el capítulo cuatro, y también cómo se describen las teorías que lo conectan con Sullivan y Wright, los desarrollos del Segundo Bauhaus y la HfG de Ulm, podemos afirmar que sí se puede considerar como deudor de la revolución científica, y de la estrategia de representación cuantitativa de la naturaleza por medio de las ciencias exactas. En principio esto puede corroborarse fácilmente, dado que todas las producciones y construcciones posteriores a la Revolución Industrial - sobre todo a partir del siglo XIX-, incluían los avances científicos y técnicos, emanados sobre todo de la física, la termodinámica, las matemáticas y la geometría, la biología y la economía. Sin la geometría descriptiva - que permitía la representación de objetos y construcciones-; las nuevas fuentes de energía; la división del trabajo; la mecanización; la intercambiabilidad de componentes; la producción en serie y luego en cadena; la gestión científica; los nuevos materiales (acero, vidrio y hormigón), no hubieran sido posibles en las construcciones de los nuevos edificios y productos. Estos avances, dieron paso al uso de ascensores, la construcción de plantas abiertas, el uso de amplias entradas de luz, la producción de máquinas y herramientas para la producción de utensilios, y las unidades de transporte para trasladar tanto materias primas como productos y pasajeros. A esto debe sumarse, un tratamiento racionalizador del proceso proyectual, que partía de la tradicional división y tratamiento de las partes del método cartesiano, y una visión pragmática de la disciplina asociada a un interés político. Ya en Ulm se aplicaron programas científicos en la proyectación, la experimentación y comprobación en laboratorios de leyes físicas y ópticas, el uso de la estadística y las matemáticas para decidir programas comunicacionales.

No obstante, se responderá a este interrogante analizando caso por caso, en cada una de las tres escuelas. Se dedujo de las fuentes primarias, en esta investigación, al analizar la trayectoria de Sullivan y Wright como representantes de la Primera Escuela de Chicago, que la inspiración orgánica y la frase la forma sigue a la función, sí evidencian un vínculo con las ciencias biológicas y las ciencias de la naturaleza, en especial con la teoría de la Selección Natural de Darwin. Se aclara, que se implementa el término: 'inspiración', porque las formas resultantes de sus edificios, - aunque no tenían nada que ver con la bioquímica一, sí se caracterizaron por la emulación del crecimiento de los organismos vegetales y animales, que se produce de adentro hacia fuera, conjuntamente con una adaptación a sus entornos de vida.

En segundo lugar, en el caso de los inicios del Bauhaus, se afirma que partió de una visión romántica de los oficios medievales, las experimentaciones artísticas y esotéricas de Itten; las influencias teosóficas y espiritualistas de Kandinski, Klee y otros, y las metáforas 
alrededor del rescate - en palabras de Gropius, de un espíritu epocal; expresiones que Rykwert, (1971), reseña en su texto: El lado oscuro de la Bauhaus. De esto se deduce que solo en la segunda y tercera fase del Bauhaus se podría sostener, y con reservas, que se verifica lo que enuncia Carmagnola (1995). Cuando los proyectos abandonaron la experimentación artística originaria de las artes plásticas, y comenzaron a sustentarse en la objetividad de los materiales, los procesos industriales, la geometrización de las formas, los métodos proyectuales, la tipificación, la serialización, las necesidades humanas y las decisiones formales enfocadas en la función. Solo aquí es cuando se podría hablar del racionalismo, que Carmagnola aborda con puntualidad.

De todas formas, es en la HfG, donde Carmagnola, podría sostener sus afirmaciones plenamente, dado que Tomás Maldonado puso énfasis en la incorporación de materias científicas al pensum. Estas materias, que heredadas del paradigma físico matemático de la naturaleza y sus sistemas de representación, se complementarían con estudios semióticos y de bioingeniería, muy adelantadas para ese momento. En principio, en la HfG Ulm se mixtificaron las influencias del neo positivismo, los estudios de lógica aplicados al lenguaje de la Escuela de Viena y los principios marxistas de igualdad. A ellos, se suman la distinción kantiana y universal entre el objeto de uso, en oposición al objeto de placer.

En cuanto a la pedagogía, a la par que rechaza el learning by doing (aprender haciendo) de la Bauhaus, tanto como el neo-humanismo y su educación conservadora, Maldonado (1963), en su artículo: 4 Conferencias cev/di, propicia una filosofía educativa, donde el operacionalismo científico, constituye su fundamento. Sobre esta base, se busca que "la máquina proyectada en relación al producto resultante sea reemplazada por la máquina proyectada en relación a las operaciones fundamentales a realizar"; tesis que Maldonado cita de Laevery y Brown (Maldonado, 1963, p. 37).

Las influencias positivistas se revelan en la entrevista de Tomás Maldonado con María Amalia García:

La ideología de renovación, de innovación de hacer en el campo de los productos, vehículos de una concepción nueva, y esa es la contribución, diríamos que, los intereses que expresaba el diseño industrial es lo que me ha llevado precisamente a aceptar la invitación a la Escuela de Ulm, que era digamos, el nuevo Bauhaus. Ese neo positivismo que me caracterizaba en esos momentos ha tenido una influencia muy benéfica en esos primeros años de Ulm [...] de haber hecho un nuevo Bauhaus que trataba de superar el Bauhaus, superar los límites del Bauhaus. (Colección Cisneros, 2011, 00:02:00)

A esto tendríamos que añadir también, las influencias externas, que fueron absorbidas en Ulm, que Gui Bonsiepe (1999) enumera en su texto: Del objeto a la interfase: El Círculo de Viena, de parte de Carnap y Neurath; el pragmatismo americano de Peirce y Dewey; $e l$ racionalismo crítico de la Escuela de Frankfurt, con Adorno, Horkheimer, Marcuse y Habermas; la filosofía anglosajona del lenguaje cotidiano, importada de Wittgenstein, Ryle y Richards; la Teoría de los Sistemas de Wiener y Churchman; el Arte Concreto; el Constructivismo; la dinámica social de la cultura; el Iluminismo; y por último, la Estética de la Informática de Moles y Bense; todo ello conforma, según Bonsiepe, los fundamentos del 
discurso que ejercitaría la práctica proyectual en Ulm (Bonsiepe, 1999, p.136). De todas formas, Bonsiepe hace hincapié en que, si bien en la HfG se instituyeron aspectos que provinieron desde distintas direcciones, la proyectación como dominio autónomo no puede ser instrumentalizada y tampoco definida por otras disciplinas. De allí que el Diseño, para él, no pueda ser "ni arte, ni tecnología, ni ciencia, porque ninguno de estos dominios posee las distinciones necesarias para revelar la esencia de la proyectación" (Bonsiepe, 1999, p. 137).

A partir de lo expuesto, el autor de la presente tesis afirma que - gracias a la puesta en práctica de la racionalización y la visión sistemática de la forma, característica en Ulm-, se llegó a ejercer una faceta de funcionalismo. Se aclara que esto sería siempre y cuando, como sostiene Bonsiepe, no se le defina como una tesis simplista, de formas que devinieron del uso y de objetivos lineales carentes de iteración. Aun cuando el término sea, para Maldonado y Bonsiepe, un término problemático —en razón a las imprecisiones elaboradas sobre este concepto desde disciplinas no proyectuales-, la legitimación de una relación entre el funcionalismo y Ulm, solo podría aceptarse en tanto se abandone la concepción de este término como un aspecto superficial, ligado a las formas austeras y geométricas de los productos diseñados.

¿Existe una relación entre (HfG) Ulm [sic] y el funcionalismo? Seguramente no, si se identifica el funcionalismo con la tesis simplista de que las formas derivan de las modalidades de uso o que se determinan linealmente por los objetivos, así como la forma de una gota de agua se define por el plano de apoyo y por la tensión superficial. Seguramente si, si en cambio se sostiene la tesis de que la dimensión del uso, de la relación instrumental de los artefactos, se encuentran en el centro de las problemáticas proyectuales. (Bonsiepe, 1999, p. 138)

No obstante, se debe aclarar que, de funcionalismo, solo se podría hablar en Ulm; asimismo, debe recordarse que no se podría interpretar como un sinónimo de ciencia, sino como una iniciativa que propendió a la construcción de metodologías proyectuales, que dignificaron el diseño como una práctica rigurosa. Allí, proyectar formas que fueran coherentes con las necesidades humanas, se trazó como su interés fundamental. Así, lo asevera Bonsiepe (1999), en su apartado de Metodología Proyectual:

... (HfG) Ulm [sic] es conocida por su interés por la metodología proyectual. Dicho interés fue a menudo mal interpretado como una tentativa de practicar un diseño científico o de directamente transformar el diseño en una ciencia. En verdad (hfg) ulm nunca cultivaba estas ideas absurdas. El programa de la institución pretendía, al contrario, explorar el rico potencial de la ciencia, según el razonamiento asumido de que los conocimientos científicos podían enriquecer el proyecto y hacerlo más fundamentado. (Bonsiepe, 1999, p. 139)

A esta fundamentación racional en la HfG, se le deben añadir, tanto el curso de semiótica, - impartido por Maldonado en Ulm, dado que para él la comunicación humana no puede darse con la ausencia de signos-, y también, la metametodología, como campo de 
la filosofía de la ciencia, desde la que se estudian los métodos adecuados que se desarrollan para resolver problemas. Estas ideas, Maldonado (1974) las expone en su libro Vanguardia y Racional (1974) cómo: “... los fundamentos epistemológicos y operativos que justifican la elección de determinadas tareas. Es lo que podríamos llamar una «metametodología», una metodología de la metodología" (Maldonado, 1974, p. 126).

Con respecto a la poética, retórica, y en particular, a las metáforas, Maldonado (1977), en su texto: Montaje fílmico y retórica, propone examinarlas desde el punto de vista semiótico y lógico. Este autor manifiesta no sentir repugnancia de estas figuras — según sus palabras-, ya que se encuentran en lo profundo del lenguaje. Asimismo, propuso investigaciones específicas sobre todo en la retórica visual para alejarse de la persuasión y del marketing (Maldonado, 1977, pp. 114-117).

Sobre la base de estos antecedentes, que privilegianla precisión en lo comunicacional, surgió posteriormente la Gráfica Suiza, conocida por estar dirigida a optimizar la función comunicativa en el comercio internacional, sobre todo, gracias a la tipografía Helvética, que fue uno de los tipos transferibles de mayor impacto a partir de los '50.

En esta renovación revolucionaria, metodológica y sistematizada protagonizada por Suiza, tiene suma importancia, la implantación de la letra tipográficaen este caso la Helvética - en las cabeceras de carteles y anuncios, por medio de otro recurso de la nueva tecnología: la ampliación fotográfica de los tipos. En este punto es en el que se fragua una generación de jóvenes diseñadores formados bajo criterios y pautas racionales [... para conceder definitiva credibilidad al proyecto estilístico expansionista de la gráfica comercial suiza. Todo movimiento moderno en la historia del diseño gráfico se ha apoyado en una nueva tipografía alternativa, que tiene la virtud de renovar la forma al tiempo que contribuye eficazmente a llenar de contenido epistemológico el ideario correspondiente. (Revista ON, 1974)

\subsubsection{El funcionalismo en otros campos}

Empero, se debe explicar que, si bien el funcionalismo, parecería inscribirse en las ciencias físico matemáticas y en las ciencias de la naturaleza, éste se manifiesta también en otros campos del conocimiento. Aunque sus diversas líneas disciplinares, poseen un rasgo genealógico compartido, derivado de las teorías de la Selección Natural de Darwin y del Utilitarismo, no conservan las mismas definiciones, y tampoco se encuentran adscritas a los fenómenos del diseño que se estudian en esta investigación. Estas vertientes, entre otras, se visualizan en las posturas que asume el funcionalismo antropológico, de Bronislaw Malinowski; el funcionalismo sociológico, de Émile Durkheim; y el funcionalismo lingüístico, de Ferdinand de Saussure. Por lo que se concluye aquí, que el funcionalismo, propio de las áreas proyectuales, no se usó, o no tuvo el mismo tratamiento que en las demás ciencias.

\subsubsection{El funcionalismo como matriz disciplinar}

$\mathrm{Al}$ concepto de funcionalismo, analizado por Carmagnola, y otros teóricos - ya tratados previamente-, que lo toman en sentido genérico, ¿se lo podría catalogar de paradigma o 
como un concepto del que emergieron diversos modelos contenidos en una matriz disciplinar para las áreas proyectuales?

El filósofo e historiador americano Thomas Kuhn (2004), en su texto: La estructura de las revoluciones científicas, podría brindarnos una respuesta, desde los sentidos que podría llegar a asumir este concepto. Refiriéndose a los paradigmas, Kuhn explica: “...Considero a éstos como realizaciones científicas universalmente reconocidas que, durante cierto tiempo, proporcionan modelos de problemas y soluciones a una comunidad científica..." (Kuhn, 2004, p. 13). Para este autor, los paradigmas también son: “...la fuente de los métodos, problemas y normas de resolución aceptados por cualquier comunidad científica madura...” (Kuhn, 2004, p. 165). Kuhn sugiere que el paradigma tiene un estatus superior, y de algún modo anterior al que corresponde a las creencias compartidas y a las reglas. En cualquier caso, el paradigma no implica la existencia de un conjunto completo de reglas; pueden ser de muy diferentes clases y, en general, no se manifiestan explícitamente. Este autor relaciona las reglas específicas de cada paradigma con diversos compromisos, que están implícitos en la propia adopción de ese paradigma. Mientras éste se mantiene vigente, Kuhn habla de período de ciencia normal. Cuando sus presupuestos entran en crisis, se abre el campo para dar lugar a una nueva formulación.

En este sentido, efectivamente, el funcionalismo operó como paradigma de analogía biológica para todas las ciencias, y tuvo su extensión a las disciplinas proyectuales. No obstante, en su epílogo de 1969, el propio Kuhn prefiere hablar de matriz disciplinar, que implica una concepción más amplia, en lugar de paradigma — como lo hizo en su versión anterior de 1962- Habla de 'matriz' porque se compone de elementos ordenados de varios tipos, cada uno de los cuales precisa una especificación ulterior. Y por 'disciplinar' porque alude a la posesión común por parte de los que practican una disciplina concreta.

... por una parte, significa toda la constelación de creencias, valores, técnicas, etc., que comparten los miembros de una comunidad dada. Por otra parte, denota una especie de elemento de tal constelación, las concretas soluciones de problemas que, empleadas como modelos o ejemplos, pueden reemplazar reglas explícitas como base de la solución de los restantes problemas de la ciencia normal... (Kuhn, 2004, p. 269)

Desde esta caracterización más amplia, se puede decir que el concepto de funcionalismo en las disciplinas proyectuales - a partir de la escuela de Chicago, el segundo Bauhaus y HfG Ulm-, efectivamente se conformó como una matriz disciplinar. Esto se generó desde el momento en que a su alrededor se formó una comunidad de investigadores proyectistas, que pretendían romper con los modelos de los estilos arquitectónicos históricos y de las escuelas de Arte. Al mismo tiempo, concibieron al ejercicio proyectual como la resolución de un problema, con metodologías y técnicas específicas, creando tipologías formales y constructivas que operaron como nuevos modelos ejemplares. No solo compartieron valores y compromisos de construcción y producción democratizantes, sino que también, se mantuvieron en la creencia del progreso basado en el aporte científico.

En la Bauhaus - y solo en su segunda y tercera etapa-, se inicia un proceso de tratamiento de las ciencias como la garante que conduciría a separar la belleza de la utilidad, pero 
es en la HfG, donde se establece la superación oficial y la escisión de las artes plásticas respecto de la fundamentación del pensamiento y las prácticas del diseño. El programa de la Escuela de Ulm pretendió robustecer la noción del proyecto, a partir de los razonamientos provenientes de la ciencia. Esto condujo a que, en ella, y solo en ella, el funcionalismo, se estableciera con un rigor que, aunque no fuera necesariamente científico, entrañaría un cambio en las reglas que venían rigiendo a las prácticas proyectuales anteriores.

De esta manera, se puede decir que el concepto de funcionalismo se fue formando como matriz disciplinar desde finales de siglo XIX, pero alcanza su madurez en los años '50 del siglo XX. A partir de finales de los '60, estos modelos, metodologías, técnicas, valores y creencias comienzan a ser cuestionados y reconstruidos.

\subsubsection{Aspectos ético-políticos subyacentes a los proyectos, orientados según la fun- ción. Utilitarismo, marxismo y ética puritana}

\subsection{Utilitarismo}

Históricamente, la cuestión funcional siempre ha estado inscripta en el horizonte de la utilidad. Al punto que, a veces, funciona y útil, se han usado indistintamente o con íntima ligazón. La reflexión sobre la utilidad estuvo presente en la filosofía desde la antigüedad, y en los inicios de la época moderna se desarrolló, particularmente, a partir de las ideas de Hume (1739/1923), en quien abrevaron las doctrinas utilitaristas.

Entre las diversas fuentes de ideas que nutrieron los programas funcionales, del siglo XIX y hasta bien entrado el siglo XX, una de las corrientes más importantes, —si no la más significativa-, la constituyó el utilitarismo; tratado por Jeremy Bentham (2010), Stuart Mill (2014) y Henry Sidgwik (2012), etc. Uno de los filósofos políticos que más claramente ha estudiado esta corriente es Will Kymlicka (1995), del cual extraeremos las principales ideas para construir nuestro análisis. Este apartado está destinado a responder la pregunta: ¿cuáles fueron los presupuestos ético-políticos que posibilitaron el surgimiento, la expansión y/o difusión del funcionalismo, como doctrina o corriente de las disciplinas proyectuales? En su texto Filosofía Política contemporánea. Una Introducción, Kymlicka (1995), sostiene que el utilitarismo, exige la búsqueda de una 'sociedad de la utilidad' o el bienestar huma$n o^{84}$ con el fin de que se lleve a cabo o se practique de manera imparcial. Así, sus principios consistirían en su adecuación a las instituciones preocupadas por la importancia del bienestar de la humanidad y, cómo las reglas que dictaminan la moral se deben analizar exclusivamente a partir de las consecuencias que puedan acarrear sobre dicho bienestar. Kymlicka describe, al menos, cuatro variables identificables del utilitarismo, como lo son: el hedonismo del bienestar, la utilidad no hedonista de los estados mentales, la satisfacción de las preferencias y las preferencias informadas. De todas ellas, la que más representa a la filosofía política subyacente en las prácticas proyectuales enfocadas en la función, y que estuvo presente en el ideario de las tres escuelas estudiadas (Chicago, Bauhaus y HfG), con excepción de las artes plásticas-, es la de las preferencias informadas. Esta postura del utilitarismo, y los conceptos que involucra, se invocaba consciente o inconscientemente en las tres escuelas, aunque muchas veces se mezclaba con otros ideales de la época.

El utilitarismo, conforme a esta postura, pretende satisfacer aquellas preferencias basadas en una plena información y en juicios correctos, a la vez que re- 
chaza aquellas preferencias que son erróneas e irracionales. Tratamos de proporcionar aquello que las personas tienen buenas razones para preferir, aquello que realmente mejora sus vidas. Los utilitaristas dicen que la acción correcta es aquella que incrementa al máximo la utilidad, esto es, aquella que satisface tantas preferencias informadas como sea posible. Las preferencias de algunas personas quedarán insatisfechas, si entran en conflicto con lo que desarrolla al máximo la utilidad general. (Kymlicka, 1995, p. 28)

En este sentido, todas las etapas de transformación de los discursos y prácticas originadas en Chicago, Bauhaus y Ulm, - pero sobre todo en las dos últimas-, se dirigieron a un público informado, o al que había que formar. Para el segundo Bauhaus y Ulm, educar e inculcar nuevos hábitos y usos basados en la racionalidad, se convirtió en un objetivo primordial; tanto en el trabajo como en los modos de vida, distantes de las costumbres atávicas y burguesas. Se entiende entonces, el por qué en estas escuelas, —al apostar a la figura de un hombre nuevo respaldado por un objetivo socializador-, se incluyera y defendiera en sus principios, las permanentes demandas de igualdad que siempre las destacó. En Chicago, la preocupación de los arquitectos - como figuras que debían detectar y sintetizar los aspectos esenciales de una civilización-, constituía el canon de su obligación moral. En la Bauhaus, posteriormente a la fase de adhesión entre artistas y artesanos, es solo a través de la racionalización, la tipificación y la serialización de los productos, como se halla aquello que las personas tendrían buenas razones para preferir, por caso, las viviendas estandarizadas proyectadas allí. Y en Ulm, esta preocupación que ya estaba en Meyer, fue importada por el segundo Bill ${ }^{85}$, para luego ser dignificada por Maldonado y Aicher.

Por otra parte, Kymlicka advierte:

Existen dos versiones diferentes, dentro del utilitarismo, respecto de quién construye el «nosotros» relevante, o el grupo de destino relevante en una formulación: todos estamos obligados a actuar conforme a principios utilitaristas, incluso en nuestra conducta personal (utilitarismo moral exhaustivo); en la otra formulación, son las principales instituciones sociales las que se encuentran específicamente obligadas a actuar conforme a principios utilitaristas (utilitarismo político) [...] Concurren además dos versiones diferentes acerca de qué es lo que significa «actuar de acuerdo con principios utilitaristas». Desde un punto de vista, esto significa que quien debería decidir cómo actuar mediante un cálculo utilitario consciente, sería un hipotético agente tratando de determinar de qué manera, diferentes acciones podrían influir en la satisfacción de preferencias informadas (utilitarismo directo). [La cursiva es del autor] (Kymlicka, 1995, pp. 32-33)

En el caso que se analiza aquí, este fue el rol de las direcciones de las tres escuelas en todos sus momentos. Sin embargo, si bien en todas se puso en práctica lo que Kymlicka denominó como utilitarismo moral exhaustivo y utilitarismo político, la situación contextual de Bauhaus y Ulm, difirió de la de Chicago. La sumisión exigida por las presiones de las políticas de estado alemanas, en búsqueda de la recuperación de una Europa atomizada en los períodos de entre y pos-guerras, obtuvo de la HfG - y de sus direcciones-, una respuesta 
intransigente y rotunda. El no servir de coartada a la economía de mercado que iba en contravía de los idearios de este claustro, configuró una de las causas que llevó al cierre definitivo, de la HfG de Ulm en 1968. La ilusión de conciliar los intereses de la producción con las necesidades, y los intereses de los usuarios — según Maldonado-, se basó en un utilitarismo moral exhaustivo; que, encarado por cada uno de sus miembros, se convirtió en actitudes institucionales generalizadas. Y aunque la situación en Chicago fue diferente, dado que se luchaba contra los revivals, lo común entre las tres escuelas fue empujar la palanca causal que fuera capaz de producir al máximo la utilidad.

Algunos teóricos como Raphael (1981), Brandt (1959) y Hosper (1961), conciben al utilitarismo como "un equilibrio o compromiso entre los valores de la utilidad y la igualdad". Dichos principios se encuentran evidenciados en los ideales socialdemócratas de Walter Gropius, Mies y otros, como bien lo menciona Argan (1983). Estos valores, con ciertas distinciones, fueron objetados desde la izquierda.

La crítica izquierdista más frecuente a la justicia liberal, es que ésta acepta la igualdad formal, entendida como igualdad de oportunidades o derechos civiles y políticos iguales, mientras que desatiende las desigualdades materiales al no ocuparse de promover un igual acceso a los recursos. (Kymlicka, 1995, p. 179)

En efecto, esta crítica se encuentra en la base de la diferencia entre los movimientos comunistas y socialdemócratas, aunque hay que dejar claro que, tanto al interior del comunismo, como de la social democracia alemana, de entreguerras y posguerras, había distintos criterios y también profundos debates. Lo cierto es que una Europa empobrecida por la guerra e influenciada por la revolución rusa, hizo de la distribución de los recursos, la reconstrucción, la producción y el crecimiento de los países, una verdadera prioridad.

Otros autores, como Thomas Nagel (2004) apunta a que debemos completar nuestra obligación de incrementar lo bueno mediante la obligación de tratar a las personas como iguales. Este autor sugiere añadir una limitación 'deontológica' — de igual tratamiento-, al utilitarismo, que en su opinión se centra tan sólo en seleccionar el "mejor resultado impersonal" (Nagel, 1986, p. 176). Este enunciado muestra la neutralidad o imparcialidad del objetivo universalista y equitativo de las soluciones funcionales buscadas. Pero en el caso de estas escuelas, también se sumaban valores.

Por esto, el funcionalismo, además de inscribirse en una lógica teleológica, orientada a los fines, como lo es la ética utilitarista, podría categorizarse también como deontológica, en tanto destinada a prescribir valores y principios morales. Esta observación es particularmente evidente, en el carácter prescriptivo de la moral de la escuela de Ulm, no así en las anteriores. Así lo atestigua Maldonado en su discurso inicial en la HfG Ulm:

La escuela de Ulm quiere señalar el camino a seguir para lograr el más alto nivel de creatividad, pero a la vez, y no en menor medida, señalar cuál ha de ser la finalidad social de esta creatividad, es decir, indicar cuáles son las formas que merecen ser creadas y cuáles no [...] La HfG hace suya la tesis según la cual el proyectista, aun trabajando para la industria, ha de continuar asumiendo sus responsabilidades frente a la sociedad. En ninguna circunstancia sus obligacio- 
nes para con la industria podrán anteponerse a sus obligaciones con la sociedad. (Maldonado, 1955a/1974. p. 70)

Todavía debemos preguntarnos ¿porqué el utilitarismo está en la base de las corrientes productivas y constructivas de fines del siglo XIX y principios de siglo XX? Kymlicka explica el utilitarismo como un movimiento que se expandió por toda Europa y Estados Unidos, donde su sentido original mutó hacia nuevas significaciones, tal como pensamos que le sucedió al concepto de funcionalismo, en contextos y circunstancias diferentes:

El utilitarismo, como movimiento político y filosófico consciente de sí, surgió como una crítica radical de la sociedad inglesa. Los utilitaristas originarios eran «radicales filosóficos» que creyeron en un replanteamiento completo de la sociedad inglesa, una sociedad cuyas prácticas creían que eran el producto de la superstición feudal y no de la razón. Al utilitarismo, en ese tiempo, se le identificaba con un programa político progresista y reformista: la ampliación de la democracia, la reforma penal, medidas relativas al bienestar[...] los utilitaristas contemporáneos, por su parte, son «sorprendentemente conformistas», de hecho, parecen ansiosos por mostrar que el utilitarismo deja todo tal cual está [...] Esto demuestra que el utilitarismo ya no puede presentarse como el lenguaje correcto para el debate político. El utilitarismo moderno, a pesar de su herencia radical, ya no define una posición política clara y distinta. (Kymlicka, 1995, pp. 60-62)

\subsection{Influencias del Marxismo}

Lo que nos interesa aquí es desentrañar cuáles de las ideas del marxismo influyeron enlos conceptos fundamentales asociados a la noción de proyecto. Para ello tomaremos dos conceptos importantes, asociados al perfeccionismo marxista: la alienación y la necesidad. Para Kymlicka (1995), al parafrasear a Steven Lukes (1985), la crítica de Marx al capitalismo, si bien se enfoca en la preocupación sobre de la explotación del proletariado, también toca la preocupación por la alienación.

Los argumentos perfeccionistas, como ocurre con el marxista sobre la alienación, dicen que los recursos deberían ser distribuidos de tal manera que se aliente la «realización de las potencialidades y excelencias distintivamente humanas», y desalentar las formas de vida que carezcan de estas excelencias (Lukes, 1985, p. 87). Tales teorías son "perfeccionistas» porque afirman que ciertas formas de vida representan la "perfección» humana (o la «excelencia»), y que tales formas de vida deberían fomentarse, mientras que a las formas de vida menos valiosas se les debería imponer cortapisas. [La cursiva es del autor] (Kymlicka, 1995, p. 210)

Aunque no todos los marxistas son perfeccionistas, los argumentos perfeccionistas fueron particularmente utilizados, en pos de una labor productiva no alienada, creativa, independiente de las modas y las exigencias de los cambios fluctuantes de los mercados. Defini- 
tivamente, el ideal de Ulm anheló una forma de adquisición inexistente, deontológica y universal, donde las acciones causales que articularan al diseño, el consumo, la producción y la economía, estuvieran motivadas permanentemente por una imparcialidad casi utópica, y por ello, inalcanzable. Las preferencias de los usuarios, a las que apostaron, no siempre fueron en concordancia con las necesidades humanas, que ellos consideraron como vitales. Se recuerda que, para Marx — según Kymlicka-, "en el comunismo, la distribución se basará en el principio «a cada uno de acuerdo con sus necesidades»" (Kymlicka, 1995, p. 205), y estas necesidades, aunque han sido interpretadas de diversas maneras por los postmarxistas, son, con certeza, una invocación constante en el discurso ulmiano, ya sea de Bozzano, Aicher, Maldonado o Bonsiepe. Si bien es cierto que ya se invocaba en la Bauhaus, en Ulm, se hizo — de esta satisfacción de las necesidades—, una bandera.

\subsection{Valor de uso y valor de cambio}

En relación al funcionalismo, además de los conceptos de necesidad y alienación, la principal crítica que se extrae del marxismo es la referida al valor de uso y al valor de cambio de los objetos, y su relación con la noción de fetichismo de las mercancías. El concepto de fetichismo es entendido, por Adorno (1963) —en su texto: Disonancias. Música en el mundo dirigido-, como la actitud complaciente que oculta las condiciones de explotación en el mundo capitalista.

Si la mercancía se compone siempre de valor de cambio y valor de uso, este puro valor de uso, cuya ilusión han de conservar los bienes culturales en la sociedad capitalista, es sustituido por el puro valor de cambio, que precisamente en cuanto tal valor de cambio, toma sobre sí, engañosamente, la función del valor de uso. (Adorno, 1963/1966, p. 33)

Estos conceptos fueron arduamente debatidos en HfG Ulm, en tanto concebían al funcionalismo como una metodología especialmente focalizada en acentuar el valor de uso; categorías que merecieron referencias tanto de Maldonado como de Bonsiepe. Aunque ambos las han tratado de modo diferenciado, para Bonsiepe (1975/1978), en su libro: Teoría y práctica del diseño industrial. Elementos para una manualística crítica - publicado en 1975-, se expone su postura del funcionalismo en relación al poscapitalismo:

Cierta percepción y sensibilidad para las exigencias humanas está probablemente más presente en la austeridad de un proyecto «funcionalista» que en el aluvión de formas nuevas del irracionalismo poscapitalista. Se puede estar en contra del funcionalismo, pero no se puede prescindir de él. El funcionalismo tomado aquí como doctrina proyectual y no como estilo proyectual- contrasta con los intereses de las clases dominantes, porque insiste obstinadamente en la exigencia de las funcionaes, el «¿por qué?» del producto. Aquéllas, en cambio, están dispuestas a ofrecer buenos bocados a la furia de la innovación formal, en la medida en que ésta se declara antifuncionalista. (Bonsiepe, 1975/1978, p. 42) 
En consecuencia, Bonsiepe (1975) también recalca cómo la sociedad capitalista traza vínculos entre el diseño industrial y el valor de uso, para luego justificarse a través del valor de cambio:

Es evidente que, mientras en la sociedad socialista el diseño industrial esté llamado a participar directamente en la formación del valor de uso, en la sociedad capitalista aquél se acerca al valor de uso de manera indirecta, y solamente después de haber satisfecho las exigencias del valor de cambio. (Bonsiepe, 1975/1978, pp. 71-72)

No obstante, Tomás Maldonado (1958), en su publicación El diseño y sus nuevas perspectivas industriales, -citada en su libro Vanguardia y racionalidad (1974) -, en torno al funcionalismo y al valor de uso, opinaba lo siguiente:

... A. Smith, D. Ricardo ya decía: «la utilidad no es la medida del valor de cambio, aunque sea absolutamente esencial al mismo». Tratando de este tema, Marx escribía: «Yo no divido el valor, en valor de uso y valor de cambio, como si ambos se opusieran y como si una cosa abstracta - el valor-estuviera partida en dos. El valor de uso de un producto constituye el soporte del valor de cambio» [...] El paso del productor al consumidor, del valor de cambio a valor de uso, es extraordinariamente complejo. En él es difícil apreciar las relaciones de causa a efecto. No tiene sentido alguno asignar al diseño industrial un lugar preciso en este ámbito, por la sencilla razón de que tanto el productor como el consumidor no son dos magnitudes que puedan ser determinadas y de una forma precisa, dentro de un esquema determinado. (Maldonado, 1958, en Maldonado 1974, p. 75)

A pesar de los diferentes enfoques, en los que ambos diseñadores seguramente hubieran coincidido, es en evitar una cultura donde se asuma positivamente el valor de cambio como objeto de goce privilegiado.

\subsection{La moral de los objetos. Función-signo y lógica de clases. Según Jean Baudrillard}

Es interesante contrastar el funcionalismocomo corriente basada en los enunciados de Kymlicka - que explican los principios e ideales del utilitarismo del siglo XIX como fundamento moral, ético y político-, con la visión desencantada que Baudrillard (1974) expresa en los años 70, acerca de los resultados que atribuye al diseño de los productos provenientes de la moral protestante.

...el status actual del objeto resulta precisamente del conflicto, o mejor dicho del compromiso entre dos morales adversas: de una moral aristocrática del "otium" y de una ética puritana del trabajo. En efecto, cuando la función de los objetos se transforma en su razón inmanente, se olvida en gran medida hasta qué punto este valor funcional está regido por una moral social que pretende 
que ni el objeto ni el individuo permanezcan ociosos. El objeto tiene el deber de "trabajar", de "funcionar", y por tal motivo, de disculparse, por así decirlo democráticamente, de su antigua condición aristocrática de signo puro de prestigio. Esta antigua condición, fundada en la ostentación y el gasto está siempre presente. Pero, claramente impresa en los efectos de moda y decoración, va a menudo acompañada por un discurso funcional que puede servir de coartada a la función distintiva ("individuos distinction") [... ...los objetos son pues el lugar, no de la satisfacción de necesidades, sino de un trabajo simbólico, de una "producción" en el doble sentido del término: "pro-ducere", — se los fabrica, pero se los exhibe también como prueba. Son el lugar de la consagración de un esfuerzo, de un cumplimiento ininterrumpido, de un "stress for achievement", cuyo objetivo es hacer la prueba continua y tangible del valor social. Una suerte de "Bewährung" secular, de prueba, de prestación, heredera, bajo conductas inversas, de los mismos principios morales que fueron los de la ética protestante, $y$, según Weber, del espíritu capitalista de producción, la moral del consumo reemplaza la de la producción o se mezcla con ella en una misma lógica social de la salvación. [La cursiva es del autor] (Baudrillard, 1974, pp. 40 y 42)

En rigor, este enfoque concentrado sólo en la ética puritana, si bien coadyuvante, es unilateral y limitado; en todo caso, la ética puritana configura un factor condicionante entre muchos otros. Como hemos visto anteriormente, el acento en las cuestiones operativas, el ascetismo formal y expresivo de los productos denominados 'funcionales' tuvo otras influencias posibles, proveniente de varias fuentes. Entre estas fuentes se cuentan: el utilitarismo promotor de soluciones impersonales, como lo concibe Nagel; los remanentes pitagóricos; el constructivismo ruso; el neoplasticismo que buscaba la expresión 0; y las propias influencias del ascetismo de origen oriental, del primer Bauhaus. Una muestra de este ascetismo de origen oriental, lo describía Oskar Schlemmer (1928/1987), en su libro: ESCRITOS SOBRE ARTE: pintura, teatro, danza, cartas y diarios, desde antes de llegar a dicha escuela: "Buda, ayuno, ascesis. Los pensamientos están absorbidos en la actitud, en la idea. Ahora ayuno. Cuando hago esto y aquello, lo hago al estilo budista, ascético, prudente" (Schlemmer, 1928/1987, p. 17).

\subsubsection{Estética}

En contraste con las críticas estéticas y tendencias formalistas provenientes del arte, en este apartado se exponen los aportes de la cuestión funcional, sus justificaciones y las fases concretas que dieron luz a cada una de ellas, al interior de estas instituciones. En el caso específico de la primera Escuela de Chicago, se puede hablar de tres momentos.

El primero: el único Sullivan, autor del pensamiento orgánico, que con su visión romántica desarrolló un lenguaje arquitectónico superador de los estilos del pasado, a partir de una nueva relación que debían guardar las formas con sus funciones, y logrando que, sin negar el ornamento, éste fluyera desde el interior hacia el exterior. El Wanwright Building, de 1891, y el Guarantee Building, de 1894, que diseñó junto a Dankmar Adler, entre otros, son ejemplos de ello. 
El segundo: a Sullivan, se le debe también la superación del paradigma de la casa como caja - que más tarde lo retomaría y desarrollaría, amplia y oficialmente, su discípulo Frank Lloyd Wright-. Esta superación fue posible, gracias a los avances tecnológicos con el acero, que les permitió diseñar y construir edificios más livianos. Estas nuevas construcciones, se caracterizaron por poseer centros o núcleos mucho más robustos, que permitieron dar paso no solo a una intensificación de la iluminación natural - gracias a la integración de ventanales mucho más grandes-, sino también a la elevación de la altura con el aumento del número de plantas habituales; de allí que se le conozca a Sullivan como el 'padre de los rascacielos'. Véase el Carson Pirie Scott de 1904, como uno de sus tantos ejemplos.

El tercero: la Primera Escuela de Chicago fue también responsable de las innovaciones estéticas de Wright. La implementación de núcleos de acero en las casas y edificios que diseñara este arquitecto americano, a finales del siglo XIX, y principios del XX, daría paso a la geometrización más pura de cada una de sus formas. Los voladizos comenzaron a hacerse presentes cada vez más - haciendo una apología al rectángulo volumétrico que descansa entre cada planta-, y paredes mucho más livianas, que más que dividir, dan cuenta de la analogía comunicativa entre el hombre y su ambiente. Si bien, los techos de cuatro aguas fueron parte de las primeras creaciones de Wright, se suele creer, erróneamente, que su transición hacia el uso de techos planos, se debe a influencias alemanas, japonesas u orientales, creencia que el arquitecto americano, en su texto Testamento, niega con puntualidad.

Para abreviar toda ambigüedad: nunca hubo influencia exterior en mi trabajo, ni extranjera, ni nativa, más que la de Lieber Meister, Dankmar Adler y John Roebling, Whitman y Emerson, y los grandes poetas mundiales. Mi obra es original, no sólo en el hecho sino en la fibra espiritual. Hasta este día ninguna práctica, de ningún europeo ha influido la mía en lo más mínimo. En cuanto a los Incas, los Mayas, aún los japoneses, sólo fueron para mí, todos, una espléndida confirmación. (Wright, 1957/1961, p. 182)

Tanto en Sullivan, como en Wright, la funcionalidad determinó las formas resultantes de los contextos climáticos y los requerimientos de habitabilidad, que debían poner al hombre en diálogo con su entorno.

Por otro lado, en relación a la Bauhaus y todos sus aportes, se le deben añadir las observaciones del fundador de la HfG de Ulm, Otl Aicher (1991), trazadas en su texto El mundo como Proyecto. La racionalidad practicada en la Bauhaus, sostiene Aicher, responsable de las formas puras, estuvo sopesada más en la predilección por un lenguaje geométrico-proveniente del arte cubista-, que en una verdadera sistematización de los factores humanos.

En la Bauhaus prevalecía el lenguaje geométrico derivado del arte, de ahí que influyera en el art decó más que la moderna producción industrial. La Bauhaus se asentó más en los museos que en la técnica y la economía actuales. Los principios del diseño geométrico quizá puedan aplicarse todavía a los muebles o a la tipografía, pero ya en los asientos estos postulados formales resultan peligrosos, sobre todo en los automóviles, máquinas o aparatos. (Aicher, 1991/1994, p. 85) 
Este argumento es compatible con la crítica que establece, no solo Carmagnola, sino también Herwin Schaefer (1970) en esta tesis, en el subcapítulo 4.6. La atemporalidad de la tradición funcional. De todas formas, esta misma predilección por las formas geométricas - con el círculo, el triángulo y el cuadrado-, en el Bauhaus no fue tan radical como Aicher, Schaefer y Carmagnola señalan. Y aunque el mobiliario diseñado por Gropius tendía hacia la geometría, los asientos eran mullidos y cómodos, como demuestran las sillas diseñadas por él que reposan en el museo del Bauhaus en Dessau. También es relevante clarificar que fue Kandinski, con su orientación espiritualista, el responsable de articular la nomenclatura cromática junto a estas formas geométricas, es decir, el cuadrado/cubo con el rojo, el triángulo/pirámide con el amarillo y el círculo/ esfera con el azul (Noack, 1978).

Para sintetizar, se podría hablar entonces de tres etapas del Bauhaus, en términos de sus aportes plásticos conectados o no con la funcionalidad. La primera, una época romántica, orgánica y expresionista, en la que la apariencia de las formas se debatió en torno al consenso entre el arte y la artesanía. Una segunda fase, la del primer intento de racionalización de las necesidades humanas, donde la predilección por las formas geométricas emerge, inicialmente, como la excusa del lenguaje que daría vida más tarde, a través de la tipificación y la estandarización, al estilo funcional. Y una tercera Bauhaus, donde la excusa por la geometrización es auténticamente desplazada por una metodología racional, que sistematiza cada aspecto en función de los requerimientos humanos y los de producción.

En Ulm, Max Bill (1949-1958), propone la sistematización del concepto de belleza, como un factor, entre tantos, que debe ser tomado en cuenta en los cálculos racionales, desde los que se proyectan las formas de los productos. Esta misma concepción dio nacimiento a la Gute Form, que más tarde, a través de Hans Gugelot y Dieter Rams, vendría a derivar en el estilo Braun.

En síntesis, si bien las apropiaciones estéticas diferenciales del término funcionalismo -en el marco de estas tres disciplinas-, son amplios y diversificados, los aspectos comunes se resumen en factores cromáticos, constructivos, estéticos y comunicativos. El inventario de los principales recursos estéticos utilizados en el diseño de productos es: el elementarismo; formas geometrizadas y facetadas; construcciones modulares; uso de materiales nobles y al natural; ausencia de símbolos u ornamentos; acabados superficiales no estridentes; pasajes formales suaves; cuidada comunicación de las normas de uso y displays; exhibición de la estructura en el mobiliario. En la arquitectura: planimetría, interpenetración de planos y espacios; horizontalidad en las propuestas espaciales; voladizos; amplio uso del vidrio para favorecer el paso de la luz natural; estandarización de aberturas y componentes internos; muebles empotrados; muros limpios; techados planos. El uso de los colores primarios o en su defecto el color blanco, como símbolo de la pureza y la sinceridad neutra que debían reflejar también las formas, se reflejó en el diseño y la construcción de edificios — en la vida media y hacia el final del Bauhaus-, entre Dessau y Berlín. En el diseño gráfico: se destaca el uso de los colores primarios, las dualidades entre el positivo y el negativo; el comunicar más con la mínima cantidad de elementos que conducen a la pregnancia; el uso de las leyes de la Gestalt; el desarrollo de íconos basados en matrices análogas cuadrangulares, que dictaminarían más tarde el pi- 
xel en entornos digitales; las tipografías racionales pertenecientes a las familias sans serif (palo seco) grotescas y neogrotescas devenidas de Suiza, Alemania, Inglaterra y Estados Unidos. Todos estos aportes se reflejarían en los sistemas de orientación, información y persuasión desde los que el diseño gráfico, o para la comunicación visual, opera.

\section{Corroboración de hipótesis}

Se plantean hipótesis teórico-interpretativas de carácter histórico — referidas a acontecimientos y sus elucidaciones teóricas - e historiográfico - referidas prioritariamente a conceptualizaciones de carácter temporal de la Historia Conceptual-. En tanto lo que se comparan son conceptualizaciones entre sí, las evidencias muestran que las hipótesis enunciadas son asertivas y razonables.

\section{Hipótesis sustantiva}

- El concepto de funcionalismo sufre constantes mutaciones interpretativas y desfases temporales sincrónicos, al interior de las escuelas, las disciplinas proyectuales y la crítica. Lo que otorga unidad a estas discontinuidades es su vinculación con la relación forma-función, cuya regularidad se manifiesta diacrónicamente con carácter estructural en el tiempo.

Desde una perspectiva historiográfica, los conceptos citados de función, funcionalidad y funcionalismo, migran de significados constantemente; entre estos, se seleccionan y documentan aquellos que se consideran fundamentales y decisivos para una historia conceptual. Lo que otorga unidad y consistencia en el tiempo a esta historia, es la relación 'forma-función, que provee las condiciones previas para el desarrollo de las distintas conceptualizaciones, y se repite en forma constante en cada una de ellas, de modo estructural. Este eje diacrónico liga permanentemente todas las divergencias sobre el modo de concebir la funcionalidad, y posibilita la emergencia del concepto de funcionalismo hacia la década de 1940, cumpliendo una regla expresada por la Historia Conceptual. En palabras de Koselleck:

Puede que se acuñe un concepto nuevo que plasme en palabras experiencias o expectativas antes inexistentes. Pero no puede ser tan nuevo como para no estar ya virtualmente presente en el lenguaje dado y no recibir su sentido del contenido lingüístico del que es heredero. (Koselleck, 2006, p. 20)

En este caso, es claramente visible a lo largo de su historia, que el funcionalismo estaba virtualmente presente y recibe su sentido de las relaciones entre los conceptos de forma, función y funcionalidad. Los gráficos que se muestran al final de los capítulos tres y cuatro, también permitirán contrastar las conceptualizaciones de las fuentes primarias con las secundarias. 


\section{Hipótesis secundaria 1}

- El concepto de funcionalismo debe su densidad histórica y semántica, a que operó como registro de experiencias de diseño funcional del pasado; a su vez, representó variadas expectativas a futuro, en cuanto a fomentar cambios sociales para la equiparación de oportunidades de uso, hábitat y nuevas formas de comunicar.

El concepto funcionalismo debe su densidad histórica e historiográfica a que se constituyó en indicador de movimiento histórico, como concepto de registro de experiencias del pasado y como concepto de expectativas a futuro. Estos últimos, son aquellos conceptos que se separan completamente del contexto del surgimiento y se enriquecen con elementos utópicos (Koselleck, 2006, p. 36). Esto se verifica del siguiente modo:

Por un lado, el concepto de funcionalismo incorporó el registro de un conjunto de experiencias de diseño desde la antigüedad, ligadas a la adecuación de la forma a la función, que, en la gran tradición funcional, De Zurco remonta a los griegos y se extiende hasta bien entrado el siglo XX. Por otro, en la relación forma-función - desde el enunciado de la emblemática frase de Sullivan, hasta el concepto de funcionalismo a partir de la HfG Ulm-, se representaron variadas expectativas a futuro. Dichas expectativas ocasionaron rupturas con la repetición de los estilos del pasado y la alienación del ejercicio proyectual, sometido a las demandas de las modas del mercado. A estas expectativas, se sumaron los cambios sociales para la equiparación de oportunidades de acceso a bienes necesarios, y cambios revolucionarios en la forma de comunicar y habitar. El cumplimiento de estas expectativas o la vivencia de su fracaso, es lo que explica los profundos debates posteriores al cierre de la HfG Ulm, consignados en el cap. 4, en las opiniones de Moles y Baudrillard, en los apartados 4.2 y 4.3 , respectivamente.

\section{Hipótesis secundaria 2}

- El funcionalismo es un concepto fundamental en la historia de las disciplinas proyectuales por haberse constituido como matriz disciplinar - al modo que lo entiende Thomas Kuhnen la teoría, la pedagogía y la práctica proyectual, a partir de los aportes de las tres escuelas y la crítica posterior a ellas.

Aunque el funcionalismo se debatió bajo este nombre, recién a principios de 1940 —en el campo del Diseño y la Arquitectura-, lo que se ha logrado identificar, a la distancia, son una serie de rasgos teóricos, formales y metodológicos comunes, que fueron agrupados bajo una tendencia, corriente o filosofía. Esto, dicho en el lenguaje de Thomas Kuhn (2004, epílogo de 1962), constituyó más una matriz disciplinar que un paradigma. Gracias a las fuentes primarias se develaron las diferencias, tanto estéticas como políticas, que relacionaron al concepto de función y de funcionalidad a partir de 1900. Pero es desde la perspectiva de las fuentes secundarias, que esta matriz disciplinar se visibiliza y se muestra en toda su claridad, junto con los factores que entrecruzaron lo ético, lo estético y lo epistemológico; Dicho en el lenguaje de Kuhn, fueron concebidos como modelos teóricos y metodológicos ejemplares. Basta recorrer los textos de Hannes Meyer, El nuevo mundo (1926), de Tomás Maldonado en Vanguardia y racionalidad (1974) y Gui Bonsiepe, Teoría y práctica del diseño industrial (1975), como una mínima muestra de la base teórica disciplinar que 
reflexiona sobre la cuestión funcional. Con ellos se formaron y ejercitaron estudiantes de diseño y arquitectura a lo largo y ancho del mundo, aún con sus debates, conformando lo que Kuhn llamaría una verdadera comunidad de proyectistas que, en algunos casos, continúa hasta hoy. En palabras de Maldonado: "Desarrollamos en nuestros alumnos el hábito de pensar con método, tanto desde el punto de vista de su formación, verdadera y propia, como desde el punto de vista de su responsabilidad social" [la cursiva es del autor] (Maldonado, 1963, p. 30) ${ }^{86}$.

Esta matriz disciplinar tiene, - como todas-, sus momentos de auge y decadencia. En principio, en Europa se difunde mayoritariamente a partir de la década de 1920, con los aportes de Vhkutemas y Bauhaus; también de Loos y Le Corbusier, entre otros (vistos en el capítulo 3). Hacia la posguerra, el diseño industrial italiano traza una línea de fuga con el diseño de la Vespa, de Fiat y de Olivetti, ampliándose al campo de la seducción y lo sensual, sin abandonar lo funcional. A partir de los 50 también comienzan a difundirse en el centro de Europa las obras de Alvar Aalto y las piezas del diseño escandinavo, como otra forma de resolver la funcionalidad a partir de la analogía orgánica.

De esto se concluye, que, el tramo cronológico trazado entre los años veinte y los sesenta, emerge como la etapa de mayor desarrollo del paradigma o la matriz disciplinar funcionalista; en ese lapso fue hegemónica, pero siempre en convivencia con otros modelos menos dominantes. Hacia los 80 se generalizan los cuestionamientos a los principios ulmianos y al Estilo Internacional, al tiempo que surgen nuevas corrientes de diseño que se desvían por completo de ellos, asociadas al imaginario de la posmodernidad. Esto no significa en absoluto el abandono del funcionalismo como matriz disciplinar, sino que comienza a convivir en situación de paridad con otras propuestas. Esto se sostuvo al punto que sigue siendo de rigor en muchas escuelas de Diseño y Arquitectura, fomentar en los primeros años las metodologías de base funcionalista, para luego ampliar el recorrido por otras perspectivas (ver ampliación en el capítulo 5).

\section{Hipótesis secundaria 3}

- El concepto de funcionalismo es una construcción de la crítica, o-dicho de otro modo-, debe su emergencia a partir de la crítica post Bauhaus, lo que evidencia desde el inicio su carácter controversial.

Bürdek (1991/2002), analizado en el apartado 4.4, plantea una controversia fundamentada en -lo que es para él- un evidente malentendido de los presupuestos de Sullivan. Según Wend Fischer (1971), citado por Bürdek, la idea de 'función' de Sullivan, aspiró a una concordancia entre la vida y la forma, y para lograr alcanzarla, los edificios debían poseer en su expresión una dimensión práctica y una dimensión semiótica. Sin embargo, esta idea de la función se interpretó solamente en lo práctico o técnico (manejo, ergonomía, construcción, ejecución), mientras que las funciones de los signos o las funciones comunicativas, continuaron siendo un tabú.

De lo relevado en esta investigación, se desprende que las funciones - tanto la comunicativa como la simbólica-, sí estaban presentes en las conceptualizaciones de Gropius desde 1914. Lo que se pierde en las dos escuelas europeas - Bauhaus y HfG_, no es el carácter comunicativo y simbólico, que Sullivan atribuía a sus edificios. De la consigna 'la forma 
sigue siempre a la función', lo que se pierde, es todo vínculo con las ciencias biológicas; si es que esa consigna cruzó el Atlántico e influenció a alguien, en ese cruce, la asociación con las ciencias biológicas se desvanece.

En las escuelas europeas, esa consigna se asocia con analogías lingüísticas, mecánicas o morales. Allí, las formas se ajustaron a una gramática específica, a analogías con la máquina o a las funciones operativas de los utensilios, herramientas, instrumentos, muebles y viviendas, entendidas como función social. Pero este planteo se hace sin perder conexión con el carácter comunicativo y simbólico de las formas resultantes, de las cuales, los diseñadores y arquitectos eran plenamente conscientes.

En cambio, el primer atisbo sobre el concepto de funcionalismo aparece en 1943 con el último Gropius, en una década posterior al cierre de la Bauhausy ya envuelto en la trama de la crítica. Gropius se muestra sorprendido por las acusaciones respecto de haber propiciado un estilo Bauhaus y un Estilo Internacional, y se defiende de ellas, acusando a su vez de actitud snob a los seguidores y replicadores de formalismos. No obstante, adopta una actitud dual frente al término, aceptándolo cuando se refiere a sus virtudes y desechándolo cuando se lo asocia a un estilo. Este origen muestra, desde el inicio, el carácter controversial del concepto. Luego, se adopta con todos sus fundamentos racionales y formales en la HfG de Ulm, pero envuelto en nuevas disputas de carácter político (ver ampliación en Cap. 3, apartados 3.3, 3.4, y 3.5, y en los gráficos finales).

\section{Hipótesis secundaria 4}

- El concepto de funcionalismo a partir de HfG Ulm, debe su extensa difusión en la proyectualidad, a que se lo asoció a referentes políticos de contenido humanista, contestatario - respecto de las lógicas de mercado-, y socializador.

Aunque las interpretaciones sobre las distintas concepciones sociales de la función cambiaban constantemente, en la escuela HfG Ulm, las exigencias provenientes de los sistemas económicos fueron interpretadas siempre como coacciones. Esto fundamentó una actitud contestataria, radical y disidente, que le otorgó unidad y consistencia a la función social que, emanada de estas instituciones, se enfocó en la accesibilidad democrática de las viviendas, los artefactos y las formas de comunicar. Cuatro citas se traen a colación para evidenciar estos aspectos humanistas, socializantes - accesibles, aptos para todos-, asociados al concepto de funcionalismo:

Siempre he destacado que el otro aspecto, la satisfacción del alma humana, es tan importante como el aspecto material, y que la realización de una nueva visión espacial significa algo más que la economía estructural y la perfección funcional. (Gropius, 1943, p. 28)

Para realizarlo de modo que funcione correctamente - un recipiente, una silla, una casa- primero se debe estudiar su esencia; puesto que debe cumplir plenamente su cometido, es decir, debe realizar útilmente sus funciones, debe ser duradero, barato y «bonito». (Gropius, 1926, pp. 143-144) 
Es una opinión corriente, al menos en algunos sectores, que el diseñador industrial, el proyectista que trabaja para la producción en serie, solo tienen una función a cumplir: servir al programa de ventas de la gran industria y estimular el mecanismo de la competencia comercial [...] Se ha de propiciar la formación de un nuevo tipo de proyectista que, en las actuales y difíciles condiciones de la sociedad capitalista, sepa crear objetos concebidos al margen de cualquier oportunismo o profesionalismo. (Maldonado, 1977, p. 70)

El funcionalismo - tomado aquí como doctrina proyectual- contrasta con los intereses de las clases dominantes, porque insiste obstinadamente en la exigencia de las funciones, el ‘¿por qué?' del producto. Aquéllas, en cambio, están dispuestas a ofrecer buenos bocados a la furia de la innovación formal, en la medida en que ésta se declara antifuncionalista. (Bonsiepe, 1972, p. 42)

La primera cita de Gropius, expone su visión humanista; la segunda su interés por la calidad - tanto utilitaria como formal - y su bajo precio, a fin de que sea accesible para todos. Maldonado refiere a la formación de un nuevo tipo de proyectista frente a la sociedad, y Bonsiepe enfatiza el enfrentamiento y la actitud contestataria frente a las clases dominantes, que impulsan la innovación como motivación para el consumo (ver ampliación de estos contenidos en el capítulo 3).

\section{Hipótesis secundaria 5}

- Las tres escuelas, Chicago, Bauhaus y HfG Ulm, difieren en el encuadre epistemológico y político de la relación forma-función, pero coinciden en la ética del utilitarismo.

\section{En el plano epistemológico}

Las analogías biológicas, invocadas por Sullivan y Wright en la Primera Escuela de Chicago -que implementan figuras retóricas en su lenguaje, junto a la inspiración orgánica de la frase la forma sigue siempre a la función-, son deudoras de las ciencias biológicas y de la naturaleza, en especial con la teoría de la Selección Natural de Darwin. Este conocimiento basado en las semejanzas, propio de la pre-modernidad (Foucault, 2010), es el que sustentaba sus poéticas, sin desconocer los demás saberes de la época.

Las primeras etapas del Bauhaus se debatían entre principios teórico-estéticos, románticos y espiritualistas de distintos orígenes; con principios futuristas, cubistas, constructivistas y neoplasticistas. Recién en una segunda etapa se inicia un proceso racionalizador en los proyectos, compatible con una tékhné proyectual, dirigida al cumplimiento de las funciones con apoyo en los avances técnico-científicos ligados a la industrialización.

Es en HfG Ulm - con Tomás Maldonado-, que se busca trascender el saber de los oficios y aspirar a una episteme proyectual. Al partir de una tékhné proyectual, Maldonado inicia una búsqueda por racionalizar el proceso de diseño a través de una metodología rigurosa, basada en las funciones del producto o proyecto, y con apoyo en bases lógicas y físicomatemáticas (Maldonado, 1977) ${ }^{87}$. 


\section{En el plano político}

La Filosofía del Valor, de Sullivan, se insertaba en el pensamiento liberal de los Estados Unidos de América de su época, del que Wright era tanto seguidor como crítico; las crónicas de sus viajes a la URSS así lo demuestran (Ciucci y Fortuna, 1971). En tanto que en Bauhaus se debatían vertientes social-demócratas y comunistas, con principios que ora se acercaban al humanismo, ora al marxismo y al comunismo.

En Ulm, las corrientes no diferían en mucho lo expuesto en Bauhaus; solo se caracterizan por una mayor radicalización y compromiso en torno a los principios marxistas de la necesidad y la función social del diseño y la tecnología, lo que llevaba al debate sobre las categorías de valor de uso y valor de cambio. Maldonado siguió observando a la HfG Ulm en relación a la evolución de la URSS y a los países del este europeo, y en 1963, actualiza su definición de productivismo. De allí, que quite el contenido controvertido que lo rodeaba en la Vhkutemas (ver capítulo 3) y lo referencie a las exigencias de N. Khrushehev expresadas en 1954, de una mayor productividad en la construcción industrializada (Maldonado, 1977, p. 78).

\section{En el plano ético}

A pesar de las radicales diferencias epistemológicas y políticas expuestas con anterioridad, las tres escuelas comparten las bases éticas del utilitarismo, y los conceptos que involucra, obviamente combinado con otros ideales de la época. En palabras de Kymlicka, los utilitaristas opinan que:

...la acción correcta es aquella que incrementa al máximo la utilidad, aquella que satisface tantas preferencias informadas como sea posible. [...] Para el utilitarista, idénticas cantidades de utilidad tienen idéntica importancia, con independencia de la utilidad de quien se trate. Nadie se encuentra en una posición privilegiada. (Kymlicka, 1995, p. 32)

Los principios utilitaristas debían ser observados tanto a nivel individual como institucional, y así sucedió tanto con los profesores - excepto en los casos referidos al arte-, como con los directores de las escuelas. Para comprender esto, hay que remitirse a la historia de los ideales utilitaristas de principios del siglo XX en Inglaterra, que luego se difundieron a otros países, pero que hoy han perdido su carácter radical de antaño. Con un programa político progresista y reformista, buscaban la ampliación de la democracia, y las medidas relativas al bienestar y la igualdad generalizadas.

Este es el principal presupuesto ético que posibilitó el surgimiento y difusión del funcionalismo como doctrina, corriente o movimiento, tanto en Europa como en los Estados Unidos de América. En los casos de las escuelas europeas, a esta base ético-política, se le debe sumar la influencia de las ideas marxistas, sobre todo en relación a dos conceptos fundamentales. Primero, en la satisfacción de necesidades, proveniente de la teoría de las necesidades marxista. Y segundo, en la búsqueda de relaciones no alienadas, tanto entre el trabajador y la producción, como entre el usuario y el producto. Asimismo, a la inscripción del funcionalismo en la ética teleológica del utilitarismo, se le suma una vertiente deontológica en la Escuela de Ulm, que, en palabras de Maldonado, prescribe cuál debe ser el comportamiento moralmente correcto de un proyectista. 
Otros pensadores, como el sociólogo Baudrillard (1972, 1974), atribuyen a la ética protestante el principal factor de sustentación del funcionalismo. Si bien resultó un factor concurrente, esta opinión es relativizada al ser contrapuesta con otras filosofías y corrientes que también promovían el ascetismo formal y el trabajo común como valor supremo (ver ampliación de estos contenidos en el apartado 5.1.2).

\section{Hipótesis secundaria 6}

- El concepto de funcionalismo es atravesado por contiendas ético-políticas, libradas entre ideales, mayoritariamente socialdemócratas y marxistas.

En principio, la siguiente cita de Tomás Maldonado provee la mejor pista:

Meyer lleva al Bauhaus el espíritu de la revista Suiza $A B C$ - Beiträge zum Bauten (1924-1928), dirigida por H. Schmidt (1893-1972), R. Roth (1893) y M. Stam, y de cuya redacción era miembro desde 1925. ABC representaba el funcionalismo técnico-productivista, en contraste con el funcionalismo técnicoformalista, imperante en el Bauhaus después de 1923 [la cursiva es del autor]. (Maldonado, 1993, p. 59)

Si bien Maldonado es claro en conceptualizar las acepciones políticas del funcionalismo como representaciones, lo cierto es que al concepto funcionalismo se lo subjetiviza y se lo encuentra responsable de varios efectos indeseados. Se lo vuelve acreedor de sostenidas críticas, provenientes tanto desde la ideología de izquierda - post marxista-, como desde el humanismo y la socialdemocracia. Por izquierda, desde lo que Maldonado llama el funcionalismo técnico-productivista de raíz soviética, se acusa al funcionalismo técnicoformalista de conciliar con las metas de las empresas capitalistas, favoreciendo sus intereses al resolver las funciones utilitarias en un marco de estetización o embellecimiento de la obra o producto. En el mejor de los casos, calificará los intereses democratizadores y humanistas de fortalecer los negocios capitalistas (Bussiness), o de dejarse absorber por el establishment. Duro reproche que Maldonado hace a Max Bill: "El neocapitalismo alemán ha actuado en este caso con refinada astucia: ha cooptado la gute Form" (Maldonado, 1993, p. 68). Se acusa a la corriente técnico-formalista de no ser lo suficientemente firme en el rechazo de las fantasías y simbolismos que impregnan la subjetivación de los proyectos y facilitan la fetichización de las mercancías. En el lenguaje de T. Adorno, proceso exento de negatividad y resistencia a los intereses dominantes, por el cual, el valor de cambio, se convierte en el verdadero valor de uso del producto (Adorno, 1963/1966, p. 33). Lo que fortalece la economía de mercado y oculta la explotación, encubierta en el proceso productivo y las relaciones de producción capitalistas. Esta caracterización del funcionalismo técnicoformalista, se asimila a los ideales socialdemócratas presentes en varios protagonistas de la Bauhaus y de la propia HfG Ulm. Por añadidura, recibe también las críticas que se realizan a la socialdemocracia, sobre todo alemana, por su carácter político reformista - no revolucionario-, en todos los campos: productivos, comunicacionales y constructivos (Collotti, 1971). Asimismo, se acusa al funcionalismo técnico-formalista, de ser el causante del fracaso en revertir las lógicas de mercado capitalistas y, por consiguiente, de frustrar 
las expectativas que se depositaron en él. También es Tomás Maldonado quien mejor lo explicita: “... «modernismo de apariencias», con sus diversas variedades, a cuál más aberrante, vestigios sin gloria de un largo proceso que al principio parecía lleno de promesas” [La cursiva es del autor] (Maldonado, 1955, p. 66). Expresión que es muestra evidente de las expectativas - en este caso frustradas y lamentadas-, del autor.

Desde la visión contraria - un humanismo democratizante socialdemócrata como el que profesaban los actores acusados de técnico-formalismo-, se señala al funcionalismo técnico-productivista de privilegiar la función ingenieril y meramente utilitaria del producto o vivienda, y de alejarse de las verdaderas necesidades de los individuos - que incluyen la función estética y simbólica-. Se reprocha que esta visión promueva una relación estéril y mecanizada entre usuario y producto, tan alienada como en el sistema capitalista - pero de modo inverso-, al cercenar o reprimir las capacidades sensibles y de fruición de los usuarios. Se critica que la pretensión de evitar la economía de mercado por la vía de la negatividad es una mera ilusión, y que la consigna de la función social de viviendas o productos ha desmerecido la calidad estética y vital del entorno artificial. Asimismo, se cuestiona que en algunos lugares la metodología ulmiana se convirtiera en un canon autoritario, en tanto descalificaba y denostaba otros procesos creativos y estéticos (ver capítulos 4 y 5 ).

Ambas corrientes coinciden en visiones universalistas, pero sus presupuestos políticos y pedagógicos se basan en epistemologías diferentes. En el primer caso se trata de un funcionalismo débil - por así decirlo-, que parte de una visión de cuño antropológico y humanista, centrada en un 'sujeto', independiente en su autodeterminación, que se autorealiza, tanto en la concepción como en el uso de la obra. En el segundo caso, el funcionalismo técnico-productivista, propiciado por Maldonado, nos enfrenta a una perspectiva sin 'sujeto', de base marxista, que asienta sus principios en lógicas de clase y disputas de poder económicas, ideológicas y políticas, con la ayuda de las categorías de materialismo histórico y cultura material.

Desde una evaluación histórica actual, resulta sorprendente el enconado vigor con que en Ulm se luchaba contra la reificación del arte como ente propiciador de la fantasía del consumo (ya sea moderno, de lujo, de estatus, de libertad, etc.). Pero más sorprendente aun, es el carácter emancipador que atribuían a la tecnología. Desde su visión, la aplicación científico-técnica tenía el poder de contrarrestar estas fantasías consumistas y acallar el imaginario simbólico humano, sin advertir algo que ya tempranamente se insinuaba provocando el mismo efecto: el carácter fetichista de la tecnología.

Es inexplicable que no se haya advertido - de forma temprana-, que el proceso de fetichización en el consumo no se iba a acallar por ponerle una mordaza tecnológica y una consigna social, sino que iba a producirse un nuevo sustituto simbólico, en tanto las lógicas de mercado fagocitan todas las respuestas reactivas en su contra. (Verón, 1998). Esto no constituye una perspectiva desesperanzadora; antes bien las expectativas de cambios a futuro deben contar con estas experiencias transitadas, para que los proyectistas se encuentren mejor preparados.

A la fecha, entre los extremos de las dos corrientes nombradas se han producido multiplicidad de variantes, al punto que esta contraposición solo puede entenderse en su contexto histórico. No obstante, según cambian los contextos, se produce un movimiento pendular entre una u otra perspectiva. En tiempos de escasez — sea esta material o sanitaria—, o de 
catástrofes, se impone un funcionalismo rígido, mientras que luego, en tiempos o sociedades de abundancia, se disuelve nuevamente en infinitas variables.

\section{Conclusiones}

A partir de los cambios registrados en todas las áreas, podemos extraer las siguientes conclusiones:

- El concepto de funcionalismo no puede ser equiparado con un 'estilo'.

"Un estilo es la repetición sucesiva de una expresión ya establecida como denominador común para todo un período" (Gropius, 1943, p. 109).

Uno de los principales debates desde los principios del Bauhaus se focalizó en los conceptos de funcionalidad y estilo. Aunque Gropius arma con ellos una consigna: -estilo de la funcionalidad-, al correr de las escuelas, esta fórmula se mostró como un oxímoron, con sus términos operando en forma disyunta, conformando dos vías que se contradicen. En el último Bauhaus, y posterior a ella - sobre todo en Ulm, con sus metodologías disruptivas que apuntaban a un cambio epistemológico-, los estilos, entendidos como lo hace Gropius, resultaban una verdadera interferencia con dicho objetivo.

El funcionalismo también encarna los debates por el estilo, al considerar que, al cristalizarse en un mero formalismo, se perdería el carácter contestatario y revulsivo de su propuesta anti-mercado. Por otro lado, el concepto de funcionalismo no puede usarse como sinónimo unívoco de las formas divergentes de pensamiento y prácticas que emergieron de los conceptos: función, forma y funcionalidad. Las reflexiones sobre estos últimos tres conceptos en relación al debate por las formas que debían configurar el espacio artificial fueron previos al funcionalismo mismo, presentes en la Gran Tradición Funcional.

En vista que la concepción de estilo se mira en esta tesis desde un enfoque proyectual y no desde el arte, al funcionalismo, en lugar de un formalismo podría definírselo como un movimiento que goza de características adaptativas a los contextos que le son heterónomos a él. Como movimiento, parte de la Arquitectura y el Diseño, con un intento de fundamentación, biológica, lingüística o moral, y luego concretamente científica, con fines menos estéticos y más argumentativos.

Al funcionalismo, no puede considerársele de manera unívoca como un 'estilo'. Se podría decir que, en la historia del Diseño, han existido varios modelos de funcionalismo, y que aún en la actualidad se siguen ajustando para generar nuevas combinaciones metodológicas en las prácticas proyectuales. Si bien en esta tesis se descubre que porta rasgos epistemológicos y estéticos divergentes, lo que sí es común en él, es su finalidad ética utilitarista. Esta ética, se encuentra enfocada en el acceso y en cada una de las funcionalidades que portan los objetos, con el fin de hacer de este mundo un mejor lugar para vivir. En vista de que se encuentra vigente en los productos de Apple — como lo declara Bonsiepe (2016)—, 
es posible que se esté abriendo camino en las nuevas formas de proyectar que no se han documentado hasta ahora.

- El concepto de funcionalismo desarrolla una historia diferente en cada área proyectual. El derrotero que el concepto despliega en la historia de la Arquitectura no es el mismo que en el Diseño Industrial ni en el Diseño Gráfico y Comunicacional.

En esta investigación queda en evidencia que el funcionalismo, lejos de tener una historia unívoca, desarrolla cronologías diferentes según sean las ramas del saber proyectual al que se refiere. También cambian las cadenas de los principales referentes en relación a la tradición funcional, tanto personales como conceptuales.

Así, en forma general y sucinta, en la historia de la funcionalidad en la Arquitectura, luego de las grandes obras para estaciones, mercados y fábricas, es insoslayable pasar por Sullivan - que marca un hito histórico con su emblemática frase- y se continúa en las obras de Wright. Luego se pasa a revisar el papel de Loos; las ideas y obras de Ruskin; Morris y arquitectos en Inglaterra; las vanguardias europeas y rusas; los debates iniciales de la Werkbund; las obras alemanas y austríacas, para culminar con la escuela Bauhaus, Ulm y los CIAM. Gropius, Le Corbusier, Mies van der Rohe y Hannes Meyer son las principales figuras de este último recorrido.

En cambio, el diseño de productos, en líneas generales, ya sea semiartesanal o industrial, se inicia con la gran tradición funcional de los ingenieros y técnicos diseñadores de máquinas, transportes, mobiliario y utensilios en Europa y EUA, luego de la Revolución Industrial. Esta producción funcional de los siglos XVIII y XIX, que se apartaba de los cánones artísticos de la época, fue relevada por Erwin Schaefer (1970), Giedion (1978), y Adrian Forty (1986), entre otros. Luego se pasa a las obras de personalidades individuales, como Peter Behrens para la AEG; emprendimientos productivos - racionalizados y normalizados-, de equipamiento doméstico en Austria y Alemania; productos y mobiliario de W. Tatlin, Rodchenko, Malevich y otras obras de Vhkutemas. El funcionalismo comienza a registrarse directamente asociado a la escuela Bauhaus con Walter Gropius, Marcel Breuer, Mies van der Rohe y Hannes Meyer, pero, sobre todo, como paradigma consolidado en la escuela de Ulm. Allí convergen Max Bill, Tomás Maldonado, Otl Aicher, Gui Bonsiepe, Hans Gugelot, Dieter Rams, entre sus principales exponentes.

Por su parte, la vertiente funcional en Diseño Gráfico y Comunicacional parte de Bauhaus + Vhkutemas: Jan Tschichold con sus desarrollos en cartel y tipografía; Mondrian e Itten en color; Moholy-Nagy en fotografía; Rodchenko, Popova, Maiakovsky, Lissitzky y Herbert Bayer, entre otros, en semiótica y comunicación. En la HfG de Ulm, con los investigadores en las áreas de la comunicación visual y diseño de información, se destacaron los desarrollos en tipografía, semiótica, proyectación de íconos, afiches, cine y diseño básico constructivo, gracias a Otl Aicher, Anthony Froshaug, Tomás Gonda, Herbert Kapitzki, Friedrich Vordemberge-Gildewart, Tomás Maldonado, Gui Bonsiepe, Gert Kalow, Abraham Moles, Christian Staub, Alexander Kluge, Edgard Reitz, Bernhard Dörries y Detten Schleiermacher. En síntesis, mientras que desde 1880 a 1980, el funcionalismo en la Arquitectura elabora un arco histórico geográfico que va desde Chicago al Reino Unido, Europa y la URSS, en la historia del Diseño Industrial realiza un arco diacrónico mayor, que registra los anteceden- 
tes funcionales desde el siglo XVIII — tanto europeos como americanos-, hasta la década del 80 del siglo XX. El Diseño Gráfico y Comunicacional desarrolla su historia asociada a imperativos funcionales solo en el siglo XX, pero comparte la misma fecha de declinación. Esto explica por qué en el Diseño Industrial, Gráfico, o en el Comunicacional no registren a Sullivan y Wright entre sus máximos antecedentes históricos ligados a la funcionalidad. Menos aún, a la analogía biológica. En ambas orientaciones, se acusan preferentemente analogías lingüísticas, como: 'lenguaje visual', y 'gramática de la composición'.

No obstante, estas tres historias comparten objetivos comunes, siendo estos: la racionalidad en el proceso proyectual y productivo, la ausencia de ornamento, austeridad y geometrización en las formas, alejamiento del arte historicista, modernización técnica y científica y fundamentos ético-políticos (ver ampliación de estos contenidos en los desarrollos de los capítulos 3 y 4 ).

- La historia conceptual de la noción de funcionalismo en las escuelas estudiadas, migra de una argumentación poética y romántica - basada en analogías y metáforas-, hacia una argumentación de base científica y política.

La siguiente recopilación se realiza con el propio lenguaje de las fuentes (resaltadas en cursivas):

En primer lugar, con Sullivan, el concepto de función, adquiere un perfil poético de resabios románticos: los edificios como pantallas de una sociedad y el espíritu de una época, vinculado a una filosofía de la naturaleza moral, son argumentados con base en las analogías biológicas. La frase la forma sigue siempre a la función expresa un orden teleológico, creacionista y móvil de sucesión; posee dos aspectos distintivos de causalidad, ya que la finalidad o propósito, que es determinada por un contexto, se encuentra - al mismo tiempo-, motivada por una intención. La forma existe a causa (because) de la función (abstracción de las necesidades), que se materializa por un pensamiento creativo (proveniente de una entidad superior: La naturaleza y/o Dios); aspectos inseparables que, en Sullivan, exigen una compresión unitaria. De allí, se pasa a una función entendida de modo orgánico como poesía de la naturaleza, dicha con voz nativa, asociada al imaginario de la técnica en Wright. Con él se genera una transición, que parte de un orden de sucesión hacia uno de unidad y simultaneidad, donde la forma y la función son una. Todavía no se nombraba el concepto de funcionalismo, en los textos de los autores.

En un Gropius pre-Bauhaus, el concepto de función — sin referencias biológicas-, parte de una fundamentación espiritual, para buscar un estilo de la funcionalidad, que debía ser la expresión simbólica del movimiento moderno, basado en la unidad orgánica entre arte y técnica. Ya en Bauhaus, se pasa a una visión esencialista de la función, que incorpora los aportes científicos y estéticos, para lograr una gramática del diseño y la composición. En un proceso racional, se busca lograr tipos 'estándar' que cubran las necesidades sociales, que son consideradas iguales en lo esencial. Este procedimiento no es considerado formalista ni funcionalista por Gropius.

En la HfG Ulm, con Max Bill, se parte de una visión multifacética y exacta del estudio de la función, asociado a la belleza, en una unidad concebida como Gestalt. Con Tomás 
Maldonado, se pasa a una Función Social Proyectual, entendida en su doble faz: como analogía moral y como metodología centrada en la resolución de funciones esencialmente técnicas y comunicativas, destinadas a cubrir necesidades operativas específicas. De este modo, la función termina siendo inscripta en un método científico. El funcionalismo no es reconocido como tal mientras signifique un mero formalismo, pero sí se lo reconoce si éste representa el centro de las problemáticas proyectuales.

Aunque el concepto funcionalismo es siempre deudor de la ética del utilitarismo, políticamente, es parte de las polémicas entre ideales liberales, socialdemócratas y marxistas. Históricamente, el concepto surge así, atravesado por estas controversias, y este carácter controversial le da vida y sustento. El sufijo 'ismo', según Max. Bill, aparece como insignia y sinónimo de progresividad, pero debe evitarse su uso como el sufijo de cualquier etiqueta que conduzca a la replicabilidad de la forma.

Recién ahora se puede apreciar en su verdadera magnitud que el concepto de funcionalismo es testigo privilegiado de profundos cambios en el conocimiento; en la medida que su historia, a partir del siglo XIX, es correlativa a la transición que se produce en el saber, cuando las Ciencias Sociales se desprenden de las Ciencias Naturales. En el cambio del siglo XIX al XX, con el impulso de las Ciencias Sociales dado por Émile Durkheim, Max Weber, John Stuart Mill y otros, hay un giro importante en la constitución del saber, y se ponen en crisis las explicaciones de las sociedades y de las culturas, que estén dadas en términos biológicos. Así, en el concepto de funcionalismo opera un doble quiebre entre dos formas de constituir el saber. Por un lado, entre las Ciencias Naturales y las Ciencias Sociales. Por otro, entre el saber pre-científico de las analogías y las creencias, y el conocimiento científico de las Ciencias Físico-Matemáticas. En términos de Maldonado, Ulm, realizó este giro esencialmente de la mano del Círculo de Viena, sobre todo a partir del positivismo lógico de Carnap, Schlick y Neurath; de la semiótica de Peirce; la nueva retórica de Perelman y Olbretchs-Tyteca; el pragmatismo de James y de Dewey, y la lingüística general de Saussure, entre otros (Tomas Maldonado, 1977, pp. 86-87).

En síntesis, tanto en la escuela de Chicago como en Bauhaus, el concepto de función nace envuelto en una trama poética y romántica, ligada al mundo de la biología —en el primer caso-, y del espíritu moderno - en el segundo-. De los resabios románticos se despega cuando es asociado a la racionalidad proyectual, a una política social, a la Gestalt y, finalmente, al positivismo del mundo técnico-científico, de donde emerge el concepto de funcionalismo.

\section{Notas}

1. El concepto de 'experiencia' debe entenderse en un sentido ontológico, en tanto se inscribe en la tradición hermenéutica alemana, diferente del arraigo 'experimental' que conlleva su asociación a las prácticas científicas en el positivismo anglosajón.

2. A diferencia de Collins, De Zurko no implementa las palabras: 'idea de' o 'término' muy común en Collins. En su lugar, De Zurko usa la palabra 'concepto'.

3. Gropius usa el concepto de 'realidad' como sinónimo de 'contexto de exigencia'. 
4. Se elaboró una revisión de los textos de Sullivan en sus versiones originales en inglés: The Kindergarten Chats and other writings (1918) y en The Autobiography of an Idea (1922), correspondientes en su mismo orden, en sus versiones en español: Charlas con un Arquitecto (The Kindergarten Chats y otros escritos) (1957) y Autobiografía de una Idea (1961), para verificar que los conceptos asociados al objeto de estudio de esta tesis, al ser traducidos al español, no presentaran deslizamientos o incoherencias semánticas y también para correlacionar la contemporaneidad cronológica con otros textos de autores con los que se conectan o distancian. De allí, que se implemente la nomenclatura Sullivan (1918/1957) y Sullivan (1922/1961).

5. En razón de todas las referencias que se presentan durante el diálogo entre las partes, la relación humana tan cercana que se recrea, los detalles cronológicos, materiales y las expresiones contrastantes que los caracterizan, se podría llegar a afirmar que el maestro y su aprendiz, corresponden a Sullivan y Wright.

6. Sullivan usa los términos en par: 'diseñar' y 'construir', en vez de 'proyectar'. Esto, debido a que el término proyectar lo vincula al ademán del 'habla' a través de las imágenes que el edificio encarna, cuando funciona como 'pantalla'; como sinónimo de 'reflejar,' 'hablar' o 'comunicar'. Es decir, cuando el edificio nos 'dice' a través de su aspecto, la civilización, el tiempo y la cultura a los que pertenece.

7. Aquí se advierte, en Sullivan, un matiz de la analogía moral.

8. No en el sentido de la accesibilidad política o a la accesibilidad de la vivienda, sino en la habilidad de anticipar en las futuras formas de un edificio, las imágenes correspondientes a los valores, costumbres, hábitos y esencia del ser cultural, de las masas que conforman una sociedad.

9. Sullivan implementa el concepto 'significación' para simbolizar lo que el arquitecto busca imbuir y reflejar en los edificios, a partir de los aspectos semánticos de la verdad que portan, gracias a las imágenes que lo configuran y lo distinguen de los demás.

10. Sullivan no usa la expresión marxista 'valor de cambio.' En cambio, implementa 'valor monetario' o 'valor dólar.'

11. Referido a los edificios.

12. Como la acumulación primaria del conocimiento.

13. Sullivan usa la expresión 'feudalismo' para referirse, en términos económicos, al modelo hegemónico de la época en la que pensaba estaba inscrito.

14. Sullivan se refiere a la mente y a las emociones del hombre.

15. Referido a sus alcances estéticos.

16. Expresión en alemán usada por Wright para referirse a su maestro: Louis Henri Sullivan.

17. Si bien esta Filosofía del Carácter Orgánico aparecería como una expresión homologable a la Filosofía de la Naturaleza Moral, de Sullivan, que otorga al arquitecto la capacidad de abstraer el espíritu de un pueblo, se debe analizar si existen o no similitudes y/o diferencias, o en su defecto, puntos liminares o de lejanía entre las dos expresiones.

18. Wright implementa la palabra concept, en la versión original en inglés de sus textos The Future of Architecture (1953), y A Testament (1957), cuando los asocia a sus ideas. Si bien la base de las citas corresponde a las versiones traducidas al español, en su mismo orden, Testamento (1961) y El Futuro de la Arquitectura (1978), se tuvo que hacer un rastreo de 
los conceptos asociados a sus significados desde la lengua original para corroborar que 'concept', se traduce a 'concepto' en español. Ello, debido a que el traductor en ocasiones usa de manera imprecisa las palabras concepto y término para la misma designación.

19. En el mismo orden: a la repetición del estilo clásico griego y románico, y la influencia de la École National des Beaux Arts.

20. American Institute of Architects. Con una ausencia evidente de concordancia entre el lugar y las necesidades de los americanos, el enfoque dogmático del A.I.A., presente en la práctica arquitectónica en Estados Unidos señalada por Wright, representó para él una abominación continua e influyente.

21.

22. Se refiere a las exigencias del entorno y a los contextos diversificados.

23. Si bien Wright, en su rol como arquitecto, diseñó edificios, dentro de su creación artefactual también diseñó objetos, específicamente de tipo mobiliario.

24. En el sentido de lo originado en América, el origen, lo autóctono, es decir todo lo opuesto a lo importado de otros lugares.

25. Como Wright específicamente lo describe, la vida del estilo es completamente fresca y genérica; es decir, se actualiza según los requerimientos que el hombre le exija a la arquitectura misma.

26. Cabe recordar que ya existía una práctica precedente de la arquitectura orgánica, que consistía en edificar de adentro hacia fuera, tal como crecen los organismos; Wright le debe parte de las bases de su teoría a Sullivan y Adler. Sin embargo, a propuesta de Wright era mucho más avanzada que la de sus maestros.

27. En el sentido de expresión de la individualidad y las necesidades de cada ciudadano. 28. La edición original en inglés del texto de Wright: MODERN ARCHITECTURE, fue publicada en 1931. La edición correspondiente a su traducción al español implementada aquí es del 2010.

29. Se tuvo que remitir nuevamente a las versiones en inglés de los textos, debido a un error en la traducción del concepto. En el caso del libro A Testament (1957), en su versión en español Testamento (1961), el concepto devenido de tensión que da lugar a la tensidad, proviene del concepto en inglés 'tenuity', que se refiere a la resistencia a la tracción donde su traducción es fidedigna. En cambio, en el libro The Future of Architecture (1953), traducida al español como obra póstuma a Wright: El Futuro de la Arquitectura (1978), se presenta un error de traducción en el mismo concepto. En vez de 'tensidad', el traductor lo migró como 'tenacidad', que desvía completamente el sentido proveniente de su significación original.

30. Wright se refería específicamente a una especie de pino, dado que, en muchas de sus especies, sus ramas poseen trayectorias horizontales, similares a los voladizos diseñados por él.

31. También llamada por Wright calefacción por gravedad. Se refiere a una serie de tuberías que corrían por los pisos de los edificios diseñados por Wright, donde el agua caliente circulaba por toda el área. De esa manera en invierno se mantenía la temperatura ideal, porque según Wright, mientras los pies se mantengan tibios, el cuerpo no sentirá frío.

32. Wright usa el concepto de 'contener' en el sentido de 'apresar', 'encerrar'; luego le otorga el sentido de 'replicar'. 
33. Gropius desde el principio expresó que en la Bauhaus no habría profesores y alumnos, sino maestros y aprendices.

34. Equivale a Señor Director.

35. En su versión en español se halla en Conrads, U. (1973) Programas y Manifiestos de la Arquitectura del Siglo XX. Barcelona: Editorial Lumen. En su versión original en alemán. Conrads, U.(1964) PROGRAMME UND MANIFESTE ZUR ARCHITEKTUR DES 20. JAHRHUNDERTS. Berlin /Frankfurt: Verlag Ullstein GmbH.

36. Título original en alemán: Der stilbildende Wert industrieller Bauformen.

37. En su versión en español: La contribución de las Estructuras Industriales para la formación de un nuevo Estilo, en Maldonado, T. 1979. Técnica y Cultura.

38. Hasta aquí, para Gropius las formas orgánicas son aquellas que surgen en coherencia con el ideal espiritual de una época, como indicios de una unitaria voluntad de cultura, que constituye el valor determinante de la obra de arte. Y que este valor trasciende en la materialidad de un estilo, debido a que refleja el ideal de muchos en una sola expresión.

39. En su versión en español se halla en Conrads, U. (1973). Programas y Manifiestos de la Arquitectura del Siglo XX. Barcelona: Editorial Lumen. En su versión original en alemán. Conrads, U.(1964) PROGRAMME UND MANIFESTE ZUR ARCHITEKTUR DES 20. JAHRHUNDERTS. Berlin /Frankfurt: Verlag Ullstein GmbH.

40. Denominadas en alemán como: Vereinigten ehemals Grossherzoglichen Schulen für Bildende Kunst und Kunstgewerbe.

41. Gropius, en ocasiones, no es preciso con respecto al tiempo. Es decir, habla de décadas anteriores, pero no especifica un tramo temporal especial o particular.

42. En su versión en español se halla en Conrads, U. (1973). Programas y Manifiestos de la Arquitectura del Siglo XX. Barcelona: Editorial Lumen. En su versión original en alemán. Conrads, U. (1964) PROGRAMME UND MANIFESTE ZUR ARCHITEKTUR DES 20. JAHRHUNDERTS. Berlin /Frankfurt: Verlag Ullstein GmbH.

43. Aquí Gropius, cuando usa el término 'campos', se refiere a áreas de estudio.

44. Gropius no especifica la constante de tiempo y su referente, que podría determinar la durabilidad del objeto.

45. Gropius tampoco especifica o profundiza sobre qué lineamientos estéticos estará configurado el objeto para determinar si es bello o no.

46. Se refiere a la ornamentación innecesaria.

47. La versión original en inglés de este texto, bajo el título Scope of Total Architecture, corresponde al año de 1943. Su versión en español: Alcances de la Arquitectura Integral corresponde al año de 1956 en su primera edición, y a 1959 en su tercera edición. Esta última fue la que empleamos. No obstante, se verifican la migración de los conceptos desde la publicación originaria, con el objeto de asegurar una correcta traducción de ellos. 48. Aquí Gropius se refiere al Bauhaus, no como escuela o instituto, sino como un movimiento en formación.

49.

50. Aristóteles. Poética. Trad. Eduardo Sinnot (2004). Argentina: Colihue Clásica.

51. Aspecto que influenciará a otros, y que más tarde evolucionará como el concepto Ulm.

52. Conocido también como La Rosa Blanca o 'The White Rose'.

53. HfG-Archiv Museum, HISTORY «... let's start, here in Ulm» 
Recuperado el 8 de abril de 2020 de: https://hfg-archiv.museumulm.de/en/the-hfg-ulm/ history/2/

54. Maldonado usa los conceptos 'Diseñador Industrial' y 'Proyectista', como si fueran sinónimos.

55. Por primera vez en este texto, Maldonado implementa el uso de 'término' en lugar de concepto.

56. Referido a la época en la que Konrad Adenauer, Canciller y Ministro de Asuntos Exteriores de la República Federal alemana, trabajó por restaurar la economía alemana gracias a los vínculos que edificó a partir de sus gestiones diplomáticas con Francia, la Unión Soviética y los Estados Unidos. De allí que Maldonado, asociara la época Adenauer con el ascenso del neocapitalismo alemán.

57. HfG Archiv Ulm Museum, BUILDING. Recuperado el 8 de abril de 2020 de: https:// hfg-archiv.museumulm.de/en/the-hfg-ulm/building/3/

58. Expresión que sabemos fue un concepto originario del Bauhaus, pero ampliado en términos metodológicos en la HfG.

59. Die welt als entwurf, en su edición original en alemán de 1991. La traducción al español que se implementa aquí es de 1994.

60. Max Bill usa las palabras: 'concepto' o 'término', como sinónimos.

61. Traducidos por el autor de esta investigación.

62. Entrevista a Max Bill por Juan Manuel Bonet (1980). Recuperado el 8 de noviembre de 2018. De: https://elpais.com/diario/1980/01/31/cultura/318121207_850215.html

63. En sus primeros textos, Maldonado, al referirse a la HfG, lo hace con el término de 'escuela'. En otros textos usa el término 'instituto'. Bonsiepe utiliza indistintamente los dos términos.

64. Betts, M. (2016). Entrevista a Gui Bonsiepe. Funcionalismo. Entrevistador Mark Michael Betts Alvear Copyright (C) Gui Bonsiepe 2016. P. 5. Párrafos: 2, 3 y 4.

65. La concepción de 'función' en Max Bill, presentó varios cambios. Recordemos que inicialmente Bill sostiene que la belleza, al 'funcionar de manera paralela' a las 'funciones técnicas', debe ser desplazada por la 'armonía' de las 'funciones' que se conjuga en la Gestalt, y luego, esta misma definición debe ser superada por una visión causal y matemática de la función. Esto se refleja en sus escritos y publicaciones de 1949 a 1979.

66. Aclaración: Moles, se refiere al 'funcionalismo' como a una 'escuela' y también como una 'doctrina'.

67. Aclaración: Aquí, Moles se refiere a los 'métodos' del funcionalismo.

68. En su versión en español: La contribución de las Estructuras Industriales para la formación de un nuevo Estilo, en Maldonado, T. 1979. Técnica y Cultura.

69. En su versión en español: La contribución de las Estructuras Industriales para la formación de un nuevo Estilo, en Maldonado, T. 1979. Técnica y Cultura.

70. Si bien Michl publica el artículo por primera vez en mayo de 1997, se aclara que la publicación The Form follows WHAT?, montada en su sitio web personal desde el año 1997 fue actualizada en el 2018 por él, en el apartado denominado como: SUMMARY, and CAVEAT. 71. Aclaración: Michl cataloga la frase: la forma sigue a la función, como 'doctrina', y al mismo tiempo, como 'lema', que condensa el quid de la filosofía del funcionalismo, a través del significado que contiene. 
72. Cuando Michl usa la noción 'actual', no aclara a que época se refiere.

73. Cita original en inglés: "The only point of employing the dictum in this way seems to remind the designer that the chosen aesthetic solutions must support the non-aesthetic purposes the product is supposed to fulfill". Recuperado el jueves 20 de diciembre de 2018 de: http://janmichl.com/eng.fff-hai.html\#anchorHEREb

74. Cita original en inglés: "Sullivan himself drew attention to it again in his memoirs of 1924, published under the ostentatious title The Autobiography of an Idea. There the dictum was mentioned - though without much elaboration - as the hub of his design philosophy. Sullivan wrote that in the beginning of the 1880s he was putting to the test a formula that he had evolved". (párr. 7) Michl, J. (2018). Form Follows WHAT? The modernist notion of function as a carte blanche. Oslo, Norway. Jan Michl Design Theory website. Recuperado el Jueves 20 de diciembre de 2018 de: http://janmichl.com/eng.fff-hai.html\#anchorHEREb 75. Cita original en inglés: "Gropius learned of the dictum only after his emigration from Germany; at any rate, it seems fairly certain that at the Bauhaus, the dictum itself, in contrast to the philosophy which it summarizes, was virtually unknown.) Since the mid-1930s in the US, and late 1940s in Europe, Sullivan's dictum then started to be used as a shorthand summary of the ambitions of the modernist architects and designers. It summed up the modernist claim that the Modern Epoch was pregnant with new, preordained forms, a new, predestined aesthetics intrinsic to this Epoch, implying that the primary duty of the modernist designer, overshadowing all his other duties and loyalties, was to serve as a kind of midwife (32, 19a) for this new objective aesthetics, which was deemed independent of anybody's taste preferences". Párr. 8) Michl, J. (2018). Form Follows WHAT? The modernist notion of function as a carte blanche. Oslo, Norway. Jan Michl Design Theory website. Recuperado el Jueves 20 de diciembre de 2018 de: http://janmichl.com/eng.fff-hai.html\#anchorHEREb

76. Cita original en inglés: "No contemporary science, natural or social, uses the notion of function in the sense functionalist designers and architects did. No matter whether these sciences deal with material objects or immaterial phenomena, the scientific notion of function always refers to what an existing object or phenomenon does within a certain context. Whether we wonder about the function of the heart in human physiology, or the function of facades in a townscape, hearts and facades have to exist before anybody starts wondering about their functions. In both natural and social sciences form predates function: the notion of function is born from observing existing forms or phenomena. In functionalist design theory, on the other hand, it is exactly the other way around: function is claimed to predate form". (párr.13) Michl, J. (2018). Form Follows WHAT? The modernist notion of function as a carte blanche. Oslo, Norway. Jan Michl Design Theory website. Recuperado el Jueves 20 de diciembre de 2018 de: http://janmichl.com/eng.fff-hai.html\#anchorHEREb 77. Aclaración: los aportes de Lodoli, fueron conocidos a partir de historiador Francesco Algarotti (1753), en su texto: Saggio sopra l'Architettura. Algarotti, figura como uno de los alumnos que difundió gran parte de sus ideales y desarrollos.

78. Aclaración: cuando Schaefer se refiere a la actualidad, es obvio que lo hace para la época en la que escribió este artículo, es decir para 1970.

79. El grupo KURI, fueron estudiantes de la Bauhaus que mostraban abiertamente afinidades con el constructivismo soviético.

80. Cita Original en inglés, traducida por el autor de esta tesis, del texto de Margolin, V. 
(1998) The Struggle for Utopia. Rodchenko, Lissitzky, Moholy-Nagy 1917-1946. “Opposing the artistic construction of everydays objects, wich was the aim of the Russian Productivists, he argued that if one were to make objects of use, then one should take a utilitarian approach and leave aesthetic concerns behind. As examples, he cited architectural designs by Oud, Mies van der Rohe, Hilberseimer and others as well as the work of engineers".

81. Se refiere a los formalistas, constructivistas, suprematistas y Vjutemás.

82. Se utiliza el término para referirse al núcleo interdisciplinar que parece fundamentar las bases del funcionalismo.

83. Se refiere a la Primera Escuela de Chicago, La Bauhaus y la HfG.

84. El autor usa las expresiones 'sociedad de la utilidad' y 'bienestar humano', de manera indistinta.

85. Max Bill tuvo varias fases de pensamiento. En la primera fase, era obvia su afinidad con el pensamiento del primer Gropius; en su segunda fase, Bill propone la secularización de los conceptos del gusto y la belleza, porque hacían parte de las subjetividades que el diseñador debía evitar. Esto, con el objeto de superar el lastre, que proveniente de las artes plásticas, no permitía establecer nuevas y claras metodologías sistemática para el diseño.

86. Maldonado (1963). 4 conferencias, cev/di Bs. As. Argentina.

87. Maldonado, T. (1977). Ciencia y Proyectación. Idem anterior.

\section{Bibliografía}

Adorno, T. (2008). Crítica de la Cultura y Sociedad I. Prismas sin imagen directriz. El Funcionalismo Hoy. Madrid: Akal.

Aicher, O. (1991). Die Welt als Entwurf: Schriften zum Design. Germany: Ernst \& Sohn.

Aicher, O. (1994). El mundo como proyecto. México: Gustavo Gili.

Argan, G.C. (1957). Walter Gropius y el Bauhaus. Barcelona: Gustavo Gili.

Argan, G.C. (1983). Walter Gropius y la Bauhaus. Barcelona: Gustavo Gili.

Aristóteles, Traduc. Eduardo Sinnot (2004). Poética. Argentina: Colihue Clásica.

Baudrillard, J. (1968). Le système des objets. France: Gallimard.

Baudrillard, J. (1972). Pour une critique de léconomie politique du signe. France: Gallimard. Baudrillard, J., Moles A., Boudon P., Van Lier, H., Wahl, E., Morin, V. (1974). Los Objetos. Argentina: Tiempo Contemporáneo.

Baudrillard, J. (2007). Crítica a la Economía Política del Signo. Argentina: Siglo XXI.

Baudrillard, J. (2009). La Sociedad de Consumo. Sus Mitos, sus Estructuras. España: Siglo XXI. BBC. (2013). Mundo. Los Jóvenes Alemanes que intentaron derrocar a Hitler. La Rosa Blanca. [Artículo]. Recuperado el: sábado, 7 de marzo de 2015. De: http://www.bbc.co.uk/ mundo/noticias/2013/02/130223_cultura_movimiento_aleman_rosa_blanca_bd.shtml

Bentham, J. (2010). Un fragmento sobre el gobierno. Madrid: Editorial Technos.

Bernatene, R. (2005). Ética y Estética del Funcionalismo. La estrategia de exhibición funcionalista como enmascaramiento de procedimientos formalistas en Diseño y Arquitectura del siglo XX. Publicación del Seminario FOINDI de formación de investigadores FADU UBA. 
Bernatene, R. (2015). La historia del diseño industrial reconsiderada. Capítulo 1: Mitos y zonas oscuras en las narraciones de la historia del Diseño Industrial, pp. 14-37. Capitulo 8: Perspectivas historiográficas aplicadas a la Historia del Diseño Industrial, pp. 157-167. Argentina: Editorial Nacional de la Plata.

Bertalanffy, L.V. (2007). Teoría General de los Sistemas. Buenos Aires: Fondo de la Cultura Económica de Argentina S.A. y Fondo de la Cultura Económica de México.

Bill, M. (2010). Architecture Words 5. Form, Function, Beauty = Gestalt. London: Architectural Association. Bill's Compiler Articles: (1949) Gute Form. (1952) Beauty from Function and as Function. (1953) The Basis and aim of Aesthetics in the Machine Age. (1958) Function and Gestalt.

Bonet, J.M. (1980). Max Bill: "En la Bauhaus la pintura era casi clandestina". en Pintura Artes Plásticas Arte. Entrevista con el Arquitecto y Pintor suizo Max Bill. Recuperado de: https://elpais.com/diario/1980/01/31/cultura/318121207_850215.html el: 2 de marzo de 2018.

Bonsiepe, G. (1975). Diseño Industrial. Artefacto y Proyecto. Madrid: Alberto Corazón.

Bonsiepe, G. (1978). Teoría y Práctica del Diseño Industrial. Barcelona: Gustavo Gili.

Bonsiepe, G. (1999). Del objeto a la interfase. Argentina: Infinito.

Bonsiepe, G. (2003). Sobre la relevancia de la HfG Ulm. En Revista de Artes Visuales Ramona No. 79 (2008). Especial diseño. Macroscopías y hallazgos.

Bonsiepe G. (2003).1.10 El Discurso de Ulm (1962-1968). En Modelos de Ulm, Modelos Post-Ulm. Hochschule für Gestaltung Ulm 1953-1968.

Bonsiepe, G. (2004). Diseño / Globalización / Autonomía. Argentina: Nodal.

Bonta, J.P. (1977). Sistemas de Significación en Arquitectura. Un estudio de la arquitectura y su interpretación. Barcelona: Gustavo Gili.

Bozzano, J.N. (1998). PROYECTO: RAZÓN Y ESPERANZA. Escuela Superior de Ulm. Buenos Aires: Eudeba.

Brooks, B. (1995). La Arquitectura Orgánica. Organic Architecture. AV Monografías 54. pp.20-23.

Bürdek, B. (2002). Historia, Teoría y Práctica del Diseño Industrial. Barcelona: Gustavo Gili.

Burns, M. (2012). Sophie Scholl y la Rosa Blanca. The International Raoul Wallenberg Foundation. [Artículo]. Recuperado el: sábado, 7 de marzo de 2015.

De: http://www.raoulwallenberg.net/es/holocausto/articulos-65/sophie-scholl-rosa-blanca/

Calduch, J. (2002). Temas de Composición Arquitectónica: Modernidad y Arquitectura Moderna. San Vicente, España: Club Universitario.

Campi, I. (2008). Diseño y Nostalgia. El consumo de la historia. Barcelona: Santa \& Cole.

Carli, C.L. (2000). Los Misterios de la Arquitectura. Santafé, Argentina: Publicaciones Universidad Nacional del Litoral.

Carmagnola, F. (1995). El Alma de los Objetos. Experimenta: Ediciones de Diseño.

Cohen, J.L. Cook, K. Anatolevich, A. Tafuri, M. (1994). Constructivismo Ruso. Sobre la arquitectura en las vanguardias ruso-soviéticas hacia 1917. Estudios Críticos. Barcelona: Ediciones del Serbal. 
Coleridge, S.T. (1907). Coleridge's essays \& lectures on Shakespeare: \& some other old poets \& dramatists. From the personal library of James Buell Munn 1890-1967.London: J.M. Dent \& Sons, Ltd.

Collins, P. (1970). Los Ideales de la Arquitectura Moderna; Su Evolución (1750-1950).Barcelona: Gustavo Gili.

Collins, P. (1998). Los Ideales de la Arquitectura Moderna; Su Evolución (1750-1950).Barcelona: Gustavo Gili.

Conrads, U. (1964). PROGRAMME UND MANIFESTE ZUR ARCHITEKTUR DES 20. JAHRHUNDERTS. Berlin /Frankfurt: Verlag Ullstein GmbH.

Conrads, U. (1973). Programas y manifiestos de la arquitectura del siglo XX. Barcelona: Lumen.

Controspazio [Compilador]. Fonseca, D. [Traductora al Castellano]. (1971). Comunicación 12 BAUHAUS. Rykwert, Joseph. El lado Oscuro de la Bauhaus. P. 101. Bonfanti, Ezio. Los Gropius y la "Bauhaus Virtual",p. 113. Maldonado, Tomás. Otra Vez la Bauhaus,p. 175. Madrid: Editor Alberto Corazón

Darwin, C. (1859). El Origen de las Especies. Londres: John Murray.

De Maeztu, A. (2010). Alma Mahler Gropius.Barcelona: J.P. Libros.

De Ponti, J. Fernández, S. Gaudio, A. Heiner, J. Magioni, V. (2005). Diseño HfG Ulm, América Latina, Argentina, La Plata. Visión Personal de un experimento en democracia y educación de Diseño. La Plata: Nodal.

Devalle, V. (2009a). La Travesía de la Forma. Emergencia y Consolidación del Diseño Gráfico (1948-1984). Buenos Aires: Paidós.

Devalle, V. (2009b). Historia de los Diseños en América Latina, contenido y perspectivas teóricas y metodológicas. Buenos Aires: FADU-UBA.

Devalle, V. (2012). Lenguaje, comunicación y Diseño.Buenos Aires: Centro de Estudios en Diseño y Comunicación. Cuaderno 39. Universidad de Palermo.

De Zurko, E.R. (1970). La Teoría del Funcionalismo en la Arquitectura. Buenos Aires: Nueva Visión.

Dorfles, G. (1957). La Arquitectura Moderna. Barcelona: SEIX BARRAL, S.A.

Dorfles, G. (1973). El Diseño Industrial y su Estética. Barcelona: Labor, S.A.

Droste, M. (2006). La Bauhaus, 1919-1933. Reforma y Vanguardia. Alemania: TASCHEN. Droste, M. (2012). BAUHAUS. Alemania: TASCHEN.

Eichenbaum, B. (1922). El principio melódico del verso. Petrogrado: OPOIAZ.

Eichenbaum, B. (1970). La teoría del Método Formal. En Todorov ed., 21-54 (1925).

Ecured. (2015). Inge Aicher-Scholl. Sintesis Biográfica. [Artículo].

Recuperado el: sábado, 7 de marzo de 2015.

De: http://www.ecured.cu/index.php/Inge_Aicher-Scholl

Emerson, R.W. (1841). Ensayos sobre la naturaleza, seguido de varios discursos. Madrid: La España Moderna.

Fernández, J. Fuentes, J.F. (2004). A manera de introducción. Historia Lenguaje y Política. Revista Ayer: 53. Recuperado el 20 de junio de: http://www.ahistcon.org/PDF/numeros/ ayer53_HistoriaConceptos_Fernandez_Fuentes.pdf

Foucault, M. (2010). Las palabras y las cosas. Madrid: Ediciones de la Piqueta. 
Foucault, M. (2010). La Arqueología del Saber. Madrid: Ediciones de la Piqueta.

García, A. (2011). Conversando con Tomás Maldonado. Tomás Maldonado en conversación con María Amalia García. Nuevo libro de la serie CONVERSACIONES/CONVERSATIONS.Fundación Cisneros/Colección Patricia Phelps de Cisneros. Recuperado el12 de octubre de 2019 de:

https://www.youtube.com/watch?v=Ii0RK1lIBKU

García, M.P. Puentes, Y. (2008). Modelos de Ulm. 1953-1968. El Diseño de la Nueva Alemania. Revista. Colombia: Banco de la República. Goethe Institut Kolumbien. IFA Institut für Auslands-beziehungen e.V.

García, V. (2008). Alma Mahler. El fin de una época. España: Trajecte S.A.

Gay, A. Samar, L. (2004). El Diseño Industrial en la Historia. Argentina: Ediciones Tec Córdoba.

Gideon, S. (1978). La mecanización toma el mando. Barcelona: Gustavo Gili.

Goethe, J.W.V. (2002). Goethe y la Ciencia. España: Ediciones Siruela.

Goethe, J.W.V. (2014). Escritos de Arte. Madrid: Sintesis.

Goethe, J.W.V. (2014). Teoría de la Naturaleza. España: Tecnos.

Greenough, H. (1858). Form and function: remarks on art, design, and architecture. London: University of California Press.

Grenough, H. (1947). Form and Function: Remarks on Art. Edited by Harold A. Small with and Introduction by Erle Loran. Berkeley and Los Angeles. University of California Press London England. Printed in the United States of America. [Artículo].

Gropius, W. (1914). Der stilbildende Wert Bauformen, en Der Verkehr, Jena 1914, pp. 29-32. En su versión en español: La contribución de las estructuras industriales para la formación de un nuevo estilo, en Maldonado, T. (1979). Técnica y Cultura. El debate entre Bismark $y$ Weimar) pp. 182-187.

Gropius, W. (1919a). Pp. 76-82. Programa de la Staatliches Bauhaus de Weimar, en Conrads, U. (1973) Compilador. Programas y Manifiestos de la Arquitectura del Siglo XX. Barcelona: Editorial Lumen. En su versión original en alemán. Conrads, U. (1964) PROGRAMME UND MANIFESTE ZUR ARCHITEKTUR DES 20. JAHRHUNDERTS. Berlin/Frankfurt: Verlag Ullstein GmbH.

Gropius, W. Taut, B. Behne, A. (1919b). Pp. 72-75. El Nuevo pensamiento en Arquitectura, en Conrads, U. (1973) Compilador. Programas y Manifiestos de la Arquitectura del Siglo $X X$. Barcelona: Editorial Lumen. En su versión original en alemán. Conrads, U. (1964) PROGRAMME UND MANIFESTE ZUR ARCHITEKTUR DES 20. JAHRHUNDERTS. Berlin/Frankfurt: Verlag Ullstein GmbH.

Gropius, W. (1926). Pp. 143-146. Principios de la Producción de la Bauhaus (Dessau) (Extracto) en Conrads, U. (1973) Compilador. Programas y Manifiestos de la Arquitectura del Siglo XX. Barcelona: Editorial Lumen. En su versión original en alemán. Conrads, U. (1964) PROGRAMME UND MANIFESTE ZUR ARCHITEKTUR DES 20. JAHRHUNDERTS. Berlin/Frankfurt: Verlag Ullstein GmbH.

Gropius, W. (1943). Scope of Total Architecture. New York: Collier Books.

Gropius, W. (1959). Alcances de la Arquitectura Integral. Buenos Aires: La Isla.

Heskett, J. (1985). Breve Historia del Diseño Industrial. Barcelona: Ediciones del Serbal, S.A. 
HfG - Archiv Ulm. (1948). Page 2. History «... let's start, here un Ulm» Recuperado el 8 de enero de 2018 de: http://www.hfg-archiv.ulm.de/english/the_hfg_ulm/history_2.html

Jarauta, F. (2006). Editor. Cuadernos de Diseño. Arte y Diseño No. 2. Madrid: Instituto Europeo di Design y Talleres Gráficos Hermanos Gómez.

Kant, I. (1961). Crítica del Juicio. Seguida de las observaciones sobre el asentimiento de lo bello y lo sublime. Buenos Aires: Losada.

Klein, C. (1969). De los Espartaquistas al Nazismo: la república de Weimar. Barcelona: Península.

Koch, P. (2003). Form follows function. Digital Web Magazine. Recuperado el 17 de mayo de 2020. De: http://www.digital-web.com/articles/form_follows_function/

Konzett, M. (2000). Encyclopedia of German Literature. Fitzroy dearborn Publishers. Chicago, London.

Koselleck, R. (1993). Futuro Pasado. Barcelona: Paidós.

Koselleck, R. (2004). Historia de los Conceptos y Conceptos de Historia. Revista Ayer: 53. Recuperado el 20 de junio de: http://www.ahistcon.org/PDF/numeros/ayer53_HistoriaConceptos_Fernandez_Fuentes.pdf

Koselleck, R. (2012). Historias de conceptos. Estudios sobre semántica y pragmática del lenguaje político y social. Madrid: Trotta. Publicado originalmente en Alemania en el año 2006.

Kuhn, T. (2004). La estructura de las revoluciones científicas. Mexico D.F.: Fondo de Cultura Económica.

Kymlicka, W. (1995). Filosofía política contemporánea. Una introducción. Barcelona: Ariel S.A.

Le Corbusier. (2006). Hacia una Arquitectura. Barcelona: Apóstrofe.

Lissitzky, E. (1920). En Constructivismo. Monografías compiladas. Madrid: Felmar.

Löbach, B. (1981). Diseño Industrial. Bases para la configuración de los productos industriales. Barcelona: Gustavo Gili.

Lodder, C. (1988). El constructivismo ruso. Madrid: Alianza.

Loos, A. (1908). Ornamento y Delito. Y otros Escritos. Barcelona: Industria Gráfica Ferrer.

López, R. (1972). La Crisis del Racionalismo Arquitectónico en México. Hacia un nuevo enfoque metodológico. Cuadernos del Museo I, UNAM. México D.F.: Museo Universitario de Ciencias y Arte, CU.

Maldonado, T. (1974). Vanguardia y Racionalidad. Artículos, ensayos y otros escritos: 19461974. Barcelona: Gustavo Gili.

Maldonado, T. (1977). El Diseño Industrial Reconsiderado. Barcelona: Gustavo Gili.

Maldonado, T. (1979). Técnica y Cultura. El debate alemán entre Bismarky Weimar. Buenos Aires: Infinito.

Maldonado, T. (1990). El Futuro de la Modernidad. España: Jucar.

Maldonado, T. (2004). Proyectar Hoy. Argentina: Nodal.

Maldonado, T. (2008). Una Cartografía Textual. Córdoba, Argentina: Museo Caraffa. Formas y Miradas, Plaquetas de Museo.

Margolín, V. (1998). The Struggle for Utopia. Rodchenko, Lissitzky, Moholy-Nagy, 1917-1946.

United States of America: The University of Chicago Press.

Margolín, V. (2005). Las Políticas de lo Artificial. México: Designio. 
Meyer, H. (1926). Die neue Welt. Daswerk / Siebentes Heft 1926. Revolutionsprojekt für die umgestaltung eines Platzes in Leningrad, 1918.

Meyer, H. (1926). Die neue Welt. El Nuevo Mundo. En su versión en español: Maldonado, T. 1979. P.247-254. Técnica y Cultura. El debate alemán entre Bismark y Weimar.

Meyer, H. (1928). Edificación. Pp. 176-180. en Conrads, U. (1973) Compilador. Programas y Manifiestos de la Arquitectura del Siglo XX. Barcelona: Editorial Lumen.

Michl, J. (2012). Funkcionalismus, design, skola, trh. Slovakia: Slovensko: Barrister \& Principal. [Artículo].

Michl, J. (2014). Taking Down the Bauhaus Wall. Towards living design history as a tool for better design. United Kingdom: Issue the Design Journal. Volume 17, Issue 3 PP 445-454. [Article]. The Oslo School of Architecture and Design (AHO), Norway. Bloomsbury Publishing PLC. Printed in UK.

Michl, J. (2018). Form Follows WHAT? The modernist notion of function as a carte blanche. Oslo, Norway. Jan Michl Design Theory website. Recuperado el Jueves 20 de diciembre de 2018 de: http://janmichl.com/eng.fff-hai.html\#anchorHEREb

Mies, L.R. (1923). Tesis de Trabajo. Pp. 115-116. en Conrads, U. (1973) Compilador. Programas y Manifiestos de la Arquitectura del Siglo XX. Barcelona: Editorial Lumen.

Mies, L.R. (1927). Sobre la forma en la Arquitectura. En Conrads, U. (1973) Programas y Manifiestos de la Arquitectura del Siglo XX. Barcelona: Editorial Lumen.

Mill, S. (2014). El Utilitarismo. Un sistema de la lógica. Libro VI.España: Editorial Alianza.

Moles, A. (1968). La Crisis del Funcionalismo. En Form, No. 41. [Artículo] Redireccionado y citado en: Bürdek, Bernhard. (2002). Historia, Teoría y Práctica del Diseño Industrial. Barcelona: Gustavo Gili.

Moles, A. (1973). El Kitsch. El arte de la felicidad. Barcelona: Paidós.

Moles, A. (1974). Teoría de los objetos. Barcelona: Gustavo Gili.

Moles, A. (1988). El Concepte Funcionalista del Bauhaus en la societat del miracle econòmic, la Hochschule Für Gestaltung d'Ulm 1. 02 Diseño, Comunicación y Cultura. Barcelona: Copyright 20120. ELISAVA Escola Superior de Disseny TdD. [Artículo Web] Recuperado el: viernes 6 de marzo de 2015 .

De: http://tdd.elisava.net/coleccion/2/moles/view?set_language $=\mathrm{es}$

Noack, D. (1978). Bauhaus: preliminares, objetivos, métodos y consecuencias. Argentina: Instituto Goethe. Revista Summarios No. 17.

Lippincott, J. P. (1896). Lippincott's. Monthly Magazine. Philadelphia: J:B:Lippincott. Co

Norberto, C. Bavio, G. (2000). Días Felices. Los usos del orden: de la Escuela de Chicago al Funcionalismo. Comunicación y Sociedad. Buenos Aires: Editorial Eudeba.

O'gorman, J. Montes, V. (2006). De la Arquitectura Funcionalista a la Arquitectura como Arte. México: UNAM.

Palmarola, H. (2002). Diseño industrial estatal en Chile 1968-1973. Conferencia presentada en el ciclo -Testimonios de la Modernidad-, 12 de Noviembre de 2002. Extensión FADEU. Santiago: Pontificia Universidad Católica de Chile. [Artículo].

Pelta, R. (2004). Diseñar Hoy. Temas contemporáneos de Diseño Gráfico. Barcelona: Editorial Paidós.

Pevsner, N. (2011). Pioneros del Diseño Moderno. De William Morris a Walter Gropius. Buenos Aires: Infinito. 
Polanyi, M. (1966). The Tacit Dimension. New York: Double Day \& Company, Inc.

Ramírez, N. (2012). Diseño y Bienestar Humano. Puntos de encuentro a partir de metodologías de diseño. Design and human welfare: concurrence points from design methodologies. Iconofacto, Volumen 8 Número 10, enero-junio de 2012. [Artículo].

Rinker, D. Quijano, M. Reinhardt, B. (2003-2006). Compiladores. Modelos de Ulm. Hochschule für Gestaltung Ulm 1953-1968. Ulm: Institute für Auslands-beziehungen e.V. Stadt Ulm Ulmer Museum HFG Archiv.

Roberts, L. Baldwin, J. (2007). Comunicación Visual, de la Teoría a la Práctica. Barcelona: Parramón.

Salinas, O.F. (1992). Historia del Diseño Industrial. México: Editorial Trillas.

Saussure, F. (1945). Curso de Lingüística General. Buenos Aires: Losada.

Schaefer, H. (1970). Las raíces del Diseño Moderno. Tradición funcional en el siglo XIX. Londres: Studio Vista.

Schlemmer, O. (1977). Escritos sobre arte: pintura, teatro, danza. Cartas y diarios. Barcelona: Paidós estética.

Scolari, M. (1971). Hannes Meyer e la scuola di architettura, En: Controspazio. Milano: Dedalo (1970), anno II no 4-5 aprile-maggio; p. 83-91: fot., il.

Skinner, Q. (2000). Significado y comprensión en la historia de las ideas. Prismas. Revista de Historia Intelectual, núm. 4, pp. 149-191.

Sottsass, E. (2006). Cuadernos de Diseño. Arte y Diseño No. 2. Perplejidades y Proyectos. Compilador: Francisco Jarauta. Barcelona: Ediciones Aldeasa. Instituto europeo di Design Madrid. Talleres Gráficos de los hermanos Gómez. [Artículo].

Sparke, P. (2010). Diseño y Cultura. Una introducción desde 1900 hasta la actualidad. Barcelona: Gustavo Gili.

Spitz, R. (2013). René Spitz (2013). Kurze Geschichte der HfG Ulm. Párrafo: 3. Recuperado el 8 de Enero de 2018 de: http://renespitz.de/index.php?id=54

Sullivan, H.L. (1896). The Tall Office Building Artistically Considered. Lippincott's Monthly Magazine. William T. Nichols. (Compilator) Minneapolis. 1856-1924.

Sullivan, H.L. (1918). Kindergarten Chats and other writings. New York: GeorgeWittenborn Inc.

Sullivan, H.L. (1922). The Autobiographyof an Idea. New York: Press of the American Institute of Architechts.

Sullivan, H.L. (1957). Charlas con un Arquitecto. (Kindergarten Chats y otros escritos). Buenos Aires: Infinito.

Sullivan, H.L. (1961). Autobiografía de una idea. Buenos Aires: Infinito.

Tafuri, M. (1973). Socialismo realizado y las crisis de las Vanguardias. En: VVAA Socialismo, Ciudad y Arquitectura. URSS 1917-1937. Madrid: Alberto Corazón.

Todorov, T. (1970). Teoría de la literatura de los formalistas rusos. Madrid: Siglo XXI.

Todorov, T. (2005). Crítica de la crítica. Barcelona: Paidós.

Torrent, R. Marín, J. M. (2005). Historia del Diseño Industrial. Madrid: Anzos.

Tupitsyn, M. (2009). Rodchenko y Popova. Madrid: Museo Nacional Centro de Arte Reina Sofía - TF Editores.

Tzara, T. (1972). Siete Manifiestos Dadá. Barcelona: Tusquets. 
Valdés, G. (2003). Bauhaus: Crítica al saber sacralizado. Buenos Aires: Cuaderno del Centro de Estudios en Diseño y Comunicación. Ensayos. No. 15. P.68-91. [Artículo].

Verón, E. (1998). La Semiosis social: fragmentos de una teoría de la discursividad. España: Gedisa.

VVAA (1971). Bauhaus. Madrid: Alberto Corazón Editor. Comunicación 12.

Weber, M. (1991). La ética protestante y el espíritu del capitalismo. México: Premia.

Wolfe, T. (1988). ¿Quien teme al Bauhaus Feroz? Barcelona: Anagrama.

Wright, F. Y. (1908). In the Cause of Architecture.Art Humanities Primary Source Reading 51.

Wright, F. Y. (1931). Modern Architecture: Beign the Kahn Lectures for 1930. USA: Princeton University Press.

Wright, F. Y. (1953). The Future of Architecture. New York: Horizon Press.

Wright, F. Y. (1957). A Testament. New York: Horizon Press.

Wright, F. Y. (1961). Testamento. Buenos Aires: Compañía General Fabril.

Wright, F. Y. (1978). El Futuro de la Arquitectura. Barcelona: Poseidón.

Wright, F. Y. (2010). Arquitectura Moderna. Madrid: Paidós.

Zevi, B. (1980). Historia de la Arquitectura Moderna.Madrid: Editorial Poseidón.

Zubiri, C. (1988). Cinco lecciones de Filosofía. Madrid: Alianza.

\begin{abstract}
The relationship between the concepts of form and function ran through the entire history of Design and production, from ancient times to the present. This relationship was debated in design disciplines in the 19th and 20th centuries, to the point of originating a current called functionalism, as a theory and methodology in constant reformulation. Functionalism appears in the history of design as a fundamental concept, because it condensed ideological-political debates around the social function of projectation. These debates spanned the pedagogical, productive and constructive spheres, from the United States to the Soviet Union, at least from 1900 to 1980 . However, not all functional design is functionalist. Functionalism is conceived here as a historical-conceptual delimitation, detached from the Great Functional Tradition - of a timeless nature- that brought together principles, values and models of a theoretical and procedural nature. Hence, the conceptualizations of three representative schools are relieved and contrasted: First Chicago School (1885-1915 approx.); Bauhaus (1919-1933); and HfG Ulm (1953-1968), understood as primary sources, and his later critiques, understood as secondary sources. For this, the historiographic perspective of Conceptual History was adopted. From a historical and semantic point of view, the concept of functionalism operated as a record of past functional design experiences; in turn, it represented expectations for the future, by fostering social changes to equalize opportunities for use, habitat and new ways of communicating. Although in the history of Design and Architecture it appears associated with the phrase of Sullivan L.H. (1896), 'form always follows function', in this research it is shown that it is a construction of criticism, or owes its emergence to post-Bauhaus criticism. This shows its controversial character, due to its ethical-political contentions between liberal, social democratic and Marxist ideals.
\end{abstract}


Keywords: Design - Divergences - Form - Function - Functionalism - Conceptual Historical - Mythologies - Bauhaus - Chicago First School - HfG.

Resumo: A relação entre os conceitos de forma e função percorreu toda a história do Design e da produção, desde os tempos antigos até o presente. Esta relação foi debatida nas disciplinas de design dos séculos XIX e XX, a ponto de originar uma corrente denominada funcionalismo, como teoria e metodologia em constante reformulação. $\mathrm{O}$ funcionalismo surge na história das disciplinas de design como um conceito fundamental, porque se condensou debates político-ideológicos em torno da função social da projeção. Esses debates abrangeram as esferas pedagógica, produtiva e construtiva, dos Estados Unidos à União Soviética, pelo menos de 1900 a 1980. No entanto, nem todo design funcional é funcionalista. O funcionalismo é aqui concebido como um recorte históricoconceitual, desvinculado da Grande Tradição Funcional — de natureza atemporalque reunia princípios, valores e modelos de natureza teórica e procedimental. Assim, as conceituações de três escolas representativas são aliviadas e contrastadas: Primeira Escola de Chicago (1885-1915 aproximadamente); Bauhaus (1919-1933); e HfG Ulm (1953-1968), entendidos como fontes primárias, e suas críticas posteriores, entendidas como fontes secundárias. Para tanto, adotou-se a perspectiva historiográfica da História Conceitual. Do ponto de vista histórico e semântico, o conceito de funcionalismo operou como um registro de experiências anteriores de design funcional; por sua vez, representou expectativas para o futuro, ao promover mudanças sociais para equalizar oportunidades de uso, habitat e novas formas de comunicação. Embora na história do Design e da Arquitetura apareça associada à frase de Sullivan L.H. (1896), "a forma sempre segue a função", nesta pesquisa é mostrado que é uma construção da crítica, ou deve seu surgimento à crítica pós-Bauhaus. Isso mostra seu caráter polêmico, devido às suas contenções éticopolíticas entre os ideais liberais, social-democratas e marxistas.

Palavras-chave: Design - Divergências - Forma - Função - Funcionalismo - Histórico Conceitual - Mitologias - Bauhaus - Chicago First School - HfG.

[Las traducciones de los abstracts fueron supervisadas por el autor de cada artículo] 